Tobias Heimfarth

Desenvolvimento de sensores magnéticos tipo fluxgate miniaturizados utilizando ligas ferromagnéticas eletrodepositadas

Ribeirão Preto

Maio, 2014 

Tobias Heimfarth

\title{
Desenvolvimento de sensores magnéticos tipo fluxgate miniaturizados utilizando ligas ferromagnéticas eletrodepositadas
}

\author{
Tese apresentada à Faculdade de Filosofia, Ciên- \\ cias e Letras de Ribeirão Preto da Universidade \\ de São Paulo para obtenção do título de Doutor \\ em Ciências. \\ Universidade de São Paulo - USP \\ Faculdade de Filosofia, Ciências e Letras de Ribeirão Preto \\ Programa de Pós-Graduação em Física Aplidada à Medicina e Biologia
}

Orientador: Marcelo Mulato

Ribeirão Preto

Maio, 2014 



\section{Agradecimentos}

Aos meus pais por todo apoio dado. Ao meu professor orientador Marcelo Mulato pela amizade. Aos meus colegas e ex-colegas de laboratório por tornar o trabalho mais agradável: Guilherme, Hugo, Jessica, Júlio, Marina, Rafael e Shirlei. Ao professor Marcelo Carreño e seu ex-aluno Murilo pelo suporte prestado. Ao professor Oswaldo Baffa Filho pelo empréstimo de equipamentos fundamentais. Aos técnicos Natalia, Élcio e Aziani pela ajuda no desenvolvimento experimental da minha pesquisa e a secretária Nilza. A CAPES, CNPq e Fapesp pelo apoio financeiro. 



\section{Resumo}

Foram desenvolvidos sensores magnéticos tipo fluxgate miniaturizados, paralelos planos e ortogonais, com os núcleos compostos por ligas ferromagnéticas eletrodepositadas.

O foco no desenvolvimento dos sensores paralelos planos foi a redução da complexidade do processo de microfabricação, utilizando apenas uma camada de bobinas. Para isto foi proposto um leiaute em que a bobina de excitação e as coletoras estão posicionadas no mesmo plano. Mas os testes com protótipos em escala mostraram que a falta de excitação direta em uma das extremidades dos núcleos era fonte de ruído. Foi então proposto um segundo leiaute para mitigar este problema adicionando bobinas excitadoras em paralelo com as coletoras. Levando em conta as outras consequências que esta mudança trouxe, o leiaute mais simples apresentou melhores caraterísticas para baixas amplitudes de excitação. Foram então construídos sensores miniaturizados com ambos leiautes, utilizando um processo de microfabricação simplificado com apenas quatro máscaras fotolitográficas. Obteve-se os núcleos dos sensores eletrodepositando NiFe em condições previamente estudadas, de maneira a formar filmes com alta permeabilidade magnética. Os dispositivos resultantes apresentaram boa linearidade para campos de até $200 \mu \mathrm{T}$, com responsividades máximas de 16 e $8 \mathrm{~V} / \mathrm{T}$ dependendo do leiaute, quando operados com a excitação senoidal e frequência de $100 \mathrm{kHz}$. Também foi medido o ruído rms contidos na faixa de $0,1 \mathrm{a} 10 \mathrm{~Hz}$. O sensor mais simples, sem as bobinas extras, obteve os melhores resultados com $40 \mathrm{nT}$ para a faixa de amplitudes de excitação estudada, contra 59 nT do segundo leiaute. Entretanto o primeiro leiaute atinge o mínimo de ruído para amplitudes de excitação baixas de modo que não é possível reduzi-lo com um simples aumento de corrente. As bobinas extras do segundo contornam este problema e seus resultados sugerem que, com o aumento da resolução espacial utilizada na confecção das bobina, pode-se atingir os níveis de ruído de sensores muito mais complexos.

Também foram desenvolvidos sensores tipo fluxgate ortogonais com núcleos eletrodepositados sobre fios de cobre. Foi proposto e testado um modelo matemático para o sinal de saída quando este tipo de sensor é operado em constante saturação, de maneira que a permeabilidade magnética é modulada pela rotação da magnetização. Isto é obtido adicionando-se uma componente constante ao campo de excitação. A vantagem deste método é a redução dos saltos de Barkhausen, uma das principais fontes de ruído. Os sensores foram construídos a partir de fios de cobre com diâmetros de 45 e $120 \mu$ m eletrodepositados com ligas de NiFe e NiFeP, e envoltos por um solenoide. Foram investigadas as características destes sensores em relação à: densidade de corrente utilizada na eletrodeposição, aplicação de um campo tangencial durante a eletrodeposição e às amplitudes de excitação tanto no modo de operação convencional quanto no modo de rotação da magnetização. As características dos sensores estudadas foram: responsividade, efeito perming e ruído. Os núcleos de $\mathrm{NiFeP}$ sofreram com problemas de forte anisotropia e altos níveis de ruído. Os melhores dispositivos, com núcleo de NiFe, operados no modo de rotação da magnetização apresentaram redução do ruído em cerca de 10 vezes se comparado com o modo convencional. Por exemplo, a amostra menos ruidosa foi de $8 \mathrm{nT}$ para $0,55 \mathrm{nT} r m s$ contidos na faixa de $0,1 \mathrm{~Hz}$ a $10 \mathrm{~Hz}$. O preço pago foi uma diminuição na responsividade, de 796 para $211 \mathrm{~V} / \mathrm{T}$ e o aumento no efeito perming, de 2 para $4,5 \mu \mathrm{T}$. 



\section{Abstract}

Two kinds of miniaturized fluxgate magnetic sensor have been developed, a planar parallel and an orthogonal one, with electroplated ferromagnetic alloy cores.

The parallel one was built using microfabrication techniques with the main focus on the overall manufacture complexity reduction, making use of only one layer of coils. The proposed layout has both excitation and pick-up coils placed in the same level. Scaled-up prototypes had shown that the lack of excitation in the cores' extremities was a noise source. To counter that, a second layout added extra excitation coils parallel to the pick-up ones. Taking into account the overall consequences brought up by this change, the simpler one performs better for lower excitation amplitude, getting reverse at higher ones. Based on these results, miniaturized versions of both layouts were built making use of a simplified manufacture process that needed only four photolithography masks. The sensors' cores were obtained by electroplating NiFe in previous studied conditions, associated with the high magnetic permeability. The resulting devices presented good linearity for external fields up to $200 \mu \mathrm{T}$, with maximum sensitivity of 16 and $8 \mathrm{~V} / \mathrm{T}$, depending on the layout, for a $100 \mathrm{kHz}$ sine excitation. Also the rms noise levels contained in the $0.1-10$ $\mathrm{Hz}$ range has been measured. The simplest device, without the extra coils, achieved the best results with $40 \mathrm{nT}$ in the studied excitation amplitude range, a little lower than the $59 \mathrm{nT}$ related to the second sensor. But as the excitation amplitude increase, the first one reaches a low noise minimum removed by the addition of the extra coils. Extrapolation of the second layout data suggests that, by a small decrease in the coils pitch, it is possible to achieved more complex sensors' noise levels.

It has been also developed some orthogonal fluxgate sensors, consisting of electroplated wires inside solenoids. The output signal generated by this kind of sensor operated in constant saturation mode was mathematical modeled. To keep the core in permanent saturation a dc bias was added to the excitation field. In this case, the core magnetic permeability is no longer modulated by the domain walls movement but rather by the magnetization rotation. The advantage being the suppression of Barkhausen jumps, one of the main sources of noise. The sensors were build using cooper wires with two diameter, 45 and 120 $\mu \mathrm{m}$, electroplated with $\mathrm{NiFe}$ and $\mathrm{NiFeP}$ alloys. The resulting devices characteristics were measured with respect to: electroplating current density, tangential magnetic field intensity during the electroplating process and excitation field amplitude in both conventional and magnetization rotation mode. The studied characteristics were: sensitivity, perming effect and noise. NiFeP cores suffer from a high anisotropy and noise levels. The best devices, with NiFe cores, operated in the biased mode had their noise levels reduced by a factor of about 10 when compared to the non-biased conventional mode. For example, the less noisy sample went from $8 \mathrm{nT}$ to $0.55 \mathrm{nT} r m s$ contained in the $0,1-10 \mathrm{~Hz}$ range. The drawback was a decrease in the sensitivity, from 796 to $126 \mathrm{~V} / \mathrm{T}$ and an increase in the perming error, from 2 to $4,5 \mu \mathrm{T}$. 



\section{Lista de ilustrações}

Figura 1.1.1 - Intensidade dos campos magnéticos gerados pelo corpo humano e outras fontes comuns . . . . . . . . . . . . . . . 25

Figura 1.3.1 - Curva de magnetização e curva de chaveamento . . . . . . . . . . . . . 29

Figura 1.3.2 - Esquema de um fluxgate básico . . . . . . . . . . . . . . . . . . . 29

Figura 1.3.3 - Fluxgate como uma válvula de fluxo magnético . . . . . . . . . . . 30

Figura 1.3.4 - Esquema da transformação da função de excitação no sinal de saída . 31

Figura 1.3.5 - Esquema da transformação da função de excitação no sinal de saída de um fluxgate ortogonal operado com deslocamento na excitação . . . . . 32

Figura 1.4.1 - Esquema dos campos de um fluxgate básico . . . . . . . . . . . . . . 32

Figura 1.4.2 - Campo de desmagnetização de pedaço de material ferromagnético . . . 33

Figura 1.5.1 - Esquema de um fluxgate de Vacquier e de Förster . . . . . . . . . . . . 35

Figura 1.6.1 - Exemplo de fluxgate ortogonal . . . . . . . . . . . . . . . . . 36

Figura 1.6.2 - Curva de chaveamento ortogonal. Permeabilidade na direção 1 em função do campo $\mathrm{H}_{2}$. Compare com a figura 1.3.1b. . . . . . . . . . . . . 38

Figura 1.7.1 - Esquema dos dois tipos de indutor mais comuns construídos com filmes finos . . . . . . . . . . . . . . . . . . . 39

Figura 1.7.2 - Esquema explodido de um fluxgate plano . . . . . . . . . . . . . 40

Figura 1.7.3 - Corte lateral de um sensor fluxgate microfabricado . . . . . . . . . . . 41

Figura 1.8.1 - Exemplo comum de curva de resposta de um fluxgate . . . . . . . . . . 42

Figura 1.8.2 - Exemplo do efeito perming . . . . . . . . . . . . . . 43

Figura 1.8.3 - Salto de Barkhausen, representação de um domínio magnético e curva de magnetização . . . . . . . . . . . . . . . . . . . . . . . 44

Figura 2.2.1 - Leiautes testados . . . . . . . . . . . . . . . . . . . 48

Figura 2.2.2 - Campo gerado por uma bobina plana espiral calculado por elementos finitos . . . . . . . . . . . . . . . . . . . . 49

Figura 2.3.1 - Curvas B(H) do núcleo utilizado nos sensores em escala . . . . . . . . 52

Figura 2.3.2 - Montagem experimental utilizada na obtenção das curvas de resposta dos sensores em escala . . . . . . . . . . . . . . . . . . 53

Figura 2.3.3 - Exemplo das curvas de resposta utilizadas no cálculo da responsividade 53

Figura 2.3.4 - Responsividade em função da amplitude de excitação dos protótipos em escala . . . . . . . . . . . . . . . . . . . 54

Figura 2.3.5 - Montagem experimental utilizada nas medidas de ruído . . . . . . . 55

Figura 2.3.6 - Ruído não normalizado em função da amplitude de excitação . . . . 56

Figura 2.3.7 - Exemplo de flutuações de baixa frequência medidas para ML2. . . . . 57

Figura 2.3.8 - Níveis de ruído normalizado em função da amplitude de excitação. 59 
Figura 2.4.1 - Superposição das quatro máscaras utilizadas na microfabricação dos minifluxgates . . . . . . . . . . . . . . . . 60

Figura 2.4.2 - Substrato de corning. . . . . . . . . . . . . . . . 61

Figura 2.4.3 - Camada de titânio depositada por sputtering necessária para a boa adesão do cobre. . . . . . . . . . . . . . . . . . . . . 62

Figura 2.4.4 - Camada de cobre depositada que será utilizada como semente na eletrodeposição das bobinas. . . . . . . . . . . . . . . 63

Figura 2.4.5 - Revelação dos moldes de fotoresiste das bobinas. . . . . . . . . . . . 64

Figura 2.4.6 - Espessamento das trilhas das bobinas por eletrodeposição através de moldes de fotoresiste. . . . . . . . . . . . . . 65

Figura 2.4.7 - Remoção da semente de cobre e titânio deixando as bobinas essencialmente inalteradas. . . . . . . . . . . . . . . . 66

Figura 2.4.8 - Recobrimento de toda a amostra com o fotoresiste SU8. . . . . . . . . 67

Figura 2.4.9 - O polimento retira o excesso de SU8 para tornar as trilhas acessíveis e suaviza a superfície para melhor recobrimento pelas próximas camdas.

Figura 2.4.10 - $\mathrm{O}$ isolamento elétrico entre as camadas de metal foi feita por uma camada de óxinitreto depositada por PECVD . . . . . . . . . . . . . . . 69

Figura 2.4.11 - Abertura dos contatos no oxinitreto para ter acesso as trilhas. . . . . . . 69

Figura 2.4.12 - Deposição de uma camada de aderência de titânio seguida de uma de cobre. . . . . . . . . . . . . . . . . 70

Figura 2.4.13 - Definição das trilhas, pads e semente da eletrodeposição do núcleo na segunda camada condutora. . . . . . . . . . . . . . 71

Figura 2.4.14 - Molde de fotoresiste para a eletrodeposição dos núcleos. . . . . . . . . 71

Figura 2.4.15 - Núcleos de NiFe eletrodepositados. . . . . . . . . . . . . . 72

Figura 2.4.16 - O sensor concluído foi preso a um PCB com contatos externos para evitar esforços mecânicos sobre as frágeis estruturas microfabricadas. .

Figura 2.4.17 - Corte transversal do sensor ilustrativo pronto, mostrando a estrutura das camadas formadas . . . . . . . . . . . . . . 73

Figura 2.4.18 - Microscopia ótica da região do substrato contendo os sensores C e D. . 74

Figura 2.4.19 - Componente do campo $\mathbf{H}_{\text {exc }}$ paralela ao núcleo e calculada ao longo deste 75

Figura 2.4.20 - Curva de resposta dos sensores microfabricados. . . . . . . . . . 76

Figura 2.4.21 - Responsividade em função da amplitude de excitação. . . . . . . . . 77

Figura 2.4.22 - Ruído rms não normalizado contido na faixa de frequência $0,1 \mathrm{a} 10 \mathrm{~Hz}$ como função da amplitude de excitação. . . . . . . . . . . . . . 78

Figura 2.4.23 - Ruído rms normalizado contido na faixa de frequência 0,1 a $10 \mathrm{~Hz}$ como função da amplitude de excitação. . . . . . . . . . . . . . . . . . . 79

Figura 2.4.24 - Exemplos dos espectros da densidade de ruído capturados para os sensores microfabricados . . . . . . . . . . . . . . . 79

Figura 3.1.1 - Mecanismos associados a magnetização de materias ferromagnéticos. . 81 
Figura 3.3.1 - Esquema de um fluxgate ortogonal por rotação da magnetização. . . . .

Figura 3.4.1 - Esquema vetorial da modulação da permeabilidade magnética de um FORM .......................... 86

Figura 3.4.2 - Esquema experimental utilizado para testar o modelo matemático . . . 90

Figura 3.4.3 - Montagem experimental utilizada no teste do modelo matemático . . . 91

Figura 3.4.4 - Sinal medido e ajustado pelo modelo matemático . . . . . . . . . . . 92

Figura 3.4.5 - Curvas de resposta para diversos $H_{a c}$, experimental e teórica para os dois primeiros harmônicos. . . . . . . . . . . . . . 93

Figura 3.4.6 - Responsividade experimental e teórica ajustada em função do campo de excitação alternado para os dois primeiros harmônicos. . . . . . . . . . . 94

Figura 3.4.7 - Ajustes da responsividade utilizando o modelo matemático . . . . . . . 95

Figura 3.6.1 - Suporte utilizado na eletrodeposição do núcleo ferromagnético sobre os fios de cobre. . . . . . . . . . . . . . . . . . . . . 98

Figura 3.6.2 - Sistema de eletrodeposição dos fios recobertos com NiFe. . . . . . . . 99

Figura 3.6.3 - Sistema de eletrodeposição dos fios recobertos com NiFe com um campo magnético tangencial . . . . . . . . . . . . . . . . . 100

Figura 3.6.4 - Sistema de eletrodeposição dos fios recobertos com NiFeP. . . . . . . . 101

Figura 3.6.5 - Processo e parte mecânica do equipamento responsável pelo enrolamento das bobinas coletoras . . . . . . . . . . . . . . . . . . . 102

Figura 3.6.6 - Esquema elétrico da bobinadora, principais componentes . . . . . . . . 102

Figura 3.6.7 - Foto de um fio bobinado. . . . . . . . . . . . . . . . 103

Figura 3.6.8 - Contatos elétricos dos fios . . . . . . . . . . . . . . 103

Figura 3.6.9 - Microscopia óptica do contato elétrico do núcleo. . . . . . . . . . . . . 104

Figura 3.6.10 - Montagem final do sensor tipo fio . . . . . . . . . . . . . . . . . . . 104

Figura 3.7.1 - Composição química dos núcleos eletrodepositados em função da densidade de corrente utilizada, medida por EDS. . . . . . . . . . . . . . 106

Figura 3.7.2 - O volume de solução imediatamente disponível por unidade de área para um cilindro é maior do que para um plano.

Figura 3.7.3 - Microscopia eletrônica das amostras de NiFe utilizadas na análise por

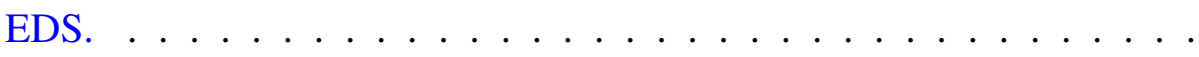

Figura 3.7.4 - Microscopia eletrônica das amostras de NiFeP utilizadas na análise de composição por EDS. . . . . . . . . . . . . . . . . . . . . . 108

Figura 3.8.1 - Esquema utilizado nas medidas de magnetização dos sensores ortogonais 109

Figura 3.8.2 - Esquema da magnetização ortogonal para um material ferromagnético com apenas uma direção de fácil magnetização . . . . . . . . . . . . . 109

Figura 3.8.3 - Curvas de magnetização paralela dos sensores com substrado de $120 \mu \mathrm{m}$ de diâmetro. . . . . . . . . . . . . . . . . . . . . . 110

Figura 3.8.4 - Curvas de magnetização ortogonal dos sensores com substrado de 120 um de diâmetro. . . . . . . . . . . . . . . . . . . . . 111 
Figura 3.8.5 - Curvas de magnetização paralela dos sensores com substrado de $45 \mu \mathrm{m}$ de diâmetro. . . . . . . . . . . . . . . . . . . . . . . . 112

Figura 3.8.6 - Curvas de magnetização ortogonal dos sensores com substrado de 45 $\mu$ m de diâmetro. . . . . . . . . . . . . . . . . 113

Figura 3.8.7 - Resumo das propriedades magnéticas dos núcleos dos sensores FORM 114

Figura 3.9.1 - Montagem experimental padrão dos sensores ortogonais . . . . . . . . 115

Figura 3.9.2 - Exemplo de calibração da corrente de excitação . . . . . . . . . . . . 116

Figura 3.9.3 - Relação entre as componentes ortogonais do sinal de saída X e Y . . . 117

Figura 3.9.4 - Exemplo de calibração da fase em função de um parâmetro da excitação A.117

Figura 3.9 .5 - Exemplo de curva de resposta. . . . . . . . . . . . . . . . 118

Figura 3.9.6 - Exemplo do comportamento da responsividade em função de um parâmetro A. . . . . . . . . . . . . . . . . . 118

Figura 3.9.7 - Campo externo aplicado em uma medida do efeito perming. . . . . . . 119

Figura 3.9.8 - Exemplo de medida do efeito perming em função da amplitude do choque de campo. . . . . . . . . . . . . . . . . . . . 120

Figura 3.9.9 - Exemplo de comportamento do efeito perming em função de um parâmetro A. . . . . . . . . . . . . . . . . 120

Figura 3.9.10 - Montagem experimental das medidas de ruído utilizando o gerador de funções . . . . . . . . . . . . . . . . . . . . . . 121

Figura 3.9.11 - Modulador de corrente . . . . . . . . . . . . . . . . . 122

Figura 3.9.12 - Montagem experimental, medidas de ruído utilizando o modulador de corrente . . . . . . . . . . . . . . . . . 123

Figura 3.9.13 - Exemplo do sinal gerado pelos sensores dentro da blindagem . . . . . . 123

Figura 3.9.14 - Exemplo de dependência do ruído rms com um parâmetro A . . . . . . 124

Figura 3.9.15 - Exemplo de ruído (a) e perming (b) normalizados. . . . . . . . . . . 124

Figura 3.10.1 - Curva de chaveamento ortogonal do sensor N50 . . . . . . . . 125

Figura 3.10.2 - Responsividade do sensor N50 calculada numericamente em função deslocamento da excitação para o primeiro e segundo harmônio . . . . 126

Figura 3.10.3 - Responsividade do sensor N50 calculada numericamente em função da corrente de excitação alternada para alguns valores de corrente contínua 127

Figura 3.11.1 - Responsividade dos sensores do grupo A para o modo de operação convencional . . . . . . . . . . . . . . . . . 130

Figura 3.11.2 - Responsividade dos sensores do grupo A com a aplicação de $H_{d c} \quad \ldots \quad$. 131

Figura 3.11.3 - Efeito perming para os sensores do grupo A operados no modo convencional . . . . . . . . . . . . . . . . . . . 132

Figura 3.11.4 - Efeito perming para os sensores do grupo A com a aplicação de $H_{d c}$ . 133

Figura 3.11.5 - Ruído rms presente na faixa de 0,1 a $10 \mathrm{~Hz}$ gerado pelos sensores do grupo A operados no modo convencional . . . . . . . . . . . . . . . 134 
Figura 3.11.6 - Ruído rms presente na faixa de 0,1 a $10 \mathrm{~Hz}$ gerado pelos sensores do grupo A com a aplicação de $H_{d c} \ldots \ldots \ldots$. . . . . . . . . 135

Figura 3.11.7 - Responsividade dos sensores do grupo B para o modo de operação convencional . . . . . . . . . . . . . . . . 136

Figura 3.11.8 - Responsividade calculada para os sensores N50 e N15 . . . . . . . . . 137

Figura 3.11.9 - Responsividade dos sensores do grupo B com a aplicação de $H_{d c} \quad \ldots 138$

Figura 3.11.10 - Efeito perming para os sensores do grupo B operados no modo convencional . . . . . . . . . . . . . . . . . . . . 139

Figura 3.11.11 - Efeito perming para os sensores do grupo B com a aplicação de $H_{d c}$ . 140

Figura 3.11.12 - Ruído rms presente na faixa de 0,1 a $10 \mathrm{~Hz}$ gerado pelos sensores do grupo B operados no modo convencional . . . . . . . . . . . . . . 141

Figura 3.11.13 - Ruído rms presente na faixa de 0,1 a $10 \mathrm{~Hz}$ gerado pelos sensores do grupo B com a aplicação de $H_{d c} \ldots \ldots$. . . . . . . . . . . . . 142

Figura 3.11.14 - Ruído rms presente na faixa de 0,1 a $10 \mathrm{~Hz}$ gerado pelos sensores do grupo B com a aplicação de $H_{d c}$, medido com o modulador de corrente

Figura 3.11.15 - Curvas de resposta do sensor P13 exemplificando (a) a baixa quantidade de pontos para se obter a responsividade quando em modo convencional e (b) a falta de simetria obtidas para as amostras do grupo C. . . . . . . 144

Figura 3.11.16 - Responsividade dos sensores do grupo C para o modo de operação convencional . . . . . . . . . . . . . . . . . 145

Figura 3.11.17 - Responsividade dos sensores do grupo C com a aplicação de $H_{d c} \quad$. . . 146

Figura 3.11.18 - Efeito perming para os sensores do grupo $\mathrm{C}$ operados no modo convencional . . . . . . . . . . . . . . . . . . . . . 147

Figura 3.11.19 - Efeito perming para os sensores do grupo B com a aplicação de $H_{d c}$ . 148

Figura 3.11.20 - Ruído rms presente na faixa de 0,1 a $10 \mathrm{~Hz}$ gerado pelos sensores do grupo C operados no modo convencional . . . . . . . . . . . . . 149

Figura 3.11.21 - Ruído rms presente na faixa de 0,1 a $10 \mathrm{~Hz}$ gerado pelos sensores do grupo B com a aplicação de $H_{d c} \ldots \ldots$. . . . . . . . . . . 150

Figura 3.11.22 - Trecho da série temporal coletada para o sensor P09 utilizada estimar o valor do ruído para $I_{d c}=0,35$ A e $I_{d c}=0,15 \mathrm{~A} \ldots \ldots \ldots \ldots$

Figura 3.11.23 - Responsividades medidas para todos os sensores com a excitação de referência. . . . . . . . . . . . . . . . 152

Figura 3.11.24 - Efeito perming medido para todos os sensores com a excitação de referência. . . . . . . . . . . . . . . . . 153

Figura 3.11.25 - Ruído medido para todos os sensores com a excitação de referência. . . 154

Figura A.1.1 - Montagem para a medida da curva de magnetização. . . . . . . . . . . . 169

Figura A.2.1 - Sistema experimental utilizado nas medidas das curvas $M\left(H_{0}\right) \ldots \ldots 171$

Figura A.3.1 - Exemplo dos sinais envolvidos na medida da magnetização de uma amostra de $\mathrm{NiFe}$. . . . . . . . . . . . . . . . . . 172 
Figura A.3.2 - Curva de magnetização em função do campo externo aplicado $\left(M\left(H_{0}\right)\right)$ de uma amostra de NiFe utilizando o método descrito nesta secção. . 172

Figura B.2.1 - Exemplo de estimativa da densidade espectral de potência . . . . . . . 175

Figura C.2.1 - Prisma retangular com o sistema de coordenadas. . . . . . . . . . . 178

Figura C.3.1 - Plano central sobre o qual é calculada a média de $H_{d, i}$, dado origem ao fator de desmagnetização associado a coordenada $i, D_{i}$. . . . . . . . . 179

Figura C.4.1 - Uma bobina maior que o núcleo tem menor fluxo devido a magnetização. 181

Figura C.4.2 - O fator de acoplamento compensa a redução no fluxo que passa pela bobina causado pelas cargas magnéticas induzidas. . . . . . . . . . . 181

Figura C.5.1 - Plano central sobre o qual é calculada a média de $H_{d, i}$, dado origem ao fator de desmagnetização ortogonal associado a coordenada i, $D_{i}^{\prime}$. . . 182 


\section{Lista de tabelas}

Tabela 1.1.1 - Algumas aplicações médicas de magnetômetros . . . . . . . . . . 26

Tabela 1.2.1 - Tabela comparativa entre os principais parâmetros dos magnetômetros mais utilizados . . . . . . . . . . . . . . . . . 26

Tabela 1.8.1 - Valores dos principais parâmetros de um fluxgate encontrados na literatura para disposivitos com dimensões reduzidas . . . . . . . . . . . 45

Tabela 2.3.1 - Solução de eletrodeposição de NiFe . . . . . . . . . . . . . . . . . 50

Tabela 2.3.2 - Parâmetros geométricos dos protótipos em escala macroscópica . . . . 51

Tabela 2.3.3 - Responsividade máxima e os valores de excitação associados para os protótipos em escala . . . . . . . . . . . . . . . . 54

Tabela 2.4.1 - Lista dos sensores posicionados no substrato. . . . . . . . . . . . . . 61

Tabela 2.4.2 - Parâmetros utilizados na deposição de titânio por sputtering . . . . . . 62

Tabela 2.4.3 - Parâmetros utilizados na deposição de cobre por sputtering. . . . . . . . 63

Tabela 2.4.4 - Solução utilizada na deposição de cobre para o espessamento das bobinas. 64

Tabela 2.4.5 - $\quad$ Parâmetros de deposição do oxinitreto $\left(\mathrm{Si}_{1} \mathrm{O}_{0,6} \mathrm{~N}_{0,4}\right)$ por PECVD. . . . 68

Tabela 2.4.6 - Parâmetros geométricos dos sensores miniaturizados. . . . . . . . . . . 74

Tabela 2.4.7 - Responsividade máxima e campo de excitação associado dos sensores microfabricados. . . . . . . . . . . . . . . . 77

Tabela 3.2.1 - Resumo da bibliografia encontrada sobre sensores tipo fluxgate de domínio magnético único . . . . . . . . . . . . . . . . . 83

Tabela 3.4.1 - Características do núcleo do sensor utilizado no teste do modelo matemático. . . . . . . . . . . . . . . . . . 90 90

Tabela 3.6.1 - Reagentes utilizados na solução de eletrodeposição de NiFeP. . . . . . 100

Tabela 3.6.2 - Principais parâmetros dos sensores ortogonais construídos . . . . . . . 105

Tabela 3.11.1 - Conjunto de medidas realizadas para cada sensor. *Somente para o modo de operação com excitação deslocada. . . . . . . . . . . . . . 128

Tabela 3.11.2 - Reimpressão da tabela das características dos sensores ortogonais com a separação em grupos . . . . . . . . . . . . . . . . . 128

Tabela 3.11.3 - Parâmetros de entrada de referência e o campo aproximado que geram . 129 



\section{Lista de abreviaturas e siglas}

$\begin{array}{ll}\text { ppm } & \text { Parte por milhão } \\ \text { PCB } & \text { Placa de circuito impresso (do inglês Printed circuit board) } \\ \text { PSD } & \text { Densidade de potência espectral (do inglês power spectral density) } \\ \text { rms } & \text { Valor quadrático médio (do inglês root mean square) } \\ \text { sccm } & \text { Standard cubic centimeters per minute } \\ \text { HF } & \text { Ácido fluorídrico } \\ \text { PECVD } & \text { plasma-enhanced chemical vapor deposition } \\ \text { FORM } & \text { Fluxgate ortogonal por rotação da magnetização } \\ \text { EDS } & \text { Energy Dispersive Spectrometry }\end{array}$





\section{Sumário}

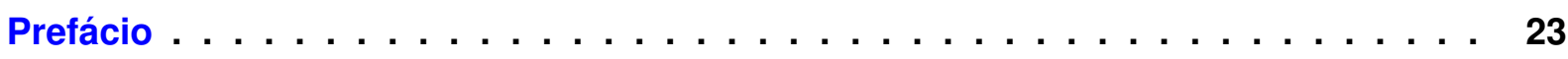

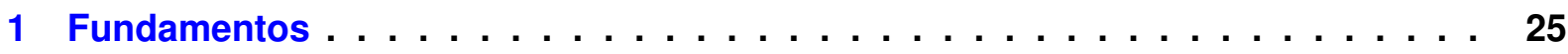

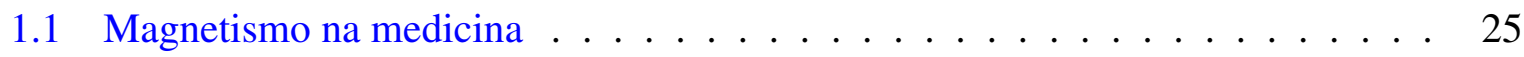

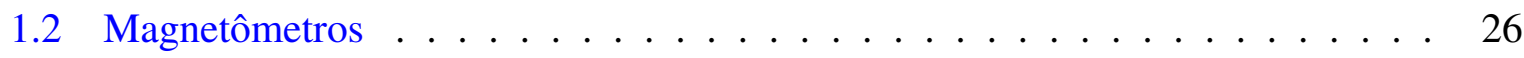

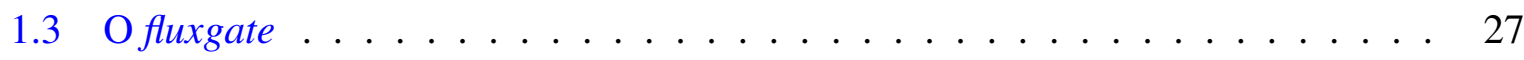

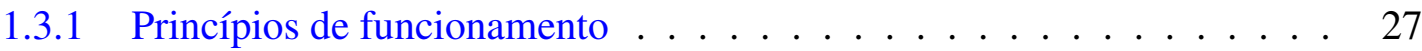

1.4 Equação do fluxgate básico . . . . . . . . . . . . . . . . . . . . . . . 32

1.5 Fluxgate paralelo de dois núcleos . . . . . . . . . . . . . . . 35

1.5.1 Equação do fluxgate paralelo de dois núcleos . . . . . . . . . . 35

1.6 Equação fluxgate ortogonal . . . . . . . . . . . . . . . . . . . . . . 36

$1.7 \quad$ Fluxgate plano miniaturizado . . . . . . . . . . . . . . . . . 38

1.7 .1 Indutores planos . . . . . . . . . . . . . . . . . . . . 39

1.7.2 Fluxgate miniaturizado em tecnologia planar . . . . . . . . . 39

1.8 Principais parâmetros de transdutância de um fluxgate . . . . . . . . . . . . 41

1.8 .1 Responsividade . . . . . . . . . . . . . . . . . 41

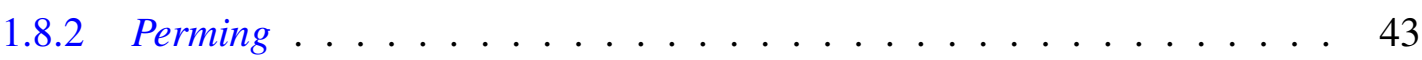

1.8 .3 Ruído . . . . . . . . . . . . . . . . . . . . . 43

1.8.3.1 Ruído eletrônico . . . . . . . . . . . . . . . . . 43

1.8.3.2 Ruído magnético . . . . . . . . . . . . . . . . . . . . 44

1.8.4 Alguns valores encontrados na literatura. . . . . . . . . . . . . 44

2 Fluxgate plano utilizando uma única camada de bobinas $\ldots \ldots \ldots \ldots 4$

2.1 Fluxgate plano e o número de camadas . . . . . . . . . . . . . . . . 47

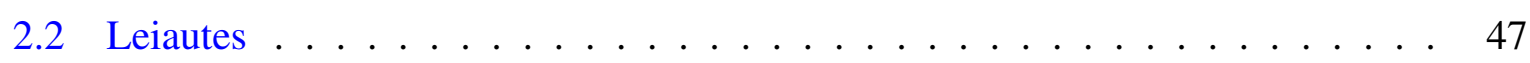

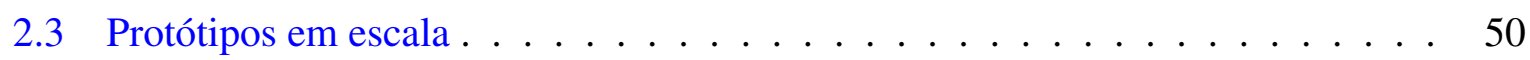

2.3.1 Descrição dos sensores macro $\ldots \ldots \ldots \ldots$

2.3.2 Curvas de magnetização . . . . . . . . . . . . . . . . . 51

2.3.3 Medidas de responsividade . . . . . . . . . . . . . . 52

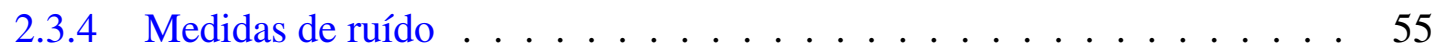

2.3.5 Conclusão para os protótipos em escala . . . . . . . . . . . . . 59

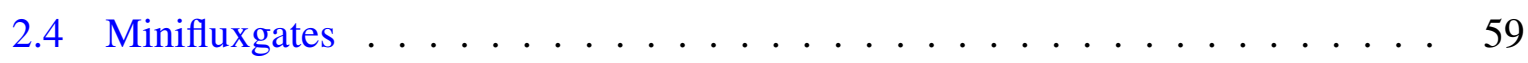

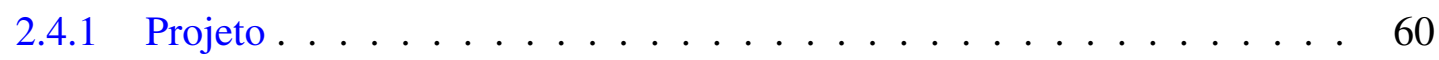

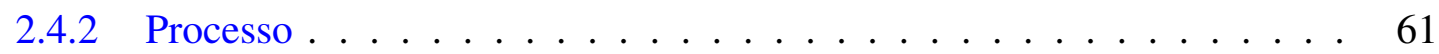

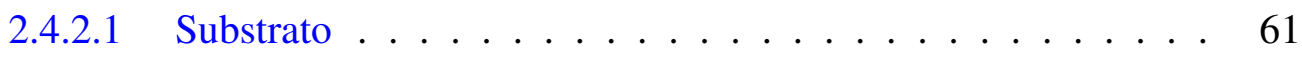

2.4.2.2 Deposição de titânio por sputtering . . . . . . . . . . 62 
2.4.2.3 Deposição de cobre por sputtering . . . . . . . . . . . . . 62

2.4.2.4 Fotogravação dos moldes das bobinas . . . . . . . . . . 63

2.4.2.5 Espessamento do cobre por eletrodeposição . . . . . . . . . . 64

2.4.2.6 Remoção fotoresiste . . . . . . . . . . . . . . . . 65

2.4.2.7 Remoção da semente de cobre e titânio. . . . . . . . . . . . . 65

2.4.2.8 Aplicação de fotoresiste estrutural SU8 . . . . . . . . . . . 66

2.4.2.9 Polimento para remoção do excesso de SU8 e planarização . . 67

2.4.2.10 Deposição do óxido por PECVD . . . . . . . . . . . . . . 68

2.4.2.11 Abertura dos contatos no óxido . . . . . . . . . . . . . 69

2.4.2.12 Deposição de titânio e cobre . . . . . . . . . . . . . . . 70

2.4.2.13 Fotogravação das trilhas e pads . . . . . . . . . . . . 70

2.4.2.14 Molde de fotoresiste para eletrodeposição dos núcleos . . . . 71

2.4.2.15 Eletrodeposição dos núcleos de NiFe . . . . . . . . . . . 71

2.4.2.16 Contatos externos . . . . . . . . . . . . 72

2.4 .3 Sensores obtidos . . . . . . . . . . . . . . . . 73

2.4.4 Metodologia de caracterização . . . . . . . . . . . . . . . . . . 75

2.4 .5 Curva de resposta . . . . . . . . . . . . . . . . 76

2.4.6 Responsividade . . . . . . . . . . . . . . 76

2.4 .7 Ruído . . . . . . . . . . . . . . . . . . . . . 77

2.4 .8 Conclusões, minifluxgates ～. . . . . . . . . . . . . . . 80

3 Fluxgate ortogonal por rotação da magnetização (FORM) . . . . . . . . . . . . 81

3.1 O problema do ruído magnético . . . . . . . . . . . . . . . . . . . . 81

3.2 Revisão bibliográfica . . . . . . . . . . . . . . . . . . . . . . 82

3.3 Projeto FORM . . . . . . . . . . . . . . . . . . 82

3.4 Modelo matemático para um FORM . . . . . . . . . . . . . . 85

3.4.1 Mecanismo de modulação da permeabilidade na saturação . . . . . . . 85

3.4.2 Equação do sinal de saída de um FORM . . . . . . . . . . . . . . 86

3.4.2.1 Operação com núcleo saturado. . . . . . . . . . . . . . 88

3.4.2.2 Aproximação de H. . . . . . . . . . . . . . . . . . 88

3.4.2.3 $H_{e}$ espacialmente homogêneo. . . . . . . . . . . . 89

3.4.3 Validação experimental . . . . . . . . . . . . . . . . . . . . 89

3.5 Considerações sobre o material do núcleo . . . . . . . . . . . . . . . 95

3.5.1 NiFe eletrodepositado . . . . . . . . . . . . . . . . . . . . . 96

3.5 .2 NiFeP eletrodepositado . . . . . . . . . . . . . . . . . . . . . 97

3.6 Construção sensores ortogonais . . . . . . . . . . . . . . . . . . . 98

3.6.1 Remoção do esmalte e limpeza . . . . . . . . . . . . . . . . . . 98

3.6 .2 Eletrodeposição . . . . . . . . . . . . . . . . . . . . . . . . 98

3.6.2.1 Eletrodeposição de $\mathrm{NiFe}$. . . . . . . . . . . . . . . . . . . . 99

3.6.2.2 Eletrodeposição de $\mathrm{NiFeP}$. . . . . . . . . . . . . . . . 99 
3.6.3 Enrolamento da bobina coletora . . . . . . . . . . . . . . . . . 101

3.6.4 Contatos elétricos . . . . . . . . . . . . . . . . . . 102

3.6 .5 Montagem final . . . . . . . . . . . . . . . . . . . . 103

3.6.6 Descrição sensores construídos . . . . . . . . . . . . . . . . . . . . . . 104

3.7 Morfologia e composição das ligas eletrodepositadas . . . . . . . . . . . . . 106

3.8 Curvas de magnetização . . . . . . . . . . . . . . . . . . . . . . . 107

3.8 .1 Energia anisotrópica . . . . . . . . . . . . . . . . 108

3.8.2 Resultados . . . . . . . . . . . . . . . . . . . . 109

3.9 Metodologia de caracterização . . . . . . . . . . . . . . . . 115

3.9.1 Montagem experimental padrão . . . . . . . . . . . . . . . . . . 115

3.9.1.1 Calibração da corrente de excitação . . . . . . . . . . . . 115

3.9.1.2 Calibração da fase . . . . . . . . . . . . . . 116

3.9 .2 Curvas de resposta . . . . . . . . . . . . . . . 117

3.9 .3 Efeito perming . . . . . . . . . . . . . . . . . . 119

3.9 .4 Ruído . . . . . . . . . . . . . . . . . . . . . . 120

3.9.4.1 Montagem experimental ruído. . . . . . . . . . . . . 121

3.9.4.2 Normalização . . . . . . . . . . . . . . . . . . . 122

3.10 Alguns resultados numéricos de responsividade . . . . . . . . . . . . . 125

3.11 Resultados experimentais . . . . . . . . . . . . . . . . . . . . 128

3.11 .1 Grupo A . . . . . . . . . . . . . . . . 130

3.11.1.1 Responsividade . . . . . . . . . . . . . . . . 130

3.11 .1 .2 Efeito perming . . . . . . . . . . . . . . 132

3.11.1.3 Ruído . . . . . . . . . . . . . . . . . . . . . . 134

3.11 .2 Grupo B . . . . . . . . . . . . . . . . . 136

3.11.2.1 Responsividade . . . . . . . . . . . . . . . . 136

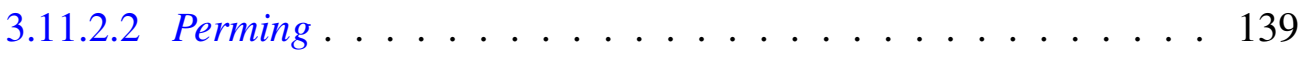

3.11.2.3 Ruído . . . . . . . . . . . . . . . . . . . . 141

3.11 .3 Grupo C . . . . . . . . . . . . . . . . . . . . . 144

3.11.3.1 Responsividade . . . . . . . . . . . . . . . . . 144

3.11.3.2 Perming. . . . . . . . . . . . . . . 147

3.11.3.3 Ruído . . . . . . . . . . . . . . . . . . . . . . . . . . 149

3.11.4 Comparação entre os valores de referência e conclusões . . . . . . . . . 152

3.11.5 Algumas melhorias possíveis . . . . . . . . . . . . . . . . . 154

Conclusão . . . . . . . . . . . . . . . . . . . 155 
ANEXO A Método de obtenção de curvas de magnetização . . . . . . . . . . . . . 169

A.1 Equação da magnetização . . . . . . . . . . . . . . . . . . . . . . . . . . 169

A.2 Sistema experimental . . . . . . . . . . . . . . . . . . 171

A.3 Exemplo . . . . . . . . . . . . . . . . . . . . 171

ANEXO B Análise do ruído . . . . . . . . . . . . . . . . . 173

B.1 Periodograma . . . . . . . . . . . . . . . . . 173

B.2 Ruídorms . . . . . . . . . . . . . . . . . . . . . . . . . . . 174

ANEXO C Cálculo dos fatores de desmagnetização por carga magnética induzida 177

C.1 Campo de desmagnetização . . . . . . . . . . . . . . . . . . . . . . . . . . . . 177

C.2 Prisma retangular . . . . . . . . . . . . . . . . . 178

C.3 Fator de desmagnetização fluxométrico. . . . . . . . . . . . . . . . . . 179

C.4 Fator de acoplamento . . . . . . . . . . . . . . . . . . . . 180

C.5 Fator de desmagnetização paralelo . . . . . . . . . . . . . . . . . . 182 


\section{Prefácio}

Sensores de campo magnético possibilitaram diversas tecnologias como sistemas de navegação veicular, leituras biomagnéticas para exames não invasivos, exploração espacial, dentre muitas outras. Para cada aplicação tem-se associado um conjunto particular de características desejadas. Por exemplo, para a navegação aeronáutica procura-se primariamente confiabilidade, enquanto que para sistemas embarcados, tem-se limitações de tamanho e consumo energético. Dificilmente há uma resposta única, fazendo-se necessário uma ampla gama de magnetômetros diferentes. $\mathrm{O}$ desenvolvimento de novos sensores tem o potencial de beneficiar as atuais aplicações com dispositivos mais adequados, mas também de tornar possível novas tecnologias.

Esta tese de doutorado apresenta os trabalhos de desenvolvimento de magnetômetros de fluxo saturado (fluxgate) realizados pelo autor na tentativa de torná-los menores, mais simples e com melhor resolução, dando ontinuidade a uma linha de pesquisa iniciada no mestrado com a construção dos primeiros sensores magnéticos.

Para construir sensores complexos do início ao fim, muitas vezes se faz necessário restringir a profundidade do estudo de uma determinada etapa por limitação de tempo. Por outro lado, uma vez percorridas todas as etapas, tem-se uma visão geral melhor e pode-se focar nos pontos críticos. Esta foi a estratégia geral do desenvolvimento.

Para o completo entendimento deste texto o leitor deve estar familiarizado com a teoria eletromagnética clássica, especialmente a parte de magnetismo. A bibliografia sugerida, e seguida nas definições e nomenclaturas, é o livro Introduction to Electrodynamics escrito por David J. Griffiths [1]. Em particular, B será denominado campo magnético e não será dado nome especial ao campo auxiliar $\mathbf{H}$. Tentou-se manter as definições das variáveis consistentes por todo o texto, mesmo entre capítulos. Algumas passagens matemáticas foram retiradas da linha principal do texto e colocadas nos anexos com o intuito de não obstruir desnecessariamente a leitura.

Dividiu-se o texto em 3 capítulos principais. No primeiro estão os fundamentos dos sensores tipo fluxgate, com a dedução das equações do sinal de saída, suas principais características e uma lista dos dispositivos similares aos desenvolvidos encontrados na literatura. $\mathrm{O}$ segundo capítulo descreve a continuação imediata do trabalho de mestrado do autor: a miniaturização dos sensores paralelos planos. Já no terceiro capítulo está o trabalho desenvolvido sobre outro tipo de fluxgate que ganhou importância nos últimos anos, o ortogonal, também em escala reduzida. 



\section{Fundamentos}

Este capítulo apresenta os fundamentos dos sensores magnéticos tipo fluxgate para um bom entendimento da pesquisa desenvolvida neste trabalho. Inicia-se com uma breve contextualização deste tipo de sensor e é discutido o mecanismo de funcionamento. São deduzidas as equações do sinal de saída e os seus principais parâmetros. Por fim é apresentada uma tabela com alguns valores destes parâmetros para dispositivos similares aos estudados encontrados na literatura, para que o leitor tenha uma referência prática.

\subsection{Magnetismo na medicina}

Pode-se utilizar os campos magnéticos gerados pelos seres vivos para tentar entender os seus sistemas biofísicos e realizar diagnósticos clínicos. No ser humano, por exemplo, estes campos têm origem nas correntes de despolarização do sistema nervoso, substâncias paramagnéticas presentes no fígado ou ferromagnéticas no pulmão, etc. Mas são tênues, na faixa de nT ou fT, muito abaixo de fontes comumente presentes no ambiente, dificultando suas medidas [2]. A figura 1.1.1 mostra a intensidade do campo magnético associada a órgãos humanos e outras fontes comuns.

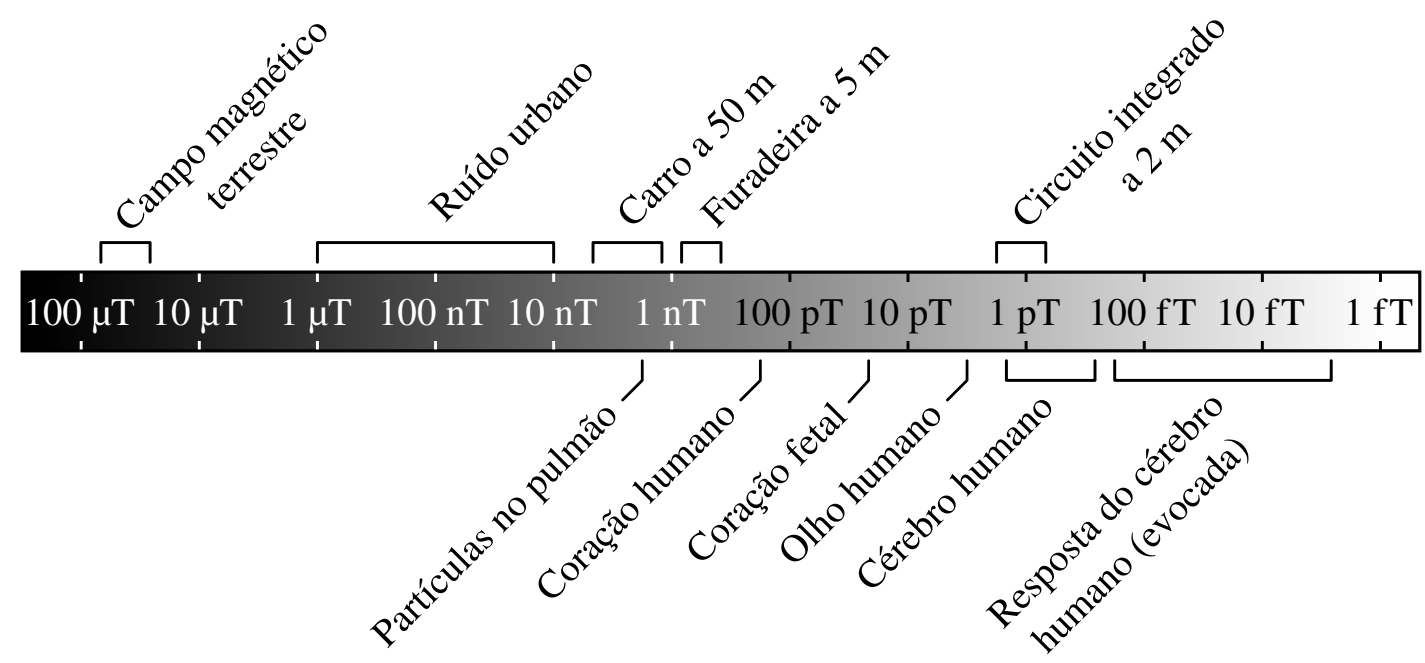

Figura 1.1.1 - Intesidade dos campos magnéticos gerados pelo corpo humano e outras fontes comuns [3].

A tabela 1.1.1 mostra algumas aplicações de magnetômetros na área médica. 


\begin{tabular}{llrr}
\hline Órgão estudado & Método & Faixa $(\mathrm{pT})$ & Largura de banda $(\mathrm{Hz})$ \\
\hline Cérebro & Magnetoencefalografia & $0,01-10$ & $0,1-100$ \\
Coração & Magnetocargiografia & $1-100$ & $0,01-100$ \\
Fígado & Magneto susceptometria & $0,1-10$ & 10 \\
Pulmão & Detecção de impurezas & $100-1000$ & $0,1-10$ \\
Estômago & Magnetogastrografia & $1-20$ & 0,05 \\
\hline
\end{tabular}

Tabela 1.1.1 - Algumas aplicações médicas de magnetômetros [3, 4].

\subsection{Magnetômetros}

Instrumentos usados para medir a intensidade (e a direção) do campo magnético são chamados magnetômetros. Como o campo magnético é uma grandeza vetorial, uma medida completa requer sua magnitude e direção. Logo os magnetômetros podem ser divididos em dois grupos pela maneira como respondem a este caráter vetorial:

- Escalares, que medem a intensidade total do campo magnético em que estão imersos.

- Vetoriais, que medem a componente do campo magnético em uma direção particular.

Dentre os escalares de maior importância pode-se citar o magnetômetro de precessão de prótons (uso geral) e o magnetômetro de bombeamento ótico (maior resolução). Já entre os vetoriais têm-se a bobina de indução (não mede campos estáticos), o fluxgate (uso geral), o SQUID (superconducting quantum interference device, maior resolução) e o magnetoresistor (tamanho e custo reduzido). A tabela 1.2.1 mostra um comparativo entre os principais parâmetros destes sensores.

\begin{tabular}{lrrr}
\hline Magnetômetro & Faixa (mT) & Resolução (nT) & Largura de banda (Hz) \\
\hline Bombeamento ótico & 0,01 a 0,1 & 0,005 & dc a 5 \\
Precessão de prótons & 0,02 a 0,1 & 0,05 & dc a 2 \\
Bobina de indução & $10^{-10}$ a $10^{6}$ & variável & $10^{-1}$ a $10^{6}$ \\
Fluxgate & $10^{-4}$ a 0,5 & 0,01 & dc a $2 \times 10^{3}$ \\
SQUID & $10^{-9}$ a 0,1 & $10^{-4}$ & dc a 5 \\
Magnetoresistor & $10^{-3}$ a 5 & 10 & dc a $10^{7}$ \\
\hline
\end{tabular}

Tabela 1.2.1 - Tabela comparativa entre os principais parâmetros dos magnetômetros mais utilizados $[5,6]$. 
Note que existem várias outras particularidades de cada dispositivo que limitam os seus usos. Por exemplo o SQUID necessita de sistemas complexos de refrigeração, geralmente por hélio líquido.

\subsection{O fluxgate}

Magnetômetros de fluxo saturado (fluxgate) são sensores magnéticos vetoriais que podem medir campos magnéticos contínuos e de baixa frequência. Surgido no início dos anos 1930, este tipo de dispositivo ainda é utilizado em muitas áreas e aplicações como geofísica, indústria aeroespacial e bússolas para veículos terrestres e aeronaves. Atualmente seus principais concorrentes são os magnetoresistores, que são menores, mais baratos e tendem a consumir menos energia, mas atingem menor resolução e são mais afetados por mudanças de temperatura. $\mathrm{O}$ deslocamento com a temperatura de um fluxgate pode ficar abaixo de $0,1 \mathrm{nT} /{ }^{\circ} \mathrm{C}$ e a sensibilidade varia por volta de $50 \mathrm{ppm} /{ }^{\circ} \mathrm{C}$. Se a aplicação requerer resolução na faixa de nT e/ou baixo deslocamento com a temperatura a melhor opção é um sensor tipo fluxgate [7].

\subsubsection{Princípios de funcionamento}

O fluxgate tem seu princípio de funcionamento baseado na lei de Faraday que descreve como uma variação no campo magnético induz um campo elétrico. Na forma integral a lei de Faraday pode ser escrita como

$$
\oint \mathbf{E} \cdot \mathrm{d} \mathbf{l}=-\frac{\mathrm{d}}{\mathrm{d} t} \int \mathbf{B} \cdot \mathrm{d} \mathbf{a}
$$

sendo $\mathbf{E}$ o campo elétrico, dl o segmento diferencial do caminho de integração, B o campo magnético e da o elemento diferencial de área [1].

Partindo da equação 1.3.1, talvez a maneira mais direta de se aplicar esta lei para medir um campo magnético seja por meio de uma espira condutora. Pode-se mostrar que a diferença de potencial induzida nas extremidades de uma bobina perfeitamente condutora imersa em um campo magnético homogêneo é dada por

$$
V=\frac{\mathrm{d}}{\mathrm{d} t}(n A B),
$$

sendo $n$ o número de espiras da bobina, $A$ a área transversal das espiras e $B$ a componente do campo magnético perpendicular ao plano da bobina. Note que foi convencionado a direção normal das espiras como antiparalela ao campo positivo de modo a deixar o sinal da equação positivo.

Utilizando a relação $B=\mu H$, onde $\mu$ é a permeabilidade do meio no interior da bobina pode-se escrever uma equação geral para sensores de indução a partir da equação 1.3.2 como 
segue

$$
V=\frac{\mathrm{d}}{\mathrm{d} t}(n A \mu H)=n A \mu \frac{\mathrm{d} H}{\mathrm{~d} t}+n \mu H \frac{\mathrm{d} A}{\mathrm{~d} t}+n A H \frac{\mathrm{d} \mu}{\mathrm{d} t}
$$

Bobinas de indução fazem uso do primeiro termo, bobinas rotatórias do segundo e sensores fluxgates do terceiro. Embora cada tipo de sensor tenha seu funcionamento baseado em um termo, outros podem aparecer no sinal medido na bobina. Por exemplo, em um fluxgate o primeiro termo pode ser não nulo.

O fluxgate se baseia na modulação temporal da permeabilidade magnética no interior da bobina. Esta é obtida inserindo-se um material ferromagnético, denominado núcleo do sensor, e aplicando-se um campo excitatório para variar sua resposta magnética. Observe na figura 1.3.1a a relação entre $B$ e $H$ para um material ferromagnético. Note que a permeabilidade magnética $(\mu=B / H)$ não é constante, de maneira que se um campo excitatório $H_{\text {exc }}(t)$ for aplicado ao núcleo, esta varia $(\mu=\mu(t))$. Entretanto para materiais com histerese, $\mu$ pode divergir para $H=0$, porque $\mu=B / H$ tende a infinito se $B$ não se anular na origem. Além disto, os valores de $\mu=B / H$ não representam o quão permeável um material com histerese é a baixos valores de $H$. Por esta razão é conveniente definir a permeabilidade diferencial:

$$
\mu_{d}=\frac{\mathrm{d} B}{\mathrm{~d} H}
$$

Agora aplicando-se o campo excitatório $H_{\text {exc }}(t)$ no núcleo varia-se permeabilidade diferencial ( $\mu_{d}=\mu_{d}(t)$ ) de acordo com a curva de chaveamento (figura 1.3.1b), produzindo uma diferença de potencial nos terminais da bobina, que carrega a informação sobre o campo externo. 

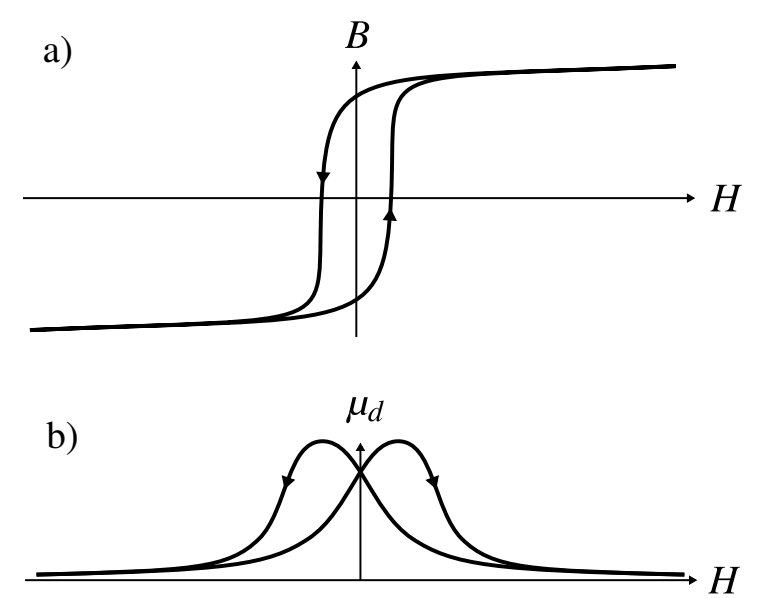

Figura 1.3.1 - (a) Campo magnético no interior de um material ferromagnético em função do campo $H(B(H))$, e, (b) curva de chaveamento $\left(\mu_{d}(H)\right)$ deste material. Estritamente falando $B$ não é função somente de $H$, mas também do estado magnético anterior do material pois exitem processos irreversíveis na mudança de magnetização. Normalmente a relação entre $B$ e $H$ é medida partindo-se do material saturado em uma direção, e aumentando-se o campo $H$ até a saturação na direção contrária. O procedimento é repetido de modo reverso, voltando-se ao estado inicial. O resultado são duas curvas que coincidem somente nas extremidades, apresentando uma defasagem na região central. Este comportamento é conhecido como histerese. As setas indicam a direção de variação do campo na medição de tais curvas.

O sensor fluxgate mais simples é mostrado na figura 1.3.2. Note que o campo utilizado para excitar o núcleo também aparece no sinal de saída $V$, e é geralmente mais intenso que a componente desejada. Isto pode representar um problema, mas há maneiras de minimizar este efeito que serão discutidas mais à frente.

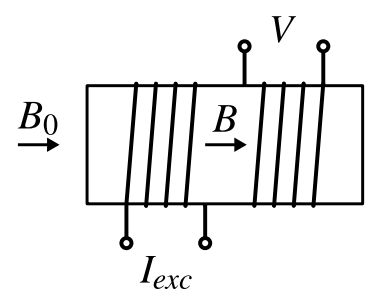

Figura 1.3.2 - Esquema de um fluxgate básico. Um núcleo de material ferromagnético envolto por uma bobina excitadora e outra coletora. O sistema está imerso em um campo magnético $B_{0}$. $B$ é o campo dentro das bobinas, $V$ a tensão gerada nas extremidades da coletora e $I_{\text {exc }}$ a corrente aplicada à bobina excitadora, responsável por $H_{\text {exc }}$. 
na bobina coletora é proporcional ao campo magnético externo e pode ser escrito como

$$
V=\frac{n A B_{0}(1-D)}{\left[1+D\left(\mu_{d r}-1\right)\right]^{2}} \frac{\mathrm{d} \mu_{d r}}{\mathrm{~d} t},
$$

sendo $\mu_{d r}=\mu_{d} / \mu_{0}$ e $D$ o fator de desmagnetização, que depende da geometria do núcleo. Esta é a equação do fluxgate básico [8].

De um ponto de vista fenomenológico o fluxgate, como o próprio nome diz, funciona como uma porta de fluxo magnético. Quando o núcleo não está saturado artificialmente pela bobina excitadora, o campo externo é atraído a passar pelo seu interior devido a sua alta permeabilidade. Quando saturado pelo campo excitatório, este mesmo núcleo se comporta como o meio externo (igual permeabilidade magnética) e o campo externo não é afetado (figura 1.3.3). Este chaveamento do fluxo magnético pode ser feito por um campo de excitação paralelo (fluxgate paralelo) ao campo externo ou ortogonal (fluxgate ortogonal).
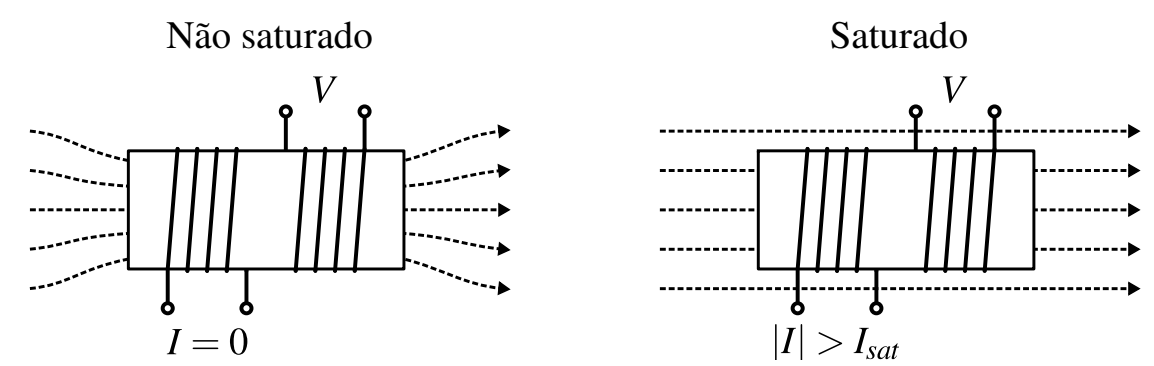

Figura 1.3.3 - O fluxgate funciona como uma válvula de fluxo magnético. A variação na quantidade de fluxo que é permitido passar pelo núcleo do sensor é responsável pela indução da tensão nos terminais da bobina coletora.

A excitação do núcleo pode ser feita com vários tipos de funções periódicas, como senoidal, triangular, quadrada ou por pulsos [9], em frequências que variam de $1 \mathrm{kHz}$ à $100 \mathrm{KHz}$ para sensores de tamanho normal e até alguns MHz para microfluxgates. Visando minimizar o ruído, a intensidade dessa excitação deve ser suficiente para garantir a saturação do núcleo, ou seja, todos os dipolos magnéticos alinhados com o campo aplicado. Claro que esta é uma idealização e na prática nunca há a total saturação. Recomenda-se valores de campo de 10-100 vezes maiores que o ponto de saturação para minimizar o efeito de perming magnético [10], que será descrito na seção 1.8.2.

Como exemplo analise o caso mostrado na figura 1.3.4, onde o transdutor é excitado por uma função senoidal. Veja que a permeabilidade magnética oscila com uma frequência duas vezes maior que a excitação. Desta maneira a componente do sinal de saída devido ao campo externo também terá esta frequência duplicada. Isto facilita a separação entre a tensão induzida pelo campo excitatório e a decorrente do campo magnético de interesse. De fato a maneira mais usual de se obter a informação do campo é analisando a amplitude do segundo harmônico da frequência de excitação. 


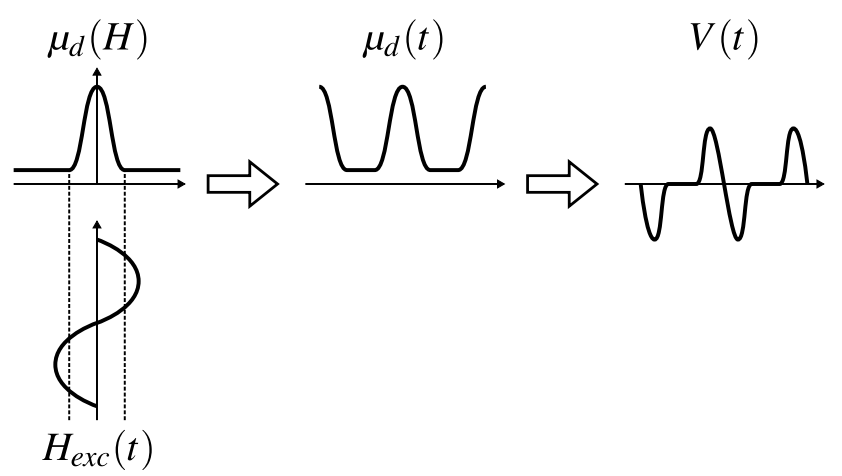

Figura 1.3.4 - Esquema da transformação da função de excitação no sinal de saída. A excitação é feita por uma corrente senoidal aplicada na bobina de excitação, gerando $H_{\text {exc }}(t)$. A curva de chaveamento do núcleo ferromagnético mapeia o campo de excitação na permeabilidade em função do tempo $\left(\mu_{d}(H(t))=\mu_{d}(t)\right)$, sem histerese por simplicidade. A tensão $V(t)$ induzida nos terminais da bobina coletora devido a variação da permeabilidade tem amplitude proporcional ao campo externo e frequência fundamental duas vezes superior à excitação.

Outra técnica de determinar a intensidade do campo externo é analisando a diferença de fase entre os pulsos de tensão. Este campo provoca uma assimetria nos tempos de saturação em cada direção, resultando em um intervalo de tempo diferente entre um pulso e seu antecessor comparado com o mesmo pulso e seu sucessor, que está diretamente ligada ao campo magnético externo. Existem ainda outras maneiras de processar o sinal gerado pelo transdutor, como por exemplo a análise dos harmônicos de paridade diferente. Entretanto o mais usual, e que apresenta melhores resultados para sensores paralelos, é a análise do segundo harmônico [7].

Para sensores fluxgate ortogonais pode-se utilizar o primeiro harmônico quando é adicionada uma componente constante à excitação de modo que $H_{\text {exc }}(t) \geq 0$, como mostra o esquema da figura 1.3.5. 


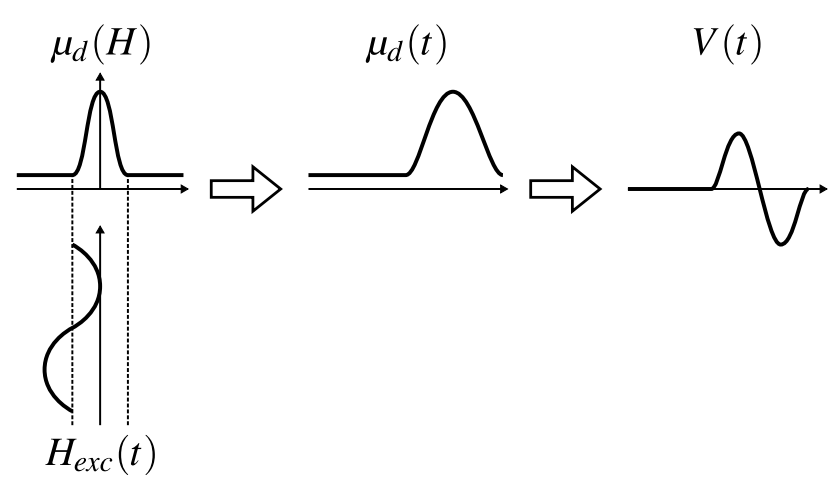

Figura 1.3.5 - Esquema da transformação da função de excitação no sinal de saída de um fluxgate ortogonal operado com deslocamento na excitação. A excitação é feita por uma corrente senoidal acrescida de uma componente constante de maior amplitude. Esta é aplicada na bobina de excitação, gerando $H_{\text {exc }}(t)$. A curva de chaveamento do núcleo ferromagnético mapeia o campo de excitação na permeabilidade em função do tempo $\left(\mu_{d}(H(t))=\mu_{d}(t)\right)$. A tensão $V(t)$ induzida nos terminais da bobina coletora devido a variação da permeabilidade tem amplitude proporcional ao campo externo e frequência fundamental igual à excitação.

\subsection{Equação do fluxgate básico}

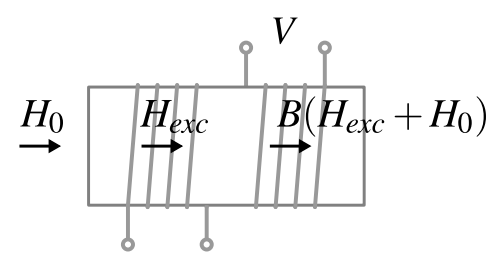

Figura 1.4.1 - Esquema dos campos de um fluxgate básico. O sistema está imerso em um campo $H_{0}$, o qual se deseja medir. A bobina excitadora gera um campo $H_{\text {exc }}$, responsável pela variação da permeabilidade. Campo magnético dentro do núcleo $B\left(H_{e x c}+H_{0}\right)$ tem sua variação temporal capturada pela bobina coletora, gerando a tensão nos terminais $V$.

Considerando o esquema da figura 1.4.1, o fluxo magnético que passa no interior da bobina é dado por $B \cdot A$ onde $B$ é a intensidade do campo paralelo ao eixo da bobina e $A$ a área de sua secção transversal. Note que o caráter vetorial dos campos foi suprimido uma vez que a geometria do problema é basicamente unidimensional. Uma diferença de potencial $(V)$ aparecerá nos terminais da bobina caso o campo magnético varie no tempo, ou seja,

$$
V=n A \frac{\mathrm{d} B}{\mathrm{~d} t} .
$$

O problema então é calcular a variação temporal do campo magnético dentro do núcleo do sensor em função do campo $H$ aplicado. Considerando um campo $B_{0}=\mu_{0} H_{0}$ pequeno pode-se 
aproximar $B$ por

$$
\begin{aligned}
B\left(H_{e x c}+H_{0}\right) & =B\left(H_{e x c}\right)+H_{0} \frac{\mathrm{d} B}{\mathrm{~d} H_{e x c}} \\
& =B\left(H_{e x c}\right)+H_{0} \frac{\mathrm{d} B}{\mathrm{~d} H} \frac{\mathrm{d} H}{\mathrm{~d} H_{e x c}} \\
& =B\left(H_{e x c}\right)+H_{0} \mu_{d} \frac{\mathrm{d} H}{\mathrm{~d} H_{e x c}} .
\end{aligned}
$$

Para calcular o campo $H$ dentro do material é necessário levar em conta o efeito de desmagnetização. Para isto considere um material magnético, como o núcleo do sensor, imerso em um campo magnético externo $B_{\text {ext }}$. Além do campo

$$
H_{\text {ext }}=B_{\text {ext }} / \mu_{0}
$$

e da magnetização $M$, tem origem um campo $H_{d}$, chamado de campo de desmagnetização. Este efeito é causado pelos polos induzidos nas extremidades ${ }^{1}$ da barra (figura 1.4.2) e age de forma a diminuir o campo no seu interior.

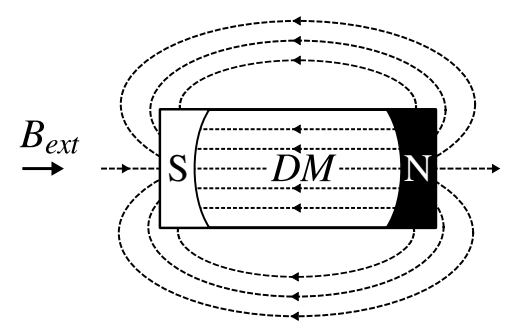

Figura 1.4.2 - Um pedaço material ferromagnético imerso em um campo magnético apresenta polos magnéticos induzidos nas extremidades que geram um campo contrário ao externo e proporcional a magnetização [5].

Este campo depende da magnetização e da geometria do material. Dentro de elipsóides de revolução é uniforme, podendo ser escrito como

$$
H_{d}=-D M
$$

onde $D$ é chamada de fator de desmagnetização. Entretanto para uma variedade de outras formas geométricas como paralelogramos e barras cilíndricas, pode-se aproximar $H_{d}$ como sendo também uniforme [5]. Com estas considerações, dentro do núcleo do sensor tem-se

$$
\begin{aligned}
H & =H_{e x t}+H_{d} \\
& =H_{e x t}-D M \\
& =H_{0}+H_{e x c}-D M .
\end{aligned}
$$

1 Cargas magnéticas reais não existem, o campo de desmagnetização tem origem nos momentos magnéticos produzidos por cargas em movimento 
Voltando a equação 1.4 .2 , pode-se agora escrever a derivada final como

$$
\begin{aligned}
\frac{\mathrm{d} H}{\mathrm{~d} H_{e x c}} & =\frac{\mathrm{d}}{\mathrm{d} H_{e x c}}\left(H_{0}+H_{e x c}-D M\right) \\
& =1-D \frac{\mathrm{d} M}{\mathrm{~d} H}{ }_{\text {exc }} \\
& =1-D \frac{\mathrm{d} M}{\mathrm{~d} H} \frac{\mathrm{d} H}{\mathrm{~d} H_{e x c}} \\
& =\frac{1}{1+D \frac{\mathrm{d} M}{\mathrm{~d} H}}
\end{aligned}
$$

A derivada da magnetização em relação ao campo $H$ é obtida derivando-se a equação

$$
B=\mu_{0}(H+M)
$$

ou seja,

$$
\frac{\mathrm{d} B}{\mathrm{~d} H}=\mu_{d}=\mu_{0}\left(1+\frac{\mathrm{d} M}{\mathrm{~d} H}\right)
$$

Desta forma pode-se reescrever a equação 1.4.6 como

$$
\frac{\mathrm{d} H}{\mathrm{~d} H_{e x c}}=\frac{1}{1+D\left(\frac{\mu_{d}}{\mu_{0}}-1\right)} .
$$

Substituindo este resultado na equação 1.4 .2 chega-se a

$$
\begin{aligned}
B(H) & =B\left(H_{\text {exc }}\right)+H_{0} \frac{\mu_{d}}{1+D\left(\frac{\mu_{d}}{\mu_{0}}-1\right)} \\
& =B\left(H_{\text {exc }}\right)+H_{0} \mu_{0} \mu_{a},
\end{aligned}
$$

onde

$$
\mu_{a}=\frac{\mu_{d r}}{1+D\left(\mu_{d r}-1\right)},
$$

com $\mu_{d r}=\mu_{d} / \mu_{0}$. Esta é chamada de permeabilidade aparente. Para se chegar a tensão nos terminais basta substituir a equação 1.4.10 na equação 1.4.1, ou seja

$$
\begin{aligned}
V & =n A \frac{\mathrm{d}}{\mathrm{d} t}\left[B\left(H_{e x c}\right)+H_{0} \mu_{0} \mu_{a}\right] \\
& =n A \frac{\mathrm{d}}{\mathrm{d} t} B\left(H_{e x c}\right)+n A B_{0} \frac{\mathrm{d} \mu_{a}}{\mathrm{~d} t} .
\end{aligned}
$$

Como já foi dito, o primeiro termo dependente da excitação será ignorado sob a alegação de compensá-lo de alguma maneira. Sendo assim, chega-se a equação final para o sinal de saída de um fluxgate básico, isto é

$$
\begin{aligned}
V(t) & =n A B_{0} \frac{\mathrm{d} \mu_{a}}{\mathrm{~d} t} \\
& =\frac{n A B_{0}(1-D)}{\left[1+D\left(\mu_{d r}-1\right)\right]^{2}} \frac{\mathrm{d} \mu_{d}}{\mathrm{~d} t}
\end{aligned}
$$


Este mesmo resultado foi alcançado, de maneira um pouco diferente, em [11]. Entretanto em alguns outros trabalhos, inclusive do mesmo autor, como [8] e [12], a permeabilidade que aparece nas equações é a permeabilidade relativa $\mu_{r}=(B / H) / \mu_{0}$. Como já foi dito, esta definição de permeabilidade pode causar problemas na região da origem. Além disto a aproximação por trás do resultado é diferente. Na prática entretanto, todos utilizam as curvas de chaveamento obtidas $\operatorname{com} \mu_{d}$.

\subsection{Fluxgate paralelo de dois núcleos}

Para reduzir a componente da excitação no sinal captado na bobina coletora utiliza-se fluxgates paralelos com dois núcleos. Estes são excitados com campos antiparalelos de modo que o fluxo resultante na(s) bobina(s) coletora(s) seja nulo. Em 1941 foi desenvolvido o fluxgate de Vacquier e em 1942 Förster criou uma variante onde separou a bobina coletora em duas e as ligou em série (figura 1.5.1).

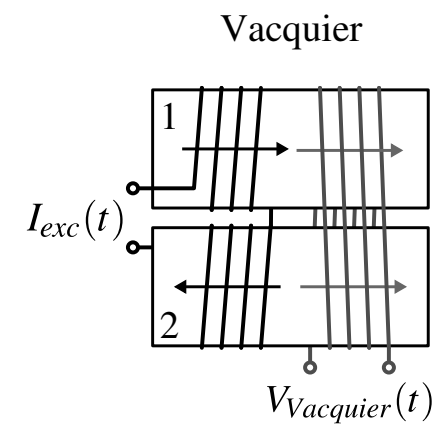

Förster

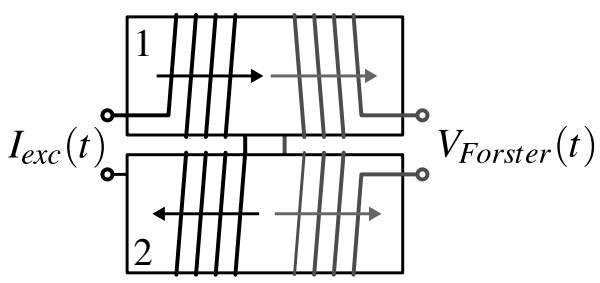

Figura 1.5.1 - Esquema de um fluxgate de Vacquier e de Förster ambos com dois núcleos de material ferromagnético excitados em sentidos opostos por bobinas antiparalelas e com coletoras paralelas.

\subsubsection{Equação do fluxgate paralelo de dois núcleos}

A equação do sinal que aparece nos terminais para o sensor tipo Förster é dada pela soma dos fluxos magnéticos, ou seja

$$
\begin{aligned}
V_{\text {Forster }} & =n A \frac{\mathrm{d}}{\mathrm{d} t}\left(B_{1}+B_{2}\right) \\
& =n A\left(\frac{\mathrm{d} B_{1}}{\mathrm{~d} t}+\frac{\mathrm{d} B_{2}}{\mathrm{~d} t}\right) \\
& =n A \frac{\mathrm{d} B_{1}}{\mathrm{~d} t}+n A \frac{\mathrm{d} B_{2}}{\mathrm{~d} t} \\
& =V_{1}+V_{2}
\end{aligned}
$$

onde $A$ é a área de cada núcleo, e os índices 1 e 2 se referem ao núcleo conforme a figura 1.5.1. Para um sensor tipo Vacquier o mesmo resultado é válido uma vez que parte-se do terceiro passo 
da equação 1.5.1, ou seja

$$
V=V_{\text {Vacquier }}=V_{\text {Forster }} \text {. }
$$

A soma dos campos dentro dos núcleos, utilizando a aproximação da equação 1.4.2 e a simetria $B(H)=-B(-H)$, é dada por

$$
\begin{aligned}
B_{1}+B_{2} & =B\left(H_{e x c}+H_{0}\right)+B\left(-H_{e x c}+H_{0}\right) \\
& =B\left(H_{e x c}\right)+B\left(-H_{e x c}\right)+2 \mu_{0} H_{0} \mu_{a} \\
& =2 \mu_{0} H_{0} \mu_{a}
\end{aligned}
$$

que quando substituída na equação 1.5.1, leva a mesma equação do fluxgate básico com um fator 2.

\subsection{Equação fluxgate ortogonal}

Como já foi dito, pode-se modular a permeabilidade do núcleo com um campo de excitação ortogonal a normal da bobina coletora. Desta maneira, idealmente, não há a contaminação do sinal de saída pela excitação, tornando desnecessária a adição de um segundo núcleo. Além disto, exitem geometrias muito naturais para este modo de excitação, como por exemplo a cilíndrica, onde a excitação pode ser feita por um fio retilíneo passando por dentro do núcleo, como mostra a 1.6.1. Agora o problema é bidimensional, por isto serão definidas duas coordenadas ortogonais, $x_{1}$ e $x_{2}$, sendo que o campo externo de interesse $B_{0}$ está alinhado com a direção 1 e a excitação com a direção 2 .

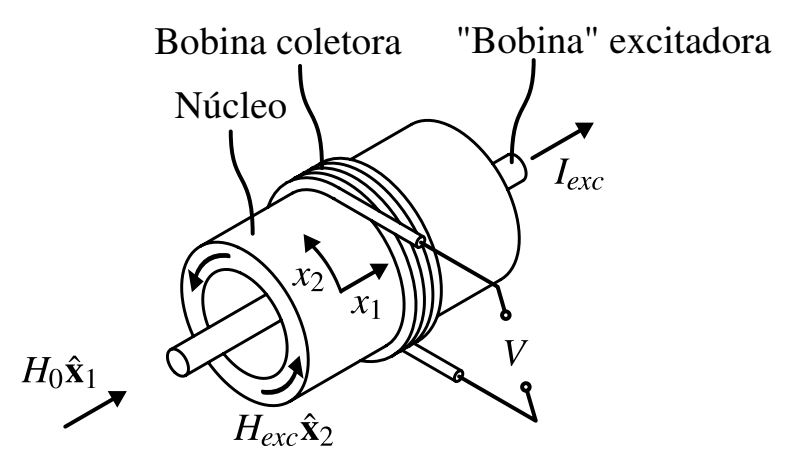

Figura 1.6.1 - Exemplo de fluxgate ortogonal. A excitação é feita na direção $x_{2}$ enquanto que o campo externo de interesse $H_{0}$ está na direção $x_{1}$, acoplado com a bobina.

Para campos $H_{0}$ pequenos, o campo magnético dentro do núcleo pode ser escrito como

$$
\begin{aligned}
\mathbf{B}\left(\mathbf{H}_{e x t}\right) & =\mathbf{B}\left(\mathbf{H}_{e x c}+H_{0} \hat{\mathbf{x}}_{1}\right) \\
& \approx \mathbf{B}\left(\mathbf{H}_{e x c}\right)+H_{0} J\left(\mathbf{H}_{e x c}\right) \hat{\mathbf{x}}_{1},
\end{aligned}
$$


onde $J\left(\mathbf{H}_{\text {exc }}\right)$ é a matriz das derivadas (Jacobiana) calculada no ponto $\mathbf{H}_{\text {exc }}$. Escrevendo-a na forma matricial, tem-se que

$$
J\left(\mathbf{H}_{e x c}\right) \hat{\mathbf{x}}_{1}=\left[\begin{array}{ll}
\left.\frac{\partial B_{1}}{\partial H_{0}}\right|_{\mathbf{H}_{e x c}} & \left.\frac{\partial B_{1}}{\partial H_{e x c}}\right|_{\mathbf{H}_{e x c}} \\
\left.\frac{\partial B_{2}}{\partial H_{0}}\right|_{\mathbf{H}_{e x c}} & \left.\frac{\partial B_{2}}{\partial H_{e x c}}\right|_{\mathbf{H}_{e x c}}
\end{array}\right]\left[\begin{array}{l}
1 \\
0
\end{array}\right]=\left[\begin{array}{l}
\left.\frac{\partial B_{1}}{\partial H_{0}}\right|_{\mathbf{H}_{e x c}} \\
\left.\frac{\partial B_{2}}{\partial H_{0}}\right|_{\mathbf{H}_{e x c}}
\end{array}\right]=\left.\hat{\mathbf{x}}_{1} \frac{\partial B_{1}}{\partial H_{0}}\right|_{\mathbf{H}_{e x c}}+\left.\hat{\mathbf{x}}_{2} \frac{\partial B_{2}}{\partial H_{0}}\right|_{\mathbf{H}_{e x c}} .
$$

Logo a componente 1 do campo, acoplada com a bobina coletora, fica

$$
\begin{aligned}
B_{1} & =\mathbf{B}\left(\mathbf{H}_{e x t}\right) \cdot \hat{\mathbf{x}}_{1} \\
& =\mathbf{B}\left(\mathbf{H}_{e x c}\right) \cdot \hat{\mathbf{x}}_{1}+\left.H_{0} \frac{\partial B_{1}}{\partial H_{0}}\right|_{\mathbf{H}_{e x c}} .
\end{aligned}
$$

Considerando um material isotrópico (ou ao menos com anisotropia diagonal), a componente da excitação desaparece e chega-se a

$$
\begin{aligned}
B_{1} & =\left.\left.H_{0} \frac{\partial B_{1}}{\partial H_{0}}\right|_{\mathbf{H}_{e x c}}\left(\frac{\partial B_{1}}{\partial H_{1}} \frac{\partial H_{1}}{\partial H_{0}}+\frac{\partial B_{1}}{\partial H_{2}} \frac{\partial H_{2}}{\partial H_{0}}\right)\right|_{\mathbf{H}_{e x c}} \\
& =H_{0} \\
& =\left.H_{0}\left(\mu_{d 11} \frac{\partial H_{1}}{\partial H_{0}}+\mu_{d 12} \frac{\partial H_{2}}{\partial H_{0}}\right)\right|_{\mathbf{H}_{e x c}},
\end{aligned}
$$

onde $H_{1}$ e $H_{2}$ são as componentes do campo $\mathbf{H}$ dentro do material. Mais expecificamente, $H_{1}=H_{0}-D_{1} M_{1}$ e $H_{2}=H_{e x c}-D_{2} M_{2}$. Mas a isotropia garante que $\mu_{d 12}=0$, logo

$$
B_{1}=\left.H_{0} \mu_{d 11} \frac{\partial H_{1}}{\partial H_{0}}\right|_{\mathbf{H}_{\text {exc }}}
$$

Similar ao caso do fluxgate básico, tem-se

$$
\begin{aligned}
\frac{\partial H_{1}}{\partial H_{0}} & =1-D_{1} \frac{\partial M_{1}}{\partial H_{0}} \\
& =1-D_{1}\left[\frac{\partial M_{1}}{\partial H_{1}} \frac{\partial H_{1}}{\partial H_{0}}+\frac{\partial M_{1}}{\partial H_{2}} \frac{\partial H_{2}}{\partial H_{0}}\right] \\
& =1-D_{1}\left[\left(\frac{\mu_{d 11}}{\mu_{0}}-1\right) \frac{\partial H_{1}}{\partial H_{0}}+\frac{\mu_{d 12}}{\mu_{0}} \frac{\partial H_{2}}{\partial H_{0}}\right] \\
& =1-D_{1}\left(\frac{\mu_{d 11}}{\mu_{0}}-1\right) \frac{\partial H_{1}}{\partial H_{0}} \\
& =\frac{1}{1+D_{1}\left(\frac{\mu_{d 11}}{\mu_{0}}-1\right)} .
\end{aligned}
$$

E finalmente, substituindo este resultado na equação 1.6.5 chega-se a

$$
\begin{aligned}
B_{1} & =\left.\mu_{0} H_{0} \frac{\mu_{d r 11}}{1+D_{1}\left(\mu_{d r 11}-1\right)}\right|_{\mathbf{H}_{\text {exc }}} \\
& =B_{0} \mu_{a 11}\left(\mathbf{H}_{\text {exc }}\right) .
\end{aligned}
$$


Se for considerado $D_{2}=0$, que é uma boa aproximação para a direção tangencial do cilindro, tem-se que $H_{2} \hat{\mathbf{x}}_{2}=\mathbf{H}_{\text {exc }}$. Neste caso pode-se definir a permeabilidade ortogonal diferencial como

$$
\mu_{d \perp}=\mu_{d 11}\left(H_{2} \hat{\mathbf{x}}_{2}\right)
$$

e a aparente

$$
\mu_{a \perp}=\mu_{a 11}\left(H_{2} \hat{\mathbf{x}}_{2}\right)=\frac{\mu_{d r \perp}}{1+D_{1}\left(\mu_{d r \perp}-1\right)},
$$

onde, como sempre, $\mu_{d r \perp}=\mu_{d \perp} / \mu_{0}$.

$\mu_{d \perp}$ é a curva de chaveamento do núcleo na direção 1 , em torno de $H_{1}=0$, em função do campo $H_{2}$ na direção ortogonal. Desta forma tem-se uma expressão para $B_{1}$ análoga à equação 1.4.10, mas naturalmente sem o termo da excitação. O resto da dedução é idêntico de modo que o sinal que aparece nos terminais da bobina de um fluxgate ortogonal é dado por

$$
\begin{aligned}
V(t) & =n A B_{0} \frac{\mathrm{d} \mu_{a \perp}}{\mathrm{d} t} \\
& =\frac{n A B_{0}\left(1-D_{1}\right)}{\left[1+D_{1}\left(\mu_{d r \perp}-1\right)\right]^{2}} \frac{\mathrm{d} \mu_{d r \perp}}{\mathrm{d} t} .
\end{aligned}
$$

A curva de chaveamento ortogonal é substancialmente diferente da paralela e pode ser aproximada pela permeabilidade na direção 2 como

$$
\mu_{d \perp} \approx \mu_{2} \approx \frac{B_{2}}{H_{2} \pm H_{c}}
$$

onde $H_{c}$ é o campo coercivo (que evita a já mencionada singularidade em $H_{2}=0$ ) [11]. $\mathrm{O}$ formato aproximado é mostrado na figura 1.6.2.

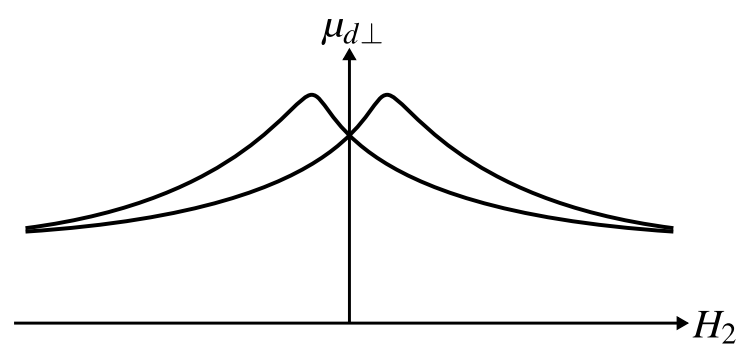

Figura 1.6.2 - Curva de chaveamento ortogonal. Permeabilidade na direção 1 em função do campo $\mathrm{H}_{2}$. Compare com a figura 1.3.1b.

\subsection{Fluxgate plano miniaturizado}

Técnicas de miniaturização são empregadas a fim de se obter sensores menores, com menor consumo energético e mais baratos. Estas técnicas geralmente passam por uma planarização dos componentes, requerida pela tecnologia de filmes finos. Uma vez compatível com esta tecnologia, os sensores podem ser produzidos em massa utilizando-se uma das indústrias mais desenvolvidas atualmente. 


\subsubsection{Indutores planos}

Componentes indutores planos, como as bobinas, são problemáticos. Se comparadas com suas similares tridimensionais, bobinas planas geram um campo menos homogêneo e menos intenso. Este tem uma componente significativa na direção perpendicular ao plano da bobina, geralmente não desejada, e o campo paralelo tem direções distintas dependendo da posição (ver figura 1.7.1). Há uma exceção a essa regra que são os solenoides feitos utilizando duas camadas de metal ao invés do formato clássico em forma de espiral [13, 14].
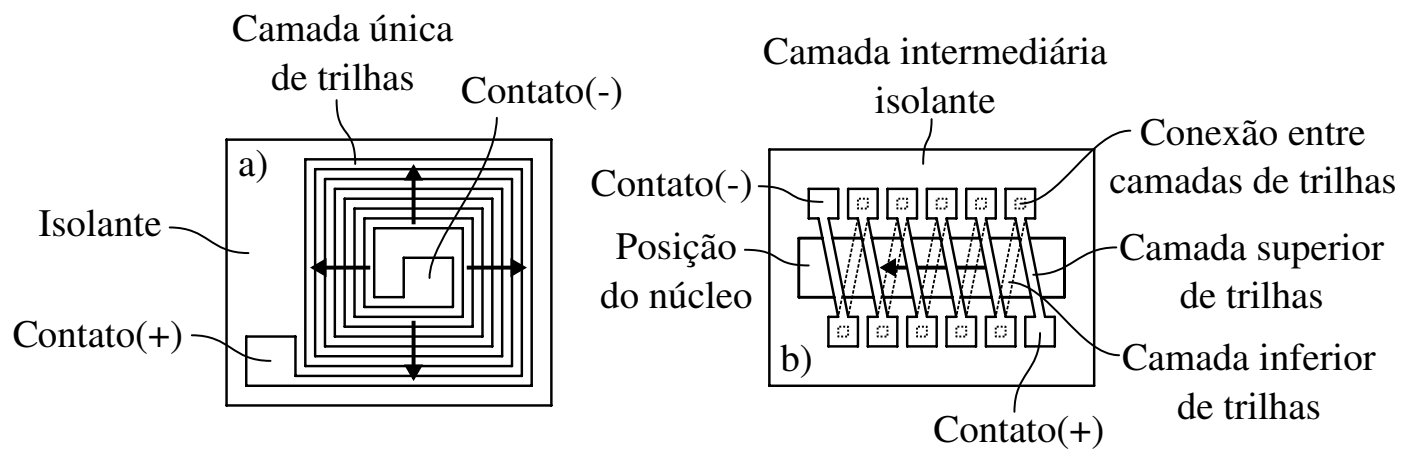

Figura 1.7.1 - Esquema dos dois tipos de indutor mais comuns construídos com filmes finos. A bobina espiral plana quadrada (a) gera um campo paralelo ao plano com direção do centro para fora (indicados pelas setas). Já o solenoide (b) utiliza dois níveis de metal e conexões, aumentando o número de etapas da construção. Entretanto o campo gerado tem componente paralela maior.

\subsubsection{Fluxgate miniaturizado em tecnologia planar}

A miniaturização pode trazer mais algumas consequências negativas para um fluxgate, como a perda de responsividade e resolução. Sabe-se que o ruído magnético cresce rapidamente com a diminuição do núcleo [7]. Mas sensores magnéticos pequenos são necessários em aplicações como leitura de tintas magnéticas e matrizes de sensores [7]. Microssensores deste tipo geralmente têm performance inferior aos similares em escala macro. Superar estas limitações é o principal desafio neste campo de pesquisa atualmente.

O esquema de um fluxgate plano, passível de miniaturização, é mostrado na figura 1.7.2. O dispositivo é composto por duas bobinas coletoras ligadas em série antiparalelamente de modo que a tensão gerada pelo campo de excitação se anule. O campo proveniente da excitação tem o mesmo sentido nas duas espiras e a diferença de potencial induzida se subtrai com esta particular ligação. Já o sinal originado pelo campo externo é naturalmente antiparalelo nas bobinas, portanto as tensões se somam. Na prática o sinal de excitação não some completamente mas é consideravelmente atenuado facilitando o processamento posterior dos dados. 


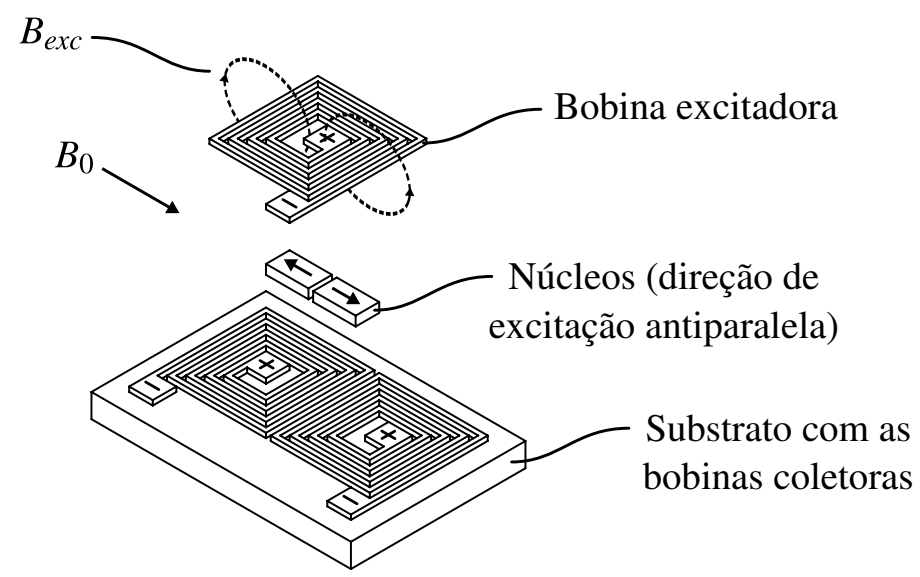

Figura 1.7.2 - Esquema explodido (componentes separados) de um fluxgate plano [15]. Uma bobina satura periodicamente os núcleos ferromagnéticos, um em cada direção. Abaixo tem-se as bobinas coletoras em um esquema similar ao fluxgate de Förster.

Note que o acoplamento entre os núcleos e as bobinas, tanto coletoras quanto excitadora, é muito inferior ao de um sensor não plano. Deste modo, na equação 1.3.5, as constantes $A$ (referente a área da secção transversal da bobina coletora) e $n$ (referente ao número de suas espiras) não são mais válidas. Entretanto pode-se substituir $A n$ por uma constante dependente da geometria das bobinas e do acoplamento, que de maneira geral é menor que o valor original. Esta perda de acoplamento é mais uma razão pela qual sensores tipo fluxgate miniaturizados planos têm desempenho inferior aos modelos tridimensionais.

O processo de fabricação deste tipo de dispositivo é uma sequência de deposições e remoções de materiais com diferentes propriedades. Por exemplo, para formar as bobinas, uma camada de material condutor, como o cobre, é depositada sobre todo o substrato. Por um processo chamado de fotolitografia, partes desta camada são protegidas contra corrosão e o dispositivo inteiro é imerso em uma solução que remove o cobre das partes não protegidas, formando a geometria desejada das bobinas. Assim são formadas as partes isolantes também, e depois de uma série de processos deste tipo tem-se o dispositivo final. A figura 1.7.3 mostra corte transversal de um sensor similar ao mostrado na figura 1.7.2. Note que se trata de uma estrutura simplificada, uma vez que processos reais podem incluir estruturas auxiliares por diversos motivos práticos. 


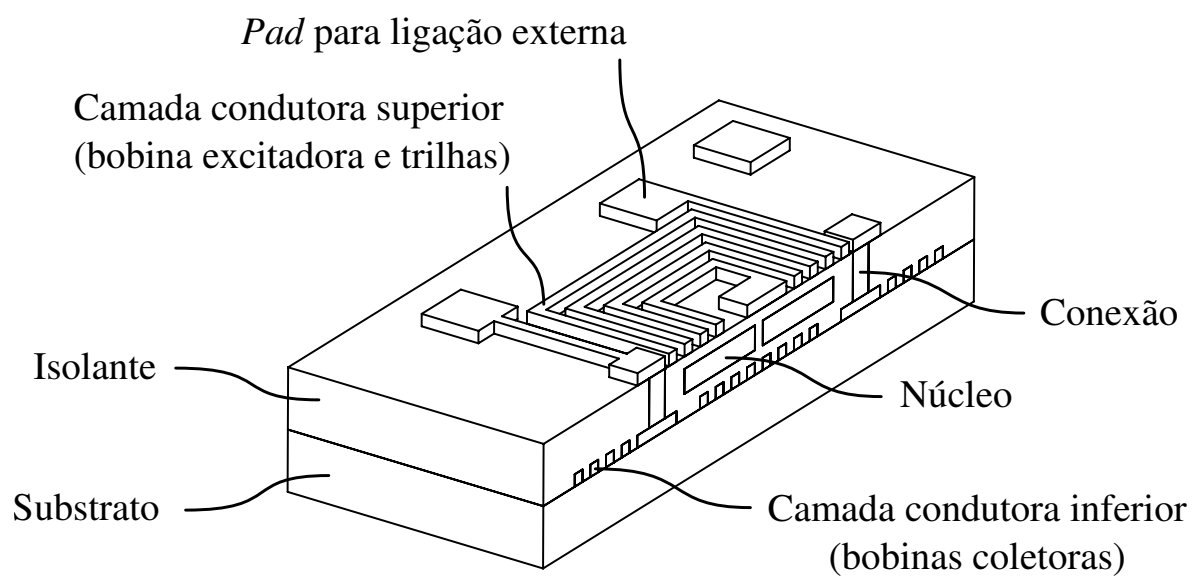

Figura 1.7.3 - Corte lateral de um sensor fluxgate microfabricado, simplificado (similar ao mostrado na figura 1.7.2). O sensor é construído depositando-se e definindo-se a geometria de uma camada por vez.

\subsection{Principais parâmetros de transdutância de um fluxgate}

O sensor fluxgate converte um sinal magnético em um sinal elétrico. A qualidade desta conversão pode ser medida através de alguns parâmetros que determinam os possíveis usos do dispositivo juntamente com outras características como preço, tamanho, consumo energético e complexidade de operação. Enquanto que estes últimos estão discutidos de forma esparsa ao longo do texto, é importante ter-se uma lista compacta dos principais parâmetros transdutância que foram medidos no desenvolvimento dos sensores fluxgate.

\subsubsection{Responsividade}

Responsividade é a razão entre a intensidade do sinal saída pelo de entrada ${ }^{2}$. Em magnetômetros a sua unidade é V/T. Entretanto a saída da bobina coletora de um fluxgate é um sinal periódico e não um nível contínuo. Deste modo a intensidade da saída utilizada no cálculo da responsividade é obtido por uma operação matemática neste sinal (segundo harmônico da transformada de Fourier por exemplo). Tem-se que tomar cuidado com os valores uma vez que essas operações podem escalar o sinal dependendo da sua definição, mascarando a responsividade. Também há casos na literatura em que a responsividade é calculada após o sinal ser amplificado [13]. Por fim, tomou-se cuidado neste texto para que todas as medidas fossem consistentes e livre de amplificações artificiais.

Geralmente a responsividade é dada por um único valor pois assume-se que a resposta do sensor é linear, desta forma o coeficiente angular da reta é suficiente para caracterizá-la. A aproximação linear é válida para uma região perto da origem como mostra a figura 1.8.1.

2 Muitos autores utilizam o termo sensibilidade como sinônimo, entretanto há uma ambiguidade com outra definição que o termo responsividade evita. 
Existem, entretanto, técnicas para compensar esta perda de linearidade. Por exemplo pode-se acoplar ao sensor um sistema de retroalimentação, onde um circuito junto com uma bobina (muitas vezes utiliza-se as bobinas já presentes) tenta manter a saída do sensor nula gerando um campo igual ao externo mas em sentido oposto [5]. Este arranjo transfere a característica de resposta do sensor para o circuito de retroalimentação, o que normalmente é uma boa troca uma vez que circuitos elétricos, em geral, tem linearidade maior que sensores fluxgate. Neste caso a responsividade é determinada somente pelo sistema de retroalimentação.

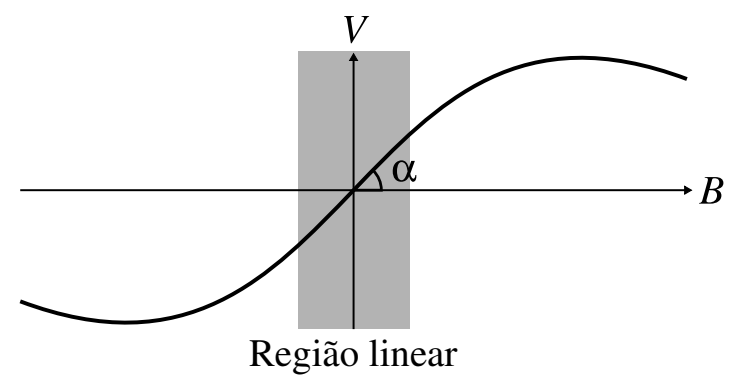

Figura 1.8.1 - Exemplo comum de curva de resposta de um fluxgate. A responsividade é definida como a inclinação da curva na origem $(\alpha)$ e caracteriza bem somente uma região aproximadamente linear.

Da equação do fluxgate (equação 1.3.5) pode-se ver que

$$
\alpha \propto n A(1-D)
$$

onde $n$ é o número de espiras da bobina coletora, $A$ a área transversal do núcleo e $D$ o fator de desmagnetização. Estes são os fatores geométricos. A responsividade depende também da excitação e das propriedades magnéticas do núcleo, mas especificamente, da curva de chaveamento. Considerando a excitação uma onda senoidal do tipo

$$
H_{\text {exc }}=H_{0} \operatorname{sen}\left(\omega_{0} t\right) \text {, }
$$

e supondo que $D=0$ (e consequentemente $H=H_{\text {exc }}$ ), tem-se que

$$
\begin{aligned}
\frac{\mathrm{d} \mu_{d}}{\mathrm{~d} t} & =\frac{\mathrm{d} \mu_{d}}{\mathrm{~d} H_{e x c}} \frac{\mathrm{d} H_{e x c}}{\mathrm{~d} t} \\
& =H_{0} \omega_{0} \cos \left(\omega_{0} t\right) \frac{\mathrm{d} \mu_{d}}{\mathrm{~d} H_{e x c}} .
\end{aligned}
$$

Deste modo, exceto pela dependência da curva de chaveamento, com as condições impostas a responsividade tem comportamento

$$
\alpha \propto n A(1-D) \omega_{0}
$$

Na literatura encontra-se uma grande variação nos valores de responsividade para os sensores tipo fluxgate construídos. A tabela 1.8.1 mostra alguns valores encontrados para dispositivos construidos com dimensões reduzidas. 


\subsubsection{Perming}

O efeito perming é um deslocamento no valor medido pelo sensor após este sofrer um choque magnético, como mostra a figura 1.8.2. É ocasionado por um fenômeno similar à histerese, mas para campos muito superiores. Todos os sensores que utilizam um material ferromagnético estão sujeitos ao perming [5]. A forma de reduzi-lo é periodicamente remagnetizar o núcleo, o que a excitação faz em um fluxgate. Mas quando miniaturizados geralmente tem-se limitações na amplitude de excitação o que os deixa mais suscetíveis a este efeito.

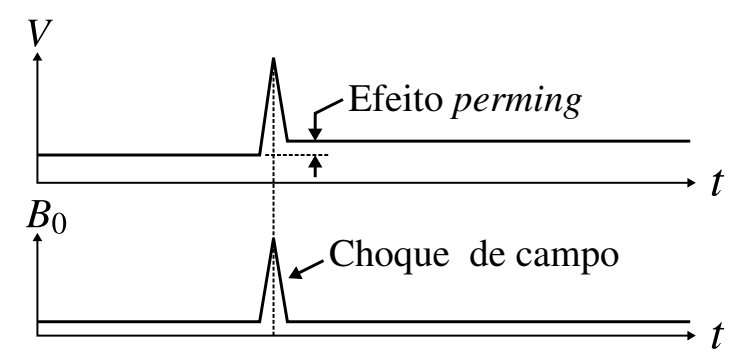

Figura 1.8.2 - Exemplo de deslocamento da saída do sensor quando este é submetido a um choque de campo externo $\left(B_{0}\right)$, o efeito perming.

\subsubsection{Ruído}

Uma das características mais importantes de um sensor é a sua resolução, definida como a menor mudança na quantidade a ser medida que pode ser detectada. Este limite existe pois sensores reais estão sujeitos a inúmeros fatores externos e internos que geram variações na saída descorrelacionadas com a quantidade de interesse. Estas variações são chamadas de ruído e têm caráter aleatório. A resolução está associada ao ponto em que não é mais possível distinguir o sinal externo de interesse destas flutuações.

Para um fluxgate pode-se separar em dois grupos as fontes de ruído: eletrônica e magnética.

\subsubsection{Ruído eletrônico}

Toda eletrônica utilizada na excitação e coleta do sinal, assim como na extração da informação do campo externo, gera ruído. Note que para operar um fluxgate é necessária uma eletrônica relativamente complexa. Em um sensor genérico simples, alimenta-se o transdutor com uma tensão fixa e mede-se uma diferença de potencial proporcional a quantidade de interesse. Já para um fluxgate, tem-se uma excitação periódica com correntes da ordem de centenas de mA e frequência da ordem de centenas de kHz. Nestas frequências os efeitos de indutância e capacitância dos circuitos não podem mais ser desprezados. Também os valores de saída do sensor são obtidos indiretamente por uma transformada integral apropriada do sinal gerado pelas bobinas coletoras. Neste cenário a eletrônica é consideravelmente mais complicada do que o sensor genérico simples, e as fontes de ruído aumentam na mesma proporção. 


\subsubsection{Ruído magnético}

As flutuações na magnetização de um material ferromagnético tem três componentes principais: ruído térmico, associado à energia térmica do sistema de spins, e em metais também à energia dos elétrons portadores; ruído de excesso, associado às variações de temperatura do material; ruído de Barkhausen, gerado quando há variação no estado magnético do material causada por um campo magnético externo. A importância de cada uma destas componentes para um fluxgate convencional é distinta. O ruído de excesso está relacionado com a estabilidade térmica da medida, mas não com as flutuações de maior frequência que aparecem nas medidas de ruído usuais. O ruído térmico tem características de ruído branco mas é mínimo se comparado com o de Barkhausen com espectro do tipo $1 / f[16,17]$.

Fluxgates convencionais comerciais atingem resoluções de $100 \mathrm{pT} / \sqrt{\mathrm{Hz}}$ (10 nT de precisão absoluta) e no estado da arte atingem $10 \mathrm{pT} / \sqrt{\mathrm{Hz}}$ ( $1 \mathrm{nT}$ de precisão absoluta). Comparando com a resolução máxima teórica sem a componente de ruído de Barkhausen (somente o ruído térmico) para um sensor factível (núcleo de $2 \times 10^{-8} \mathrm{~m}^{3}$ ) obtida por [18], aproximadamente 100 fT, vê-se que eliminação deste tipo de ruído é a chave para o aumento da resolução. Esta necessidade se torna mais evidente em sensores miniaturizados pois o ruído de Barkhausen é proporcionalmente maior em núcleos menores.

O ruído de Barkhausen é originado no deslocamento das paredes dos domínios magnéticos quando esta encontra defeitos na rede cristalina, como defeitos puntuais (ver figura 1.8.3), borda de grãos cristalinos [19], etc. Isto promove uma variação abrupta na magnetização, levando ao ruído de Barkhausen.

a)

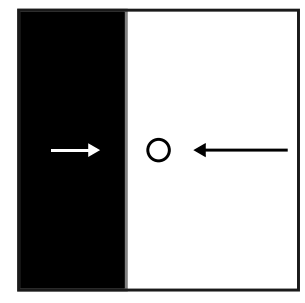

$\mathrm{H} \leftarrow$ b)

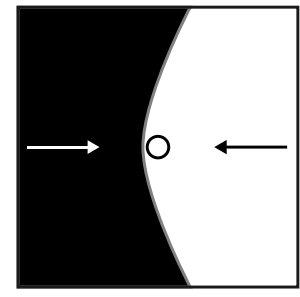

$\mathrm{H} \rightarrow$ c)

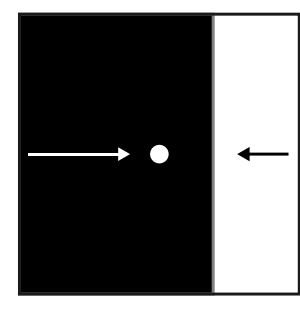

$\mathrm{H}$

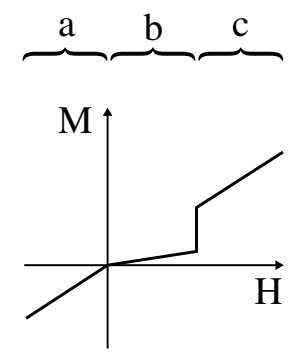

Figura 1.8.3 - Salto de Barkhausen, representação de um domínio magnético e curva de magnetização. (a) A parede do domínio crescente (preto) encontra um defeito e é bloqueada momentaneamente (b) até ter energia suficiente para ultrapassá-lo (c).

\subsubsection{Alguns valores encontrados na literatura.}

A tabela 1.8.1 mostra os valores dos parâmetros discutidos encontrados na literatura para alguns sensores tipo fluxgate com dimensões reduzidas. 


\begin{tabular}{|c|c|c|c|c|c|}
\hline Ref. & $\alpha(\mathrm{V} / \mathrm{T})$ & $\begin{array}{l}\text { Perming }(\mu \mathrm{T}) / \\
\text { choque }(\mathrm{mT})\end{array}$ & Ruído (nT) & $\begin{array}{l}\text { Dimensões } \\
(\mathrm{mm})\end{array}$ & Principal característica \\
\hline [20] & 73 & $5 / 6$ & $27(0.1-10 \mathrm{~Hz})$ & $20 \times 20$ & Núcleos simétricos. \\
\hline [21] & 28 & $5 / 6$ & $24(0,02-10 \mathrm{~Hz})$ & $0,7 \times 1 *$ & $\begin{array}{l}\text { Circuito magnético fe- } \\
\text { chado. }\end{array}$ \\
\hline [22] & 210 & $1,7 / 6$ & - & $2,6 \times 1,7$ & $\begin{array}{l}\text { Baixo consumo energé- } \\
\text { tico. }\end{array}$ \\
\hline [23] & 4,3 & $0,4 / 50$ & - & $4 \times 0,04 *$ & Fluxgate ortogonal. \\
\hline [24] & 650 & $30 / 400$ & $32 @ 1 \mathrm{~Hz}$ & $6 \times 2,4$ & $\begin{array}{l}\text { Saturação local do nú- } \\
\text { cleo e baixa potência. }\end{array}$ \\
\hline [25] & 220 & - & $5 @ 10 \mathrm{~Hz}$ & $1,6 \times 0,6$ & $\begin{array}{l}\text { Alta frequência e baixa } \\
\text { potência. }\end{array}$ \\
\hline [14] & 21,7 & - & 50 (resolução) & $6,2 \times 3,5$ & $\begin{array}{l}\text { Bobinas mutuamente } \\
\text { excitadoras e coletoras. }\end{array}$ \\
\hline [26] & 8,1 & - & 2,6@1 Hz & $2,5 \times 1,8$ & $\begin{array}{l}\text { Bobinas feitas por cola- } \\
\text { gem de fios de ouro. }\end{array}$ \\
\hline
\end{tabular}

Tabela 1.8.1 - Valores dos principais parâmetros de um fluxgate encontrados na literatura para disposivitos com dimensões reduzidas. *Somente o núcleo. 



\section{Fluxgate plano utilizando uma única ca- mada de bobinas}

Este capítulo trata sobre o desenvolvimento de fluxgates paralelos e planos utilizando uma única camada de bobinas. Depois de uma breve discussão sobre o número de camadas utilizadas na sua construção e suas consequências, são mostrados os resultados obtidos para protótipos em escala dos leiautes propostos. A seguir é apresentado o projeto de miniaturização, com o processo de microfabricação e os dispositivos resultantes. Finalmente estes são caracterizados e os resultados discutidos.

\subsection{Fluxgate plano e o número de camadas}

Geralmente sensores tipo fluxgate plano são construídos utilizando-se um número elevado de camadas como o mostrado na figura 1.7.3. Cada camada aumenta a complexidade do processo de manufatura e há situações onde tem-se um limite no número máximo de camadas utilizáveis. Note que não se trata apenas de um processo mais longo, construir uma geometria complexa sobre um substrato limpo e plano é muito mais fácil do que o fazer sobre um conjunto de filmes previamente depositados e fotogravados. A superfície neste segundo caso é em geral irregular e com uma densidade de defeitos muito superior.

$\mathrm{Na}$ literatura são encontrados sensores planos que utilizam duas ou mais (até quatro [27]) camadas de bobinas $[28,15,21,9,29,30]$. Já os que fazem uso de solenoides [31, 32, 33, 25, 34, $14,26]$ necessitam de duas camadas de trilhas com o núcleo ferromagnético entre estas (como mostra a figura 1.7.1).

A ideia foi desenvolver sensores microfabricados utilizando o menor número de camadas visando um processo mais simples. Para isto foram propostos dois novos leiautes onde todas as bobinas estão na mesma camada condutora.

\subsection{Leiautes}

Define-se por leiaute a disposição relativa dos principais elementos que constituem o sensor: núcleo, bobinas excitadoras e bobinas coletoras. O leiaute proposto em [15] servirá de referência (LR, figura 2.2.1a). Este foi escolhido pois tem a disposição dos componentes mais simples e direta. 
a)

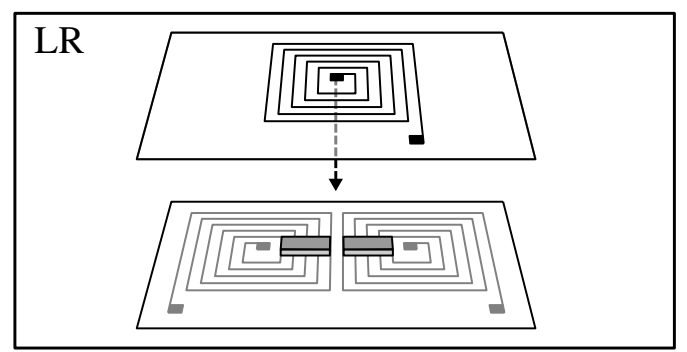

[- Bobinas de excitação

ㅁobinas coletoras

$\sqsupseteq \quad$ Núcleo ferromagnético

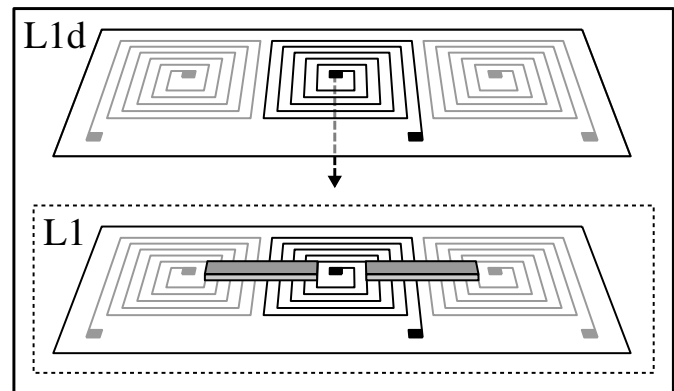

b)

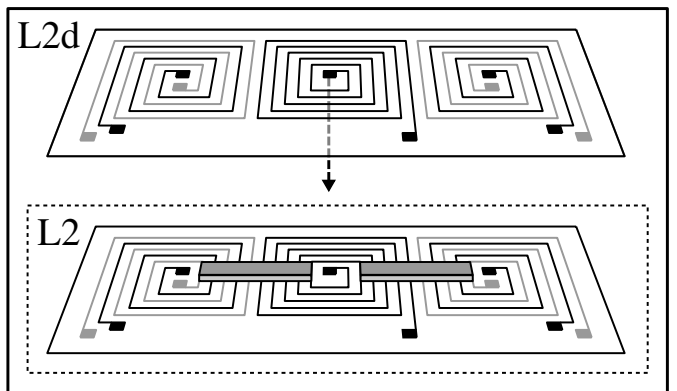

c)

Figura 2.2.1 - Leiautes testados. a) Leiaute de referência. b) Leiaute 1 simples e duplo. c) Leiaute 2 simples e duplo.

O leiaute 1 (L1, figura 2.2.1b) é uma versão do LR onde todas as bobinas se encontram no mesmo plano, reduzindo assim uma camada condutora e uma isolante associada. Por outro lado tem-se agora um núcleo mais comprido onde uma parte não está diretamente sobre a bobina de excitação. O campo criado por esta bobina é ordens de grandeza menos intenso nestas regiões externas (veja a figura 2.2.2) e isto compromete a completa saturação do núcleo. 


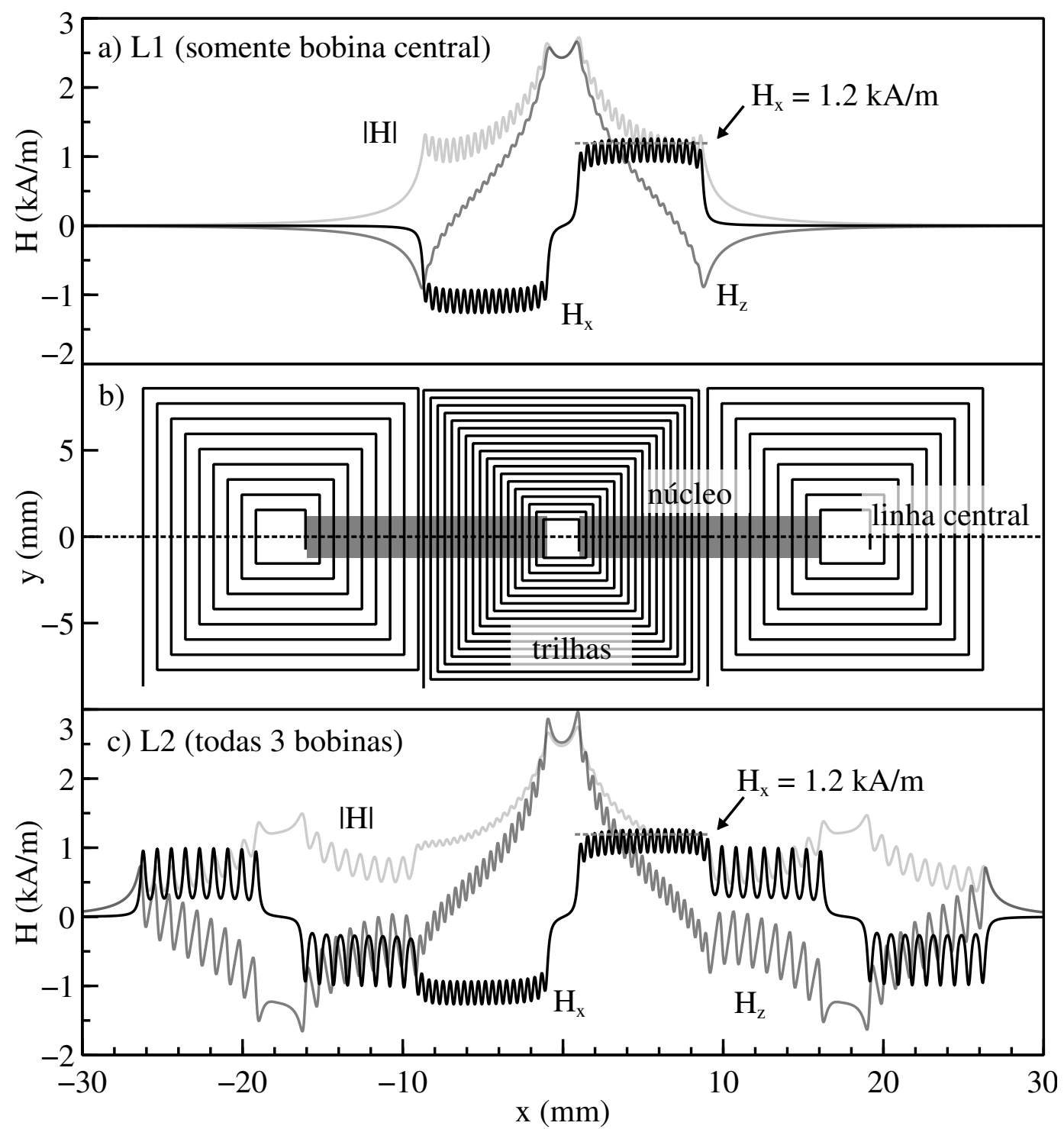

Figura 2.2.2 - Campo gerado por uma bobina plana espiral (b) calculado por elementos finitos. a) Quando somente a bobina central está presente, como no caso do L1(d) somente a região central do núcleo está imersa em um campo excitatório intenso. Note que a componente perpendicular ao plano da bobina $H_{z}$ tem intensidade similar à paralela $H_{x}$. Nos modelos deste tipo de sensor somente a componente $x$ é considerada. c) Quando as bobinas de excitação auxiliares estão presentes a região externa do núcleo é melhor magnetizada. Em ambos os casos o valor de referência para a relação entre a corrente de excitação e o campo $H_{\text {exc }}$ é de $1,2 \mathrm{kA} / \mathrm{m}$ por A.

A ideia por trás do leiaute 2 (L2, figura 2.2.1c) foi colocar bobinas excitadoras dentro das coletoras de modo que a parte do núcleo, antes imersa apenas no campo residual da bobina excitadora central, agora tenha trilhas imediatamente sobre ela. Mas note que tanto estas bobinas extras como coletoras têm reduzida pela metade a densidade de espiras. Já leiautes L1d e L2d são as versões duplicadas de L1 e L2. Com eles consegue-se eliminar a componente perpendicular da excitação $\left(H_{z}\right)$ e aumentar a relação corrente/amplitude de excitação. 


\subsection{Protótipos em escala}

Construir um sensor microfabricado envolve equipamentos e instalações somente encontradas em alguns poucos laboratórios no Brasil. Além disto o processo é longo, com custo alto e pouco flexível, no sentido que, se for constatado algum problema de projeto durante a sua execução, dificilmente isto não implicaria em recomeçá-lo. Por exemplo as máscaras litográficas utilizadas para definir a geometria de cada camada tem um valor relativamente alto e não podem ser corrigidas. Se alguma geometria necessitar mudança, não só as amostras serão perdidas, mas a máscara em questão e possivelmente todas outras, uma vez que as geometrias das camadas são correlacionadas. Por exemplo, a posição das conexões entre camadas depende da posição dos pads nas camadas conectadas. Desta maneira optou-se por construir protótipos em escala 10:1 utilizando placas de circuito impresso ( $\mathrm{PCB}$, do inglês printed circuit board) e técnicas simples, de baixo custo e disponíveis no laboratório Sensormat. A caracterização prévia dos sensores construídos por este método foram o tema da dissertação de mestrado do autor deste texto [35]. As medidas apresentadas aqui são o refinamento deste trabalho inicial utilizando uma montagem experimental melhor, não disponível na ocasião do mestrado.

\subsubsection{Descrição dos sensores macro}

As bobinas feitas em PCB têm 18 espiras com $220 \mu \mathrm{m}$ de largura cada, espaçadas pela mesma distância totalizando aproximadamente $16 \mathrm{~mm}$. Já as bobinas auxiliares utilizadas nos leiautes L2(d) têm as mesmas características mas com metade das espiras. A figura 2.2.2 foi construída baseada nestas dimensões. Os núcleos de $\mathrm{NiFe}$ foram eletrodepositados utilizando a solução encontrada em [36], onde foi substituída a sacarina ácida por sacarina sódica, como mostrado na tabela 2.3.1. A densidade de corrente utilizada na eletrodeposição foi de $14 \mathrm{~mA} / \mathrm{cm}^{2}$, feita sobre um substrato de cobre por $40 \mathrm{~min}$. O banho foi mantido em temperatura ambiente. Estes parâmetros produzem um filme com composição associada a maior permeabilidade da liga $\mathrm{NiFe}$, com a quantidade percentual de cada elemento 80/20 respectivamente [37]. O processo levou à núcleos com $7 \mu \mathrm{m}$ de espessura. As outras dimensões são: $13 \mathrm{~mm}$ de comprimento e 3 $\mathrm{mm}$ de largura. $\mathrm{O}$ substrato de cobre utilizado tem $300 \mu \mathrm{m}$ de espessura.

\begin{tabular}{llr}
\hline Reagente & & Concentração (mol/l) \\
\hline Sulfato de níquel & $\mathrm{NiSO}_{4}$ & 0.7 \\
Sulfato de ferro & $\mathrm{FeSO}_{4}$ & 0.03 \\
Cloreto de níquel & $\mathrm{NiCl}_{2}$ & 0.02 \\
Sacarina Sódica & $\mathrm{C}_{7} \mathrm{H}_{4} \mathrm{NNaO}_{3} \mathrm{~S}$ & 0.016 \\
Ácido Bórico & $\mathrm{H}_{3} \mathrm{BO}_{3}$ & 0.4 \\
\hline
\end{tabular}

Tabela 2.3.1 - Solução de eletrodeposição de NiFe. 
A tabela 2.3.2 descreve os sensores em escala construídos. Foram denominados com a letra "M" maiúscula seguido do leiaute referente.

\begin{tabular}{lrrrrr}
\hline & MLR & ML1 & ML2 & ML1d & ML2d \\
\cline { 2 - 6 } Espiras coletoras & 36 & 36 & 18 & 72 & 36 \\
Camadas de bobinas & 2 & 1 & 1 & 2 & 2 \\
Comprimento do núcleo (mm) & 6,5 & 13 & 13 & 13 & 13 \\
\hline
\end{tabular}

Tabela 2.3.2 - Parâmetros geométricos dos protótipos em escala macroscópica.

\subsubsection{Curvas de magnetização}

As características dos sensores tipo fluxgate são altamente dependentes do comportamento magnético do núcleo. A maneira convencional de analisar este comportamento é através de curvas de magnetização, onde a magnetização $M$ é medida em função de um campo externo H. Nesta relação está contida a permeabilidade que define a resposta do sensor, como pode ser visto nas equações do sinal de saída discutadas na seção 1 . O método utilizado para a obtenção das curvas de magnetização está descrito no apêndice A. Foram medidas as curvas da região central do núcleo utilizando-se o campo externo gerado por uma bobina de Helmholtz (2.3.1a) assim como as curvas das extremidades onde o campo $\mathrm{H}$ foi gerado pelas bobinas de excitação do sensor (figura 2.3.1b e 2.3.1c). É possível ver claramente a influência das bobina excitadoras auxiliares em ML2. 


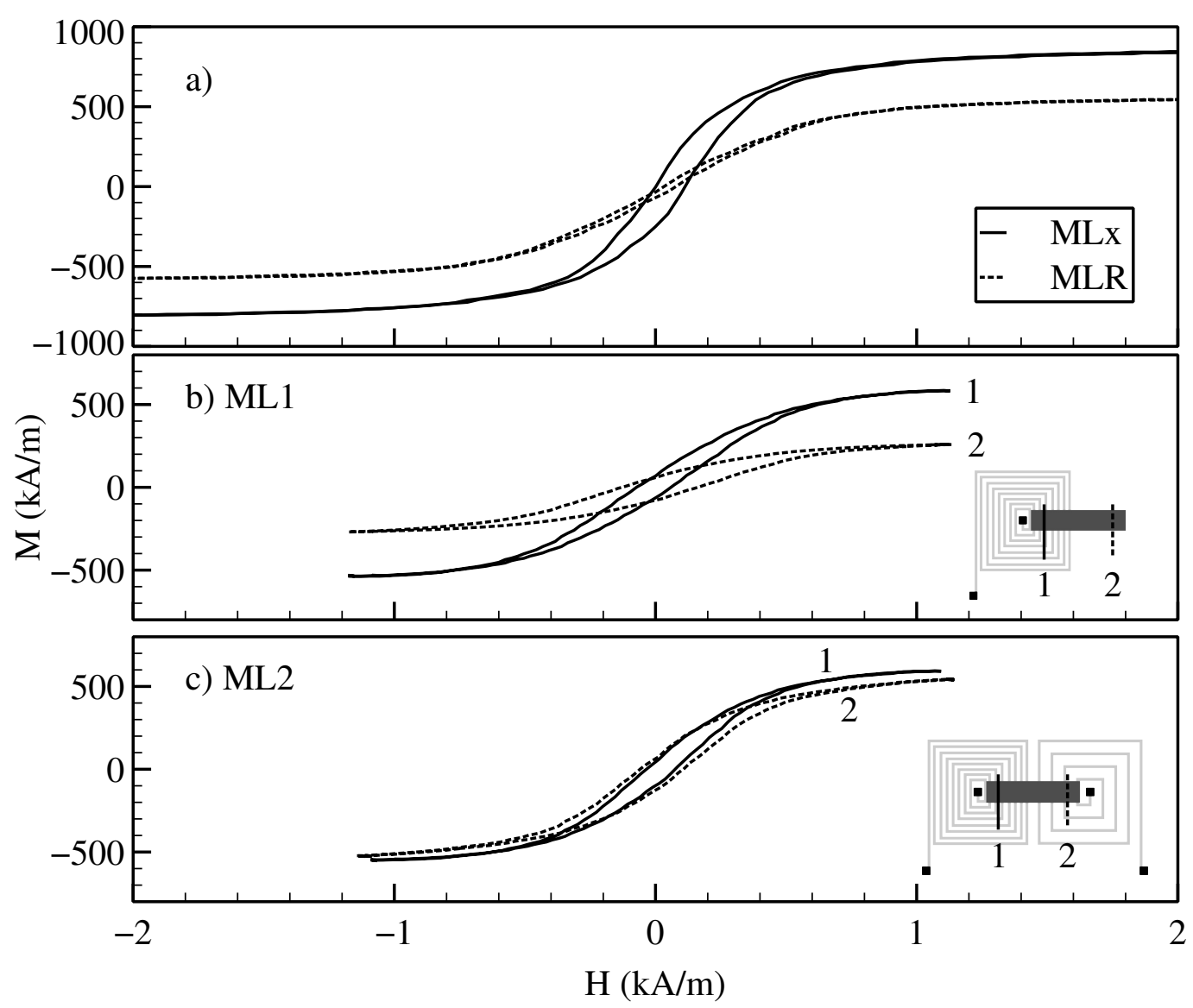

Figura 2.3.1 - Curvas $\mathrm{B}(\mathrm{H})$ do núcleo utilizado nos sensores. Todos os sensores (ML1, ML2, ML1d e ML2d) utilizaram a mesma amostra como núcleo, chamada de (MLx), exceto MLR onde esta foi cortada ao meio. (a) Uma bobina de Helmholtz produziu o campo H e a magnetização foi medida no plano central do núcleo. Tanto MLx quanto MLR têm o mesmo formato de curva, entretanto a desmagnetização é maior no caso de MLR. (b) Agora o campo H é gerado diretamente pelas bobinas excitadoras dos sensores e a magnetização é medida nas extremidades conforme mostra a inserção. A parte externa (2) tem magnetização inferior a parte interna diretamente excitada em ML1, mas o formato da curva é o mesmo uma vez que o campo magético se propaga pelo comprimento do núcleo. (c) Uma magnetização muito superior é alcançada pela parte externa (2) do núcleo em ML2, quase igual à interna (1).

\subsubsection{Medidas de responsividade}

A figura 2.3.2 mostra a montagem experimental utilizada nas medidas de responsividade. A excitação teve forma de onda senoidal com frequência fixa em $100 \mathrm{kHz}$. Foram coletadas cinco curvas de resposta para cada intensidade de excitação, na faixa de campo de 0 a $50 \mu \mathrm{T}$, contendo 11 pontos cada (veja a figura 2.3.3). A responsividade foi calculada como a média da inclinação do ajuste linear destas curvas. 


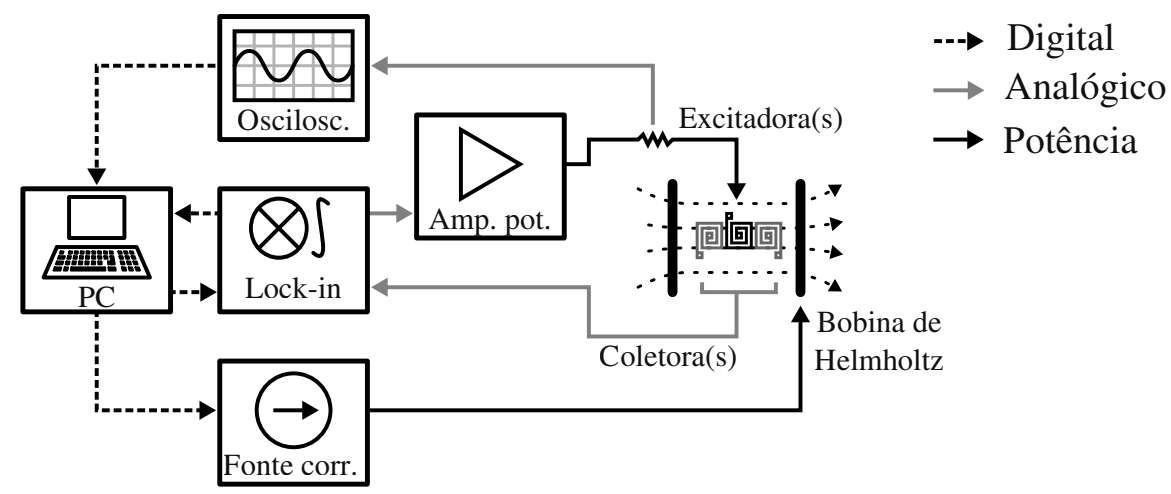

Figura 2.3.2 - Um computador controla os parâmetros do oscilador presente no amplificador lock-in (Signal Recovery 7280 DSP) que excita através de um amplificador (baseado no OPA564) o fluxgate. A amplitude de excitação é monitorada pela queda de potencial em um resistor. O sinal é coletado pelo amplificador lock-in que utiliza como referência um sinal com o dobro da frequência de excitação (multiplicada internamente). A saída do lock-in é ligada diretamente no computador. Também controlado por este tem-se uma fonte de tensão (HP 6653A) que é responsável pela geração do campo externo através de uma bobina de Helmholtz.

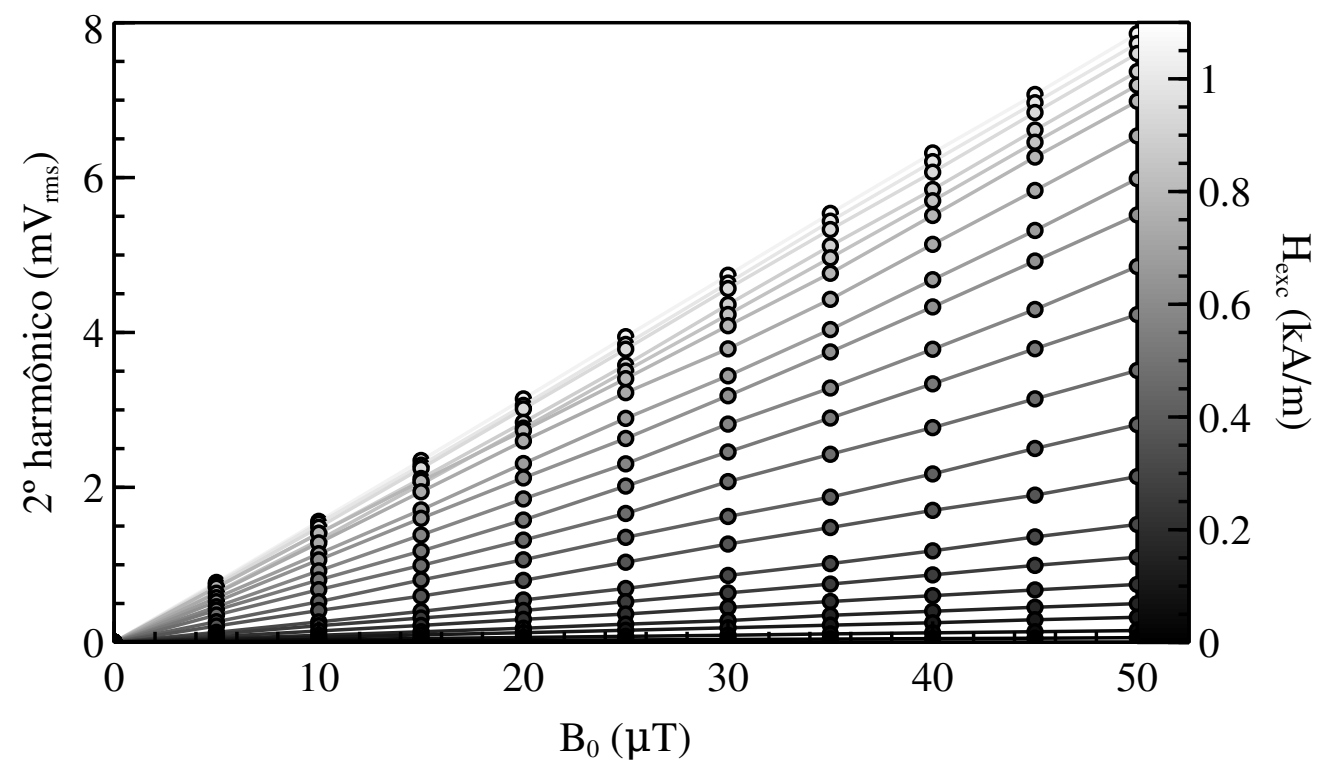

Figura 2.3.3 - Exemplo das curvas de resposta utilizadas no cálculo da responsividade, obtidas para ML1.

A responsividade em função da amplitude de excitação para os cinco leiautes pode ser vista na figura 2.3.4. O campo de excitação $H_{\text {exc }}$ máximo aplicado a cada sensor teve seu valor definido pela corrente máxima do amplificador, aproximadamente $1 \mathrm{~A}$. 


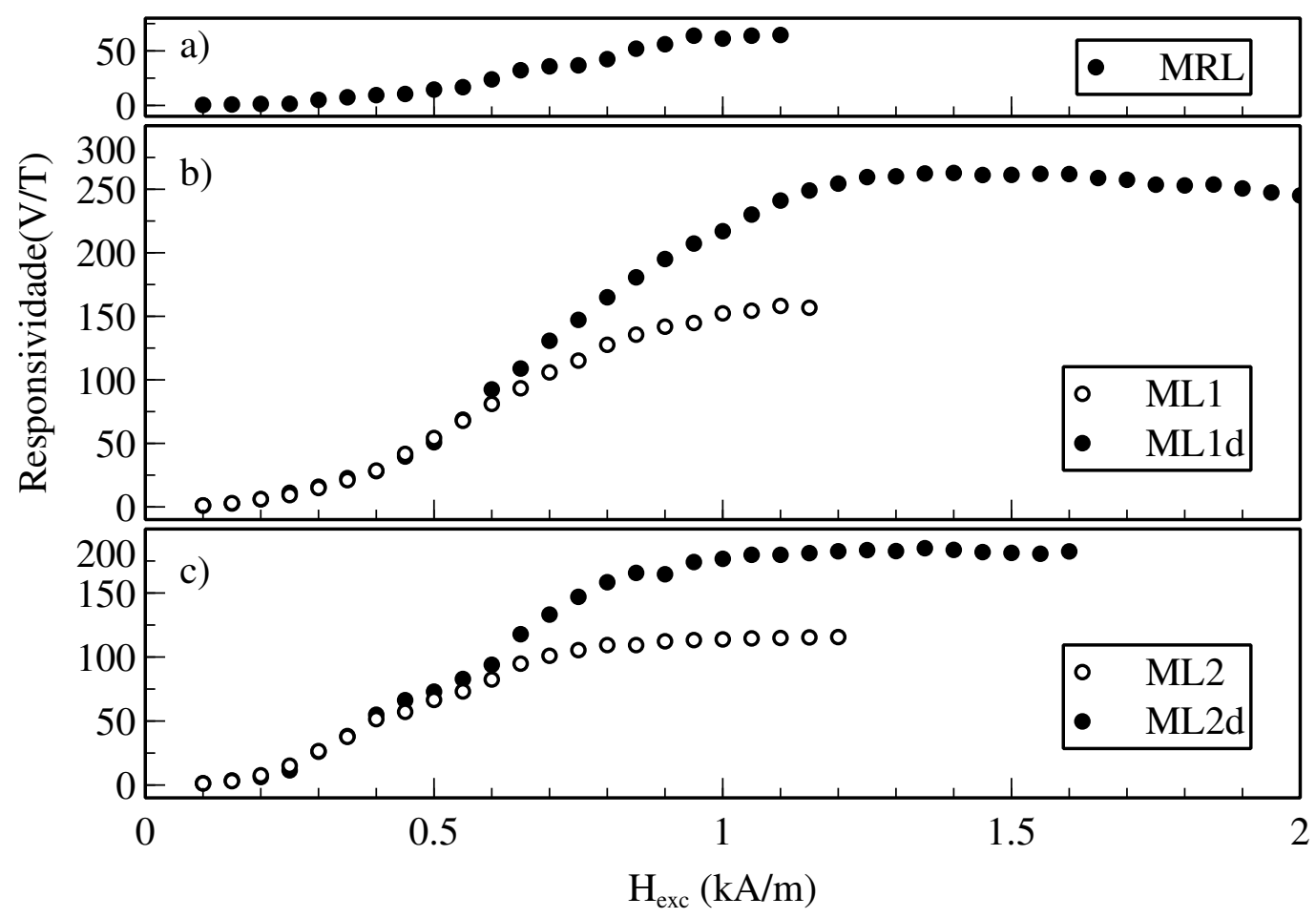

Figura 2.3.4 - Responsividade em função da amplitude de excitação dos protótipos em escala.

Todos os sensores apresentaram o mesmo comportamento geral, inicialmente a responsividade aumenta com a excitação atingindo um máximo. MLR apresentou a menor responsividade máxima devido à maior demagnetização que por sua vez é o resultado do menor comprimento do núcleo. Além disto, as bobinas coletoras estão mais distantes do núcleo devido a forma de montagem do sensor, piorando seu acoplamento. O substrato de cobre utilizado na eletrodeposição do NiFe tem espessura não desprezível $(300 \mu \mathrm{m})$ deixando um vão entre o núcleo e as coletoras. Também para os sensores com duas camadas de bobinas uma delas está mais distante. Desta forma os leiautes de camada simples apresentaram responsividade máxima com aproximadamente 0,6 vezes o valor de seus respectivos duplos, contra os 0,5 esperados se somente o número de espiras for levado em conta. Também não aumentou na mesma proporção do número de espiras a responsividade dos sensores baseados em L1, em relação a L2. Tem-se um fator de aproximadamente 1,4 contra os 2 esperados, mostrando que a excitação extra fornecida pelas bobinas de excitação auxilia na responsividade. A responsividade máxima dos dispositivos é apresentada na tabela 2.3.3.

\begin{tabular}{lrrrrr}
\hline & MLR & ML1 & ML2 & ML1d & ML2d \\
\cline { 2 - 6 } Responsividade máxima (V/T) & 65 & 158 & 115 & 263 & 185 \\
$H_{\text {exc }}(\mathrm{kA} / \mathrm{m})$ & $>1,1$ & 1,15 & 0,8 & 1,0 & 1,25 \\
\hline
\end{tabular}

Tabela 2.3.3 - Responsividade máxima e os valores de excitação associados para os protótipos em escala. 


\subsubsection{Medidas de ruído}

A figura 2.3.5 mostra a montagem experimental utilizada na medidas de ruído.

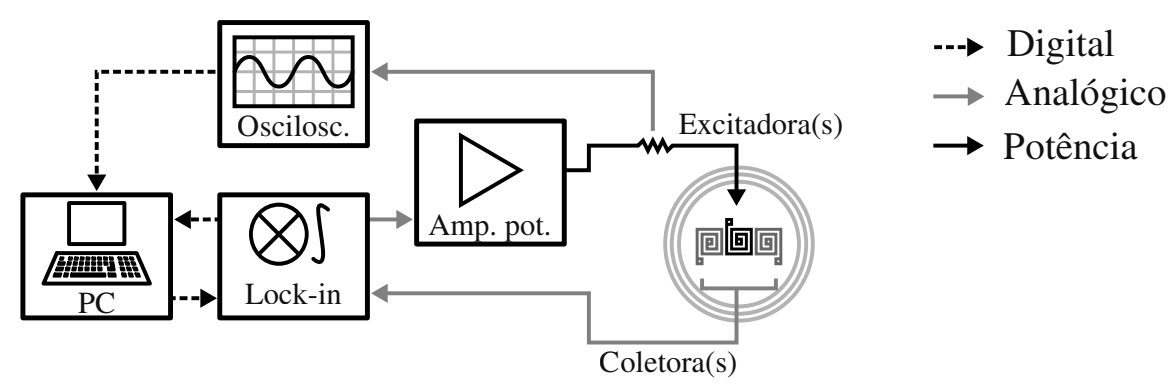

Figura 2.3.5 - Montagem experimental utilizada nas medidas de ruído. O esquema é parecido com o da figura 2.3.2 com a malha responsável pela geração do campo externo substituída por uma blindagem magnética de três camadas.

Para cada $H_{\text {exc }}$, foram coletadas cinco séries temporais de 60 segundos cada com intervalo entre pontos de 2 milisegundos. A densidade de potência espectral (PSD, do inglês, power spectral density) foi estimada pelo método de Welch usando 10000 pontos por segmento. Para o cálculo do valor quadrático médio do ruído ( $r m s$, do inglês, root mean square) foi tomado o espectro médio entre as cinco medidas. $\mathrm{O}$ anexo $\mathrm{B}$ contém os detalhes utilizados na estimativa. A figura 2.3.6 mostra este ruído contido na banda espectral de 0,1 a $10 \mathrm{~Hz}$. Todos leiautes apresentaram níveis de ruído similares e com o mesmo comportamento geral na região de baixa excitação, onde o núcleo não é saturado a cada ciclo, crescendo uma ordem de grandeza para campos de até $0,5 \mathrm{kA} / \mathrm{m}$. Entre 0,5 a $1 \mathrm{kA} / \mathrm{m}$, a região onde ocorre a saturação, são encontrados os maiores níveis de ruído. 


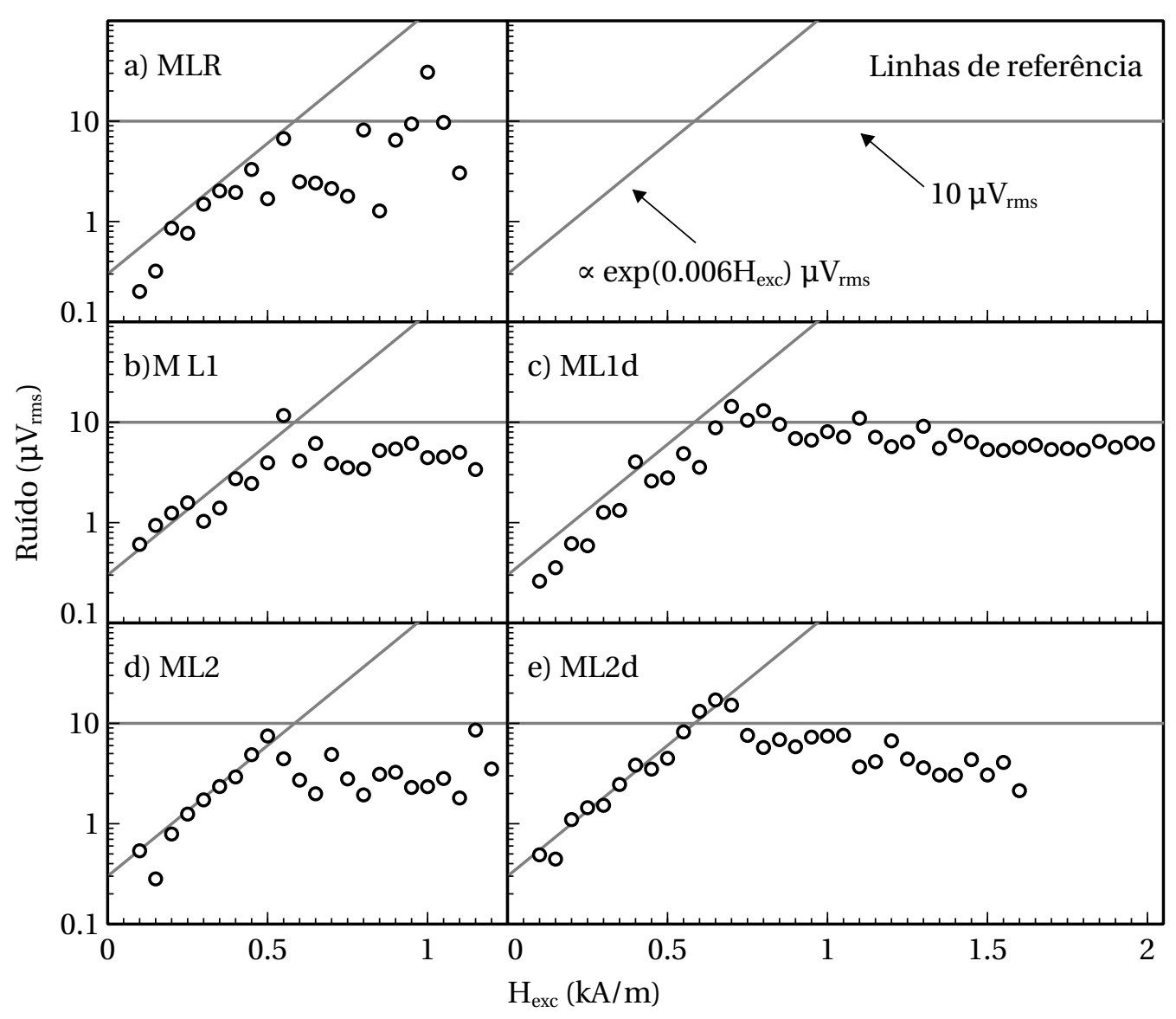

Figura 2.3.6 - Ruído não normalizado em função da amplitude de excitação. As linhas de referência são funções empíricas para ajudar a comparação entre os sensores.

Algumas flutuações fortes foram medidas para campos de excitação altos, em particular para MLR (em $1 \mathrm{kA} / \mathrm{m}$ ) e ML2 (em 1,15 kA/m). Elas podem ser explicadas por porções do núcleo de difícil manetização que não se alinham com o campo $H_{\text {exc }}$ consistentemente a cada ciclo de excitação. Este tipo de comportamento já foi descrito em [38], mas para valores maiores de $H$. Estas instabilidades parecem estar relacionadas com poucos, ou um único volume, pelas suas características estatísticas: estão fortemente correlacionadas com um valor específico de $H_{\text {exc }}$. A figura 2.3.7 mostra uma sequência de sinais coletados para o ML2 com amplitudes de excitação coincidente e vizinhas a uma flutuação. No caso da hipótese levantada ser verdadeira, esperaria-se encontrar este fenômeno em ML2d com $\mathrm{H}_{\text {exc }}$ similar pois o mesmo núcleo (mesma amostra) foi utilizado em ambos sensores. De fato, em $\mathrm{H}_{e x c}=1,2 \mathrm{kA} / \mathrm{m}, \mathrm{ML} 2 \mathrm{~d}$ apresentou um pico nos níveis de ruído causados pelas mesmas oscilações de dois níveis. Da mesma forma este padrão está relacionado com os aumentos abruptos do ruído no MLR por volta de $1 \mathrm{kA} / \mathrm{m}$. 


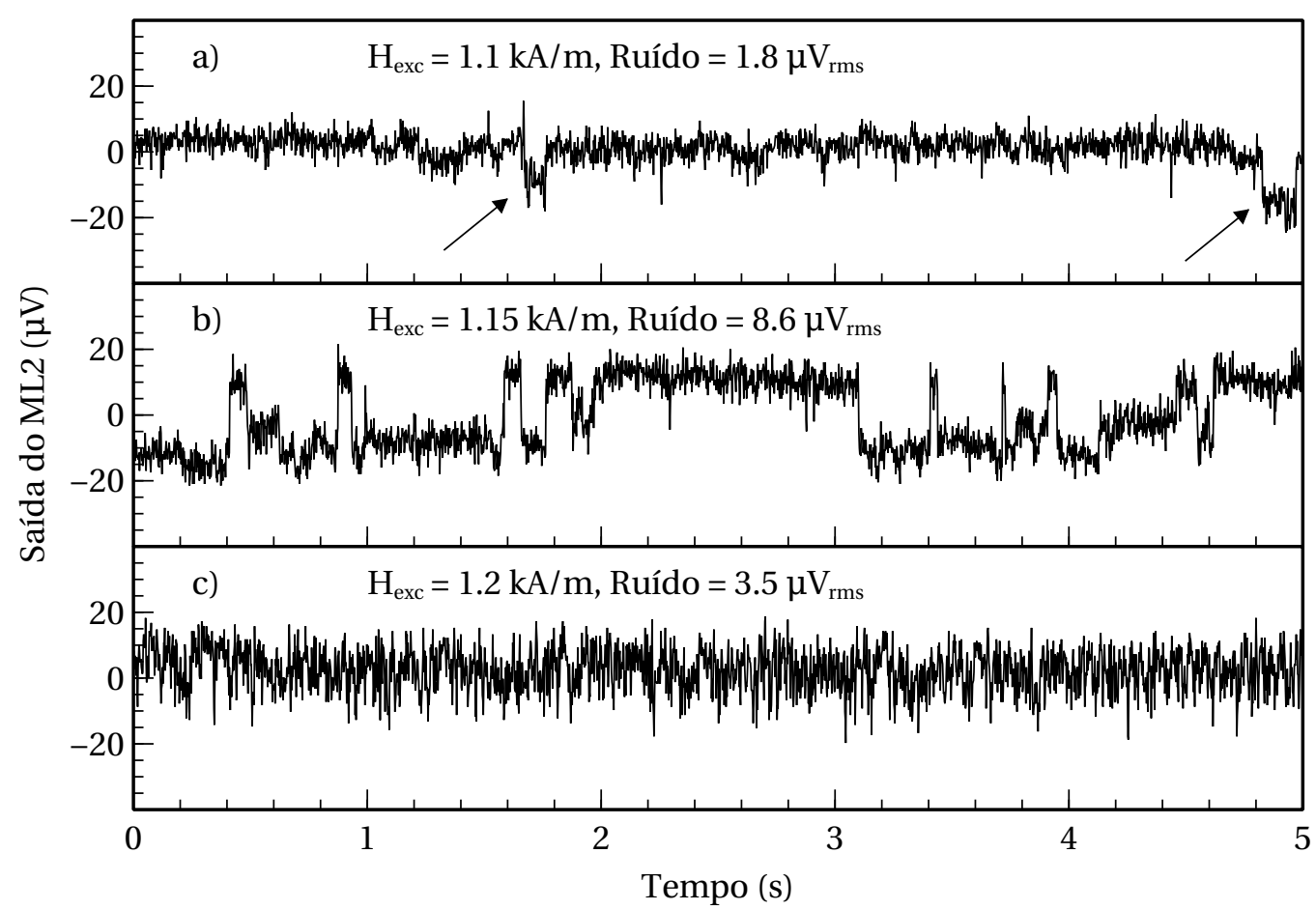

Figura 2.3.7 - Exemplo de flutuações de baixa frequência medidas para ML2. a) Em $\mathrm{H}_{\text {exc }}$ $=1,1 \mathrm{kA} / \mathrm{m}$ há pouco ruído (o valor está mostrado na figura) com algumas mudanças de nível abruptas (indicadas pelas setas). O responsável por estas mudanças, na hipótese criada, é um único volume do núcleo difícil de magnetizar. b) Aumentado o campo externo levemente para $1,15 \mathrm{kA} / \mathrm{m}$ torna esta região ativa aproximadamente metade do tempo, dando origem uma flutuação de baixa frequência que aumenta repentinamente o valor do ruído $\mathrm{rms}$, como visto na figura 2.3.6a. c) Com $H_{e x c}=1,2 \mathrm{kA} / \mathrm{m}$ o sistema consegue alinhar o volume a maior parte do tempo, aumentando a frequência e diminuindo a amplitude do ruído. Para excitações maiores, esta região do núcleo será consistentemente alinhada com o campo de maneira a não gerar mais este tipo de flutuação.

Para amplitudes de excitação maiores que $1 \mathrm{kA} / \mathrm{m}$, enquanto que o ruído de ML1d estabiliza em aproximadamente $7 \mu \mathrm{V}_{r m s}$, L2d apresenta uma tendência decrescente. Esta medida é compatível com o ruído esperado para a parte externa do núcleo com baixa excitação: para ML1(d), uma vez que a parte interna esteja totalmente saturada, incrementos em $H_{\text {exc }}$ não mais ajudam a região exterior, enquanto que este efeito é mitigado em ML2(d) pelas bobinas inseridas e o ruído continua a decrescer. Para os leiautes com uma única camada, devido ao limite experimental da corrente de excitação, não foi possível varrer esta região de campos altos. Pode-se somente inferir que o comportamento permanece. Para MLR a mesma limitação persiste, mas neste caso há evidências suficientes na literatura que o ruído decresce [5], apesar das fortes flutuações encontradas neste particular estudo. 
Os níveis de ruído normalizados, relevantes para a determinação da resolução, estão mostrados na figura 2.3.8. São o resultado da divisão dos valores da figura 2.3.4 pelos da figura 2.3.6. Uma função simples empírica $1 / H_{\text {exc }}$ descreve de maneira razoavelmente bem o comportamento dos sensores, exceto por MLR. Este tem um decaimento tipo exponencial, mas é muito afetado pelas flutuações descritas. MLR tem o melhor cenário em relação ao perfil de excitação, todo o núcleo está diretamente imerso no campo $H_{\text {exc }}$, logo é esperado que o ruído diminua com uma razão maior que os outros. Mas o seu maior campo de desmagnetização é suficiente para manter o ruído acima dos outros dispositivos para os valores de $H_{\text {exc }}$ empregados. Note que dobrar o tamanho do núcleo para restaurar seu comprimento resultaria em quadruplicar a área total do sensor.

Tanto ML1 quanto ML2 apresentaram o mesmo comportamento geral em comparação com suas versões duplas e também não diferiram significativamente entre si. Embora ML2 tenha apresentado alguns pontos com níveis de ruído mais baixos que ML1, também flutuou para valores muito maiores. Na região $H_{\text {exc }}>1,2 \mathrm{kA} / \mathrm{m}$ (não atingida por MLR, ML1 e ML2), o ruído de ML1d permaneceu aproximadamente constante, com uma leve tendência de subida, se desviando da referência $1 / H_{\text {exc }}$. A queda de sua responsividade (figura 2.3.4b) combinada com o ruído não normalizado constante nesta região de alta excitação (figura 2.3.6c) resultam nesta tendência à perda de resolução (figura 2.3.8c). L2d, por outro lado, apresentou uma responsividade constante para $H_{\text {exc }}>1 \mathrm{kA} / \mathrm{m}$ (figura 2.3.4c) que, combinado com o ruído não normalizado decrescente (figura 2.3.6e), resulta em um ruído normalizado com tendência decrescente (figura 2.3.8e), desconsideradas algumas pequenas flutuações. 


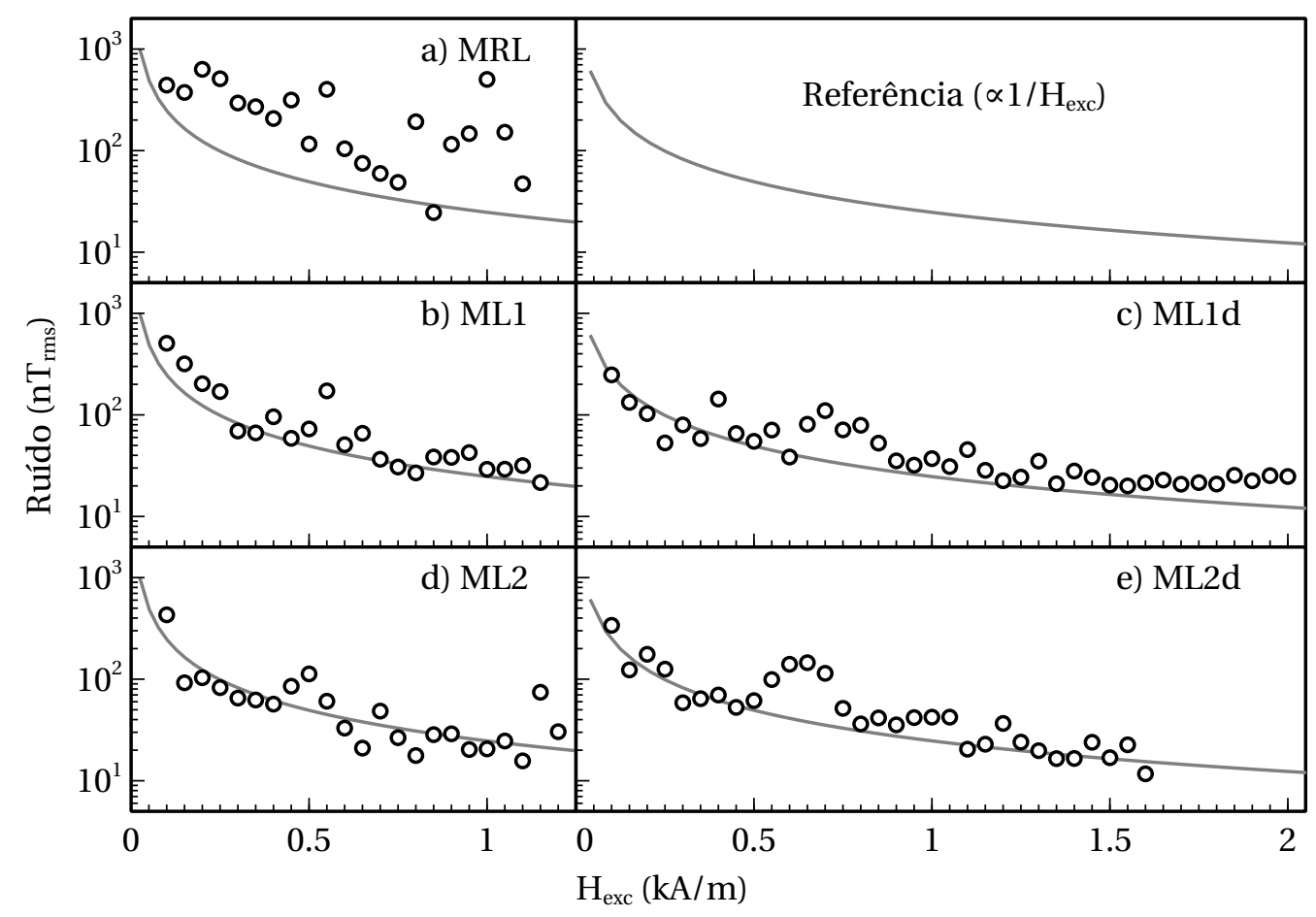

Figura 2.3.8 - Níveis de ruído normalizado em função da amplitude de excitação. A referência $\propto 1 / H_{\text {exc }}$ é um ajuste empírico para facilitar a comparação.

\subsubsection{Conclusão para os protótipos em escala}

Os fluxgates planos com uma única camada de bobinas apresentaram níveis de ruído similares ou menores que a referência construída com os mesmos parâmetros geométricos e material do núcleo, isto para a região de amplitudes de excitação estudada. O sensor baseado no leiaute mais simples proposto (L1) atingiu um valor mínimo de ruído que não pode ser reduzido apenas aumentando-se a amplitude de excitação. A causa proposta é a parte externa dos núcleos não excitada diretamente. Mas colocando-se bobinas excitadoras extras em paralelo com as coletoras, como em (L2), pode-se mitigar este problema de forma que o ruído continua decrescendo com o aumento da excitação. Por outro lado os dois leiautes propostos se mostraram viáveis e não mediu-se uma grande diferença nos valores absolutos de seus parâmetros.

\subsection{Minifluxgates}

Com os protótipos em escala construídos e caracterizados, a próxima etapa foi construílos utilizando processos mais refinados como litografia e deposição de filmes finos. Os equipamentos necessários para a construção de tais dispositivos, como uma sala limpa, uma fotoalinhadora e reatores de deposição de filmes finos, não estão disponível no campus de Ribeirão Preto. Desta maneira fez-se uma parceria com o LME (Laboratório de Microeletrônica) da Escola Politécnica da USP de São Paulo, onde os sensores foram construídos. 


\subsubsection{Projeto}

Os sensores foram projetados baseando-se nos dois leiautes já descritos, L1 e L2 (figura 2.2.1). Foram escolhidos somente os de camada de espiras única pois cada camada adicional torna o processo mais complexo, e já existem sérias dificuldades com duas (uma de bobinas e outra de trilhas). No substrato disponível foi possível posicionar seis sensores distintos (ver figura 2.4.1). Entre estes foi variado, além do tipo de leiaute, a resolução espacial mínima, o número de espiras e também o tamanho do núcleo como mostra a tabela 2.4.1. As espiras foram projetadas tendo a largura da resolução e espaçadas pelo mesmo valor.
Espiras
Conexões
Trilhas e pads
Núcleos

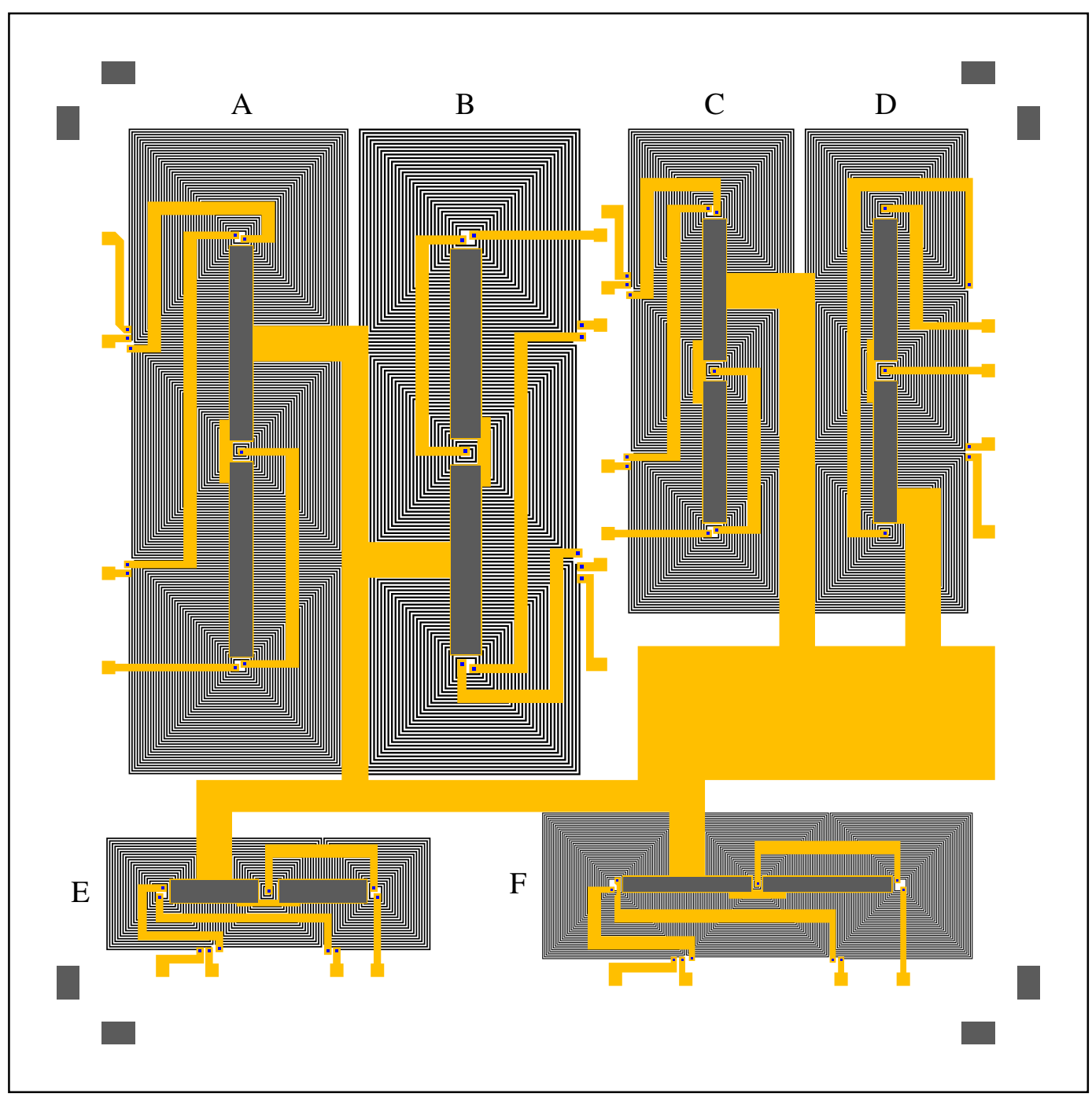

Figura 2.4.1 - Superposição das quatro máscaras utilizadas no processo com a disposição dos seis sensores (A-F, conforme tabela 2.4.1). 


\begin{tabular}{ccccc}
\hline Posição & Leiaute & Resolução $(\mu \mathrm{m})$ & Espiras & Tamanho do núcleo $\left(\mu \mathrm{m}^{2}\right)$ \\
\hline A & L2 & 30 & 40 & $4350 \times 500$ \\
B & L2 & 40 & 30 & $4220 \times 667$ \\
C & L2 & 30 & 30 & $3150 \times 500$ \\
D & L1 & 30 & 30 & $3150 \times 500$ \\
E & L2 & 30 & 20 & $1950 \times 500$ \\
F & L2 & 20 & 40 & $2870 \times 333$ \\
\hline
\end{tabular}

Tabela 2.4.1 - Lista dos sensores posicionados no substrato.

\subsubsection{Processo}

Cada descrição de etapa do processo está acompanhada com uma figura ilustrativa (figuras 2.4.2-2.4.16).

\subsubsection{Substrato}

Foram utilizadas como substratos lâminas de corning glass de uma polegada quadrada. Uma limpeza inicial foi necessária para garantir que não houvesse sujeira na superfície, como pó, resíduos orgânicos oriundos da manipulação, etc. Note que uma partícula de poeira tem tamanho suficiente para arruinar um dispositivo inteiro colocando trilhas em curto ou deixando em aberto o circuito. Processo de limpeza:

1. Imersão em solução de água deionizada, hidróxido de amônio $\left(\mathrm{NH}_{4} \mathrm{OH}\right)$ e peróxido de hidrogênio $\left(\mathrm{H}_{2} \mathrm{O}_{2}\right)$, na proporção 5:1:1, por 15 minutos no ultrasom;

2. Enxágue em água corrente por 10 minutos;

3. Imersão em álcool isopropílico (isopropanol) e aquecimento até a sua total evaporação.

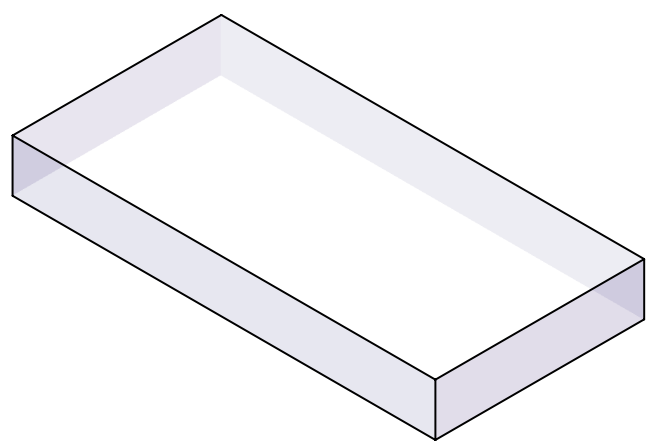

Figura 2.4.2 - Substrato de corning. 


\subsubsection{Deposição de titânio por sputtering}

Foi utilizado um radio frequency plasma magneton sputtering para depositar uma camada de titânio, necessária para garantir a aderência da camada de cobre que a seguirá. A espessura pôde ser mínima e foi estimada em $20 \mathrm{~nm}$ com base em procedimentos anteriores.

\begin{tabular}{lr}
\hline Parâmetro & Valor \\
\hline Pressão de alto vácuo antes da deposição (limpeza da câmara) & $2 \times 10^{-7}$ Torr \\
Potência de RF & $150 \mathrm{~W}$ \\
Frequência & $13,8 \mathrm{MHz}$ \\
DC Bias & $-168 \mathrm{~V}$ \\
Fluxo de argônio & $10 \mathrm{sccm} *$ \\
Pressão da câmara & $2 \mathrm{mTorr}$ \\
Tempo de deposição & $1 \mathrm{~min}$ \\
Temperatura & Não controlada \\
\hline
\end{tabular}

Tabela 2.4.2 - Parâmetros utilizados na deposição de titânio por sputtering. *Standard cubic centimeters per minute.

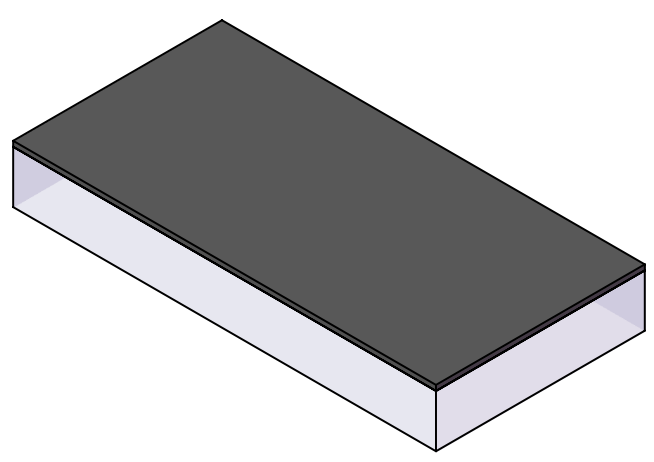

Figura 2.4.3 - Camada de titânio depositada por sputtering necessária para a boa adesão do cobre.

\subsubsection{Deposição de cobre por sputtering}

Esta camada de cobre serviu como semente para a eletrodeposição de cobre que deu origem as bobinas condutoras. Foi feita no mesmo equipamento da deposição de titânio. A espessura foi estimada em $40 \mathrm{~nm}$ com base em procedimentos anteriores. 


\begin{tabular}{lr}
\hline Parâmetro & Valor \\
\hline Pressão de alto vácuo antes da deposição (limpeza da câmara) & $2 \times 10^{-7}$ Torr \\
Potência de RF & $70 \mathrm{~W}$ \\
Frequência & $13,8 \mathrm{MHz}$ \\
DC Bias & $-118 \mathrm{~V}$ \\
Fluxo de argônio & $10 \mathrm{sccm}$ \\
Pressão da câmara & $2 \mathrm{mTorr}$ \\
Tempo de deposição & 1,5 min \\
Temperatura & Não controlada \\
\hline
\end{tabular}

Tabela 2.4.3 - Parâmetros utilizados na deposição de cobre por sputtering.

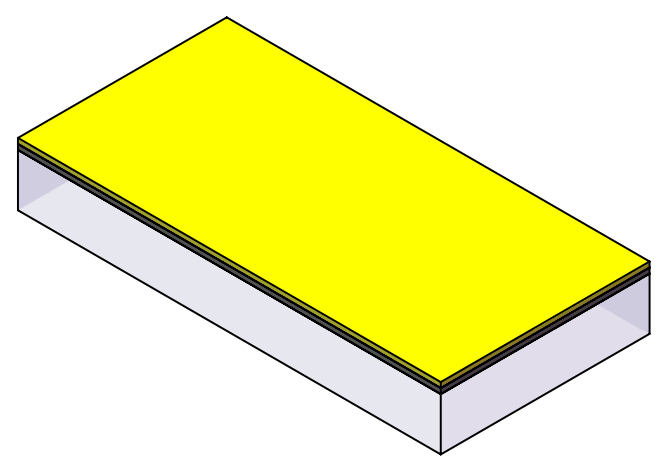

Figura 2.4.4 - Camada de cobre depositada que será utilizada como semente na eletrodeposição das bobinas.

\subsubsection{Fotogravação dos moldes das bobinas}

As bobinas foram construídas pelo espessamento do cobre através de moldes de fotoresiste. Este foi aplicado sobre a superfície da lâmina e espalhado por rotação. Para garantir sua integridade estrutural foi necessário curá-lo por aquecimento, um processo chamado de prebake. Foi utilizada a fotolitografia de contato, onde a máscara é colocada em contato com o fotoresiste, e o sistema iluminado com luz ultravioleta. Quando exposto, a luz ultravioleta quebra ligações deste polímero fotoresistivo de maneira que as regiões iluminadas podem ser removidas com um solvente enquanto que regiões não expostas à radiação permanecem intactas. Assim o padrão geométrico é passado da máscara para o substrato. Etapas seguidas:

1. Limpeza das lâminas em álcool isopropílico;

2. Aplicação de fotoresiste (AZ 1375) a $3000 \mathrm{rpm}$ (rotações por minuto) por $30 \mathrm{~s} \mathrm{(espessura}$ esperada de $3 \mu \mathrm{m})$; 
3. Prebake a $80{ }^{\circ} \mathrm{C}$ por 20 minutos;

4. Exposição a luz UV com a máscara das bobinas (figura 2.4.1);

5. Banho em solução de revelador AZ 351 diluído em água DI na proporção 1:5;

6. Postbake a $100{ }^{\circ} \mathrm{C}$ por 30 minutos.

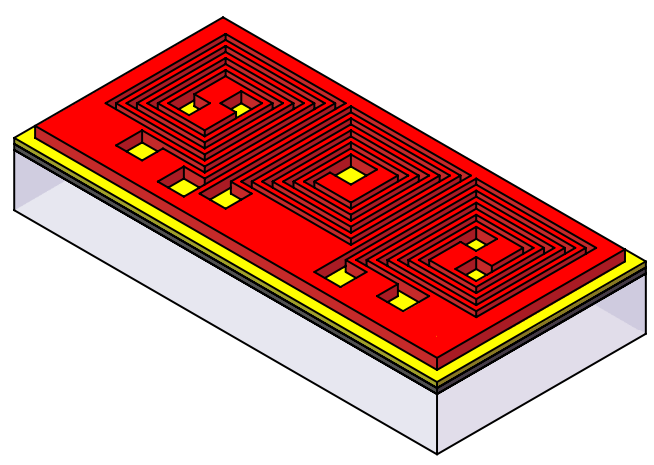

Figura 2.4.5 - Revelação dos moldes de fotoresiste das bobinas.

\subsubsection{Espessamento do cobre por eletrodeposição}

O espessamento do cobre foi necessário, pois não é viável atingir a espessura desejada de $5 \mu \mathrm{m}$ pelo sputtering. Entretanto verificou-se que, por causa da falta de uniformidade na remoção de material pelo polimento (etapa posterior), uma espessura de $15 \mu \mathrm{m}$ é mais adequada. Este aumento também ajudou a contornar problemas de não uniformidade na deposição do cobre, deixando uma margem de segurança. Para a eletrodeposição foi construído um suporte especial com contatos elétricos nas bordas da amostra. A solução de eletrodeposição utilizada está descrita na tabela 2.4.4. Foi empregado agitação linear, contra-eletrodo de cobre e uma corrente de $100 \mathrm{~mA}$ por 3 minutos.

\begin{tabular}{llr}
\hline Reagente & & Concentração \\
\hline Sulfato de cobre (II) & $\mathrm{CuSO}_{4}$ & $205 \mathrm{~g} / \mathrm{l}$ \\
Ácido sulfúrico & $\mathrm{H}_{2} \mathrm{SO}_{4}$ & $40 \mathrm{~mL} / \mathrm{L}$ \\
Ácido clorídrico & $\mathrm{HCl}$ & $0,1 \mathrm{~mL} / \mathrm{L}$ \\
E-Brite 200M (make-up) & & $6 \mathrm{~mL} / \mathrm{L}$ \\
E-Brite 200R (replenisher) & & $1,5 \mathrm{~mL} / \mathrm{L}$ \\
\hline
\end{tabular}

Tabela 2.4.4 - Solução utilizada na deposição de cobre para o espessamento das bobinas. 


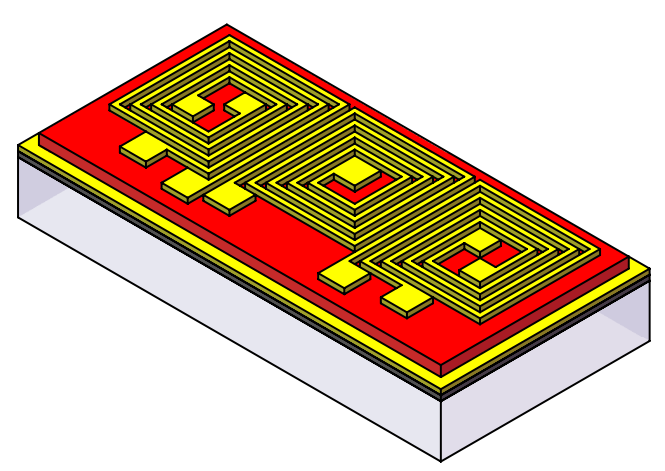

Figura 2.4.6 - Espessamento das trilhas das bobinas por eletrodeposição através de moldes de fotoresiste.

\subsubsection{Remoção fotoresiste}

A remoção do fotoresite é simples:

1. Imersão em acetona fervente por 5 minutos.

\subsubsection{Remoção da semente de cobre e titânio.}

Neste ponto do processo as sementes de cobre e titânio estão colocando toda a camada de bobinas em curto circuito. Note entretanto que, enquanto a semente de cobre tem $40 \mathrm{~nm}$ de espessura, as trilhas têm $15 \mu \mathrm{m}$. Assim um processo que remova nanômetros de cobre resulta na remoção da semente sem alterar de forma significativa as bobinas. Foi escolhido um processo que possibilita esta corrosão controlada: primeiramente oxida-se a camada superficial do cobre e depois utiliza-se uma solução que ataca somente o óxido. A oxidação do cobre é autolimitante, uma vez oxidado alguns nanômetros superficiais a camada formada serve como proteção ao restante. As etapas realizadas para a remoção da semente de cobre foram:

1. Oxidação do cobre em $100 \mathrm{ml}$ água deionizada : $1 \mathrm{ml} \mathrm{de} \mathrm{H}_{2} \mathrm{O}_{2}: 1 \mathrm{ml}$ de $\mathrm{NH}_{4} \mathrm{OH}$ por 10 minutos;

2. Remoção do óxido de cobre em ácido acético por 10 minutos.

3. Repetir as etapas 1 e 2 até a completa remoção da semente de cobre.

Já o titânio foi removido separadamente, com o uso de HF (ácido fluorídrico) diluído. Foi necessário, entretanto, cuidado com o tempo de corrosão, pois o HF é muito agressivo e há o risco de corrosão de material embaixo das trilhas assim como do substrato. As etapas seguidas foram:

1. Banho em solução de 20 partes $\mathrm{H}_{2} \mathrm{O}$ deinonizada : 1 parte de $\mathrm{HF}$ grau eletrônico por 4 segundos. 


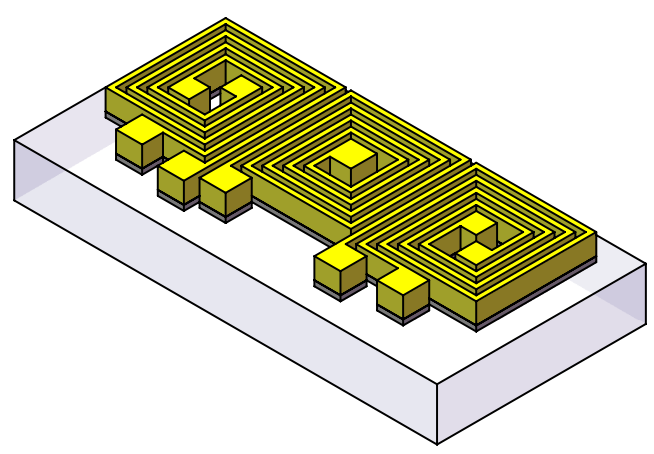

Figura 2.4.7 - Remoção da semente de cobre e titânio deixando as bobinas essencialmente inalteradas.

\subsubsection{Aplicação de fotoresiste estrutural SU8}

Neste ponto do processo, há degraus de aproximadamente $15 \mu \mathrm{m}$ formados pelas trilhas das bobinas. $\mathrm{O}$ isolamento entre as camadas (como será descrito nas próximas etapas) foi feito com um óxido crescido por PECVD (plasma-enhanced chemical vapor deposition) e não há garantia de cobertura das laterais. Além disto, também não há garantida de continuidade dos filmes condutores depositados sobre um óxido nestas condições. De fato foram feitos testes que mostraram que estes dois problemas de fato ocorrem, colocando em curto as camadas metálicas e rompendo ligações elétricas necessárias. Por estes motivos é necessária a planarização das estruturas. Com este fim foi utilizada uma resina da família SU8 para cobrir todo o dispositivo e posteriormente planarizá-lo por polimento, expondo novamente as trilhas. A variante SU8-2015, com viscosidade para formar filme por volta de $15 \mu \mathrm{m}$, se mostrou a mais adequada nesta aplicação. É necessário, para garantir a rigidez estrutural e a estabilidade térmica desta resina, tratá-la termicamente (hard bake) a temperaturas de pelo menos $10{ }^{\circ} \mathrm{C}$ acima do máximo que a amostra será submetida posteriormente, mas não ultrapassando os $250{ }^{\circ} \mathrm{C}$. Entretanto testes mostraram que quanto maior esta temperatura mais difícil é o polimento e mais o material se contrai. Contração que, devido à geometria da camada anterior de cobre, leva a uma superfície extremamente irregular. Considerando estes fatores e a temperatura mínima necessária para o depósito de óxido (etapa posterior), optou-se por uma temperatura intermediária para o hard bake, de $190{ }^{\circ} \mathrm{C}$. As etapas seguidas foram:

1. Espalhamento do fotoresiste com spinner a $500 \mathrm{rpm}$ por $10 \mathrm{~s}$, rampa de $500 \mathrm{rpm} / \mathrm{s}$ até $4000 \mathrm{rpm}, 4000 \mathrm{rpm}$ por $30 \mathrm{~s}$ (espessura esperada de $15 \mu \mathrm{m}$ );

2. Hard bake com $190{ }^{\circ} \mathrm{C}$ por aproximadamente 30 minutos em estufa. 


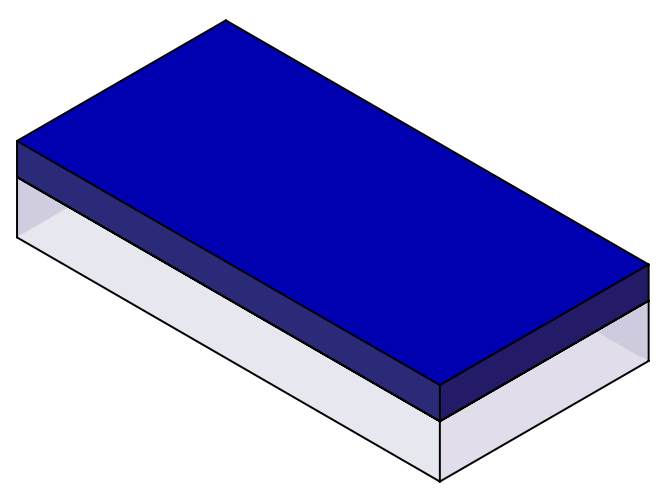

Figura 2.4.8 - Recobrimento de toda a amostra com o fotoresiste SU8.

\subsubsection{Polimento para remoção do excesso de SU8 e planarização}

Com o propósito já mencionado anteriormente, o polimento visa a remoção do excesso de resina até o aparecimento das bobinas para que o contato entre camadas possa ser feito. Esta etapa foi realizada com uma mistura de polimento manual com lixa e polidora mecânica com pasta de polir, diminuindo-se gradativamente o tamanho das partículas abrasivas. Entretanto com este processo é difícil garantir o paralelismo entre a superfície polida e o substrato. A polidora mecânica remove material com uma taxa muito superior nas bordas da lâmina, destruindo as bobinas ali posicionadas antes mesmo de expor os contatos na região central. Também o uso manual de uma lixa apresenta este problema, além da baixa reprodutibilidade. Isto levou a perda de muitas amostras. $\mathrm{O}$ aumento da espessura das trilhas de cobre de 5 para $15 \mu \mathrm{m}$ foi a solução encontrada para ter-se uma margem maior no polimento. Desta forma mesmo perdendo-se $10 \mu \mathrm{m}$ de cobre em uma região para chegar-se ao contato em outra, o dispositivo não fica inutilizável. Infelizmente na época não estavam disponíveis equipamentos mais precisos de polimento o que levou a este processo artesanal e pouco reprodutível. Etapas:

1. Polimento manual com lixa granulação 1500;

2. Polimento manual com lixa granulação 2500, até atingir o cobre nos pontos de conexão;

3. 1 hora de polimento mecânco com pasta de partículas de $6 \mu \mathrm{m}$, velocidade baixa e força baixas;

4. 1 hora de polimento mecânico com pasta de partículas de $3 \mu \mathrm{m}$, velocidade baixa e força baixas. 


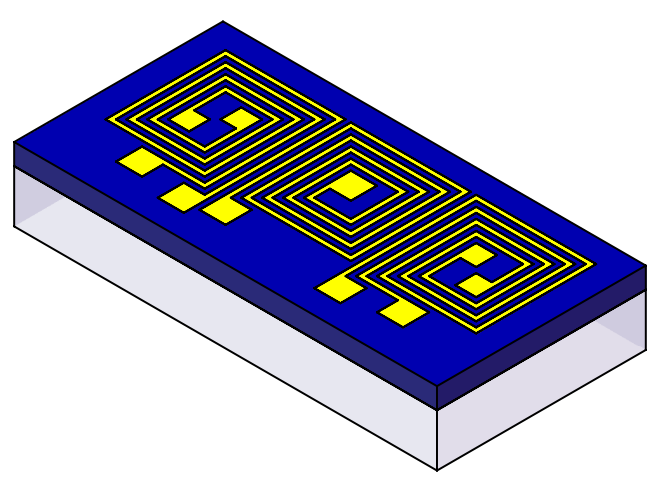

Figura 2.4.9 - O polimento retira o excesso de SU8 para tornar as trilhas acessíveis e suaviza a superfície para melhor recobrimento pelas próximas camdas.

\subsubsection{Deposição do óxido por PECVD}

Para fazer o isolamento entre as camadas condutoras utilizou-se um filme de óxido $\mathrm{Si}_{1} \mathrm{O}_{0,6} \mathrm{~N}_{0,4}$ (oxinitreto) depositado por PECVD. Embora, do ponto de vista de funcionalidade, quanto mais fina esta camada melhor o acoplamento entre as bobinas e o núcleo ferromagnético do sensor, optou-se por uma espessura de aproximadamente $2 \mu \mathrm{m}$ para garantir o isolamento das camadas condutoras. Os parâmetros de deposição deste filme estão descritos na tabela 2.4.5.

\begin{tabular}{lr}
\hline Parâmetro & valor \\
\hline Configuração em triodo & \\
Atmosfera & Nitrogênio \\
Fluxo de $\mathrm{N}_{2} \mathrm{O}$ & $37,5 \mathrm{sccm}$ \\
Pressão de abertura do $\mathrm{N}_{2} \mathrm{O}$ & $30 \mathrm{mTorr}$ \\
Fluxo de $\mathrm{SiH}_{4}$ & $15 \mathrm{sccm}$ \\
Pressão de abertura do $\mathrm{SiH}_{4}$ & $32 \mathrm{mTorr}$ \\
Pressão de processo & não controlada \\
Potência de RF & $200 \mathrm{~W}$ \\
Frequência & $13,8 \mathrm{MHz}$ \\
Temperatura do substrato & $150{ }^{\circ} \mathrm{C}$ \\
Tempo de deposição & 90 minutos \\
\hline
\end{tabular}

Tabela 2.4.5 - Parâmetros de deposição do oxinitreto $\left(\mathrm{Si}_{1} \mathrm{O}_{0,6} \mathrm{~N}_{0,4}\right)$ por PECVD. 


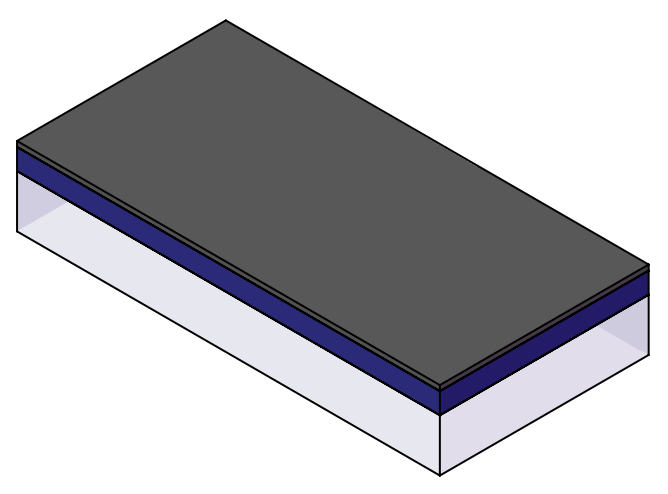

Figura 2.4.10 - O isolamento elétrico entre as camadas de metal foi feita por uma camada de óxinitreto depositada por PECVD.

\subsubsection{Abertura dos contatos no óxido}

Para permitir o acesso aos terminais das bobinas da camada superior, foi necessário a abertura de janelas no óxido por meio de fotolitografia. Semelhante a anteriores as etapas foram:

1. Limpeza das lâminas em álcool isopropílico;

2. Aplicação do promotor de aderência;

3. Aplicação do fotoresiste (AZ 1518) a $3000 \mathrm{rpm}$ por $30 \mathrm{~s}$ (espessura esperada de $1 \mu \mathrm{m}$ );

4. Prebake a $80^{\circ} \mathrm{C}$ por 20 minutos;

5. Exposição a luz UV;

6. Revelação com revelador AZ 351 diluído em água DI na proporção 1:5;

7. Postbake a $100^{\circ} \mathrm{C}$ por 30 minutos;

8. Remoção do oxinitreto em DLV (25 partes de $\mathrm{NH}_{4} \mathrm{~F}(40 \%)$ : 4 partes de $\mathrm{HF}(49 \%)$ ) durante 1 minuto.

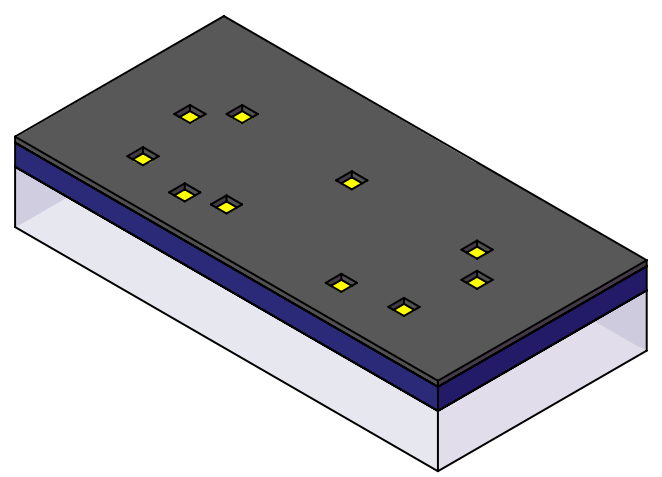

Figura 2.4.11 - Abertura dos contatos no oxinitreto para ter acesso as trilhas. 


\subsubsection{Deposição de titânio e cobre}

A próxima camada tem a mesma função da primeira de titânio, ajudar na aderência do cobre. O processo utilizado também foi idêntico (subseção 2.4.2.2), exceto pelo aumento do tempo de deposição, de 1 minuto para 2, o que aumentou a espessura para aproximadamente 40 nm. Da mesma maneira a deposição de cobre (subseção 2.4.2.3) teve o tempo alterado, foram 5 minutos. Esta camada foi utilizada para construção das trilhas sem espessamento uma vez que se pode-se fazê-las mais largas, mantendo a área da seção transversal semelhante às bobinas. Isto só foi possível pois não havia restrições de espaço entre as trilhas.

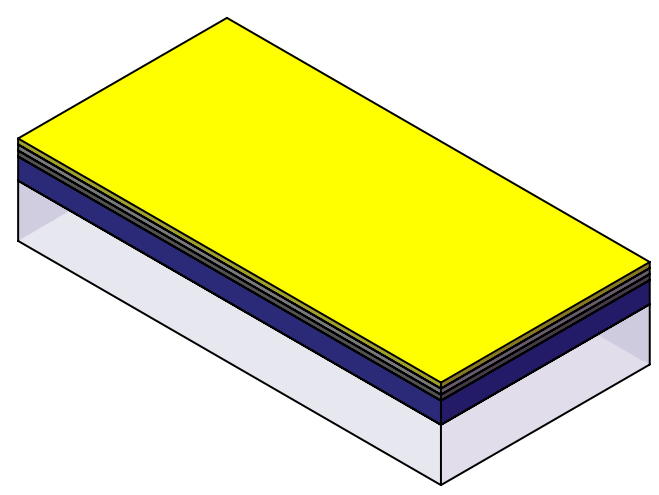

Figura 2.4.12 - Deposição de uma camada de aderência de titânio seguida de uma de cobre.

\subsubsection{Fotogravação das trilhas e pads}

Para definir as trilhas de ligação elétrica, os pads de contato externo e também as regiões onde será eletrodepositado o núcleo de $\mathrm{NiFe}$, foi feita uma fotogravação nas mesmas condições utilizadas para o oxinitreto 2.4.2.11. Já na remoção do cobre e titânio foram utilizadas soluções diferentes em relação à etapa semelhante da construção das bobinas:

1. Remoção do filme de cobre em $\mathrm{NiCr}$ (200 mL de $\mathrm{H}_{2} \mathrm{O}$ deionizada : $40 \mathrm{~g}$ de nitrato cérico amoniacal $\left(\left(\mathrm{NH}_{4}\right)_{2} \mathrm{Ce}\left(\mathrm{NO}_{3}\right)_{6}\right): 11 \mathrm{~mL}$ de ácido acético) durante 10 minutos;

2. Remoção de filme de titânio em 1 parte de HF grau eletrônico : 20 partes de $\mathrm{H}_{2} \mathrm{O}$ DI por 6 segundos. 


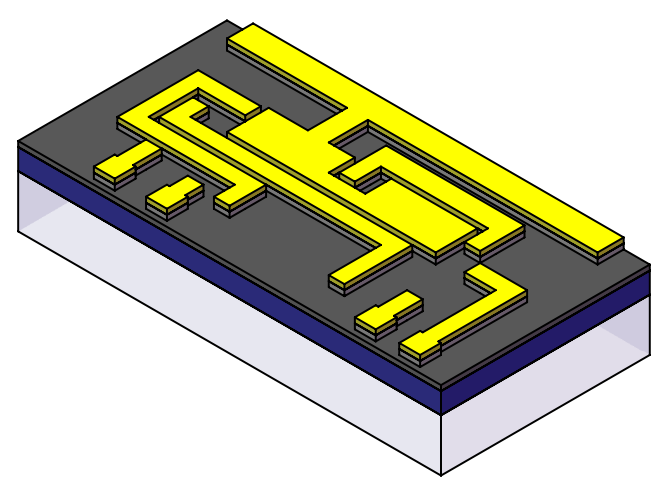

Figura 2.4.13 - Definição das trilhas, pads e semente da eletrodeposição do núcleo na segunda camada condutora.

\subsubsection{Molde de fotoresiste para eletrodeposição dos núcleos}

Para garantir que somente nas regiões de interesse fosse eletrodepositado o material ferromagnético, foram utilizados moldes de fotoresiste [36], semelhante ao processo de formação das bobinas pelo espessamento do cobre.

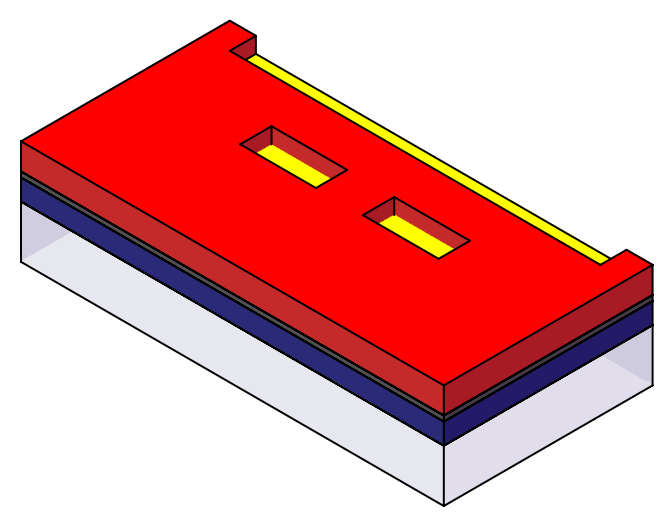

Figura 2.4.14 - Molde de fotoresiste para a eletrodeposição dos núcleos.

\subsubsection{Eletrodeposição dos núcleos de NiFe}

Esta etapa foi baseada nos métodos de eletrodeposição estudados por [39], já empregados nos protótipos macro: solução de eletrodeposição descrita na tabela 2.3.1, contra-eletrodo de níquel, densidade de corrente de $14 \mathrm{~mA} / \mathrm{cm}^{2}$ e temperatura ambiente. Para que a espessura desejada de $3 \mu \mathrm{m}$ fosse obtida, depositou-se por $15 \mathrm{~min}$. Utilizou-se o mesmo suporte da eletrodeposição de cobre mas com uma moldura apropriada, que fez o contato elétrico com a grande região deixada para este fim na máscara das trilhas (veja a figura 2.4.1). As etapas foram:

1. Lavagem da amostra com água;

2. Deposição de NiFe; 
3. Remoção do fotoresiste em acetona.

Os filmes apresentam alguns defeitos, principalmente nas partes superiores dos núcleos onde é mais difícil remover as bolhas de hidrogênio por causa da tensão superficial da solução nas dimensões reduzidas do molde. Isto ocorreu mesmo retirando as amostras da solução a cada 30 segundos, na tentativa de eliminar estes acúmulos de gás oriundos da reação na superfície.

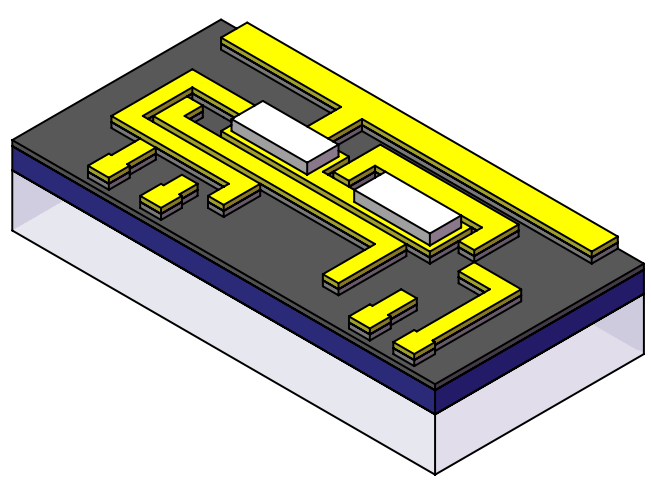

Figura 2.4.15 - Núcleos de NiFe eletrodepositados.

\subsubsection{Contatos externos}

Finalmente restou fazer os contatos elétricos com uma placa de PCB externa sob a qual o substrato foi colado. Note que o dispositivo é muito frágil para se manusear com os contatos feitos diretamente. Desta forma, os pads foram ligados a este suporte por meio de fios de cobre colados manualmente com cola prata. 


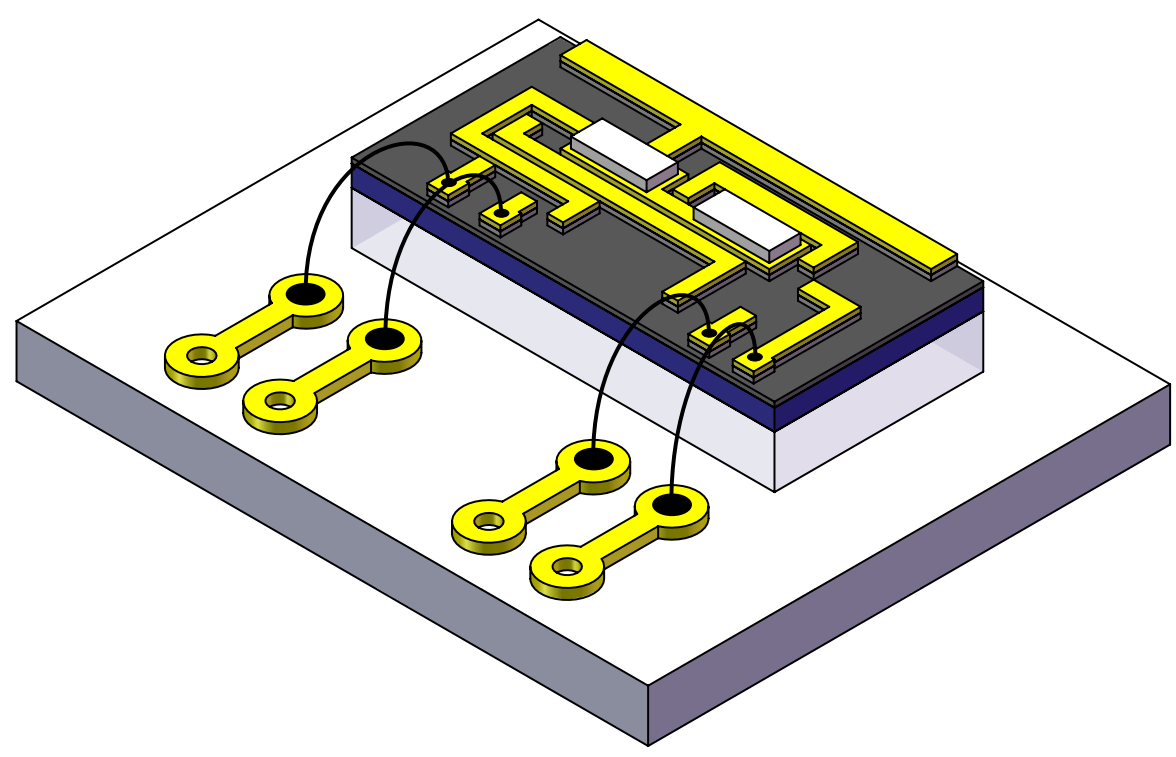

Figura 2.4.16 - O sensor concluído foi preso a um PCB com contatos externos para evitar esforços mecânicos sobre as frágeis estruturas microfabricadas.

\subsubsection{Sensores obtidos}

A figura 2.4.17 mostra a estrutura interna do dispositivo obtido.

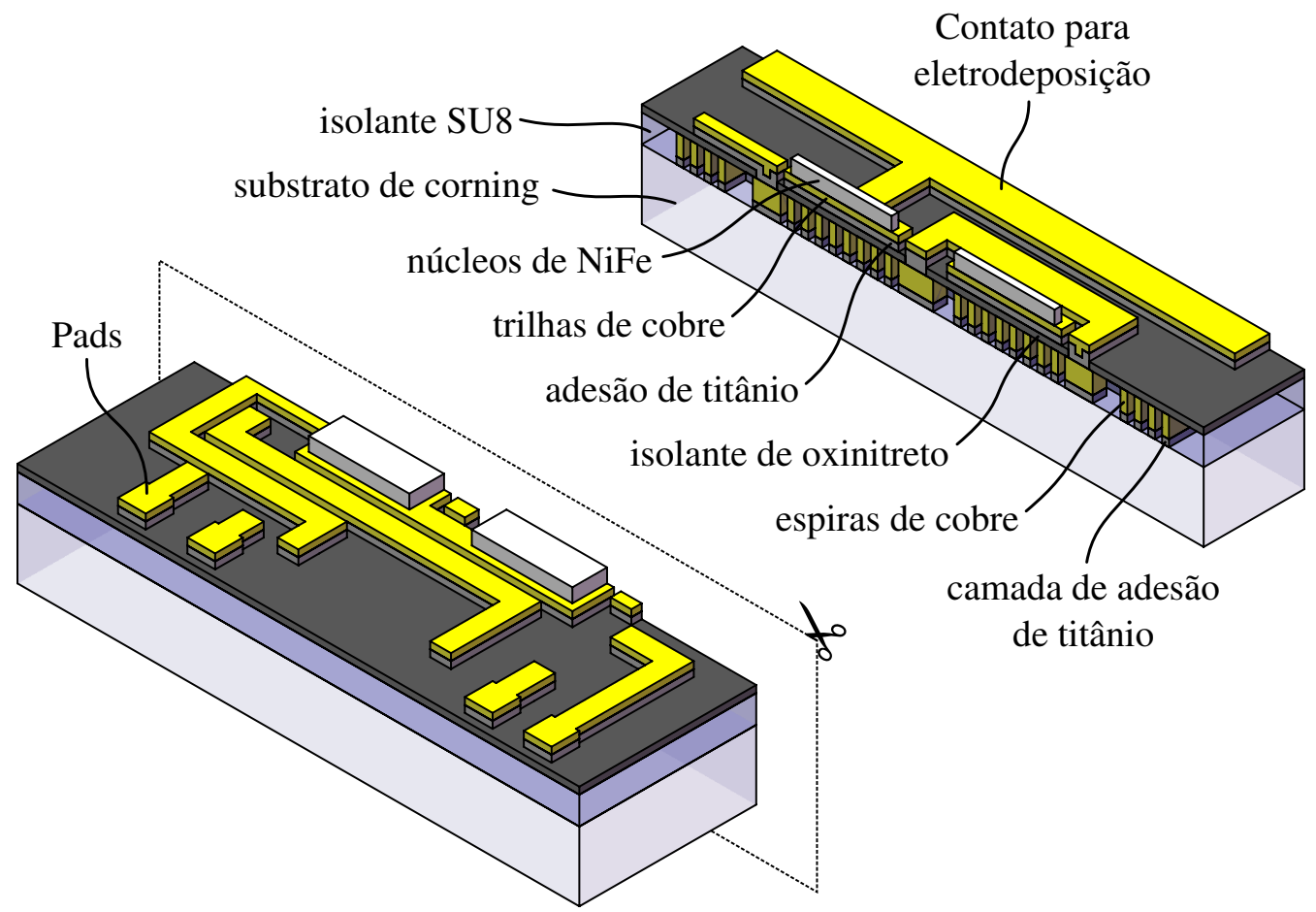

Figura 2.4.17 - Corte transversal do sensor ilustrativo pronto, mostrando a estrutura das camadas formadas. 


\begin{tabular}{lrr}
\hline & $\mathrm{mL} 1$ & $\mathrm{~mL} 2$ \\
\cline { 2 - 3 } Espiras excitatoras & 30 & $30+2 \times 15$ \\
Espiras coletoras & $2 \times 30$ & $2 \times 15$ \\
Camadas de bobinas & 1 & 1 \\
Resolução espacial $(\mu \mathrm{m})$ & 30 & 30 \\
Tamanho do núcleo $(\mu \mathrm{m})$ & $3150 \times 500$ & $3150 \times 500$ \\
\hline
\end{tabular}

Tabela 2.4.6 - Parâmetros geométricos dos sensores miniaturizados.

O processo descrito é o resultado de iterações e melhorias de um processo inicial. Foi-se ajustando as etapas de acordo com os resultados das primeiras amostras processadas, além de uma revisão geral feita após uma primeira tentativa em que todo o lote de 12 lâminas (cada uma com 6 sensores) não resultou em dispositivos funcionais. Note que, de certa maneira, este tipo de fracasso é esperado, especialmente para um processo longo como este. São centenas de etapas em sequência onde muitas tem potencial de inutilizar o sensor e muitas delas nunca foram empregadas neste tipo de estrutura. Soma-se a isto perdas de sensores por impurezas, como poeira que caem sobre as estruturas, defeitos causados pela manipulação das amostras, etc, e tem-se uma previsão pessimista para o número de sensores funcionais. De longe a etapa mais crítica foi o polimento do SU8. Foram necessários dois lotes de 12 lâminas para se chegar a sensores funcionais. Sobreviveram dois dispositivos, um L1 com posição D na lâmina e um L2 com posição C. Felizmente ambos tem a mesma resolução e mesmo número de espiras, o que permite a comparação direta. A tabela 2.4.6 mostra os parâmetros dos sensores funcionais nomeados mL1 e mL2.

A figura 2.4.18 mostra a microscopia ótica dos sensores C e D (não necessariamente dos dispositivos funcionais uma vez que pertencem a lâminas distintas).

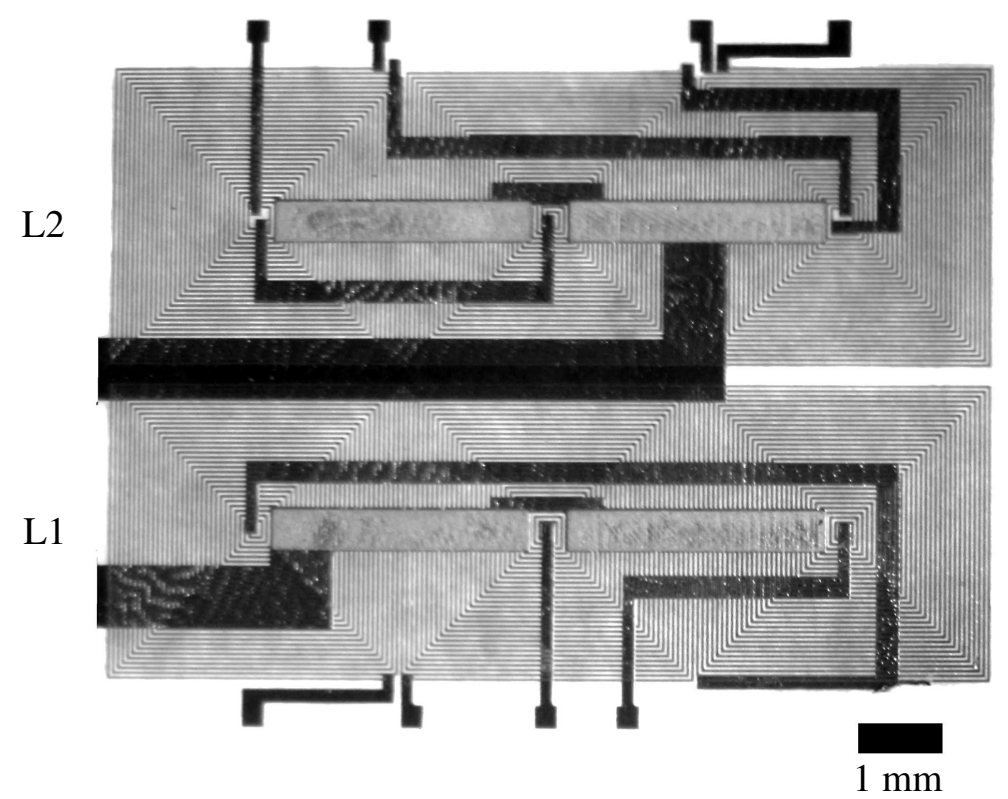

Figura 2.4.18 - Microscopia ótica da região do substrato contendo os sensores C e D. 


\subsubsection{Metodologia de caracterização}

Os sensores microfabricados foram caracterizados de maneira semelhante aos protótipos em escala. As mesmas montagens experimentais descritas nas figuras 2.3 .2 e 2.3.5 foram utilizadas para os mesmos fins. Novamente a excitação utilizada foi senoidal com frequência de $100 \mathrm{kHz}$, e o método de extração do campo o de segundo harmônico. Embora fluxgates miniaturizados normalmente operam em frequências superiores, foi mantida a mesma dos protótipos por dois motivos: comparabilidade e evitar efeitos de capacitâncias parasitas que aparecem em altas frequências. A responsividade e o ruído foram medidos em função do campo de excitação $H_{\text {exc }}$. A relação entre a corrente e o campo $H_{\text {exc }}$ foi calculada de forma análoga a da figura 2.2.2, por elementos finitos, resultando em $8,3 \mathrm{kA} / \mathrm{m}$ por A, como mostra a figura 2.4.19.

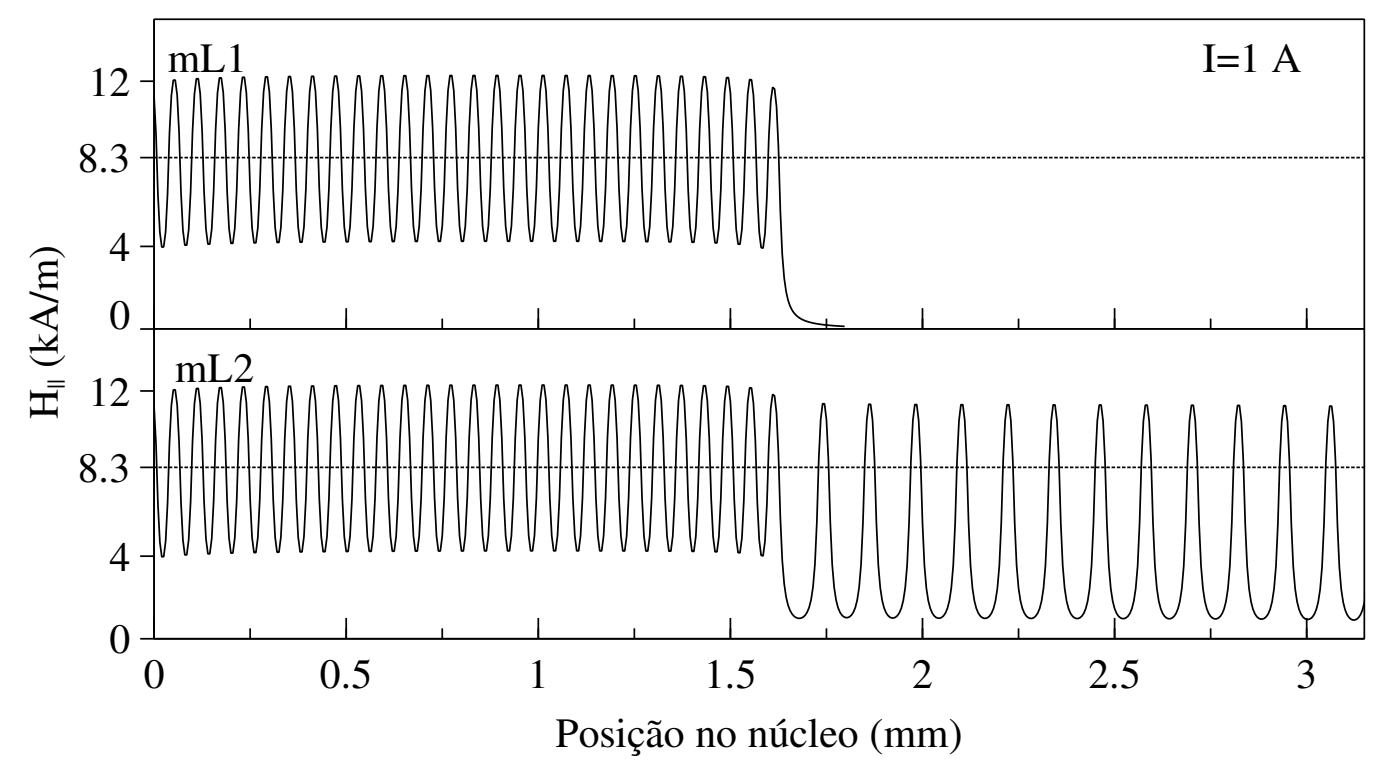

Figura 2.4.19 - Componente do campo $\mathbf{H}_{\text {exc }}$ paralela ao núcleo e calculada ao longo deste. Foi obtida por elementos finitos e a relação entre $H_{\text {exc }} / I_{\text {exc }}=8,3 \mathrm{kA} / \mathrm{m}$ por A foi calculada a partir da média do campo para a primeira metade do núcleo.

A limitação de 1 A na excitação, que foi o gargalo nos protótipos em escala, esta agora é suficiente para atingir valores muito maiores de $H_{\text {exc }}$. Entretanto tratam-se de sensores muito mais delicados, com trilhas de secção transversal reduzida, de modo que a corrente máxima aplicada ficou limitada pela temperatura. As bobinas de excitação do dispositivo baseado em L2 têm aproximadamente o dobro da resistência do baseado em L1 (aproximadamente 30/60 $\Omega$ ). Logo esta também é a mesma relação da potência dissipada para uma mesma corrente. $\mathrm{Na}$ prática o limite foi $2 \mathrm{kA} / \mathrm{m}$ para $\mathrm{mL} 1$ e $1.2 \mathrm{kA} / \mathrm{m}$ para $\mathrm{mL} 2$, isto para manter a temperatura abaixo de $80^{\circ} \mathrm{C}$. 


\subsubsection{Curva de resposta}

A curva de resposta para campos externos positivos $\left(B_{0}\right)$ é mostrada na figura 2.4.20 para os dois sensores. Esta foi medida em uma ambiente não blindado para a maior amplitude de excitação suportada. Os dois dispositivos apresentaram curvas típicas de um fluxgate com boa linearidade na faixa medida $\left(\mathrm{R}^{2} \approx 0.997\right)$.

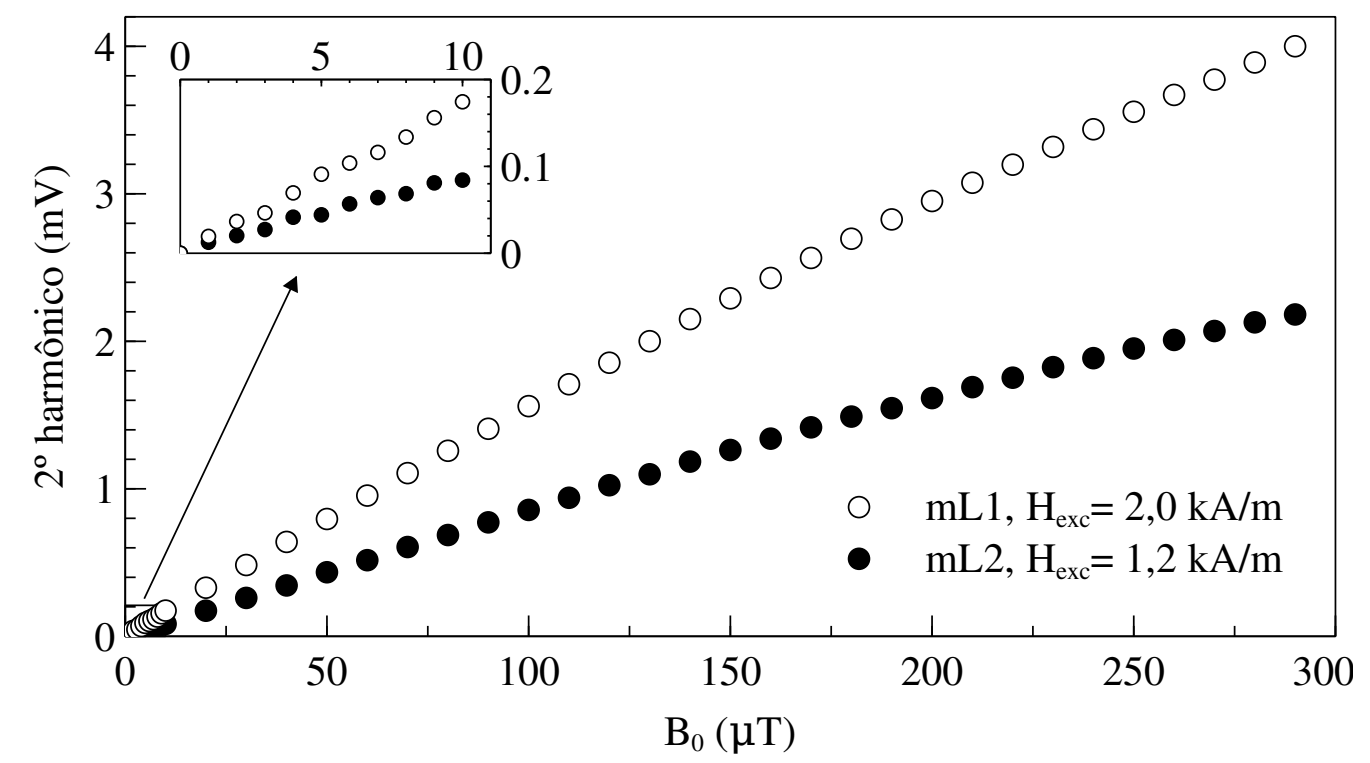

Figura 2.4.20 - Curva de resposta dos sensores microfabricados. A inserção mostra em detalhe os pontos perto da origem.

\subsubsection{Responsividade}

A responsividade também foi medida de forma análoga aos sensores em escala macro: 5 curvas de resposta curtas $(0$ a $50 \mu \mathrm{T})$ foram medidas para cada $H_{\text {exc }}$ particular, foram calculadas as sua inclinações e tirada a média entre estas, resultando na responsividade mostrada na figura 2.4.21. 


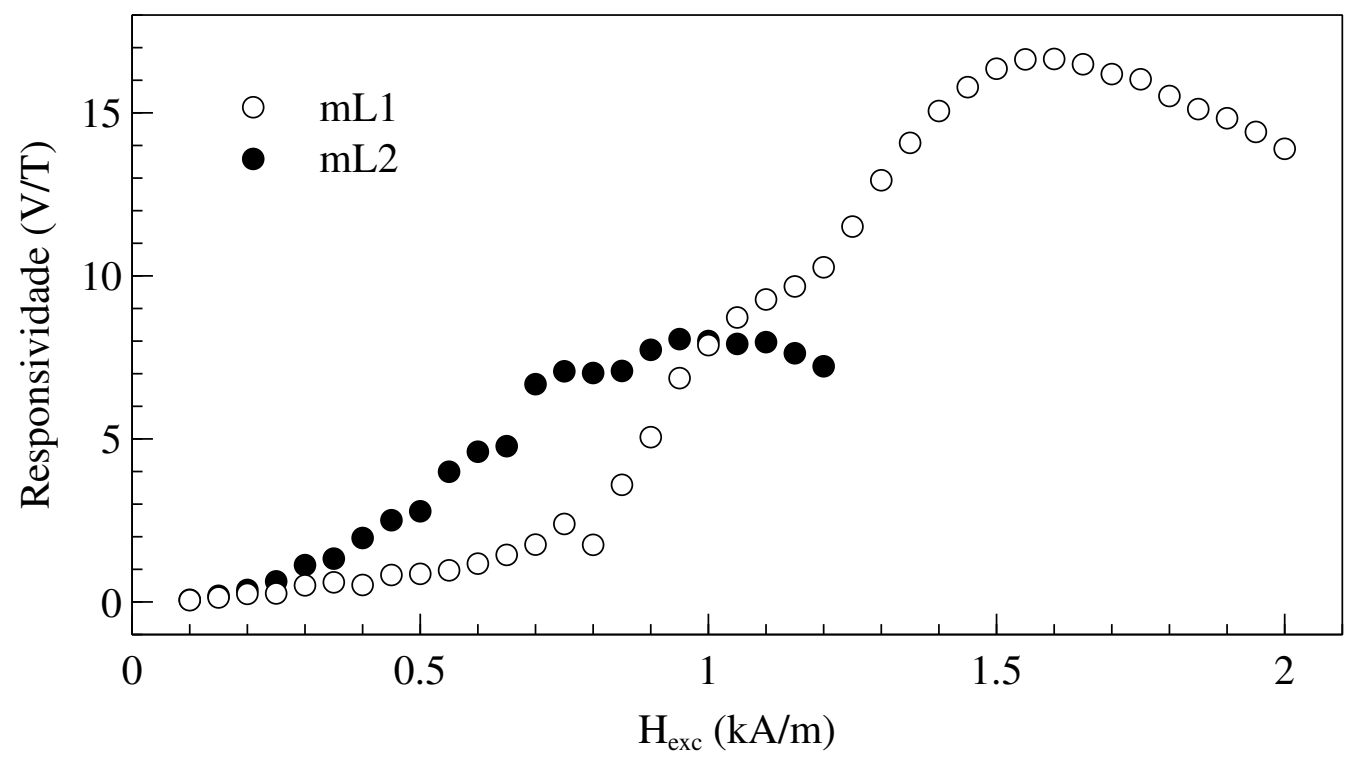

Figura 2.4.21 - Responsividade em função da amplitude de excitação.

Exceto pelo desvio encontrado para baixos $H_{\text {exc }}$ em ambos leiautes, o comportamento geral das curvas de responsividade é típica dos sensores tipo fluxgate. $\mathrm{mL} 1$ atingiu maior responsividade em relação à mL2, majoritariamente por causa das bobinas coletoras completas pois desta vez tem-se uma relação bem próxima de 2. Entretanto o máximo foi atingido para $H_{\text {exc }}$ maior. A tabela 2.4 .7 contém os valores encontrados.

\begin{tabular}{lrr}
\hline & $\mathrm{mL} 1$ & $\mathrm{~mL} 2$ \\
\cline { 2 - 3 } Espiras coletoras & 30 & 15 \\
Responsividade máxima $(\mathrm{V} / \mathrm{T})$ & 16,16 & 8,1 \\
$H_{\text {exc }}(\mathrm{kA} / \mathrm{m})$ & 1,6 & 0,95 \\
\hline
\end{tabular}

Tabela 2.4.7 - Responsividade máxima e campo de excitação associado dos sensores microfabricados.

\subsubsection{Ruído}

O sinal de saída dos sensores dentro de uma blindagem magnética de três camadas foi coletado por $60 \mathrm{~s}$ com um intervalo de $2 \mathrm{~ms}$ entre pontos. Destes dados o espectro da densidade de potência foi calculado, assim como o ruído rms contido na faixa $0,1 \mathrm{a} 10 \mathrm{~Hz}$. Os detalhes deste cálculo estão no apêndice B. Os valores obtidos para o ruído não normalizado estão mostrados na figura 2.4.22. 


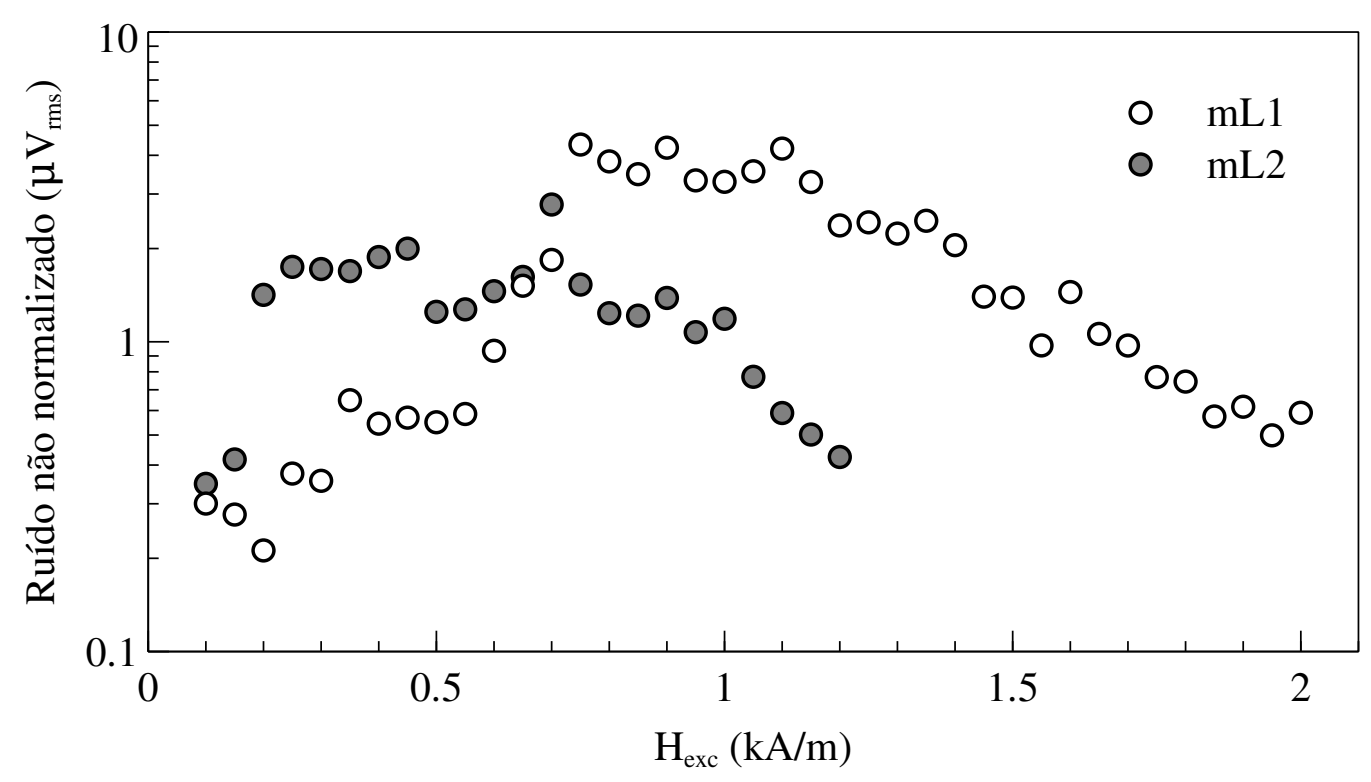

Figura 2.4.22 - Ruído rms não normalizado contido na faixa de frequência 0,1 a $10 \mathrm{~Hz}$ como função da amplitude de excitação.

Os níveis de ruído não normalizado aumentam com $H_{\text {exc }}$ na região de baixa excitação, atingem um máximo e começam a cair. Ambos leiautes apresentaram esta tendência decrescente para $H_{\text {exc }}>\approx 1 \mathrm{kA} / \mathrm{m}$, sendo a do mL2 mais acentuada. Para amplitudes de excitação maiores que $0,7 \mathrm{kA} / \mathrm{m}, \mathrm{mL} 2$ apresentou níveis de ruído não normalizado menores que $\mathrm{mL} 1$. Esta vantagem é compensada em parte pela maior responsividade do $\mathrm{mL} 1$ quando o ruído é normalizado (em unidades de campo magnético) como mostra a figura 2.4.23. Além disto, logo que a responsividade de $\mathrm{mL} 1$ começa a diminuir, os níveis de ruído deixam de ser bem descritos por um decaimento exponencial. Para este sensor, aumentar o campo de excitação diminui o ruído normalizado até um certo ponto, aproximadamente $1,75 \mathrm{kA} / \mathrm{m}$. Após este, os valores permanecem constantes uma vez que a diminuição do ruído não normalizado não é suficiente para compensar a perda de responsividade. Isto não ocorre no caso de $\mathrm{mL2}$. Seus níveis de ruído continuam a decrescer mesmo após o pico na responsividade, e com o comportamento exponencial. Caso semelhante ao observado para os protótipos em escala. Os melhores valores de ruído obtidos para $\mathrm{mL} 1$ foram $40 \mathrm{nT} r m s$ com $\sim 1,9 \mathrm{kA} / \mathrm{m}$, e para $\mathrm{mL} 2,59 \mathrm{nT} \mathrm{rms}$ com $\sim 1,2$ $\mathrm{kA} / \mathrm{m}$. 


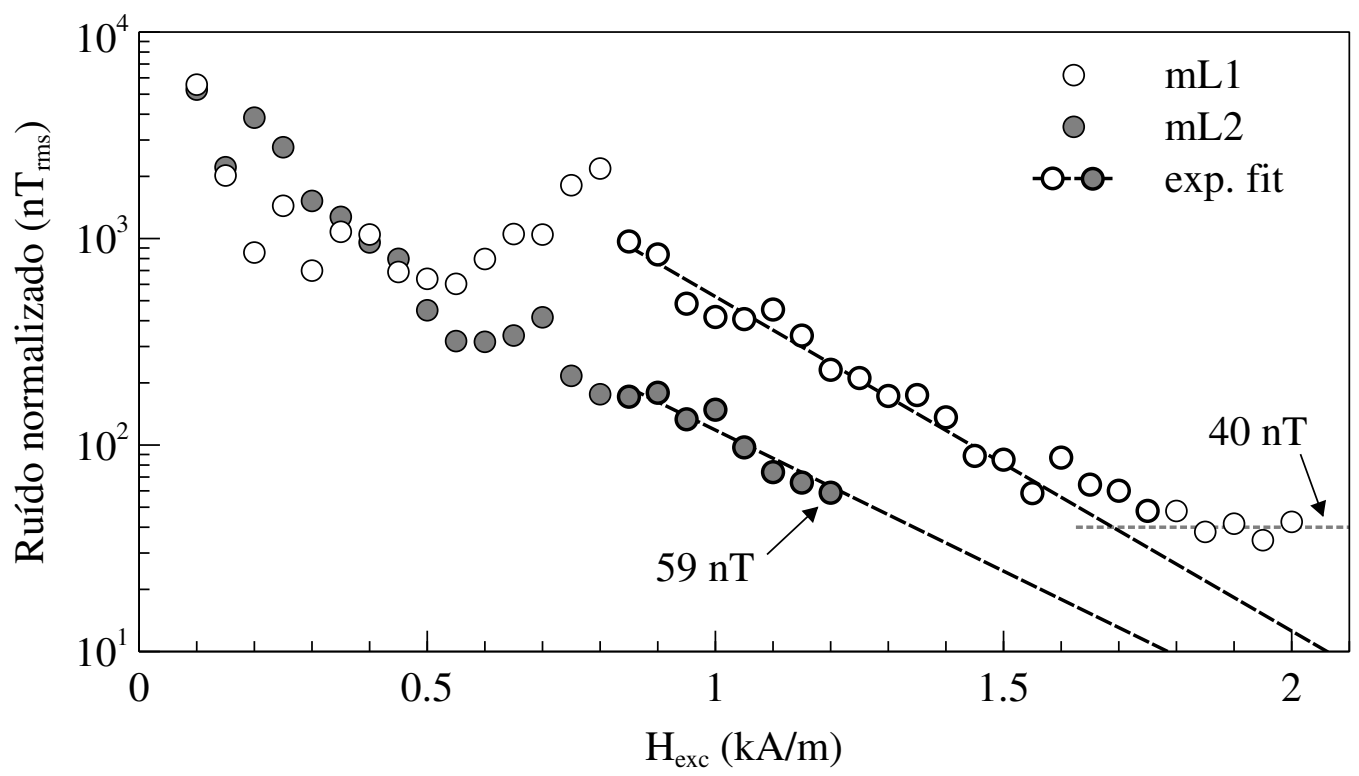

Figura 2.4.23 - Ruído rms normalizado contido na faixa de frequência 0,1 a $10 \mathrm{~Hz}$ como função da amplitude de excitação.

Os espectros do ruído utilizados para a obtenção dos valores $r m s$ têm a usual forma $1 / f$ como mostra o exemplo da figura 2.4.24. São compatíveis com as principais fontes de ruído para este tipo de sensor, como os saltos de Barkhausen.

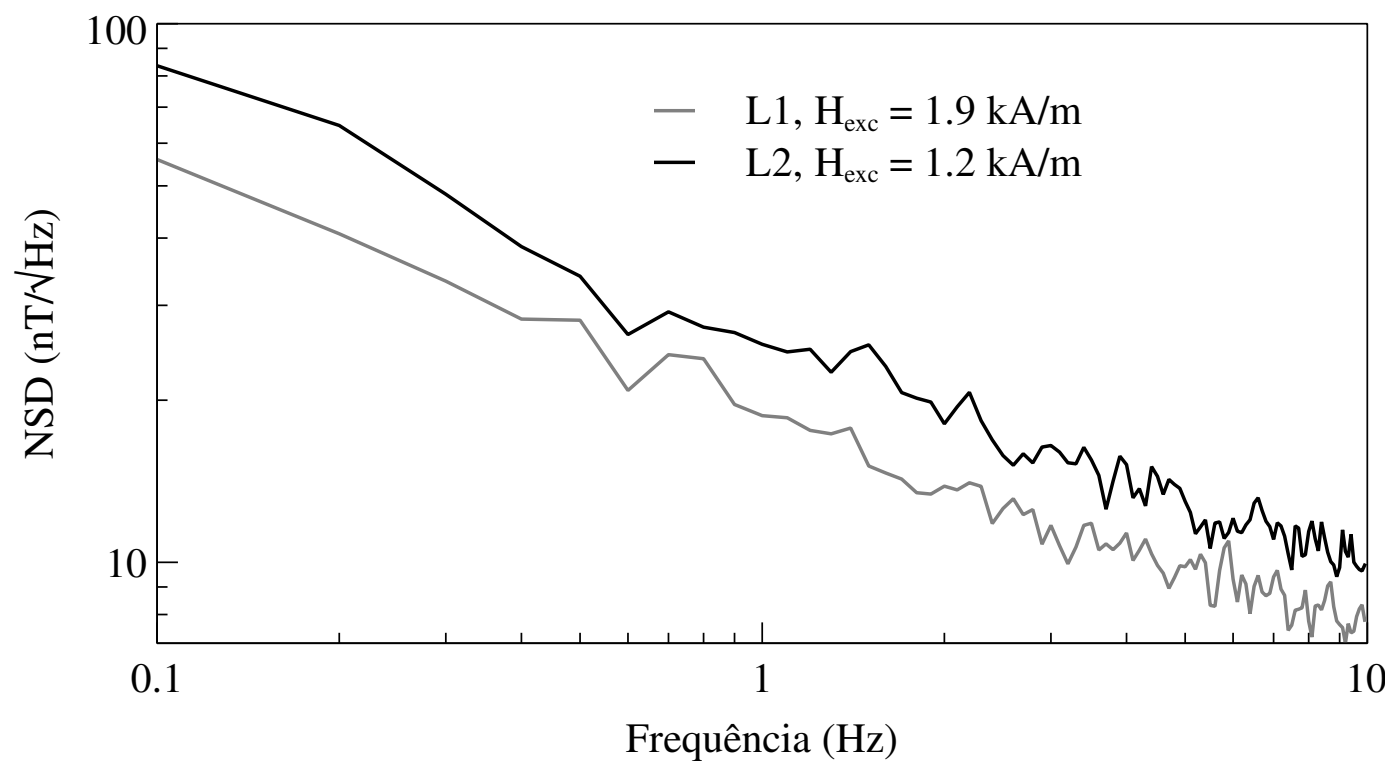

Figura 2.4.24 - Exemplos dos espectros da densidade de ruído (NSD, do inglês noise spectrum density) capturados para ambos sensores.

Pode-se melhorar a responsividade de ambos sensores aumentando o número de espiras nas bobinas. Mas para mL2, o aumento do campo $H_{\text {exc }}$ associado (mantendo a corrente de excitação constante), também contribuiria na redução do ruído. Então para densidades de espiras 
baixas, sensores baseados em L1 são uma melhor opção. Mas se for possível construir as bobinas com uma densidade alta, sensores baseados em L2 podem atingir níveis de ruído mais baixos. Considere por exemplo um sensor baseado em L2 com resolução espacial de $20 \mu \mathrm{m}$, o dobro da utilizada em [21]. Mantendo-se a mesma amplitude da corrente aplicadas nas bobinas para se obter $H_{\text {exc }}=1,2 \mathrm{kA} / \mathrm{m}$ (aproximadamente $146 \mathrm{~mA}$, praticável uma vez que o artigo mencionado utiliza até $220 \mathrm{~mA}$ ) resultaria agora em $H_{\text {exc }}=1,82 \mathrm{kA} / \mathrm{m}$. Além disto teria-se um aumento de três vezes na responsividade. Extrapolando a queda do ruído medida para $\mathrm{mL} 2$ pelo comportamento exponencial decrescente mostrado em 2.4.23, tal dispositivo operaria com um ruído rms da ordem de $10 \mathrm{nT}$. Claro que esta extrapolação direta não é facilmente justificada, mas o exemplo serve para mostrar o potencial do leiaute proposto.

\subsubsection{Conclusões, minifluxgates}

Os resultados experimentais suportam a viabilidade da construção de sensores tipo fluxgate planos, miniaturizados, utilizando somente uma camada de bobinas. Tais sensores têm um processo de fabricação simplificado utilizando apenas quatro máscaras litográficas e um número reduzido de etapas. Os dois sensores construídos, baseados em dois leiautes sugeridos, apresentaram aproximadamente o mesmo nível de ruído mínimo (40 e 59 nT rms na faixa de $0,1 \mathrm{a} 10 \mathrm{~Hz}$ ). Embora o dispositivo baseado no leiaute mais simples, $\mathrm{mL1}$, tenha apresentado o menor valor, este não pode ser reduzido a partir de um ponto apenas aumentando-se a amplitude de excitação. Em contraste com mL2, onde o ruído não atingiu um limite na faixa de campos estudada. Este comportamento já tinha sido observado nos protótipos em escala macroscópica. É esperado também, por causa do perfil de excitação utilizado, que sensores baseados em L2 sejam menos suscetíveis aos efeitos de perming. 


\section{Fluxgate ortogonal por rotação da magne- tização (FORM)}

Este capítulo trata do desenvolvimento de sensores magnéticos tipo fluxgate ortogonal onde a variação da permeabilidade magnética foi induzida pela rotação da magnetização, em contraste com o uso do movimento das paredes de domínio em sensores convencionais. A discusão começa pelo problema do ruído magnético e a proposta de solução adotada, seguida de uma revisão bibliográfica específica para sensores que fazem uso da rotação da magnetização. Depois de uma breve descrição da idéia por traz do projeto, é proposto um modelo matemático para o sinal de saída deste tipo de sensor quando operado em constante saturação. Em seguida suas previsões teóricas são comparadas com dados experimentais e são discutidas algumas de suas consequências na escolha do material do núcleo. A partir da seção 3.6 são descritos os métodos de construção e caracterização dos sensores fluxgate ortogonais propostos, e apresentados e discutidos os resultados.

\subsection{O problema do ruído magnético}

Como já foi dito, a principal fonte de ruído magnético presente em um fluxgate são os saltos de Barkhausen. Ocorrem quando a parede dos domínios em movimento encontra um defeito no material. Mas este movimentos das paredes somente é o principal mecanismo de mudança da magnetização para campos externos baixos, como mostra a figura 3.1.1.

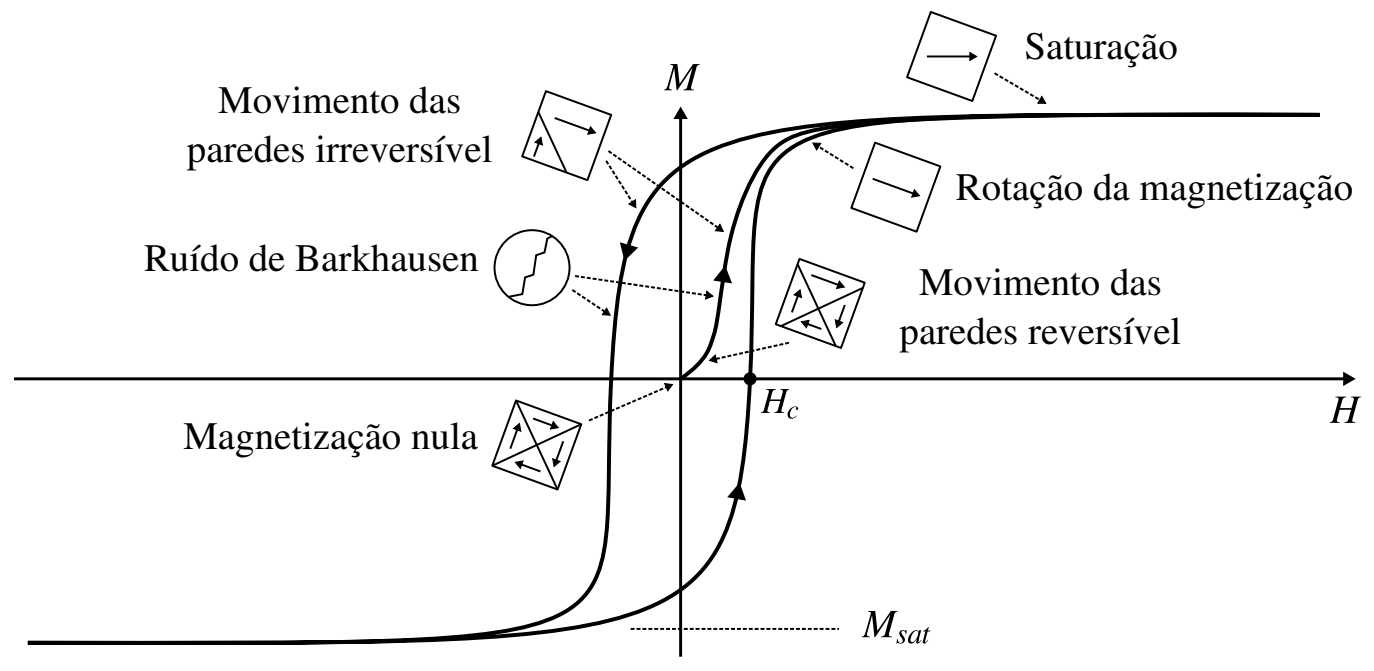

Figura 3.1.1 - Mecanismos associados a magnetização de materias ferromagnéticos.

Em um fluxgate convencional o núcleo ferromagnético é levado da saturação em uma direção para a saturação na outra duas vezes por ciclo da excitação, passando por toda a região 
central onde os saltos de Barkhausen estão concentrados. Existem maneiras de se suprimir o movimento das paredes dos domínios e mesmo assim modular a permeabilidade do núcleo. Pode-se, por exemplo, utilizar um material monocristalino com um número reduzido de defeitos. Por outro lado é possível operar o sensor somente na região onde a rotação da magnetização é predominante, evitando a região central. Para isto aplica-se um campo $H$ constante $\left(H_{d c}\right)$ forte o suficiente para atingir a região de rotação da magnetização. Um outro campo alternado $\left(H_{a c}\right)$ é responsável pela variação da permeabilidade. Note que, se o núcleo for operado em uma região de $H$ suficientemente alto, tem-se virtualmente um único domínio magnético, especialmente em materiais monocristalinos. Inclusive existem monocristais que, mesmo na ausência do campo $H_{d c}$, possuem um estado de equilíbrio de domínio único. Entretanto são escassos e apresentam inconvenientes, como a necessidade de processos térmicos a elevadas temperaturas, incompatíveis com muitos processos de filmes finos.

A justificativa para o termo virtualmente, utilizado no último parágrafo qualificando o único domínio, está no fato de que é virtualmente impossível saturar completamente materiais ferromagnéticos [40]. Deste modo o termo monodomínio não é estritamente verdadeiro, mas uma aproximação. De fato os saltos de Barkhausen diminuem de frequência gradativamente com o aumento do campo externo, mesmo na região de saturação [41].

\subsection{Revisão bibliográfica}

A tabela 3.2.1 mostra um resumo das características de sensores tipo fluxgate que operam em estado de domínio único propostos e/ou construídos presentes na literatura. São mostrados alguns parâmetros relevantes, como a direção dos campos de excitação tanto o alternado como, quando utilizado, a componente contínua, sempre em relação a componente do campo externo a ser medida. Estas direções são a base da operação do dispositivo. Originalmente somente era feita a discriminação de fluxgates paralelos e ortogonais dada pela direção do campo de excitação $\mathrm{H}_{a c}$. Com a adição de $\mathrm{H}_{d c}$ cresce o número de combinações possíveis. Soma-se a isto a direção de fácil magnetização do núcleo. Claro que nem todas as combinações são interessantes do ponto de vista de um sensor magnético, entretanto as propriedades como responsividade, sensibilidade e simplicidade de construção variam significativamente. Finalmente, não é feita distinção ao sistema de coordenadas utilizado, no sentido que, sensores planares com campos ortogonais $x, y$ não são discriminados de sensores com simetria cilíndrica onde a ortogonalidade está entre a direção axial e a componente circunferencial $(z, \phi)$.

\subsection{Projeto FORM}

A ideia foi fabricar sensores com dimensões reduzidas, simples e de baixo ruído. Foi idealizado um dispositivo nos moldes de $[46,50,52]$ mas onde fosse possível a saturação de todo o núcleo. Para isto o fio, antes composto unicamente pelo material ferromagnético, agora é 


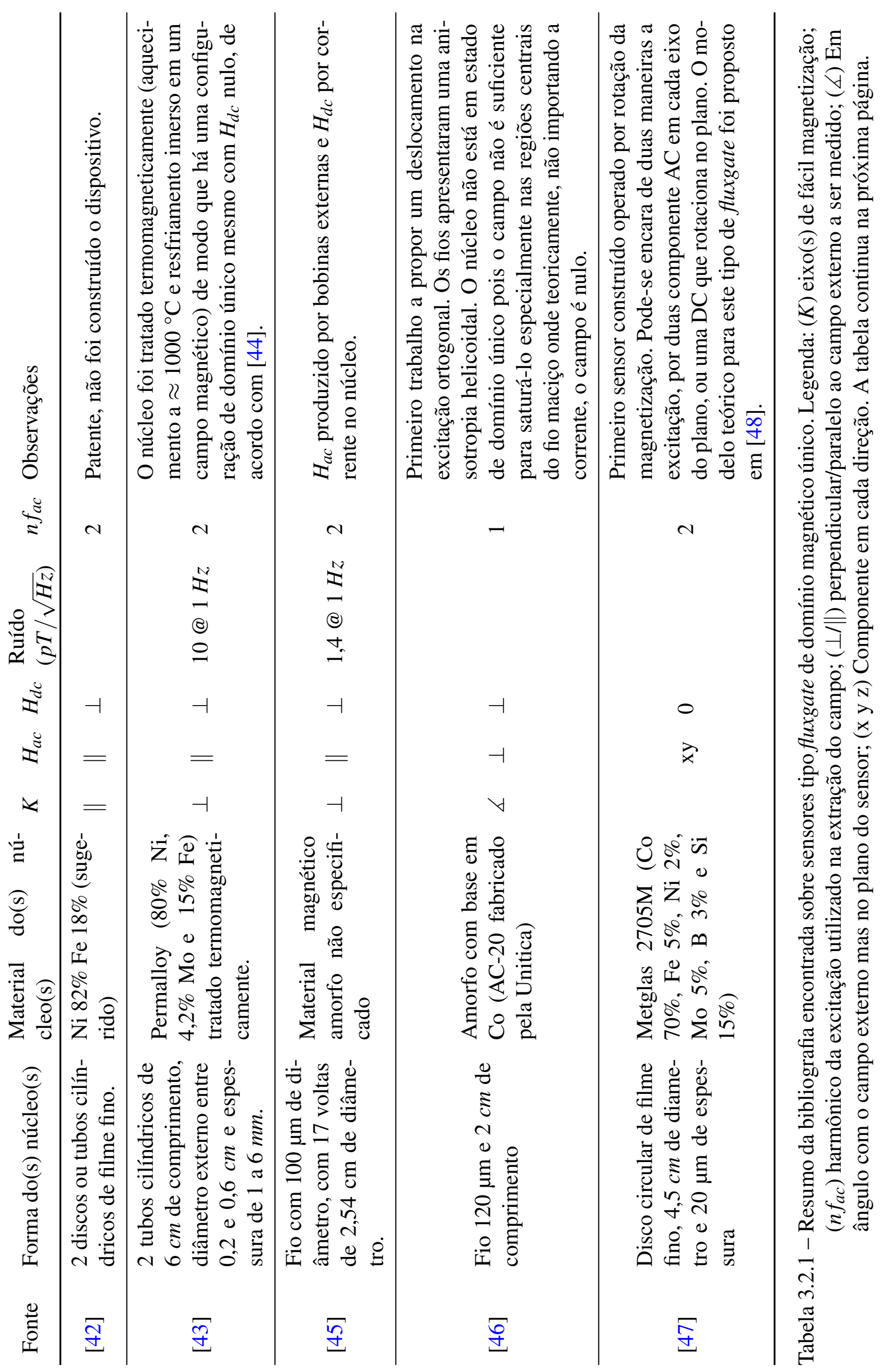




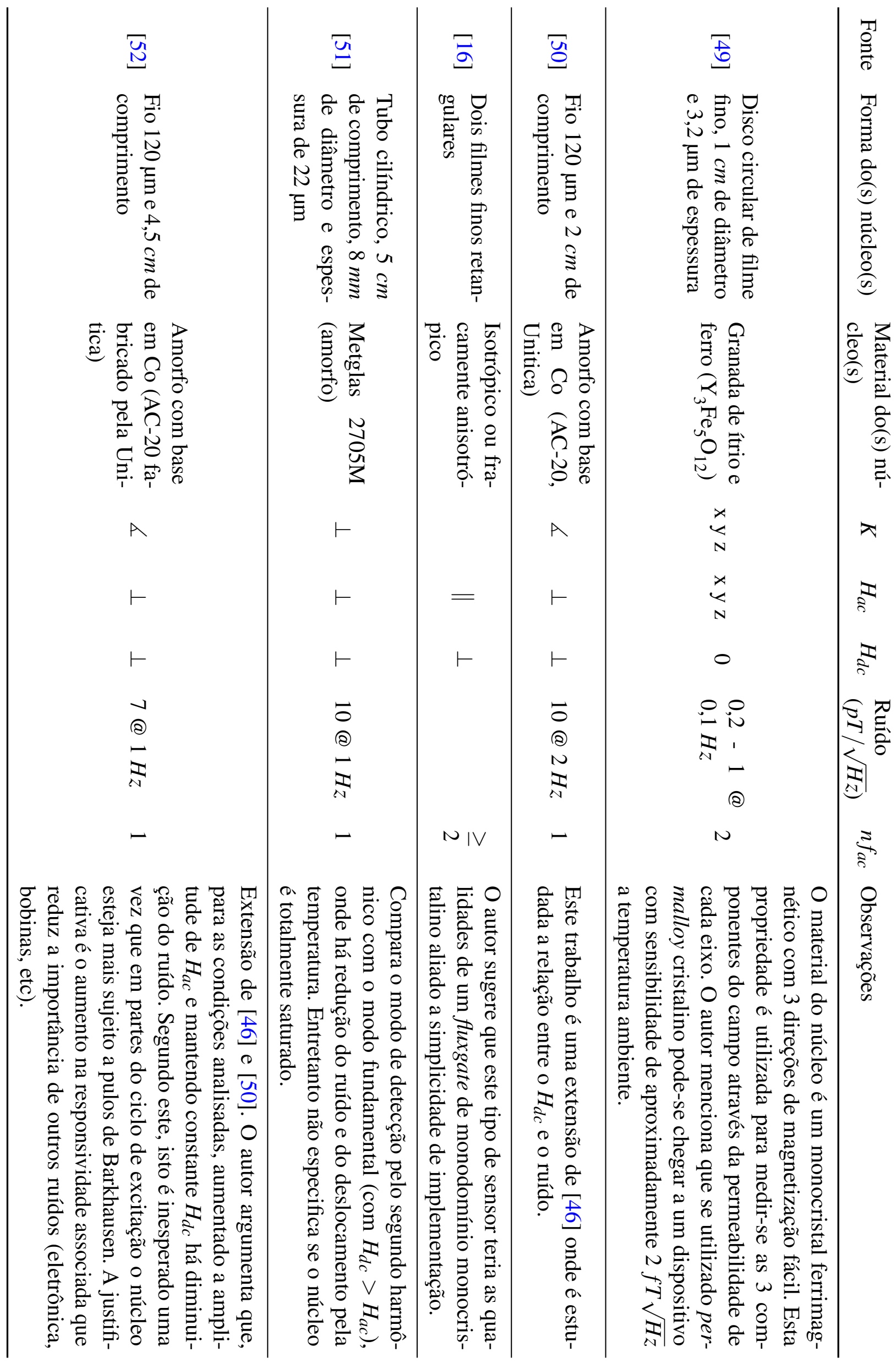


composto por um centro de cobre sobre o qual é eletrodepositado um material ferromagnético, como mostra a figura 3.3.1. Desta forma a região central do fio que tem $H \approx 0$ não é composta pelo material ferromagnético, evitando-se assim porções do núcleo não saturáveis.

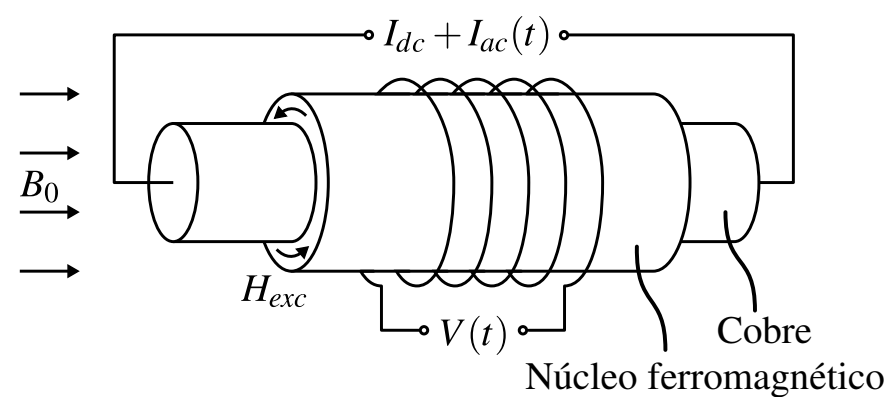

Figura 3.3.1 - Esquema de um fluxgate ortogonal por rotação da magnetização.

Para se operar constantemente com um único domínio magnético tem-se que tomar o cuidado de manter $H_{d c}-H_{a c}>H_{s a t}$. Mas a medida que $H_{d c}$ aumenta, mesmo que ainda não satisfaça esta relação, há uma graduativa mudança do mecanismo de variação da permeabilidade em favor da rotação da magnetização, e a diminuição do número de domínios. Desta maneira é possível reduzir o ruído sem necessariamente saturar o núcleo durante todo o ciclo de excitação. Como será visto, há um compromisso entre perda de responsividade e diminuição nos saltos de Barkhausen.

\subsection{Modelo matemático para um FORM}

\subsubsection{Mecanismo de modulação da permeabilidade na saturação}

A modulação da permeabilidade é feita variando-se a amplitude do campo de excitação, sempre acima do valor de saturação. $\mathrm{O}$ esquema vetorial do mecanismo é mostrado na figura 3.4.1. 


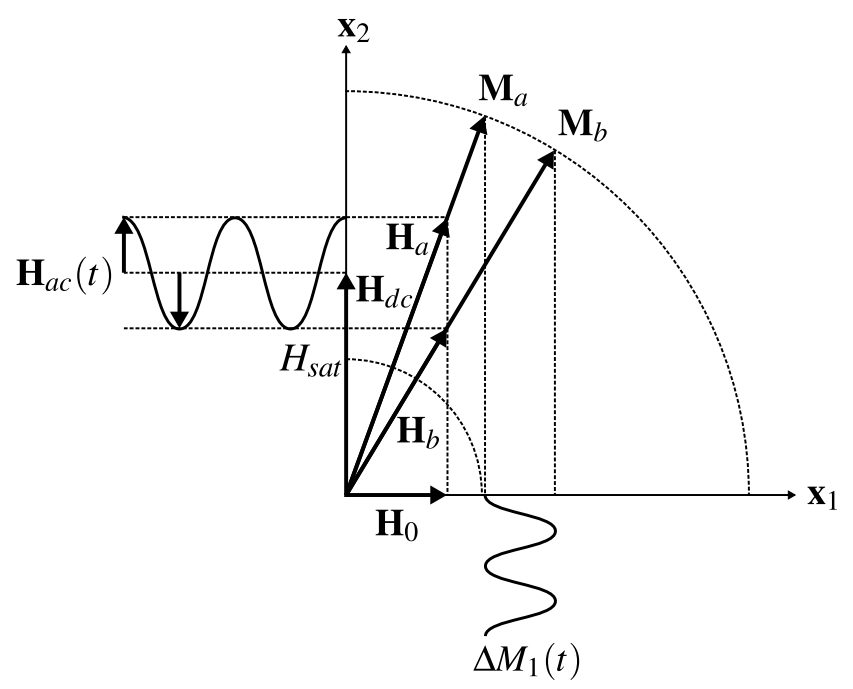

Figura 3.4.1 - Esquema vetorial da modulação da permeabilidade magnética de um FORM. Para medir o campo externo $\mathrm{H}_{0}$ na direção de $\mathbf{x}_{1}$, excita-se o material ferromagnético com uma componente contínua $\left(\mathbf{H}_{d c}\right)$ somada a uma variável periódica $\left(\mathbf{H}_{a c}(t)\right)$ na direção de $\mathbf{x}_{2}$, onde $\mathbf{x}_{1} \cdot \mathbf{x}_{2}=0$. Para garantir a saturação deve-se respeitar $H_{d c}-H_{a c}>H_{s a t}$. A permeabilidade na direção 1 , definida como $\mu_{1}=B_{1} / H_{1}$, varia no processo pois $B_{1}=\mu_{0}\left(H_{1}+M_{1}\right)$, e $M_{1}$ varia. Considere os extremos de $\mathbf{H}_{a c}$ definindo os estados $a$ e $b$, onde $H_{a c}(a)>H_{a c}(b)$. De $a$ para $b$ a magnetização rotaciona de modo que a projeção desta no eixo 1 aumenta. Sem considerar alguns detalhes (que serão vistos no modelo matemático a seguir) tem-se que $\Delta \mu_{1}=\mu_{0}\left(1+\Delta M_{1} / H_{0}\right)$

\subsubsection{Equação do sinal de saída de um FORM}

O campo $\mathbf{H}$ no interior do núcleo do sensor pode ser escrito como

$$
\mathbf{H}=\mathbf{H}_{0}+\mathbf{H}_{e}+\mathbf{H}_{d},
$$

onde $\mathbf{H}_{0}$ é o campo externo, $\mathbf{H}_{e}$ é o campo de excitação e $\mathbf{H}_{d}$ o campo de desmagnetização. Este último, pode ser aproximado por

$$
\mathbf{H}_{d}=-\bar{D} \mathbf{M},
$$

onde $\bar{D}$ é o tensor de desmagnetização e $\mathbf{M}$ a magnetização. Para esta aproximação ser válida é necessária uma magnetização uniforme do material. Com esta restrição é possível obter um campo tensorial de desmagnetização do qual $\bar{D}$ é a média volumétrica. Além disto, pode-se representar este tensor por uma matriz diagonal [53, 54], ou seja:

$$
\bar{D}=\left(\begin{array}{ccc}
D_{1} & 0 & 0 \\
0 & D_{2} & 0 \\
0 & 0 & D_{3}
\end{array}\right)
$$


Nesta representação está implícita a adoção de 3 eixos ortogonais. Existem valores de $D_{1,2,3}$ para cada escolha particular de base ortogonal. Em particular será considerado a base definida pelos versores $\left\{\hat{\mathbf{x}}_{1}, \hat{\mathbf{x}}_{2}, \hat{\mathbf{x}}_{3}\right\}$.

Para um material isotrópico a magnetização do núcleo $\mathbf{M}$ tem a direção do campo $\mathbf{H}$, ou seja

$$
\mathbf{M}=M \hat{\mathbf{H}}=M \frac{\mathbf{H}}{H},
$$

onde $M$ é o módulo da magnetização e $H$ é o módulo do campo H. Além disto, as magnitudes dos campos têm a relação

$$
B=\mu H=\mu_{0}(H+M)
$$

de onde se chega a

$$
M=\left(\mu_{r}-1\right) H,
$$

com $\mu_{r}=\mu / \mu_{0}$, chamada de permeabilidade relativa, igual em todas direções. Assim a magnetização da equação 3.4.4 assume a forma

$$
\mathbf{M}=\left(\mu_{r}-1\right) \mathbf{H}
$$

Utilizando as equações 3.4.2 e 3.4.7 pode-se reescrever o campo $\mathbf{H}$ como:

$$
\begin{aligned}
\mathbf{H} & =\mathbf{H}_{0}+\mathbf{H}_{e}-\left(\mu_{r}-1\right) \bar{D} \mathbf{H} \\
& =\left(\bar{I}+\left(\mu_{r}-1\right) \bar{D}\right)^{-1}\left(\mathbf{H}_{0}+\mathbf{H}_{e}\right) \\
& =\bar{\mu}_{r}\left(\mathbf{H}_{0}+\mathbf{H}_{e}\right),
\end{aligned}
$$

onde $\bar{I}$ é o tensor identidade e $\bar{\mu}_{r}$ é o tensor da segunda igualdade da equação. É possível mostrar que, sendo $D_{1,2,3} \geq 0$, este existe (é inversível) e tem a forma matricial

$$
\bar{\mu}_{r}=\left(\begin{array}{ccc}
\left(1+\left(\mu_{r}-1\right) D_{1}\right)^{-1} & 0 & 0 \\
0 & \left(1+\left(\mu_{r}-1\right) D_{2}\right)^{-1} & 0 \\
0 & 0 & \left(1+\left(\mu_{r}-1\right) D_{3}\right)^{-1}
\end{array}\right)
$$

O campo magnético $\mathbf{B}$ na região interior do núcleo pode ser escrita, utilizando as equações 3.4.7 e 3.4 .8 , como

$$
\mathbf{B}=\mu_{0}(\mathbf{H}+\mathbf{M})=\mu_{0} \mu_{r} \mathbf{H}=\mu_{0} \mu_{r} \bar{\mu}_{r}\left(\mathbf{H}_{0}+\mathbf{H}_{e}\right) .
$$

Para uma espira com normal na direção $\hat{\mathbf{x}}_{1}$, resistência nula e acoplada ao núcleo, tem-se

$$
V=-\frac{\mathrm{d} \Phi}{\mathrm{d} t}=-\frac{\mathrm{d}}{\mathrm{d} t} \int \mathbf{B} \cdot \mathrm{d} \mathbf{a}=-\frac{\mathrm{d}}{\mathrm{d} t} \int \mathbf{B} \cdot \hat{\mathbf{x}}_{1} \mathrm{~d} a,
$$


onde $\Phi$ é o fluxo magnético através da espira, da é o vetor infinitesimal da sua área. O produto vetorial do integrando, utilizando a equação 3.4 .10 , fica

$$
\mathbf{B} \cdot \hat{\mathbf{x}}_{1}=\mu_{0} \mu_{r} \mathbf{H} \cdot \hat{\mathbf{x}}_{1}=\mu_{0} \mu_{r} \bar{\mu}_{r}\left(\mathbf{H}_{0}+\mathbf{H}_{e}\right) \cdot \hat{\mathbf{x}}_{1} .
$$

Mas para um fluxgate ortogonal, $\mathbf{H}_{e} \cdot \hat{\mathbf{x}}_{1}=0$ e sendo $\bar{\mu}_{r}$ diagonal não há misturas de componentes, logo

$$
\begin{aligned}
\mathbf{B} \cdot \hat{\mathbf{x}}_{1} & =\mu_{0} \mu_{r}\left[1+\left(\mu_{r}-1\right) D_{1}\right]^{-1} \mathbf{H}_{0} \cdot \hat{\mathbf{x}}_{1} \\
& =\left(\frac{\mu_{r}}{1+\left(\mu_{r}-1\right) D_{1}}\right) B_{0,1}=\mu_{a} B_{0,1},
\end{aligned}
$$

onde $B_{0,1}=\mu_{0} \mathbf{H}_{0} \cdot \hat{\mathbf{x}}_{1}$ é a quantidade de interesse. Esta é a mesma equação usual 1.6.10 entretanto a permeabilidade não é a diferencial. O resultado justifica a utilização da permeabilidade não diferencial como foi sugerido na seção 1.6. Entretanto aqui não é necessário o deslocamento por $H_{c}$ pois será aplicando um campo constante $H_{d c}$ mantendo o sistema longe da região problemática.

\subsubsection{Operação com núcleo saturado.}

Dividindo a excitação em duas componentes, $H_{e}(t)=H_{d c}+H_{a c}(t)$ e garantindo que $H_{e}>H_{s a t}$ com um $H_{d c}$ suficientemente grande, pode-se operar o sensor em permanente saturação. Assim a permeabilidade relativa só depende da magnetização de saturação do material. Fazendo $M=M_{\text {sat }}$ na equação 3.4 .6 chega-se a

$$
\mu_{r}(H)=\frac{M_{s a t}}{H}+1
$$

e a permeabilidade aparente assume a forma

$$
\mu_{a}=\frac{H+M_{\text {sat }}}{H+D_{1} M_{\text {sat }}} .
$$

\subsubsection{Aproximação de $\mathrm{H}$.}

A permeabilidade depende do módulo de $\mathbf{H}$, que é a amplitude do campo dentro do material. Este é dado por

$$
H=\sqrt{\mathbf{H} \cdot \mathbf{H}}=\sqrt{\bar{\mu}_{r}\left(\mathbf{H}_{0}+\mathbf{H}_{e}\right) \cdot \bar{\mu}_{r}\left(\mathbf{H}_{0}+\mathbf{H}_{e}\right)}
$$

mas $\bar{\mu}_{r}$ depende de $H$ e tem-se uma relação desnecessariamente complicada. Para campos externos baixos pode-se descartar sua contribuição de maneira que $\mathbf{H} \approx \bar{\mu}_{r} \mathbf{H}_{e}$. Desta forma,

$$
H \approx H_{e}-D_{2} M_{\text {sat }} .
$$

Por sua vez, a permeabilidade aparente assume

$$
\mu_{a} \approx \frac{H_{e}+\left(1-D_{2}\right) M_{\text {sat }}}{H_{e}+\left(D_{1}-D_{2}\right) M_{s a t}} .
$$




\subsubsection{3 $H_{e}$ espacialmente homogêneo.}

Estritamente falando, a equação da tensão que aparece nos terminas da bobina coletora (equação 3.4.11) tem a forma

$$
V(t)=-B_{0,1} \frac{\mathrm{d}}{\mathrm{d} t}\left(\int \mu_{a}(t, \mathbf{r}) d a\right)
$$

Entretanto assumir o campo de excitação $\mathbf{H}_{e}$ homogêneo na região do núcleo é bastante razoável e uma condição presente na maioria dos modelos matemáticos de magnetômetros deste tipo. Basicamente a homogeneidade do campo de excitação depende da geometria do sensor. Quando esta condição é satisfeita ou é uma boa aproximação, a equação 3.4.19 pode ser reescrita como:

$$
\begin{aligned}
V & =-A B_{0,1} \frac{\mathrm{d} \mu_{a}}{\mathrm{~d} t} \\
& =\frac{A B_{0,1} M_{\text {sat }}\left(1-D_{1}\right)}{\left[H_{e}+M_{\text {sat }}\left(D_{1}-D_{2}\right)\right]^{2}} \frac{\mathrm{d} H_{e}}{\mathrm{~d} t},
\end{aligned}
$$

onde $A$ é a área da seção transversal da espira. Note que os cálculos foram feitos para somente uma espira, e no caso de bobinas com mais espiras é necessário acrescentar um fator $n$ as equações $(A \rightarrow A n)$.

\subsubsection{Validação experimental}

Para validar o modelo, foi construído um fluxgate ortogonal como mostra a figura 3.4.2, e operado no modo de saturação. O esquema elétrico utilizado neste experimento esta descrito na figura 3.4.3. 


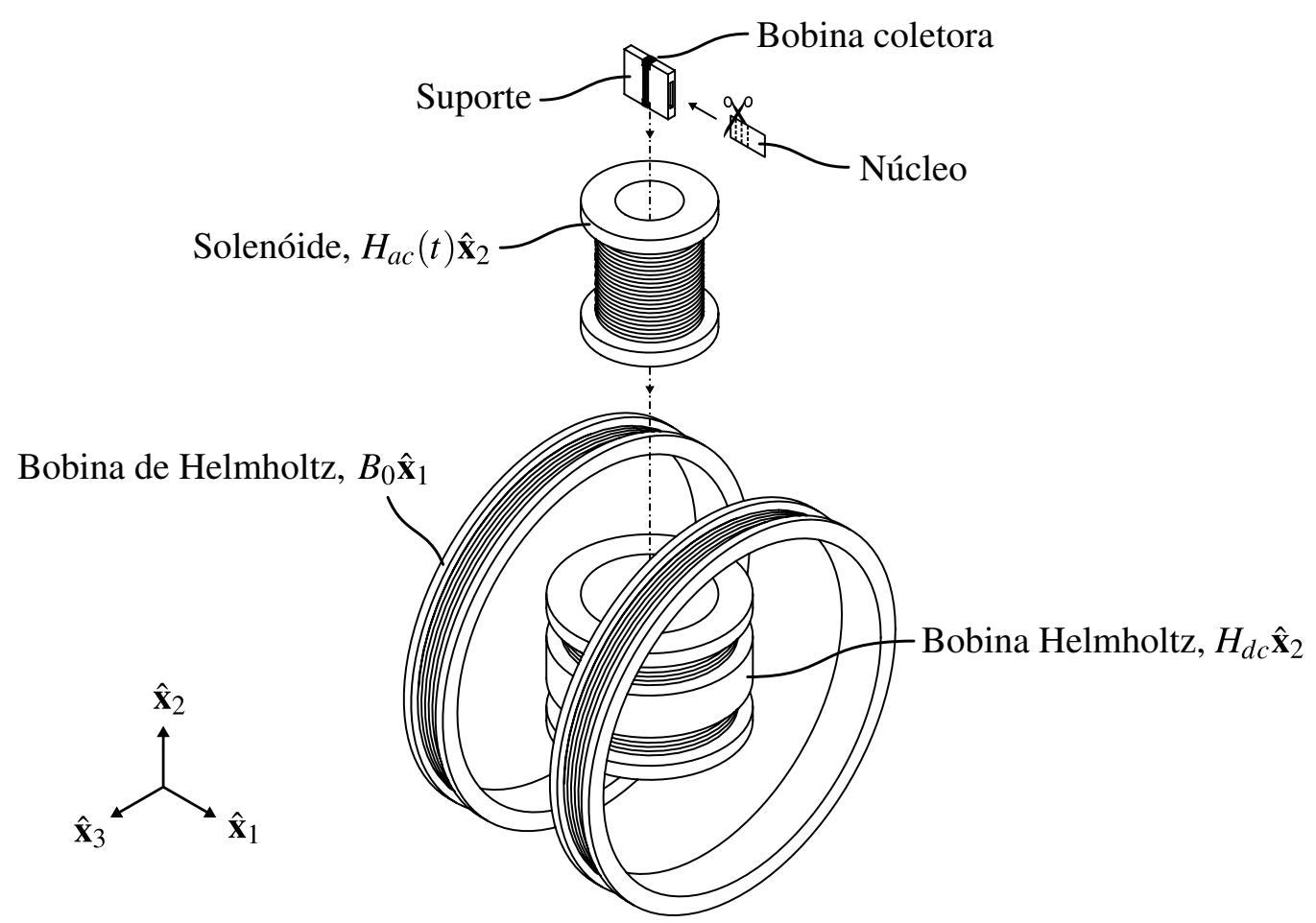

Figura 3.4.2 - Esquema experimental utilizado para testar o modelo matemático. Um núcleo formado por um filme retangular ferromagnético foi inserido em um suporte envolto por uma bobina coletora. O comprimento do núcleo foi variado cortando-se uma extremidade de maneira a alterar os fatores de demagnetização. A componente contínua e a variável do campo de excitação foram geradas separadamente. Uma bobina de Helmhotz ficou responsável pela componente $H_{d c}$ enquanto que um solenóide inserido em seu interior originou $H_{a c}$. Já o campo externo de referência $B_{0}$ foi induzido por outra bobina de Helmhotz perpendicular a primeira.

Com as aproximações propostas $H_{e}>>H_{0}$ e $H$ espacialmente homogêneo, o modelo é aplicável. A tabela 3.4.1 mostra as características do núcleo utilizado.

\begin{tabular}{lr}
\hline Material & $\mathrm{NiFe}$ \\
comprimento $\left(2 \ell_{1}\right)$ & $3-11 \mathrm{~mm}$ \\
largura $\left(2 \ell_{2}\right)$ & $8 \mathrm{~mm}$ \\
espessura $\left(2 \ell_{3}\right)$ & $26 \mu \mathrm{m}$ \\
Magnetização de saturação $\left(M_{\text {sat }}\right)$ & $10^{3} \mathrm{kA} / \mathrm{m}$ \\
\hline
\end{tabular}

Tabela 3.4.1 - Características do núcleo do sensor utilizado no teste do modelo matemático.

Os fatores de desmagnetização $\left(D_{1}\right.$ e $\left.D_{2}\right)$ foram calculados utilizando as equações deduzidas no apêndice $C$, equações C.3.6 e C.5.2. Como a bobina coletora não está idealmente acoplada com o núcleo, pois sua secção transversal é muito maior, teve-se que compensar esta perda. Para isto os resultados foram multiplicados pelo fator de acoplamento calculado no mesmo 


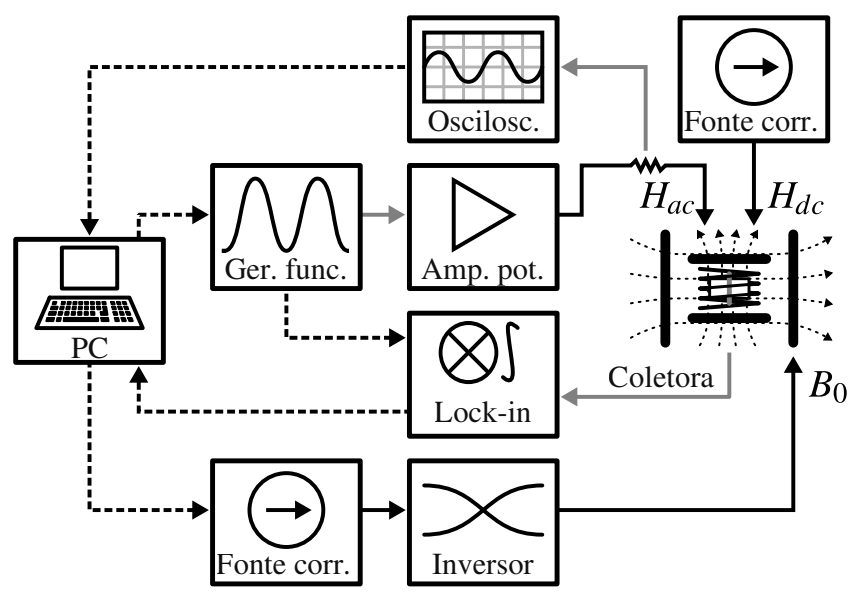

Figura 3.4.3 - Montagem experimental utilizada no teste do modelo matemático. A parte lógica das medidas é feita utilizando-se scripts que rodam em um computador. Estes controlam os parâmetros de um gerador de função (Agilent 33220A) responsável pelo sinal alternado da excitação. Um amplificador de potência (baseado em um OPA564) fornece o ganho de corrente da alimentação do solenóide. Um osciloscópio (Tektronix TDS2024B) mede a queda de potencial em cima de um resistor em série com a excitação, fornecendo o valor atual da corrente de excitação. $\mathrm{O}$ campo $\mathrm{H}_{d c}$ é mantido constante por uma fonte de corrente diretamente ligada uma bobina de Helmholtz. Já no ramo de saída do sensor, tem-se a bobina coletora ligadas a um amplificador lock-in (Signal Recovery DSP 7280). Este amplificador recebe o sinal de referência do gerador de função. O último ramo da montagem é responsável pela geração do campo externo e é composto por uma fonte de corrente programável (HP 6653A), um inversor tipo ponte $\mathrm{H}$ microcontrolado e a bobina de Helmholtz externa.

apêndice, equação C.4.3. Os campos gerados pelas bobinas de Helmholtz foram calibrados por um sensor magnético independente e o solenóide por uma bobina padrão, utilizando o mesmo formato de onda das medidas: senoidal com frequência igual a $2 \mathrm{kHz}$.

Note que são muitos os parâmetros que entram nas contas $\left(B_{0}, M_{s a t}, H_{d c}, H_{a c}, \ell_{1,2,3}\right.$, geometria da bobina coletora, etc) com aproximações e erros experimentais. Nos resultados que serão mostrados foram utilizados os valores que, dentro de suas margens de erro, melhor ajustaram os valores experimentais. Entretanto o mesmo conjunto de parâmetros foi mantido em todas as medidas. Caberia aqui uma análise de erros melhor, que fica para um trabalho futuro.

A figura 3.4.4 mostra o sinal de uma bobina coletora comparado com o previsto pelo modelo, com boa concordância. 


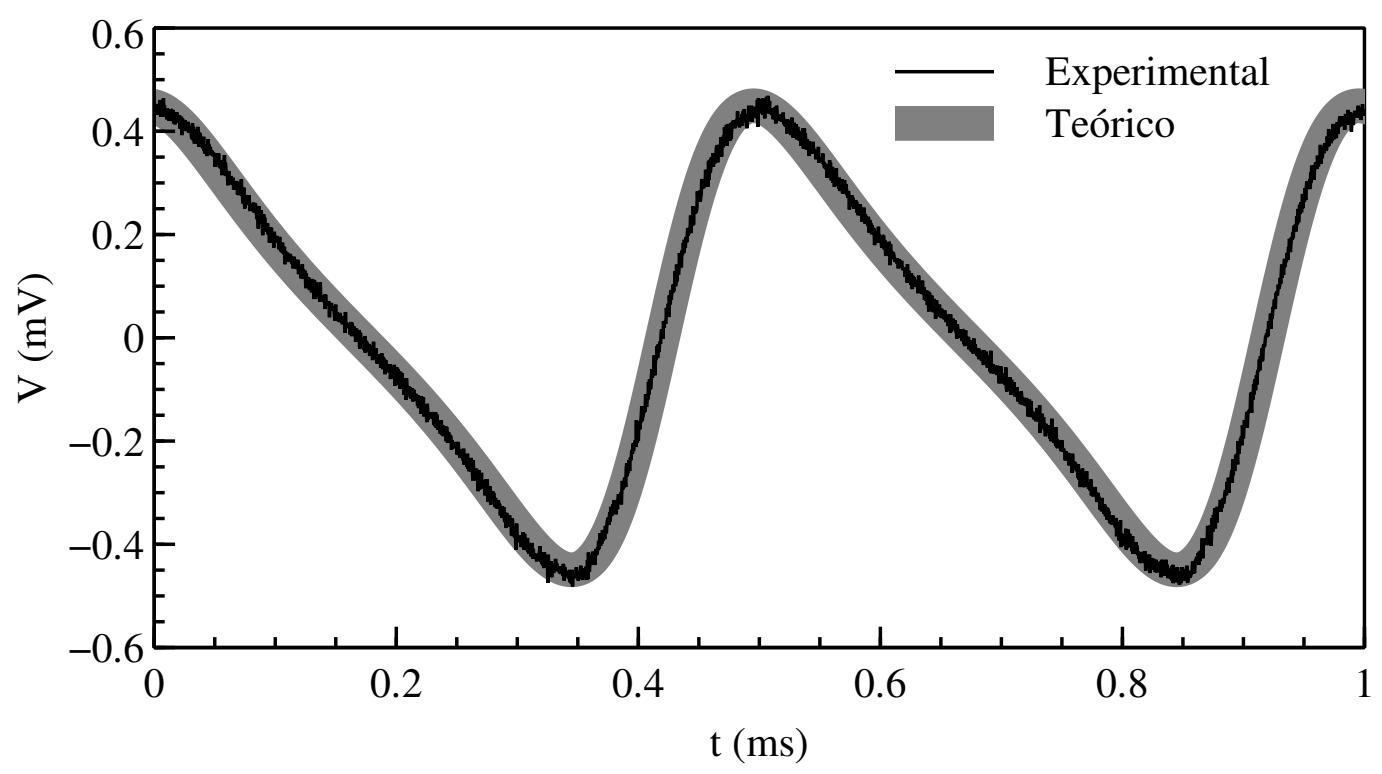

Figura 3.4.4 - Sinal medido e ajustado utilizando a equação 3.4.20.

Foram também medidas as curvas de resposta para diversas amplitudes de $H_{a c}$. O modelo prevê basicamente uma resposta linear tanto para o primeiro harmônico como para o segundo, e isto foi encontrado, como mostra a figura 3.4.5. 


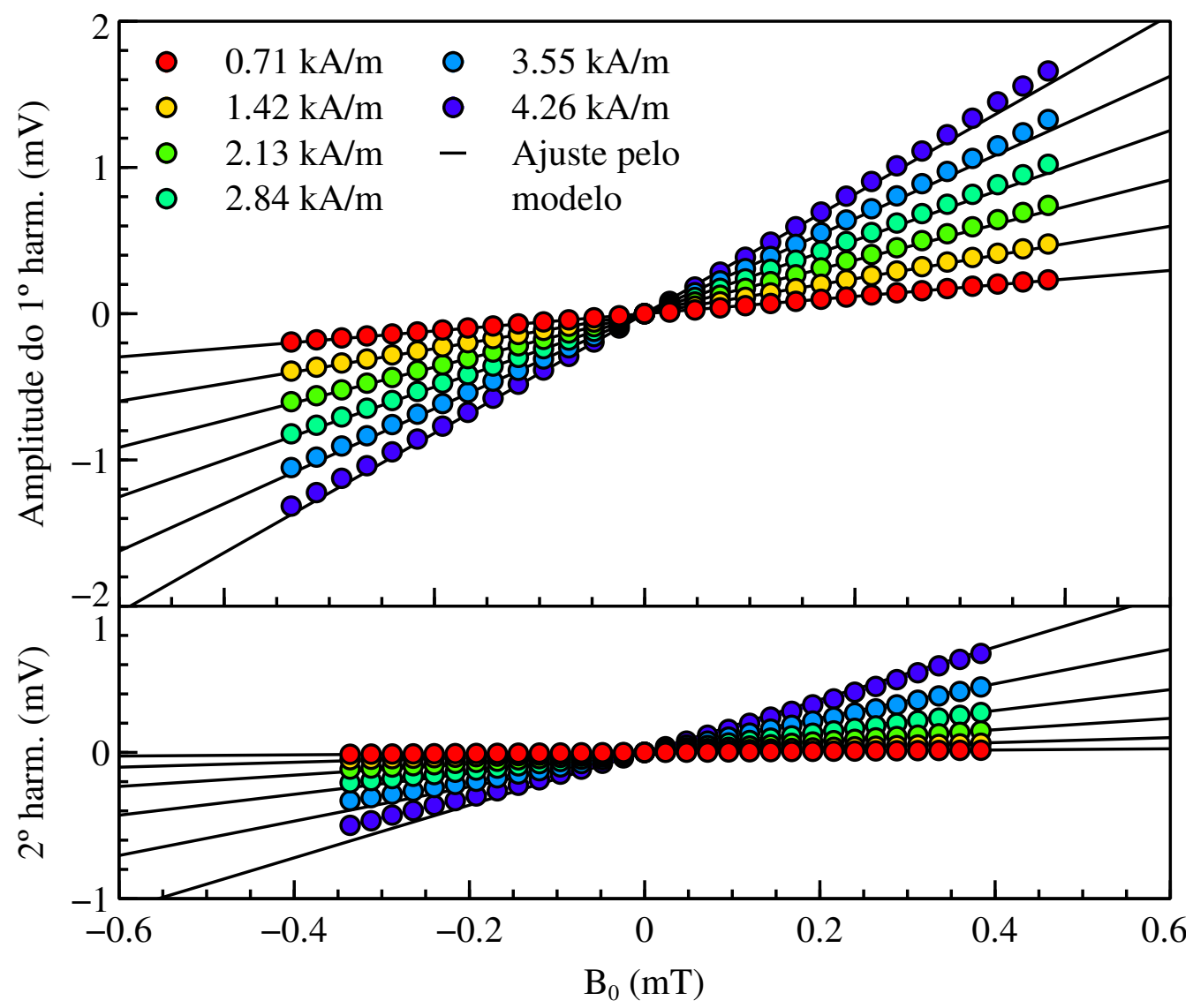

Figura 3.4.5 - Curvas de resposta para diversos $H_{a c}$, experimental e teórica para os dois primeiros harmônicos.

Das curvas de resposta pode-se obter os valores da responsividade em função de $H_{a c}$, como mostra a figura 3.4.6. O comportamento é bem descrito pelo modelo para ambos os harmônicos. Mas como o ajuste dos parâmetros foi feito para os valores do primeiro, este está ligeiramente melhor representado. 


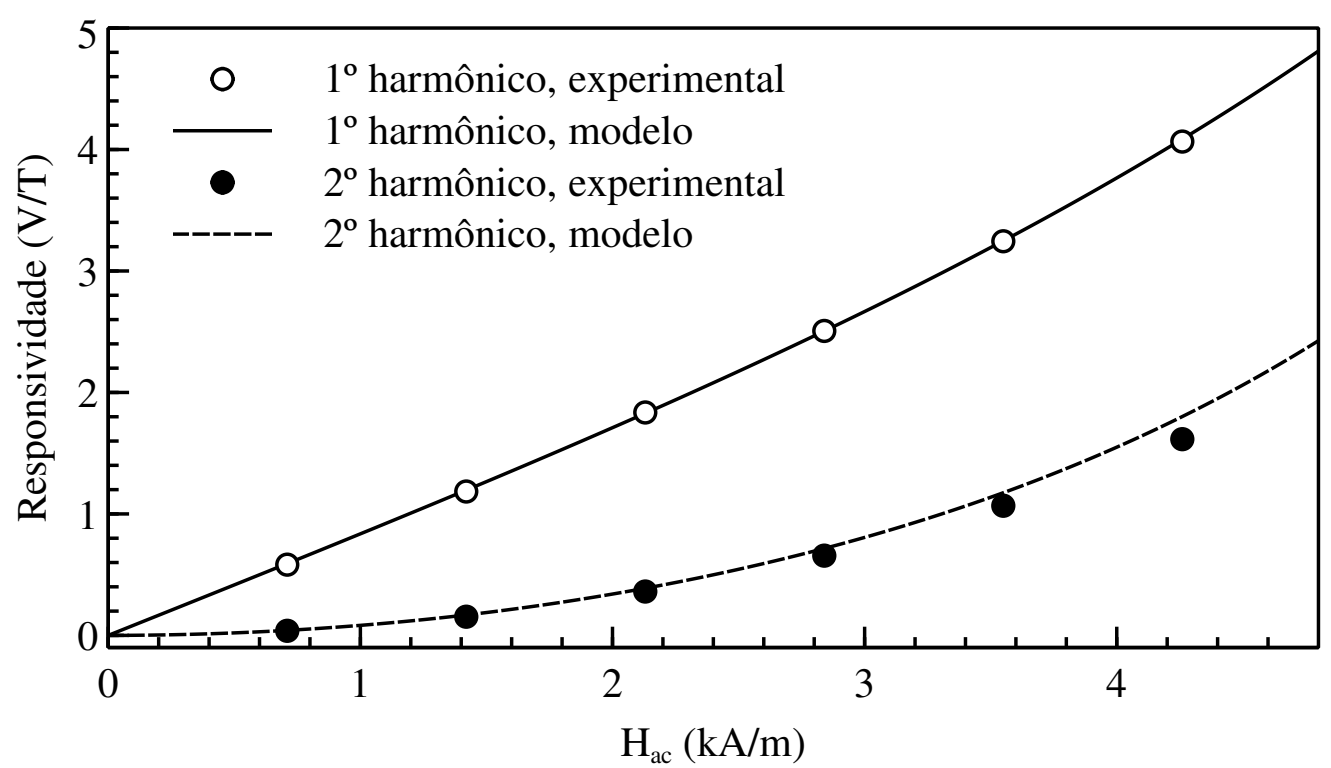

Figura 3.4.6 - Responsividade experimental e teórica ajustada em função do campo de excitação alternado para os dois primeiros harmônicos.

Para verificar o comportamento do sensor em função dos fatores de desmagnetização foram realizadas as medidas anteriores para diversos comprimentos do núcleo. A cada rodada de medidas foi removido $1 \mathrm{~mm}$ de uma de suas extremidades. Desta forma a seção transversal foi mantida constante enquanto que $D_{1}$ e $D_{2}$ mudam. Entretanto a diferença causada por este corte de $1 \mathrm{~mm}$ na saída do sensor é pequena. De fato foi necessário uma criteriosa busca para achar-se dimensões em que o sensor pudesse ser operado pelo equipamento disponível, e a diferença devido a desmagnetização fosse detectável. Principalmente quanto a espessura, uma vez que $D_{1}$ e $D_{2}$ são muito sensíveis ao seu valor. Deste ponto de vista o ideal seriam filmes espessos. Mas o campo $H_{d c}$ necessário para saturar a amostra também cresce com a expessura e logo atinge o limite do equipamento. Devido a estes limites tornou-se crucial a correção dos valores pelo fator de acoplamento, efeito mais intenso que a desmagnetização nessas condições.

Por outro lado tem-se também as variações causadas pelo corte. Imperfeições da borda do filme e as tensões geradas no processo exercem grande influência sobre a sua magnetização. Finalmente, para se cortar o núcleo, é necessária sua remoção e recolocação o que introduz variações no seu posicionamento em relação as bobinas. Por tudo isto estas medidas não tem uma precisão alta. De qualquer maneira foi possível ajustar os parâmetros de entrada do modelo (conforme já descrito) de modo a descrever bem os resultados, como mostra a figura 3.4.7. 


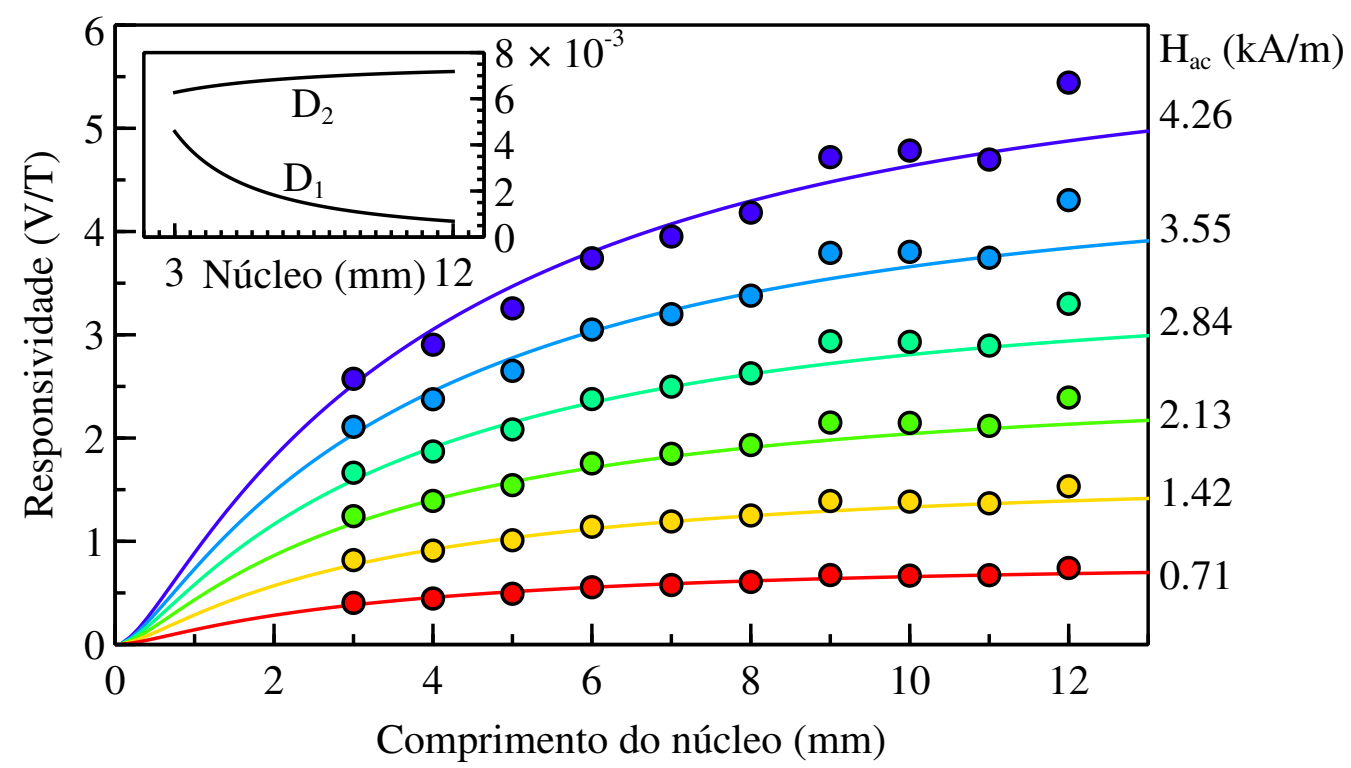

Figura 3.4.7 - Ajustes da responsividade utilizando a equação 3.4.20 para diversos $H_{a c}$ em função do comprimento do núcleo. Na inserção, os fatores de desmagnetização calculados em função do comprimento do núcleo.

De maneira geral o modelo descreve bem as características do sensor. Sendo assim, adquiriu-se segurança sobre o mecanismo envolvido na variação da permeabilidade, podendo-se utilizar esta informação no projeto de sensores deste tipo, além de estimar suas características. Por outro lado, analisando o tamanho da divergência que um suposto sensor apresenta do modelo, pode-se estimar o quão longe da completa saturação este se encontra.

\subsection{Considerações sobre o material do núcleo}

O modo de operação por rotação da magnetização, especiamente em constante saturação, muda as qualidades desejáveis do núcleo se comparado a um fluxgate convencional. Claro que cada leiaute e cada modo de operação tem suas peculiaridades, mas de maneira geral os requisitos básicos de um sensor convencional são [5]:

- Alta permeabilidade magnética;

- Baixa coercividade;

- Forma não retangular da curva de magnetização;

- Baixa magnetostricção;

- Baixo número de defeitos estruturais, baixo estresse interno;

- Superfície suave;

- Seção transversal uniforme;

- Baixo campo de saturação $H_{\text {sat }}$;

- Alta resistividade elétrica. 
Já em um FORM saturado, a permeabilidade magnética máxima não tem a mesma relevância, uma vez que não se utiliza a região com $H \approx 0$. A coercividade também perde importância pois o estado magnético do núcleo não passa na região de histerese. Igualmente, a forma retangular ou não da curva de magnetização não tem influência, pois a saída do sensor independe da não linearidade desta. Também a magnetostricção se torna irrelevante um vez que não há rotação de grande amplitude dos spins, especialmente se este for operado com retroalimentação de campo.

Por outro lado acrescenta-se à lista a magnetização de saturação, que tem relação direta na responsividade do sensor. Desta forma, uma lista simples para os parâmetros desejados em um fluxgate ortogonal de monodomínio pode ser:

- Baixo número de defeitos estruturais, baixo estresse interno;

- Superfície suave;

- Seção transversal uniforme;

- Baixo campo de saturação $H_{\text {sat }}$;

- Alta magnetização de saturação $\left(M_{s a t}\right)$;

- Alta resistividade elétrica.

- Isotropia ou anisotropia magnética controlada.

Dito isto, a primeira lista é parcialmente restaurada pelas interrelações entre as características dos materiais existentes. Baixas permeabilidades com baixos campos de saturação estão associados a baixas magnetizações de saturação. Altas magnetizações de saturação são encontradas em materiais ferromagnéticos duros, com altos $H_{s a t}$ e $H_{c}$. Por sua vez $H_{c}$ está associado a grande densidade de defeitos estruturais. Isto implica que, tanto fluxgates convencionais quanto FORMs, compartilhem materiais apropriados para o núcleo. Pode-se então tomar como ponto de partida materiais tradicionalmente utilizados.

\subsubsection{NiFe eletrodepositado}

Todos os sensores convencionais construídos pelo autor deste texto utilizam uma liga de $\mathrm{NiFe}$ policristalina, presumidamente Ni $80 \%$ e Fe 20\%, baseada nos resultados vistos em [39]. É natural que este material seja o ponto de partida para a construção de um FORM.

Variando-se a densidade de corrente de eletrodeposição muda-se o tamanho do grão e a concentração dos elementos. Foi verificado que $14 \mathrm{~mA} / \mathrm{cm}^{2}$ resulta em filmes com maior grão e menor coercividade, bom para um fluxgate convencional [37]. Mas esta liga eletrodepositada sobre um fio fino, para ser utilizado em um FORM, apresenta um inconveniente: uma expressiva anisotropia helicoidal. Desta forma mesmo com campo externo nulo um sinal forte apareçe na bobina coletora. Logo é desejável um material com baixa anisotropia quando eletrodepositado sobre este tipo de substrato. Uma das possibilidade é tratar termicamente a liga, a fim de aliviar tensões internas [55], processo chamado de recozimento. Entretanto com a mudança dos 
requerimentos, abre-se também a possibilidade para o teste de outras densidades de corrente na busca de menor anisotropia e maior magnetização de saturação.

Alternativo a busca por isotropia, pode-se evitar o problema do sinal com campo externo nulo alinhando o eixo de fácil magnetização do núcleo com um eixo principal do sensor. É possível influênciar a anisotropia durante a formação do filmes com a aplicação de um campo magnético $[56,57,58]$. Pode-se também mudar a direção de fácil magnetização por meio de um recozimento termomagnético $[59,57]$. A geometria do sensor possibilita que este último seja feito por efeito joule, ou seja, tanto o calor quanto o campo na direção tangencial são obtidos pela simples passagem de uma corrente pelo fio.

Embora todas as possibilidades descritas tenham sido testadas, nem todas serão relatadas texto. Por exemplo, tentou-se tratar os núcleos termicamente sob a influência ou não de campo magnético, mas a falta de uma atmosfera inerte adequada (foi tentado vácuo, hidrogênio e a combinação dos dois) produziu somente amostras oxidadas com propriedades magnéticas inadequadas.

Finalmente há a opção da troca do material. Isto foi feito de forma parcial com a mudança da estrutura do NiFe para amorfa, pela adição de um elemento não metálico na estrutura.

\subsubsection{NiFeP eletrodepositado}

Ligas metálicas ferromagnéticas com estrutura amorfa são idealmente, macroscopicamente, isotrópicas. Entretanto podem surgir anisotropias por diversas causas: dinâmica dos fluídos da formação do material; campo magnético durante a formação do material; estresse mecânico; inomogeneidade na composição ou geometria [60]. Podem apresentar alta permeabilidade e baixos campos coercivos, mas com baixos campos de saturação [5].

A técnica de obtenção de ligas amorfas mais utilizada é a rápida solidificação da sua fase líquida, sendo comum a adição de boro e silício [5]. Entretanto pode-se conseguir algumas destas ligas por outros métodos como sputtering e eletrodeposição. Esta última apresenta diversas vantagens. Em especial, no caso da geometria dos sensores aqui propostos, a cobertura de superfícies complexas.

Os materiais amorfos mais utilizados em sensores tipo fluxgate são ligas baseadas em cobalto com baixa magnetostricção [7]. Entretanto neste trabalho optou-se por uma liga de NiFeP. Os principais motivos foram: propriedades magnéticas compatíveis com sensores fluxgate; eletrodepositável em substrato de cobre; somente a adição de fósforo no material já utilizado; disponibilidade dos reagentes; possibilidade de cristalização posterior [61] (por tratamento térmico) com anisotropia controlada por campo externo. Este último entretanto, não foi estudado neste texto. 


\subsection{Construção sensores ortogonais}

Para construir os sensores fluxgate ortogonais como o representado na figura 3.3.1, foi necessário desenvolver algumas técnicas assim com um equipamento para enrolar as bobinas compatível com suas dimensões.

O processo começa com o substrato: fios de cobre com dois diâmetros, $120 \mu \mathrm{m}$ e $45 \mu \mathrm{m}$. Enquanto que o primeiro é achado facilmente sem cobertura alguma no comércio, somente na forma esmaltada foi entrado o segundo.

\subsubsection{Remoção do esmalte e limpeza}

Remover o esmalte dos fios não é uma tarefa trivial como se esperaria. Este polímero é bastante resistente a ataques químicos e a maioria dos compostos utilizados na tentativa de removê-lo não foram efetivos, ou então atacaram o cobre também, inutilizando o material. Há inclusive literatura científica sobre o assunto [62], mas que não foi aplicável.

O esmalte dos fios de $45 \mu \mathrm{m}$ foi removido através de sucessivos banhos em ácido acetilsalicílico a $140{ }^{\circ} \mathrm{C}$ (ponto de ebulição) e posterior limpeza com acetona e água.

\subsubsection{Eletrodeposição}

Os fios foram presos a um suporte (veja figura 3.6.1) por fitas isolantes auto-adesivas. Estas foram colocados de modo a cobrir todas as partes condutoras que não se desejava eletrodepositar. O óxido superficial dos fios foi removido por banho em ácido acético diluído por 5 minutos. Finalmente o conjunto todo foi lavado em água deionizada.

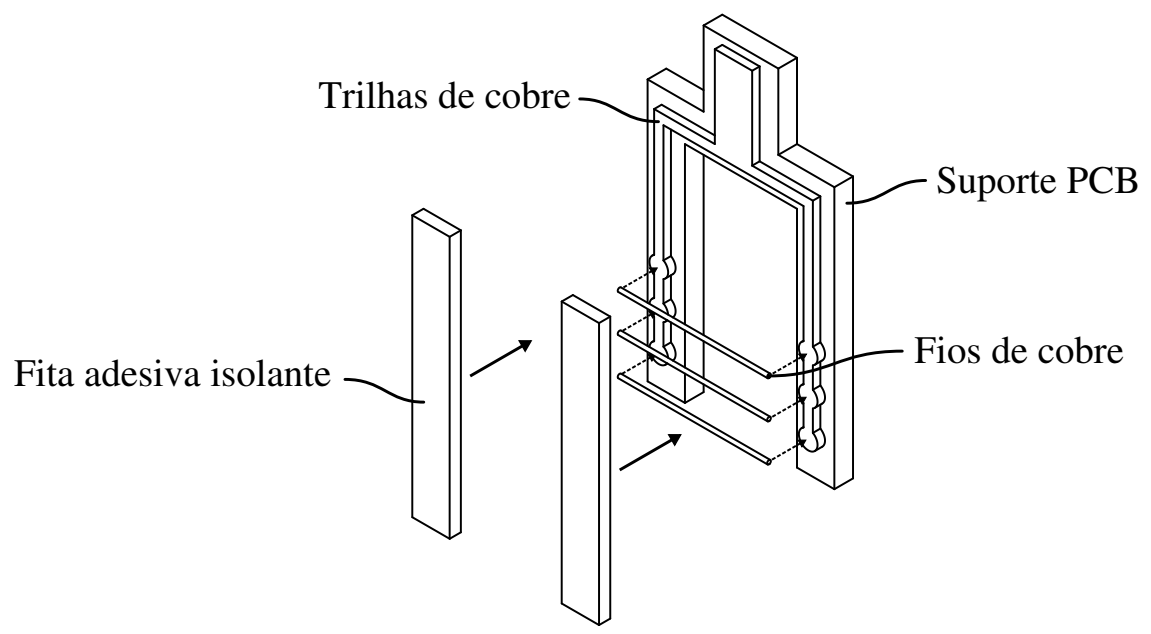

Figura 3.6.1 - Suporte utilizado na eletrodeposição do núcleo ferromagnético sobre os fios de cobre. 


\subsubsection{Eletrodeposição de NiFe}

A solução de eletrodeposição utilizada nos fios de NiFe foi a mesma citada anteriormente, tabela 2.3.1. Foram feitos alguns testes com agitador vibratório e linear que resultaram em filmes inomogêneos, sem vantagens sobre a deposição estática. A espessura foi controlada pelo tempo de deposição. O suporte foi retirado da solução a cada 30 segundos para evitar que as bolhas de hidrogênio adsorvidas na superfície do filme originassem irregularidades. $\mathrm{O}$ sistema de eletrodeposição utilizado está mostrado na figura 3.6.2.

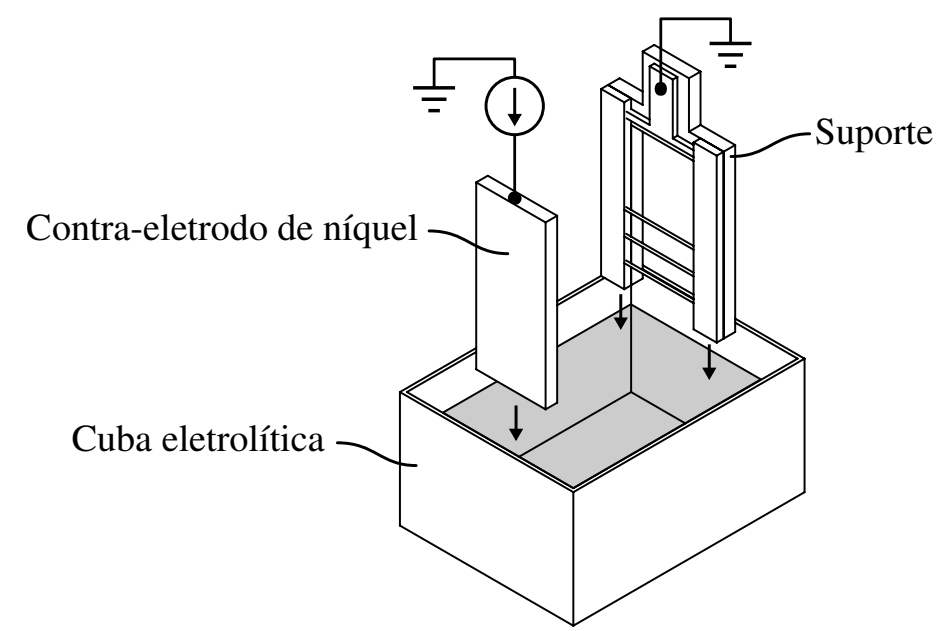

Figura 3.6.2 - Sistema de eletrodeposição dos fios recobertos com NiFe.

Para as amostras em que foi aplicada uma corrente nos fios durante a eletrodeposição, a fim de controlar a anisotropia, o suporte foi levemente modificado. Cada lado teve sua própria ligação elétrica de maneira que fosse possível passar a corrente pelos fios. Mas quando esta foi aplicada somente em uma direção durante toda a eletrodeposição, o filme formou-se inomogêneo, com grande diferença de espessura entre as extremidades. Com os valores de corrente utilizados a queda de potencial entre as extremidades do fio não é desprezível e causa este efeito. Foi utilizado então um inversor de corrente tipo ponte $\mathrm{H}$ para alternar o sentido da corrente, o que foi feito a cada segundo. A figura 3.6.3 mostra o esquema do sistema utilizado.

\subsubsection{Eletrodeposição de NiFeP}

A literatura sobre a eletrodeposição de $\mathrm{NiFeP}$ não é muito extensa, especialmente nas composições que levam a um material ferromagnético macio. De maneira geral sabe-se que uma quantidade mínima de fósforo é necessária para tornar o filme amorfo, em torno de 7\% [61, 63]. Para se obter esta quantidade o pH da solução de eletrodeposição deve ser baixo, acentuando a reação de evolução do hidrogênio, que domina o processo [64]. São necessárias portanto, densidades de corrente muito altas para compensar este efeito. As soluções de eletrodeposição encontradas são similares nos reagentes, utilizando o sulfato dos metais e hipofosfito de sódio como fonte de fósforo. É comum também o uso de agentes complexantes e uma segunda fonte de níquel (cloreto de níquel). Foram feitos testes com as soluções descritas em [64, 65, 66, 67] 


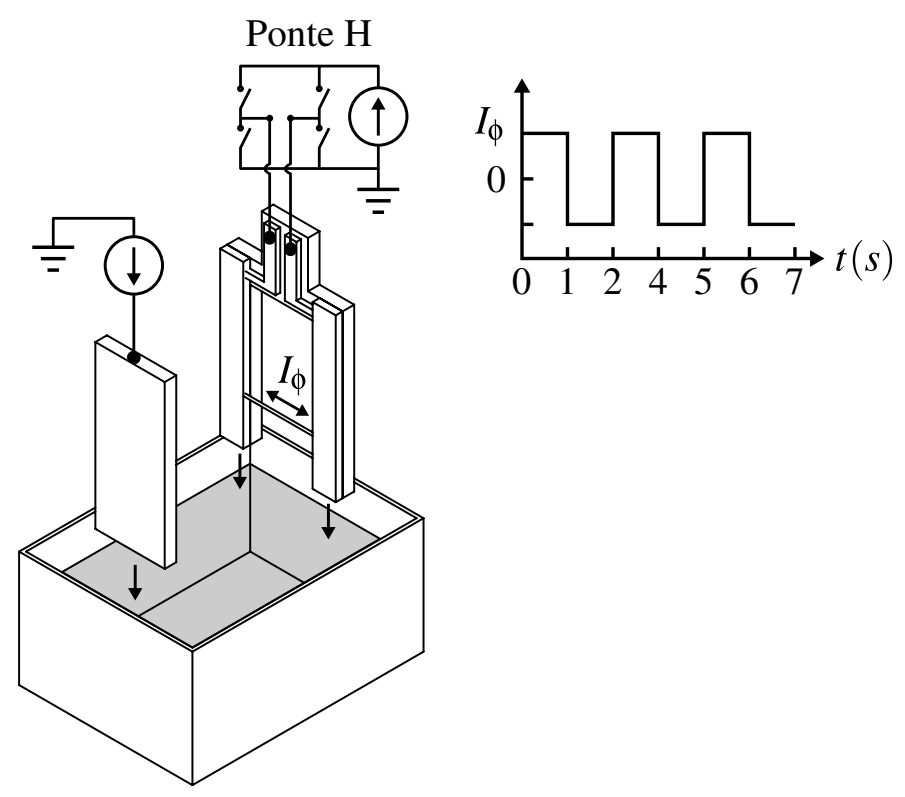

Figura 3.6.3 - Sistema de eletrodeposição dos fios recobertos com NiFe com um campo magnético tangencial. Este campo é gerado por uma corrente $\left(I_{\phi}\right)$ que tem seu sentido alternado a cada segundo para garantir a homogeneidade do filme. Uma ponte $\mathrm{H}$ controlada por um gerador de funções é a responsável pela troca de sentido da corrente. Note que o importante é a direção do campo tangencial, e não seu sentido.

com sucesso limitado, variando de resposta magnética nula a deposição totalmente inomogênea. Finalmente, os melhores resultados foram obtidos a partir do banho descrito em [68] (tabela 3.6.1).

\begin{tabular}{llr}
\hline Reagente & & Concentração (g/l) \\
\hline Sulfato de níquel & $\mathrm{NiSO}_{4}$ & 25 \\
Sulfato de ferro & $\mathrm{FeSO}_{4}$ & 5 \\
Hipofosfito de sódio & $\mathrm{NaPO}_{2} \mathrm{H}_{2}$ & 20 \\
Acetato de sódio & $\mathrm{CH}_{3} \mathrm{COONa}$ & 10 \\
\hline
\end{tabular}

Tabela 3.6.1 - Reagentes utilizados na solução de eletrodeposição de NiFeP.

$\mathrm{O} \mathrm{pH}$ de 2 foi ajustado com ácido clorídrico $\mathrm{HCl}$ e a temperatura do banho foi mantida em $60{ }^{\circ} \mathrm{C}$.

As densidades de correntes descritas nos trabalhos citados não produzem filmes magnéticos nos fios de cobre utilizados. Estas foram determinadas para substratos planos com áreas na ordem de centímetros quadrados. A dinâmica de deposição em um fio com dezenas de micrômetros de diâmetro é diferente e torna os valores relatados pouco úteis. Foi testada uma ampla faixa de densidades de correntes. Os valores que resultaram em filmes com alguma resposta ferromagnética são muito superiores aos reportados nos trabalhos originais. Agravando a situação, a grande produção de hidrogênio na superfície faz com que as bolhas que se formam 
fiquem presas no filme, tornando a deposição inomogênea. Aqui não é possível mitigar este efeito com a remoção periódica do substrato da solução, técnica utilizada na eletrodeposição de $\mathrm{NiFe}$, uma vez que a produção de hidrogênio é muito superior. A solução encontrada foi a agitação do substrato por meio do acoplamento de uma haste vibratória. Entretanto esta vibração também altera a dinâmica de deposição. Consequentemente os valores de corrente reportados aqui são muito diferentes dos originais e se aplicam somente às condições de eletrodeposição descritas. O sistema de eletrodeposição utilizado está mostrado na figura 3.6.4.

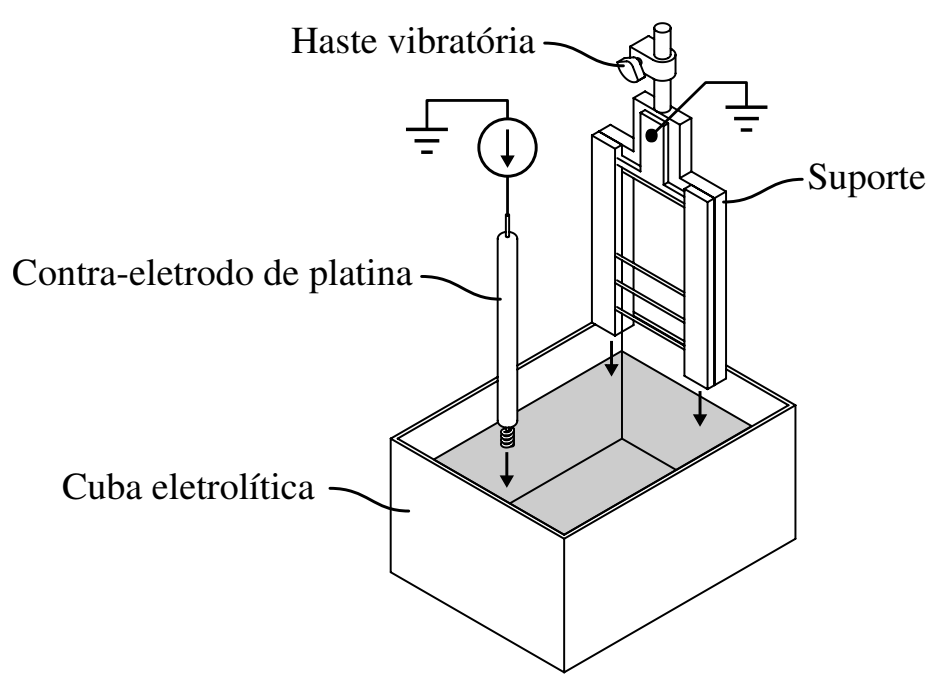

Figura 3.6.4 - Sistema de eletrodeposição dos fios recobertos com NiFeP.

Note que o diâmetro do fio aumenta durante a eletrodeposição mas a corrente foi mantida constante. Desta forma a densidade de eletrodeposição não é constante. No caso dos fios de 120 $\mu \mathrm{m}$ a variação não é grande. Mas para as amostras de $45 \mu \mathrm{m}$ a densidade se reduz pela metade entre o início e o fim do processo uma vez que o diâmetro final obtido foi de $90 \mu \mathrm{m}$.

\subsubsection{Enrolamento da bobina coletora}

Para que fosse possível enrolar uma bobina nas dimensões necessárias foi desenvolvido um equipamento. O processo de enrolamento e a parte mecânica do equipamento estão descritos na figura 3.6.5 enquanto que a parte lógica e elétrica estão na figura 3.6.6.

As bobinas coletoras foram enrodas na região central do fio eletrodepositado, evitando as extremidades menos homogêneas. Para sensores com o fio de cobre de $45 \mu \mathrm{m}$ foram utilizadas duas camadas de 100 espiras cada, resultando 7,5 mm de comprimento. Já para os com fio de $120 \mu \mathrm{m}$ foi utilizada somente uma camada de 150 espiras com $11 \mathrm{~mm}$ de comprimento. Esta diferença existe porque o equipamento foi melhorado com o tempo permitindo a adição de mais camadas. A figura 3.6.7 mostra a foto de um sensor nesta etapa do processo. 


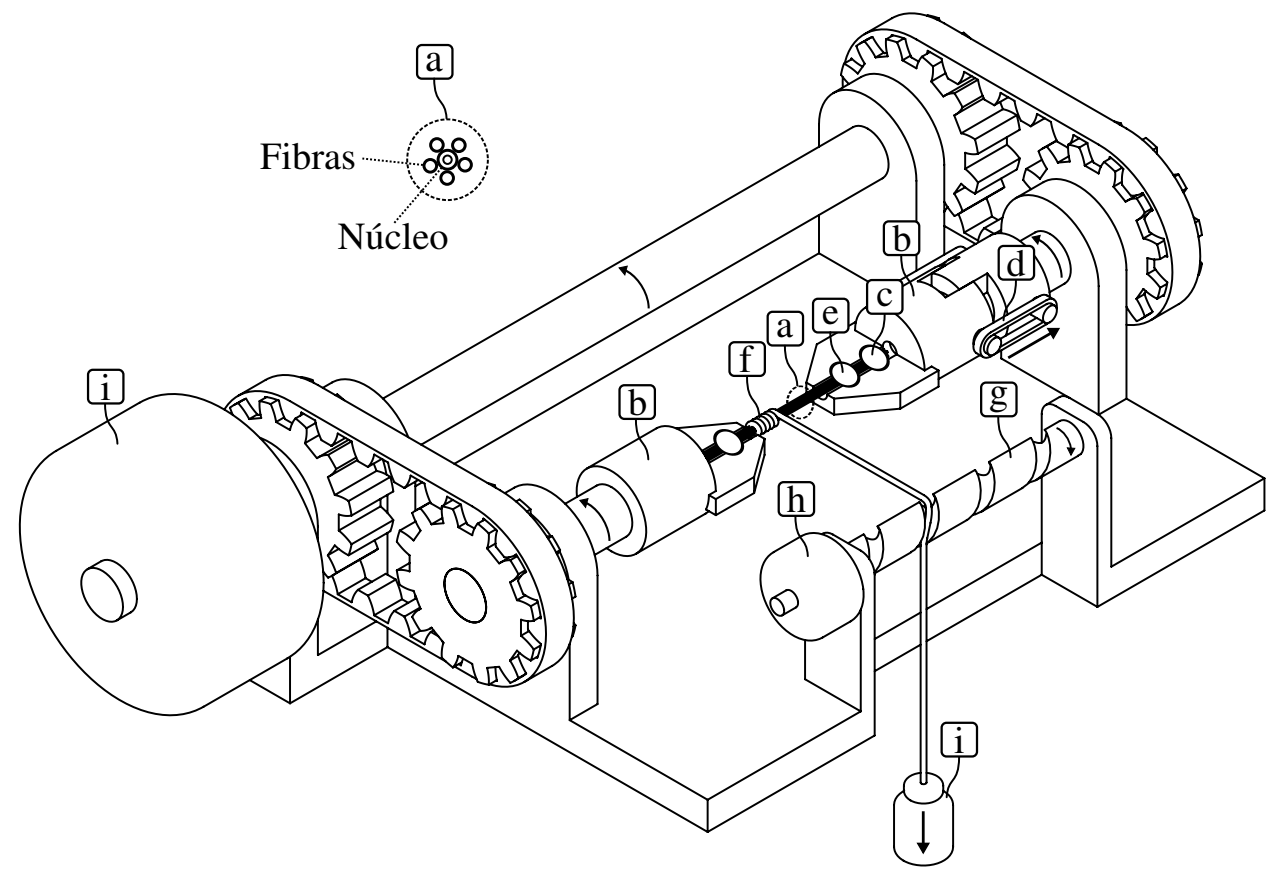

Figura 3.6.5 - Processo e parte mecânica do equipamento responsável pelo enrolamento das bobinas coletoras. Fibras de suporte (a) são presas às garras (b) por meio de um polímero termoplástico (c). Estas são pré-tensionadas por elásticos (d). $\mathrm{O}$ Núcleo (a) também é preso às garras com o polímero (e) e a tensão final é aplicada. $\mathrm{O}$ fio de cobre esmaltado (f) que forma a bobina é preso sob a garra em uma das extremidades. Este fio passa por um fuso (g) que serve de guia do passo da bobina, movimentado por um motor de passo (h) e é tensionado por um peso na extremidade (i). O conjunto de garras é movimentado por outro motor de passo (j) e um conjunto de eixos, engrenagens e polias. Os dois movimentos são sincronizados pelo circuito externo microcontrolado (figura 3.6.6).

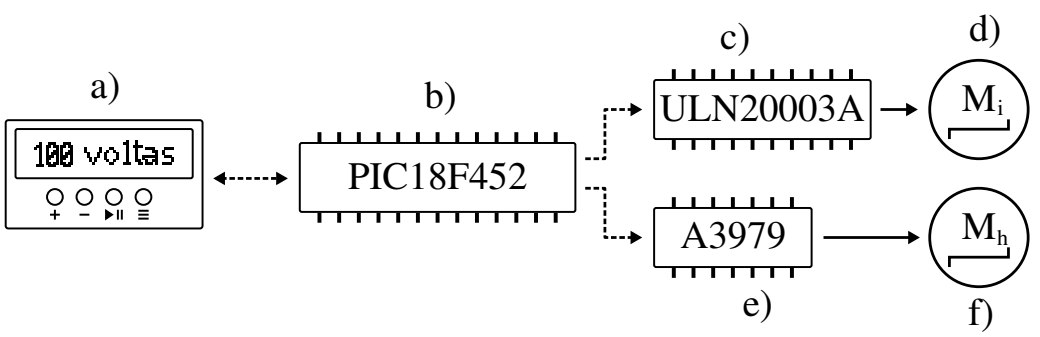

Figura 3.6.6 - Esquema elétrico da bobinadora, principais componentes. Os parâmetros (passo, número de voltas, velocidade, etc.) são a partir de um painel (a) por um microcontrolador (b) responsável pela parte lógica do sistema. Ele regula um driver de motor de passo (c) ligado ao motor responsável pela rotação da bobina (d, figura 3.6.5h). Por outro lado, o microcontrolador também gerencia outro driver em modo de micro-passo (e) responsável pelo motor do passo da bobina (f, figura 3.6.5i)

\subsubsection{Contatos elétricos}

A forma mais direta de fazer os contatos com o núcleo do sensor seria soldá-los com estanho-chumbo em um PCB. Entretanto a temperatura de fusão desta liga é aproximadamente 


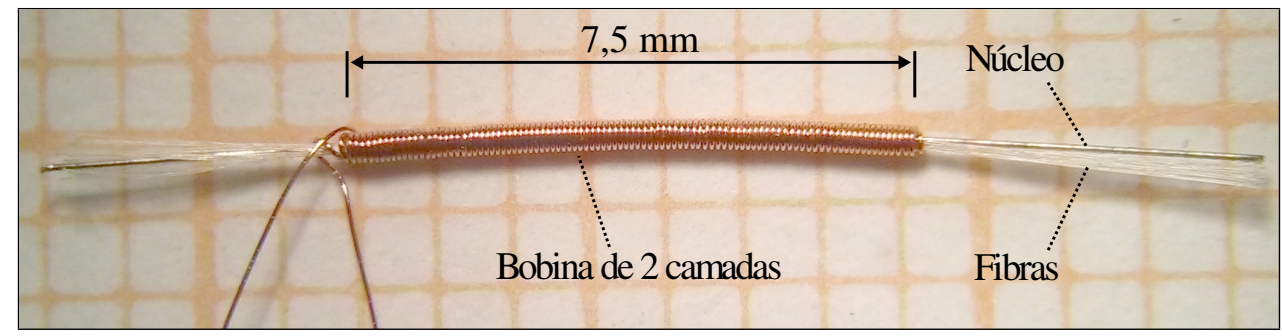

Figura 3.6.7 - Foto de um fio bobinado.

$190{ }^{\circ} \mathrm{C}$, temperatura que pode afetar as propriedades magnéticas do núcleo. Foi testado o uso de epóxi condutor entretanto a resistência de contato não se mostrou adequada, chegando a dezenas de Ohms. Assim, quando uma corrente alta era passada pelo fio durante a operação dos sensores, a potência dissipada no contato o superaquecia, fazendo sua resistência oscilar. Este fenômeno é extremamente prejudicial à estabilidade da resposta do sensor, e a técnica teve de ser abandonada. A solução encontrada para contatos de baixa resistência que não envolvessem o aquecimento do núcleo foi a eletrodeposição de cobre sobre os pads de contato com o núcleo posicionado (figura 3.6.8). A foto de um contato feito por este método é mostrada na figura 3.6.9. Já as extremidades da bobina puderam ser soldadas com solda de estanho-chumbo convencional.

Com as sobras aparadas o comprimento final do núcleo, incluindo a parte utilizada nos contatos elétricos, foi de $15 \mathrm{~mm}$. Descontando os contatos tem-se $12 \mathrm{~mm}$.

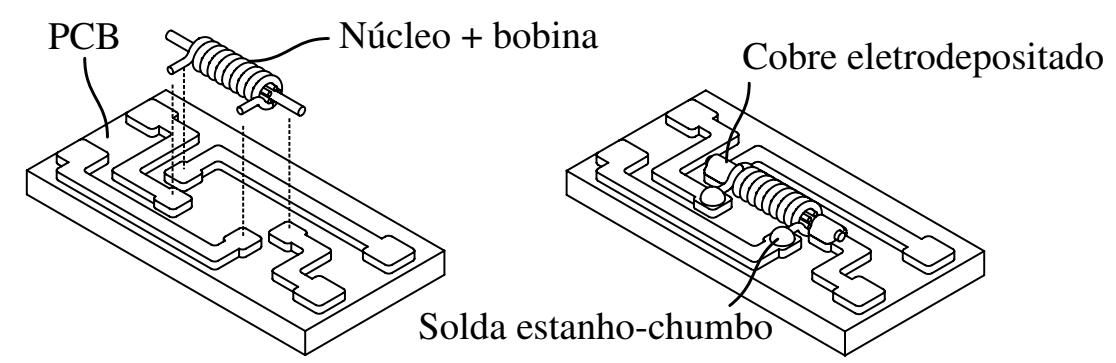

Figura 3.6.8 - Contatos elétricos. O sensor é posicionado sobre um PCB contendo trilhas para ligações externas, todas as partes condutoras são isoladas exceto os pads de conexão do núcleo, inclusive o resto do núcleo onde a bobina está. Cobre é eletrodepositado sobre o conjunto exposto fazendo o contato. Já as extremidades das bobinas tem sua conexão elétrica feita por solda convencional.

\subsubsection{Montagem final}

O PCB contendo o núcleo e a bobina foram colocados em uma caixa condutora não magnética aterrada para blindagem eletromagnética. Cabos coaxiais trazem a excitação e levam o sinal (no modo diferencial) para a montagem experimental que será detalhada mais a frente. $\mathrm{O}$ esquema da montagem pode ser visto na figura 3.6.10. A caixa também funciona como dissipador de calor pois quando operado com valores altos de corrente, o núcleo pode aquecer significativamente. Por isto, este foi coberto de pasta térmica fazendo contato físico com a caixa. 


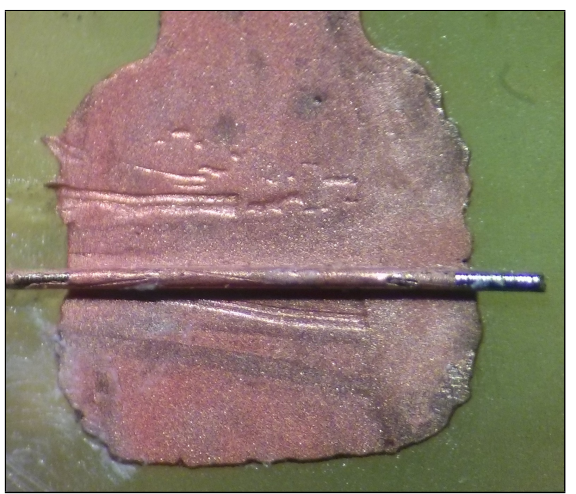

Figura 3.6.9 - Microscopia óptica do contato elétrico do núcleo.

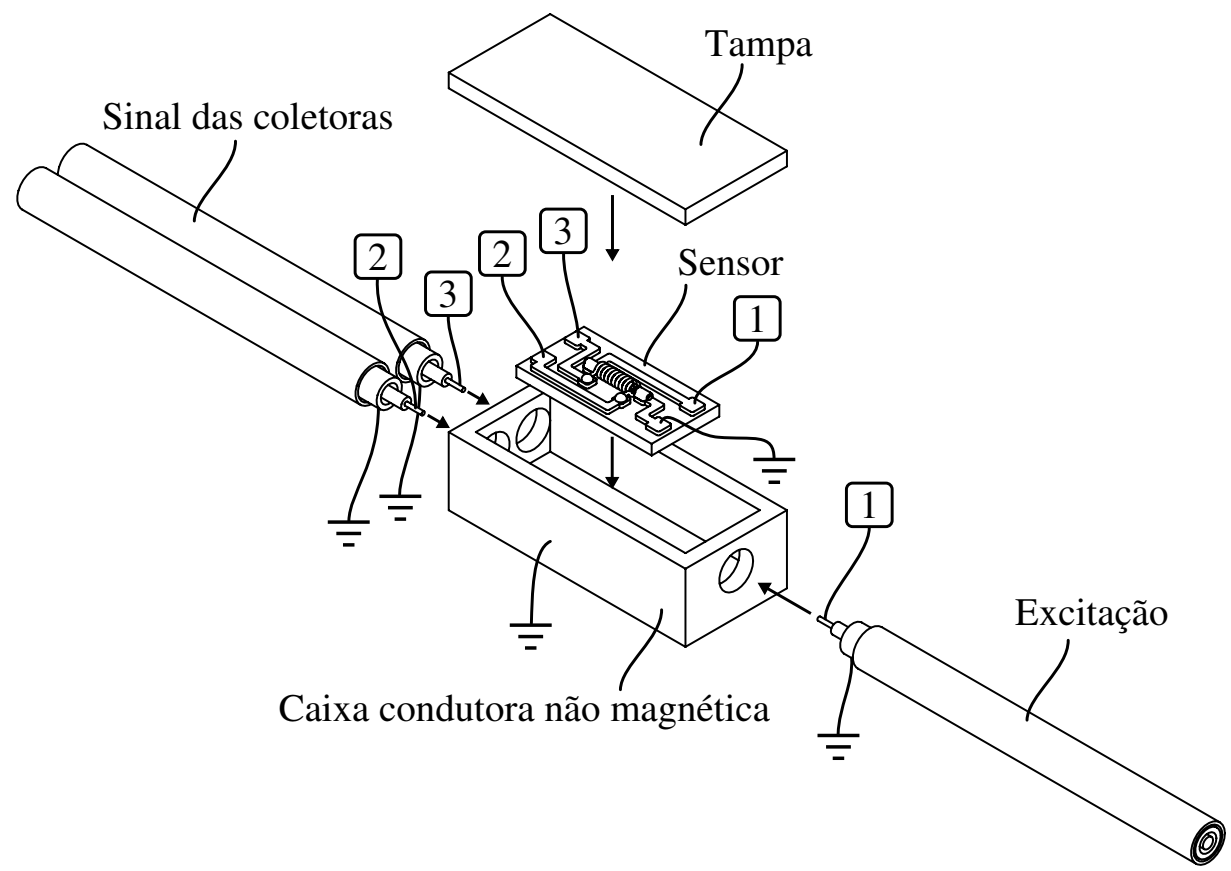

Figura 3.6.10 - Montagem final do sensor. O PCB contendo o núcleo é colocado em uma caixa condutora não magnética e as ligações externas são feitas por cabos coaxiais. Um cuidado especial foi tomado com o aterramento do sistema. Os números representam as conexões elétricas comuns.

\subsubsection{Descrição sensores construídos}

A tabela 3.6.2 lista os sensores ortogonais construídos e suas características. 


\begin{tabular}{llllllll}
\hline Sensor & Núcleo & $\rho_{d}\left(\mathrm{~mA} / \mathrm{cm}^{2}\right)$ & $\mathrm{I}_{\phi}(\mathrm{A})$ & $\mathrm{d}_{C u}(\mu \mathrm{m})$ & $\mathrm{d}_{e}(\mu \mathrm{m})$ & $\ell(\mathrm{mm})$ & espiras \\
\hline N14I00 & $\mathrm{NiFe}$ & 14 & 0 & 120 & 144 & 15 & 150 \\
N40I00 & $\mathrm{NiFe}$ & 40 & 0 & 120 & 144 & 15 & 150 \\
N40I05 & $\mathrm{NiFe}$ & 40 & 0.5 & 120 & 144 & 15 & 150 \\
N40I10 & $\mathrm{NiFe}$ & 40 & 1.0 & 120 & 144 & 15 & 150 \\
N40I15 & $\mathrm{NiFe}$ & 40 & 1.5 & 120 & 144 & 15 & 150 \\
N15 & $\mathrm{NiFe}$ & 15 & 0 & 45 & 90 & 15 & 200 \\
N25 & $\mathrm{NiFe}$ & 25 & 0 & 45 & 90 & 15 & 200 \\
N40 & $\mathrm{NiFe}$ & 40 & 0 & 45 & 90 & 15 & 200 \\
N50 & $\mathrm{NiFe}$ & 50 & 0 & 45 & 90 & 15 & 200 \\
P09 & $\mathrm{NiFeP}$ & 900 & 0 & 45 & 95 & 15 & 200 \\
P13 & $\mathrm{NiFeP}$ & 1300 & 0 & 45 & 95 & 15 & 200 \\
P16 & $\mathrm{NiFeP}$ & 1600 & 0 & 45 & 95 & 15 & 200 \\
P28 & $\mathrm{NiFeP}$ & 2800 & 0 & 45 & 95 & 15 & 200 \\
\hline
\end{tabular}

Tabela 3.6.2 - Principais parâmetros do sensores ortogonais construídos. $\rho_{d}$ é a densidade de corrente utilizada na eletrodeposição (a área de referência é a do fio de cobre), $\mathrm{I}_{\phi}$ a corrente passada pelo fio durante a eletrodeposição responsável pelo campo tangencial, $\mathrm{d}_{C u}$ o diâmetro do fio de cobre utilizado como substrato, $\mathrm{d}_{e}$ o diâmetro externo final, $\ell$ o comprimento total do núcleo incluindo os contatos e na última coluna o número de espiras da bobina coletora. 


\subsection{Morfologia e composição das ligas eletrodepositadas}

Foi feita a análise da composição dos materiais eletrodepositados pela técnica de EDS (Energy Dispersive Spectrometry). Somente alguns dos sensores foram submetidos ao teste junto com outras amostras com parâmetros de deposição intermediários às dos dispositivos construídos. Estas foram depositadas no mesmo processo das utilizadas, garantindo as mesmas condições de eletrodeposição. A figura 3.7.1 mostra os resultados.

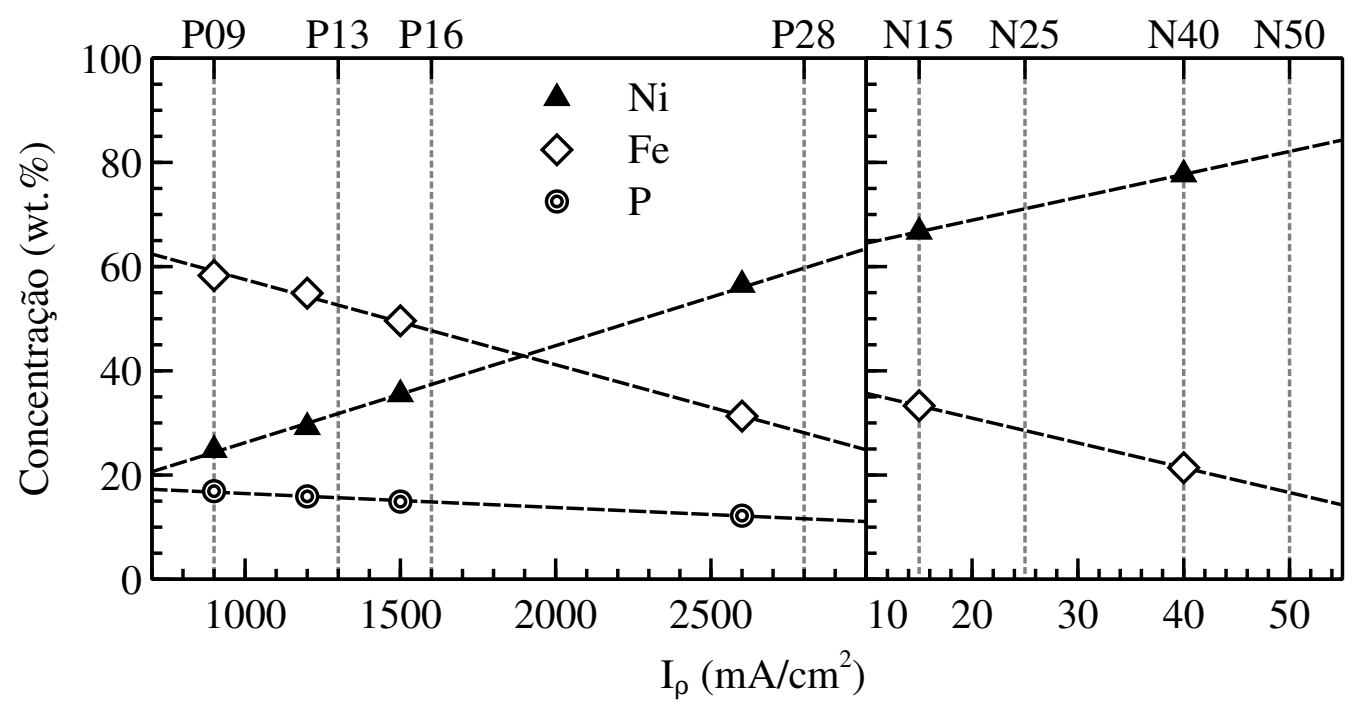

Figura 3.7.1 - Composição química dos núcleos eletrodepositados em função da densidade de corrente utilizada, medida por EDS.

O aumento da densidade de corrente favoreceu o depósito de níquel sobre o ferro em ambos as ligas. Para o NiFeP este comportamento é o inverso do descrito no trabalho do qual a solução de eletrodeposição foi retirada [68], entretanto outros autores utilizando um banho similar obtiveram o mesmo tipo de comportamento [64]. Este efeito é compatível com a deposição do ferro limitada por difusão [68]: a taxa de deposição de ferro metal não cresce na mesma proporção do aumento da corrente, diminuindo sua concentração. Também a variação linear da composição com a densidade é similar a literatura.

Em ambos os materiais as composições foram afetadas pela geometria do substrato. Em um substrato plano de $1 \mathrm{~cm}^{2}$ são necessários $14 \mathrm{~mA} / \mathrm{cm}^{2}$ [37] para produzir filmes de $\mathrm{Ni}_{80} \mathrm{Fe}_{20}$. Entretanto nos fios de $45 \mu \mathrm{m}$ de raio esta composição somente foi alcançada com $\sim 44$ $\mathrm{mA} / \mathrm{cm}^{2}$. Mesmo considerando o diâmetro final do fio, a densidade é de $\sim 22 \mathrm{~mA} / \mathrm{cm}^{2}$. Este efeito também pode ser explicado pela deposição do ferro limitada por difusão. $\mathrm{O}$ volume de solução imediatamente disponível por unidade de área de substrato é maior para um cilindro, como mostra a figura 3.7.2. Pode-se ver também em [69] os valores elevados necessários para atingir a composição ideal do filme.

As imagens de microscopia eletrônica das amostras de NiFe são mostradas na figura 

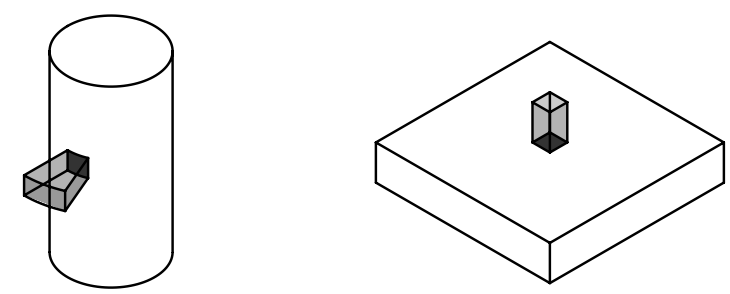

Figura 3.7.2 - O volume de solução imediatamente disponível por unidade de área para um cilindro é maior do que para um plano.

3.7.3. A amostra depositada com menor densidade de corrente tem uma morfologia acidentada onde o filme cresceu a partir de poucos pontos de nucleação. Efeitos similares podem ser vistos em [70]. Já a amostra depositada com $40 \mathrm{~mA} / \mathrm{cm}^{2}$ tem superfície mais lisa.

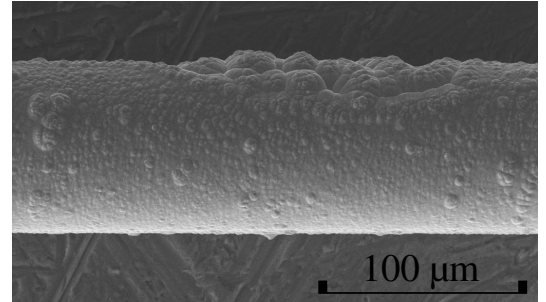

a) $\mathrm{NiFe} 15 \mathrm{~mA} / \mathrm{cm}^{2}$

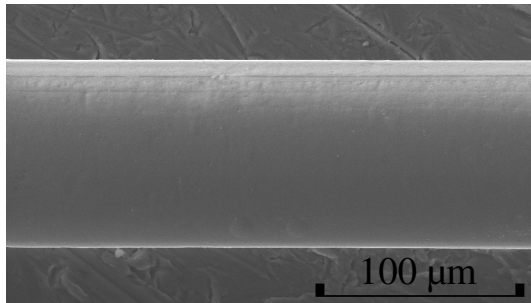

b) $\mathrm{NiFe} 40 \mathrm{~mA} / \mathrm{cm}^{2}$

Figura 3.7.3 - Microscopia eletrônica das amostras de NiFe utilizadas na análise por EDS.

Também foram feitas as imagens de microscopia da amostras de NiFeP, mostradas na figura 3.7.4. Exceto pela amostra depositada com $1200 \mathrm{~mA} / \mathrm{cm}^{2}$, que apresenta algumas estruturas na superfície, todos os fios eletrodepositados com a liga amorfa têm superfície extremamente lisa. Com a elevada taxa de deposição utilizada, era esperado que efeitos de nucleação na morfologia não estivessem presentes.

\subsection{Curvas de magnetização}

Algumas das propriedades magnéticas dos materiais relevantes podem ser obtidas através da cuva de magnetização, por exemplo a magnetização de saturação $M_{s a t}$. Como mostrado no modelo teórico (seção 3.4.2.1) este parâmetro é diretamente proporcional a responsividade dos sensores. Também é possível distinguir as regiões onde o aumento da magnetização é dominada pelo movimento das paredes dos domínios ou por sua rotação (veja a figura 3.1.1). Por fim, pode-se estimar o campo $H_{\text {exc }}$ necessário para saturar a amostra, $H_{s a t}$. Por questões práticas (é virtualmente impossível saturar totalmente um material) os valores de $H_{\text {sat }}$ reportados estão relacionado a uma magnetização de $95 \%$ da magnetização de saturação. A técnica utilizada nestas medidas é mostrada na figura 3.8.1 e detalhada no apêndice A, exceto pela utilização de um campo $H$ triangular. 


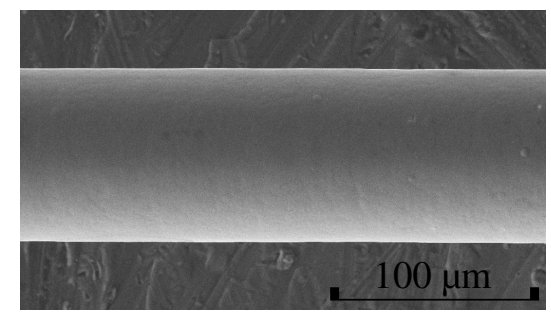

a) $\mathrm{NiFeP} 900 \mathrm{~mA} / \mathrm{cm}^{2}$

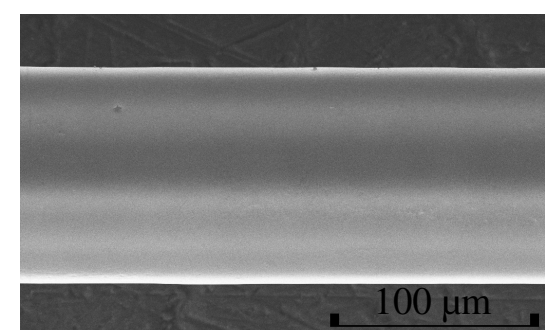

c) $\mathrm{NiFeP} 1500 \mathrm{~mA} / \mathrm{cm}^{2}$

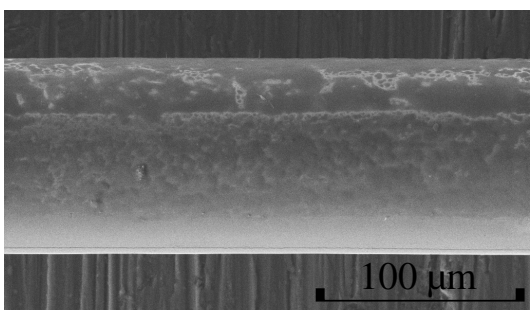

b) $\mathrm{NiFeP} 1200 \mathrm{~mA} / \mathrm{cm}^{2}$

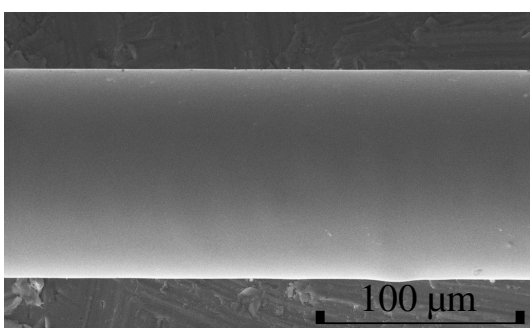

d) $\mathrm{NiFeP} 2600 \mathrm{~mA} / \mathrm{cm}^{2}$

Figura 3.7.4 - Microscopia eletrônica das amostras de NiFeP utilizadas na análise de composição por EDS.

Também foram medidas as curvas de magnetização ortogonal, em que o campo externo aplicado é perpendicular a componente da magnetização medida. Para os fios eletrodepositados, passou-se uma corrente no fio gerando um campo tangencial $H_{\phi}$ e mediu-se $M_{x}$. No caso ideal de uma amostra isotrópica a resposta seria nula. O mesmo aconteceria em amostras anisotrópicas com todos os eixos de fácil magnetização alinhados com um dos eixos principais ( $x$ ou $\phi)$. Com este tipo de medida pode-se estimar o desvio destas condições ideais. Do ponto de vista dos sensores tipo fluxgate, quanto maior a magnetização ortogonal maior o sinal na saída sem que haja campo externo algum.

\subsubsection{Energia anisotrópica}

Para entender melhor o efeito de uma anisotropia uniaxial não alinhada pode-se escrever um modelo simples utilizando a energia livre do sistema, soma das energias anisotrópica e magnetostática [3], ou seja

$$
E=K \operatorname{sen}^{2}\left(\theta-\theta_{k}\right)-M_{s} H_{\phi} \cos (\theta)
$$

onde $K$ é a constante anisotrópica, $\theta$ o ângulo em relação à $\hat{\phi}$ (veja a figura 3.8.1) e $\theta_{k}$ o ângulo do eixo de fácil magnetização. Nesta equação não está incluso o termo da desmagnetização, assumiu-se que esta é predominantemente na direção radial, transformando o problema em bidimensional. Minimizando esta energia obtém-se uma equação com os ângulos de equilíbrio do sistema. 


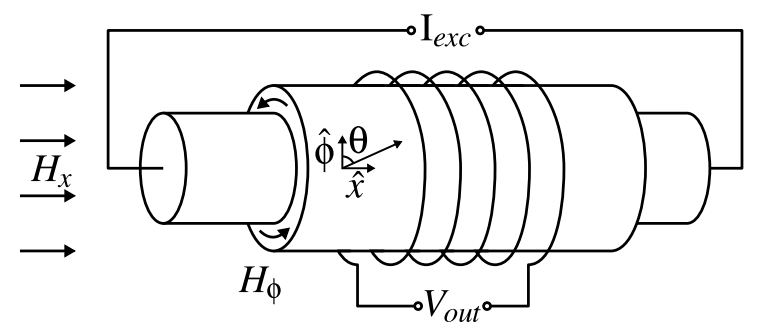

Figura 3.8.1 - Esquema utilizado nas medidas de magnetização. Para as curvas de magnetização $M_{x}\left(H_{x}\right)$ foi utilizada uma bobina de Helmholtz externa para gerar $H_{x}$. No caso das curvas ortogonais, $M_{x}\left(H_{\phi}\right)$, o campo tangencial $H_{\phi}$ foi produzido passandose uma corrente $I_{\text {exc }}$ pelo fio. Do sinal $V_{\text {out }}$ capturado pela bobina foi obtida a componente $x$ da magnetização $\left(M_{x}\right)$.

$$
\frac{\partial E}{\partial \theta}=2 K \operatorname{sen}\left(2\left(\theta-\theta_{k}\right)\right)+M_{s} H_{\phi} \operatorname{sen}(\theta)=0,
$$

Embora não se possa resolver diretamente esta equação para $\theta$, pode-se achar os valores dos mínimos numericamente. A componente $x$ de uma solução típica é mostrada na figura 3.8.2a assim como o diagrama de energia correspondente 3.8.2b. Como será visto, com este modelo simples não é possível reproduzir todos os resultados revelando que em alguns casos uma ou mais premissas não são válidas.

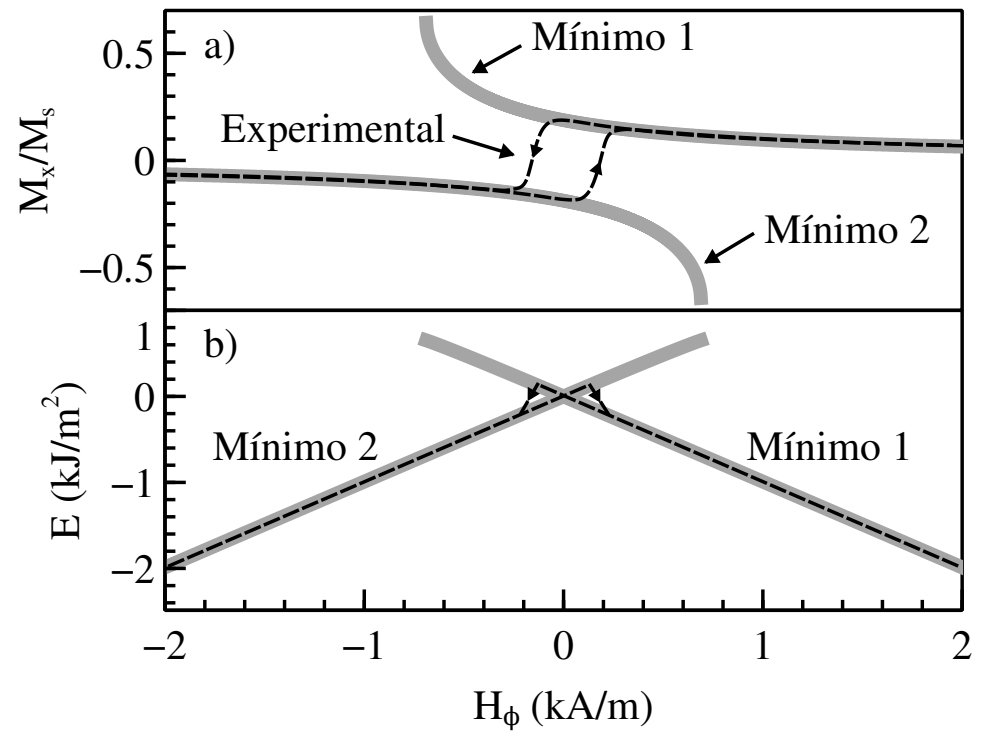

Figura 3.8.2 - Esquema da magnetização ortogonal para um material ferromagnético com apenas uma direção de fácil magnetização. a) Componente $x$ da magnetização para os dois mínimos da energia calculados, e uma curva de magnetização experimental sobreposta. b) Energia associada aos mínimos.

\subsubsection{Resultados}

As figuras 3.8.3 e 3.8.4 mostram as curvas de magnetização paralela e ortogonal dos sensores com fio de cobre de diâmetro $120 \mu \mathrm{m}$. 


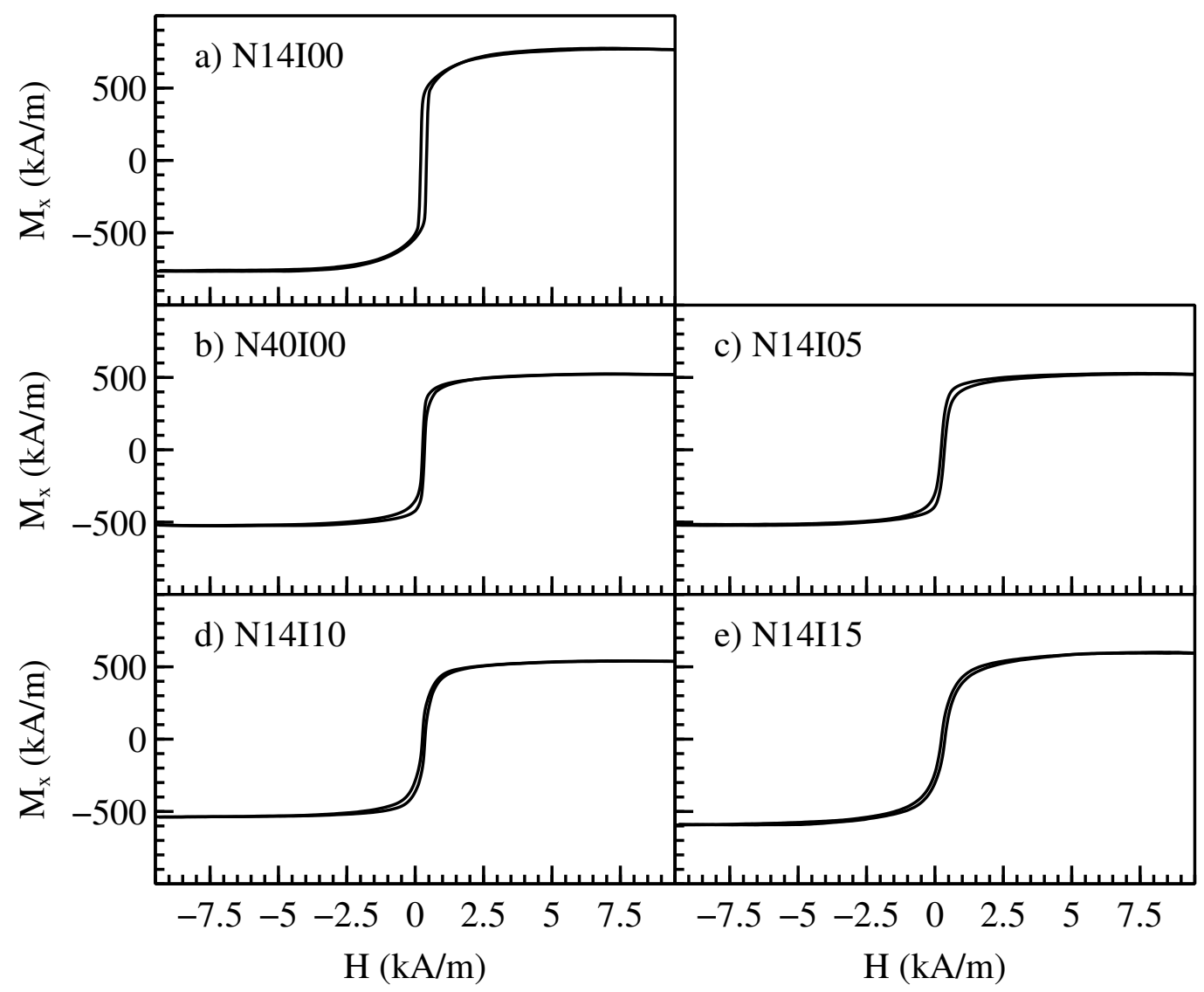

Figura 3.8.3 - Curvas de magnetização paralela dos sensores com substrado de $120 \mu \mathrm{m}$ de diâmetro.

A maior magnetização de saturação foi alcançada pelo núcleo eletrodepositado com 14 $\mathrm{mA} / \mathrm{cm}^{2}$, por volta de $750 \mathrm{kA} / \mathrm{m}$. Nesta amostra tem-se na região central uma alta permeabilidade onde vê-se o efeito da coercividade seguida da região de rotação da magnetização, para $H_{x}>$ $0,8 \mathrm{kA} / \mathrm{m}$. Esta mesma amostra apresentou a curva de magnetização ortogonal mais intensa, sugerindo uma forte anisotropia helicoidal.

Aumentando a densidade de corrente para $40 \mathrm{~mA} / \mathrm{cm}^{2}$, reduziu-se $M_{\text {sat }}$ para aproximadamente $500 \mathrm{kA} / \mathrm{m}$, valor que não foi influenciado pelo campo tangencial aplicado durante a eletrodeposição. Este campo entretanto teve influência sobre a forma da curva de magnetização, diminuindo a permeabilidade máxima. Comportamento que é compatível com a rotação do eixo de fácil magnetização em direção à $\hat{\phi}$ conforme $I_{\phi}$ aumenta, uma vez que a maior permeabilidade possível está associada ao movimento das paredes dos domínios com defasagem de $180^{\circ}$. A intensidade da resposta magnética ortogonal nestas amostras (figura3.8.4b,c,d) é significativamente menor que a da N14I00 (figura 3.8.4a). Entretanto o formato da curva não pode ser explicado inteiramente pelo modelo de energia livre da equação 3.8.2. A transição entre os estados não é suave (veja por exemplo 3.8.4c). Estas variações podem ser causadas por estresse interno do material, que altera significativamente os mínimos de energia [55]. 


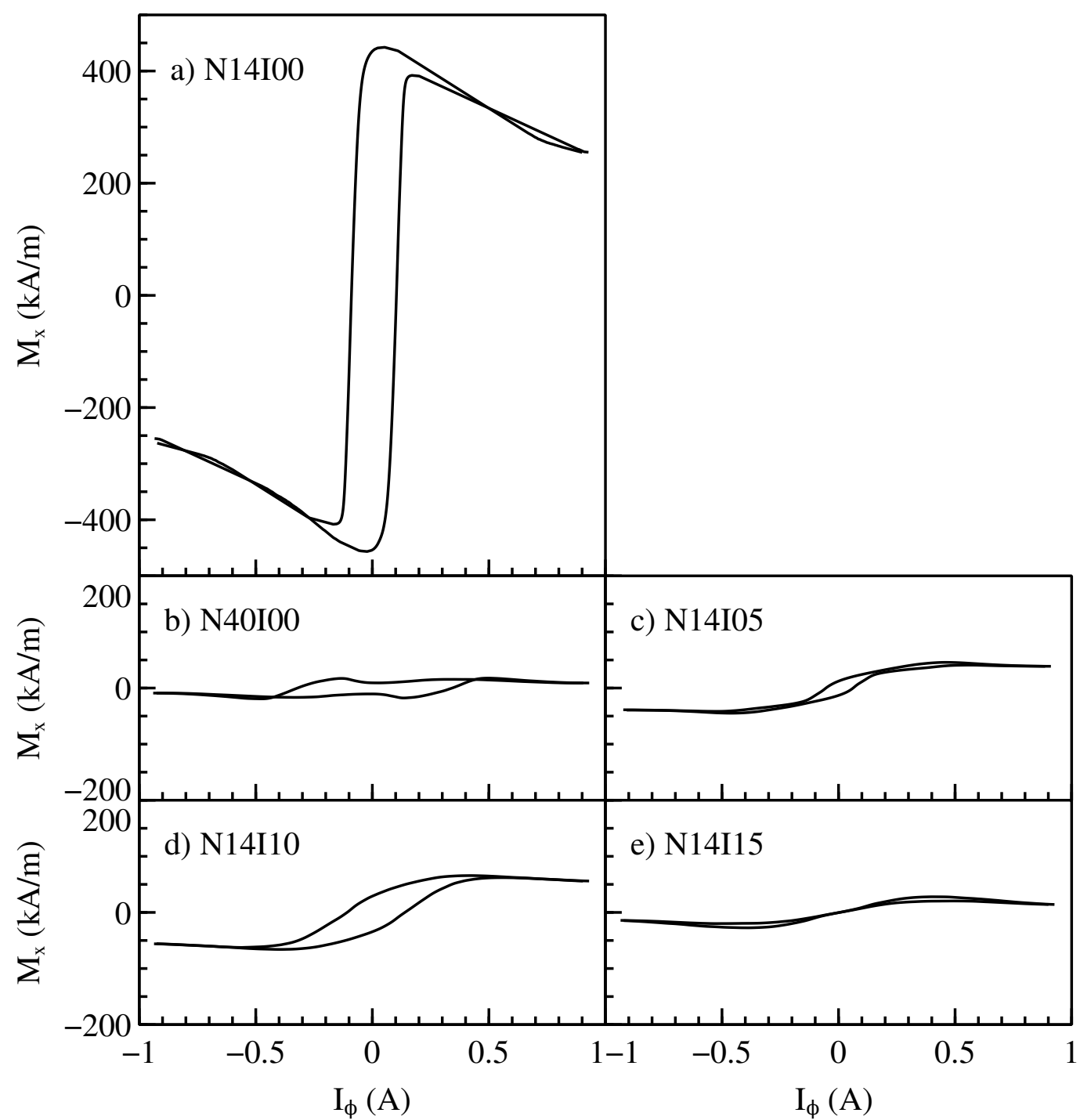

Figura 3.8.4 - Curvas de magnetização ortogonal dos sensores com substrado de $120 \mu \mathrm{m}$ de diâmetro.

As figuras 3.8.5 e 3.8.6 mostram as curvas de magnetização paralela e ortogonal dos sensores com fio de cobre de diâmetro $45 \mu \mathrm{m}$.

As amostras contendo fósforo apresentaram menor magnetização de saturação em relação as contendo somente níquel e ferro, comportamento esperado uma vez que se inseriu um elemento não ferromagnético na liga. Inicialmente o aumento da densidade de corrente de eletrodeposição aumenta $M_{\text {sat }}$, mas para valores muito elevados esta volta a cair. O comportamento característico das curvas é uma alta permeabilidade na região central seguida de um lento aumento na magnetização associado a rotação. Já as curvas de magnetização ortogonal mostram que, exceto por P09, o modelo de anisotropia uniaxial não representa bem os resultados. P13 e P16 apresentaram os maiores valores de magnetização ortogonal residual (para $I_{\phi}$ alta) o que sugere uma alta anisotropia com um eixo de fácil magnetização próximo da direção $x$.

No caso das amostras sem a adição de fósforo, o aumento da densidade de corrente de 


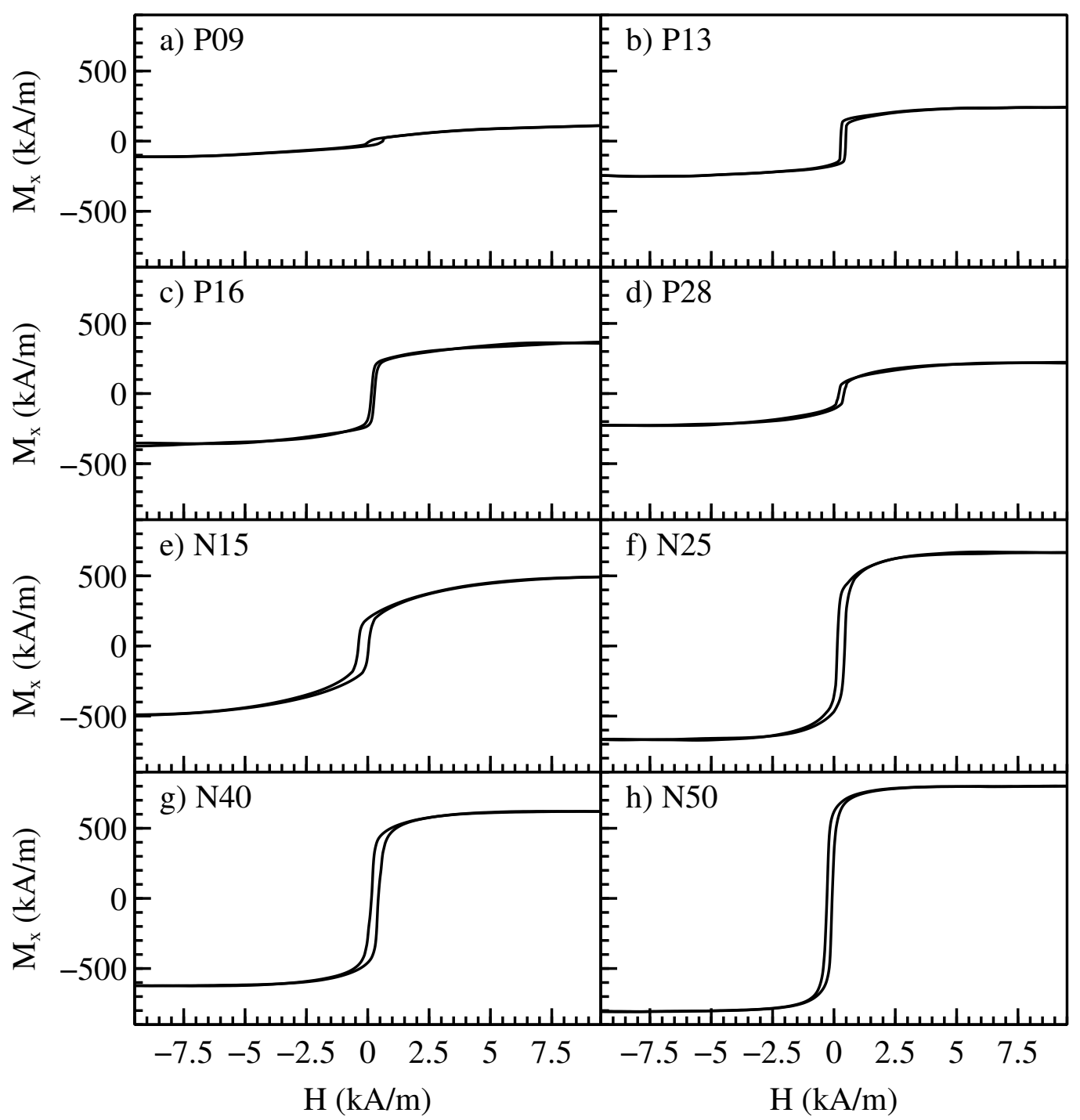

Figura 3.8.5 - Curvas de magnetização paralela dos sensores com substrado de $45 \mu \mathrm{m}$ de diâmetro.

eletrodeposição torna o material mais macio, aumentando a permeabilidade e diminuindo o campo de saturação. A densidade de $15 \mathrm{~mA} / \mathrm{cm}^{2}$ e um núcleo de cobre de $45 \mu \mathrm{m}$ resultaram em uma curva de magnetização com alto $H_{\text {sat }}$. Além da morfologia acidentada desta amostra (figura 3.7.3a), a alta concentração de ferro também contribui para a sua difícil saturação. Conforme a densidade de corrente aumenta, chega-se mais perto da composição $\mathrm{Ni}_{80} \mathrm{Fe}_{20} \mathrm{e}$ tem-se um material com maior permeabilidade, menor $H_{s a t}$ e uma superfície menos irregular. A magnetização de saturação apresentou um tendência de aumento com a densidade de corrente, sendo que N50 atingiu os valores encontrados na literatura $([25,71])$ para $\mathrm{Ni}_{80} \mathrm{Fe}_{20}$. Nas curvas de magnetização ortogonal tem-se uma boa concordância com o modelo da equação 3.8.2, exceto por N50. Sabe-se que ligas de $\mathrm{Ni}_{80} \mathrm{Fe}_{20}$ tem anisotropia uniaxial [72]. N50 apresentou um comportamento anômalo que pode ter sido causado pela alta magnetoimpedância do material, uma vez que tem alta permeabilidade magnética. Entretanto a medida foi repetida utilizando-se 


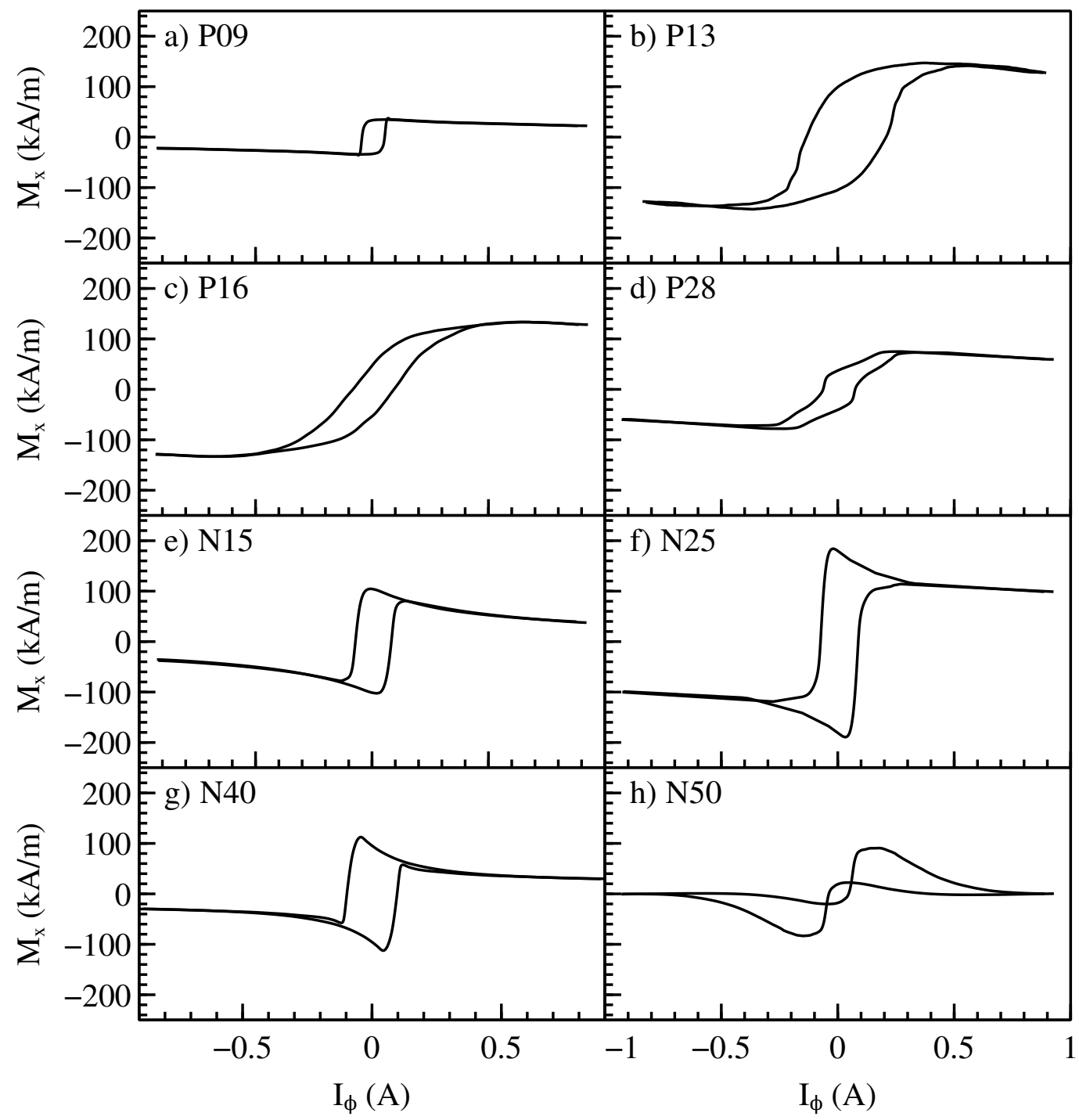

Figura 3.8.6 - Curvas de magnetização ortogonal dos sensores com substrado de $45 \mu \mathrm{m}$ de diâmetro.

uma frequência de apenas $10 \mathrm{~Hz}$ e os resultados não mudaram significativamente. Todavia o parâmetro mais importante, a magnetização ortogonal residual, pode ser extraído da medida e é, dentro da precisão do experimento, nula.

Um resumo das propriedades das amostras extraídas das curvas de magnetização está mostrada na figura 3.8.7. 


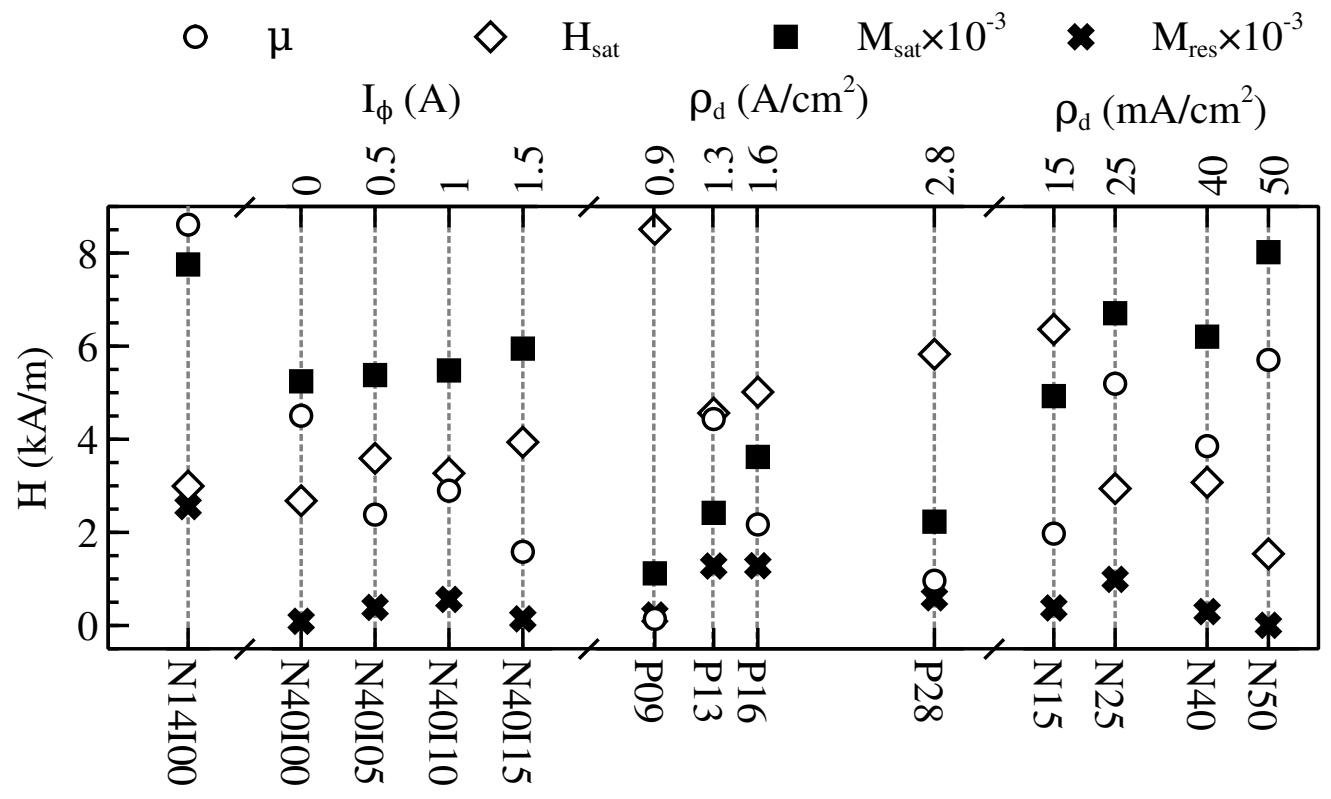

Figura 3.8.7 - Parâmetros extraídos das curvas de magnetização resumindo as propriedades magnéticas dos sensores construídos (tabela 3.6.2). 


\subsection{Metodologia de caracterização}

Para caracterizar os sensores foram feitas três tipos de medidas: curvas de resposta, efeito perming e ruído. Das curvas de resposta foi calculada a responsividade. Por outro lado cada um destes parâmetros de saída foi estudado em função dos parâmetros de entrada: corrente de excitação alternada $\left(I_{a c}\right)$ e corrente de excitação contínua $\left(I_{d c}\right)$. Mas para os exemplos ilustrativos apresentados nesta seção de metodologia, será utilizado um parâmetro de entrada genérico "A".

\subsubsection{Montagem experimental padrão}

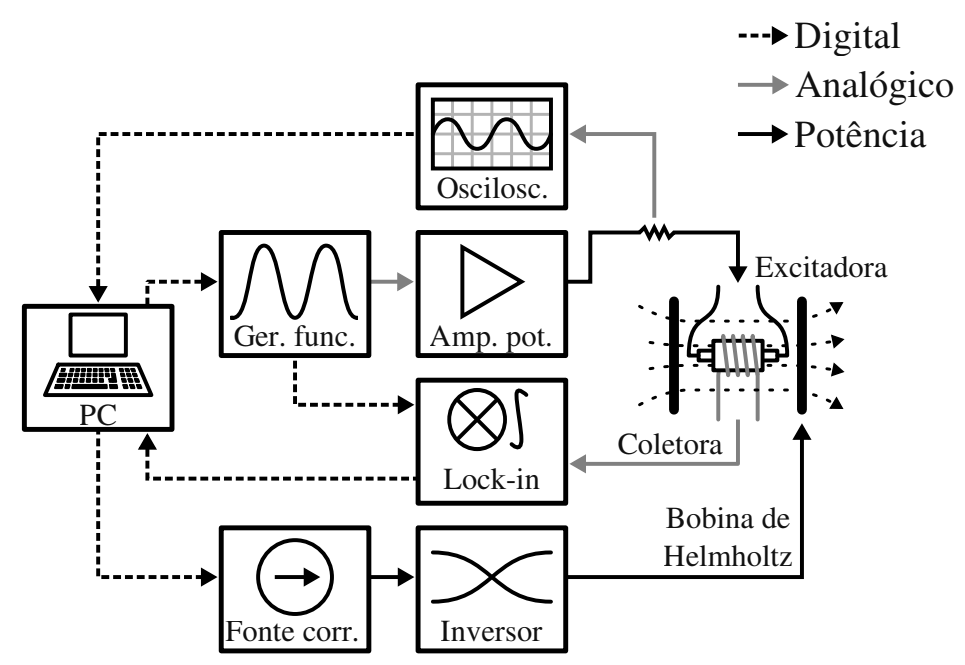

Figura 3.9.1 - Montagem experimental padrão. A parte lógica das medidas é feita utilizando-se scripts que rodam em um computador. Estes controlam os parâmetros de um gerador de função (Agilent 33220A) responsável pelo sinal de excitação. Um amplificador de potência (baseado em um OPA564) fornece o ganho de corrente, alimentando as bobinas excitadoras do sensor. Um osciloscópio (Tektronix TDS2024B) mede a queda de potencial em cima de um resistor em série com a excitação, fornecendo o valor atual da corrente de excitação. Já no ramo de saída do sensor, tem-se as bobinas coletoras ligadas a um amplificador lock-in (Signal Recovery DSP 7280). Este amplificador recebe o sinal de referência do gerador de função. O último ramo da montagem é responsável pela geração do campo externo. É composto por uma fonte de corrente programável (HP 6653A), um inversor tipo ponte $\mathrm{H}$ microcontrolado e uma bobina de Helmholtz.

\subsubsection{Calibração da corrente de excitação}

Tem-se controle direto sobre a tensão de saída do gerador de função, mas a quantidade relevante para a excitação é a corrente. Esta depende do ganho do amplificador e da impedância da malha de excitação de cada sensor (figura 3.9.1). Para garantir que a corrente passando no dispositivo fosse a desejada, antes de cada medida foram construídas curvas da amplitude de excitação $\left(I_{\text {exc }}\right)$ em função dos parâmetros do gerador de funções $\left(V_{\text {gerador }}\right)$. $I_{\text {exc }}$ foi estimada pela queda de potencial em cima do resistor em série com a excitação. A figura 3.9.2 exemplifica estas medidas feitas para um particular sensor. 


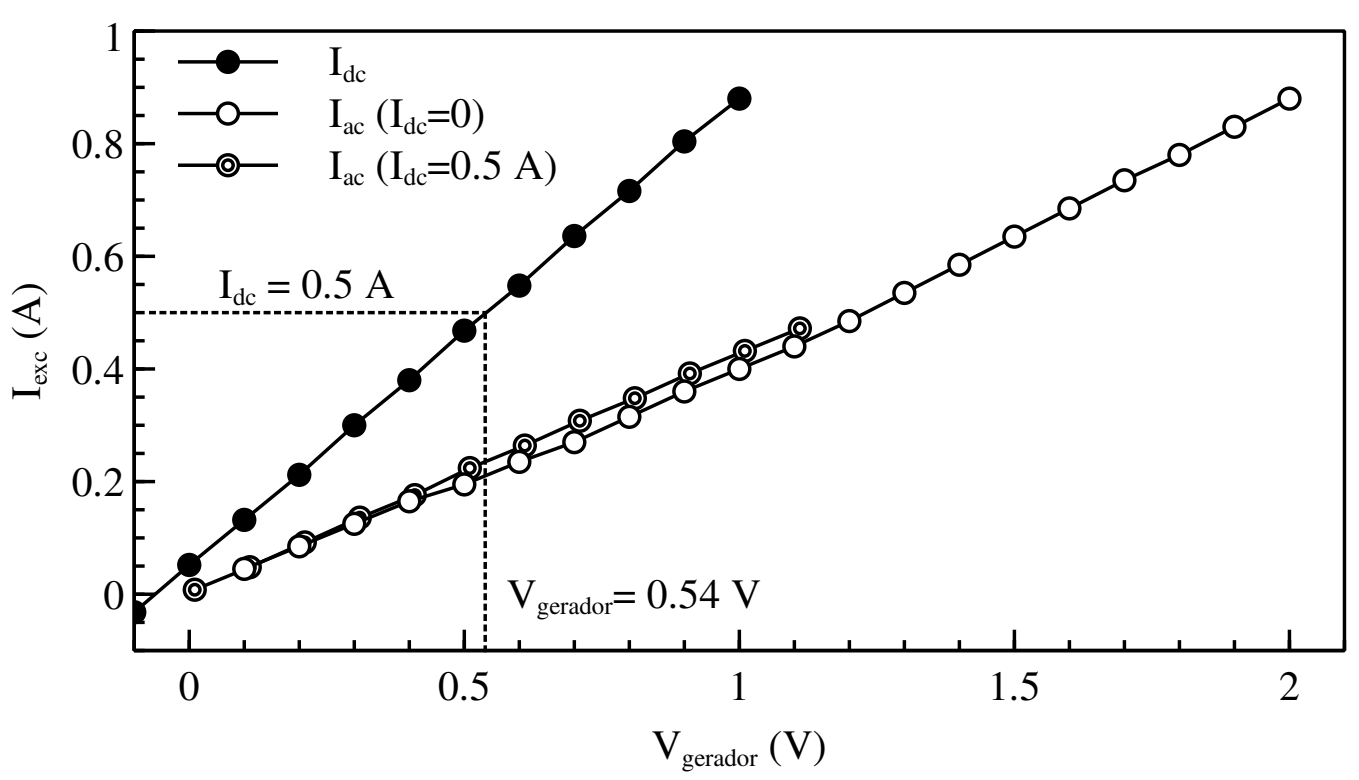

Figura 3.9.2 - Exemplo de calibração da corrente de excitação. A amplitude da excitação não é sempre linear como no caso de $I_{a c} \operatorname{com} I_{d c}=0$. Também varia dependendo de $I_{d c}$. O valor desejado de corrente é obtido interpolando os dados como mostra o exemplo para uma corrente desejada com amplitude de $0.5 \mathrm{~A}$.

\subsubsection{Calibração da fase}

A saída dos sensores é periódica com uma fase bem definida em relação a excitação. Embora com o modelo matemático seja possível determinar a defasagem teórica da resposta, na prática as impedâncias das malhas de excitação e coleção, assim como capacitâncias parasitas alteram significativamente as fases. Alterações estas que dependem de quase todos os parâmetros, como frequência e a amplitude de excitação. A solução mais simples seria monitorar a magnitude descartando a fase, mas perde-se a informação sobre a direção do campo. A melhor maneira encontrada foi calibra-la experimentalmente para cada medida. O lock-in é capaz de medir simultaneamente a componente em fase com a referência $(X)$ e a ortogonal $\left(Y\right.$, defasada de $\left.90^{\circ}\right)$. Pode-se então utilizar a fase que maximiza a resposta do sensor em torno da origem $\left(B_{0}=0\right)$. Esta pode ser obtida da seguinte forma:

$$
\theta=\tan ^{-1}\left(\frac{X\left(B_{c a l}\right)-X\left(-B_{c a l}\right)}{Y\left(B_{c a l}\right)-Y\left(-B_{c a l}\right)}\right),
$$

onde $B_{\text {cal }}$ é um pequeno campo externo aplicado ao sensor (em torno de $3 \mu \mathrm{T}$ ). A figura 3.9.3 mostra a relação entre as componentes $X$ e $Y$ parametrizadas pelo campo externo e o efeito da calibração na saída.

Por exemplo, a figura 3.9.4 mostra a variação da fase de um sensor em função de um parâmetro da excitação A, mantendo os demais fixos. 


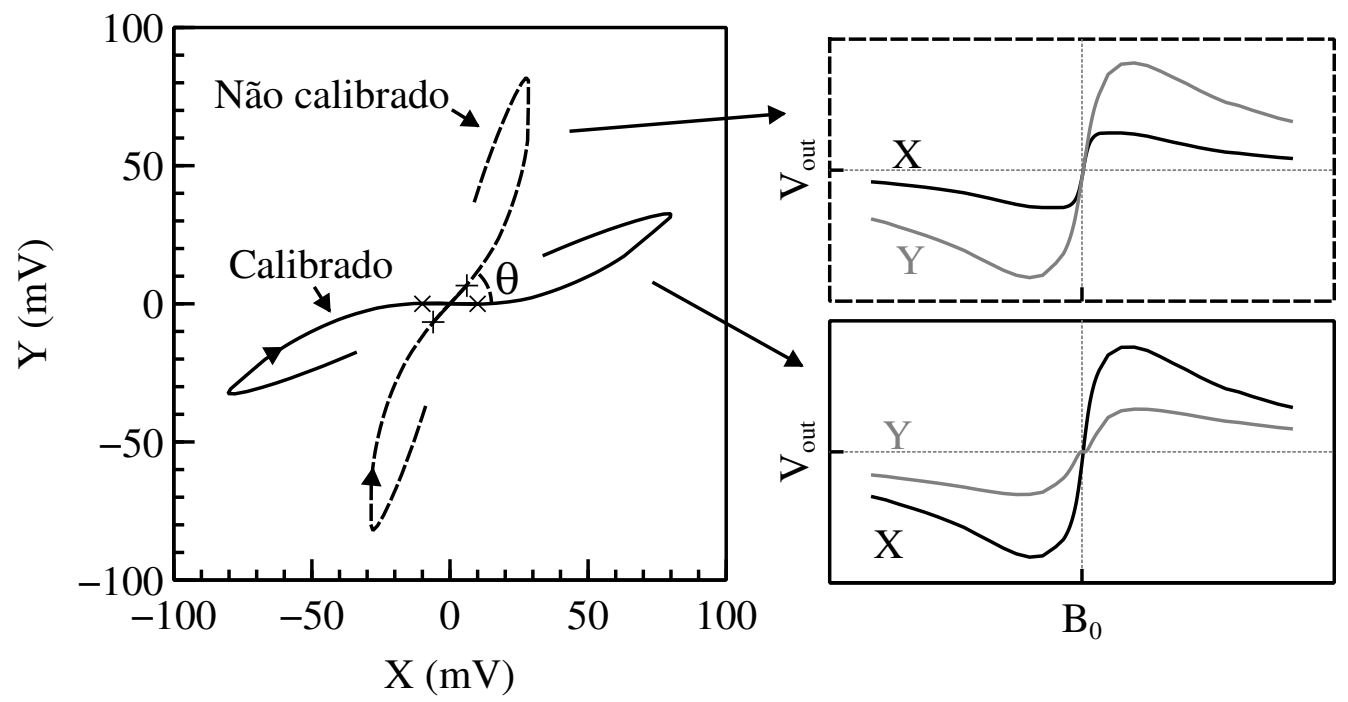

Figura 3.9.3 - Relação entre as componentes ortogonais do sinal de saída X e Y. As componentes ortogonais não são multiplas $(\mathrm{X} \neq \alpha \mathrm{Y})$, deste modo não pode-se simplesmente utilizar a magnitude. Em destaque os pontos utilizados para a calibração, que é uma rotação por um ângulo $\theta$ no plano. As inserções mostram a resposta do sensor quando não calibrado (em fase com a excitação), onde a componente $Y$ contém a maior parcela do sinal de saída. Quando calibrado o sinal contendo a informação do campo é concentrada em $\mathrm{X}$ na região da origem $\left(\mathrm{B}_{0}=0\right)$.

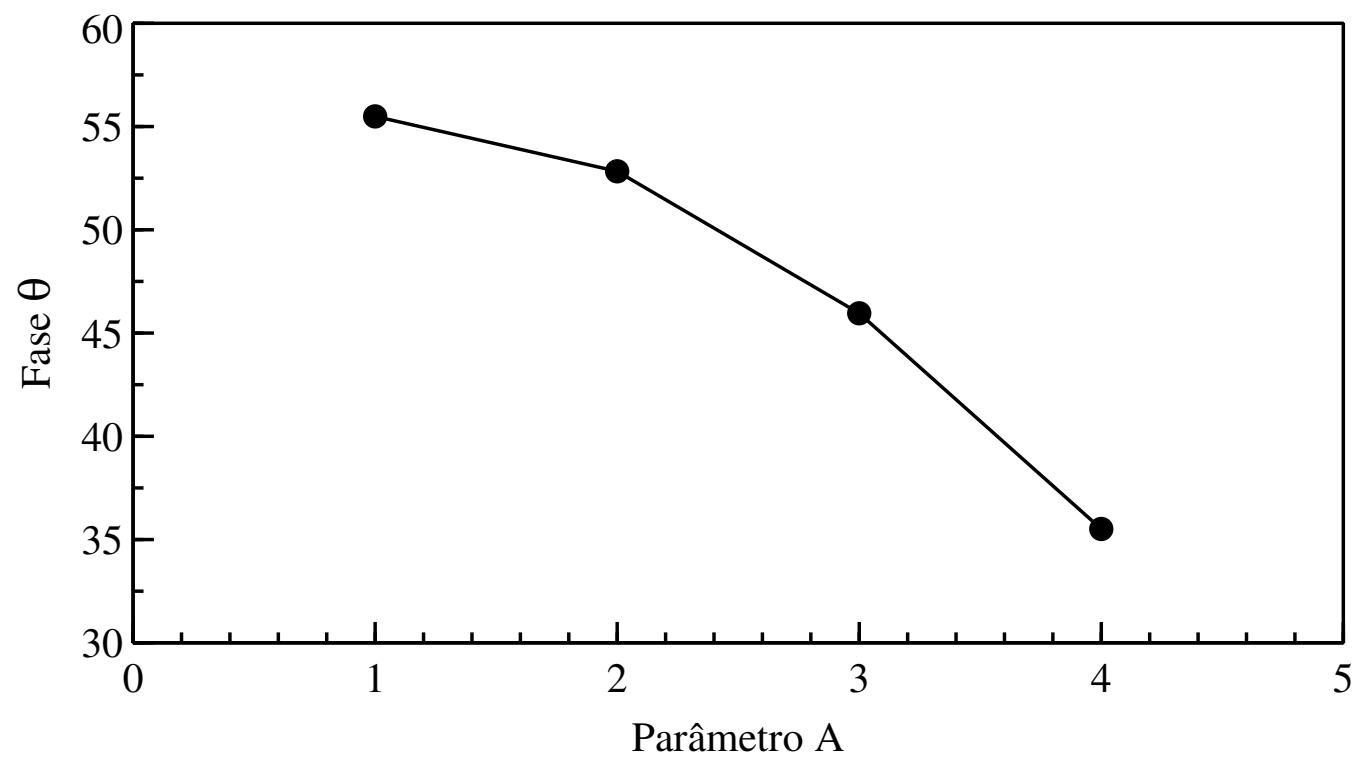

Figura 3.9.4 - Exemplo de calibração da fase em função de um parâmetro da excitação A.

\subsubsection{Curvas de resposta}

Curvas de resposta são construídas monitorando-se a saída dos dispositivos enquanto que um campo magnético externo com intensidade variada é aplicado. Foi utilizada a montagem experimental mostrada na figura 3.9.1. O resultado de uma medida pode ser visto na figura 3.9.5. 


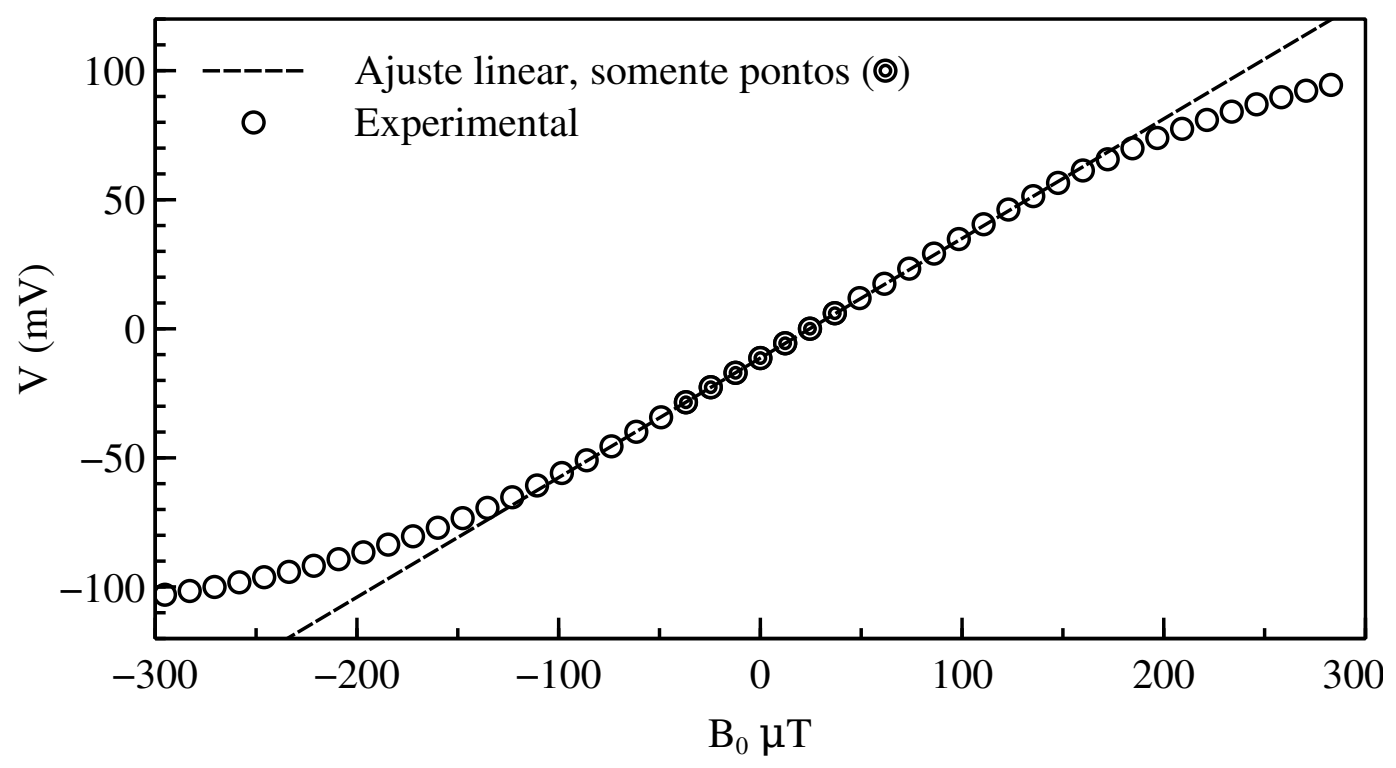

Figura 3.9.5 - Exemplo de curva de resposta.

A partir deste conjunto de dados é possível calcular a responsividade fazendo-se o ajuste linear dos pontos contidos no intervalo $(-40,40) \mu \mathrm{T}$. A escolha desta região reduzida, que não contém muitos pontos, foi necessária para evitar erros devido a perda expressiva de linearidade de alguns sensores para campos maiores. A partir de um conjunto de curvas de resposta onde um dos parâmetros de interesse é variado, construiu-se as curvas de responsividade como mostra a figura 3.9.6.

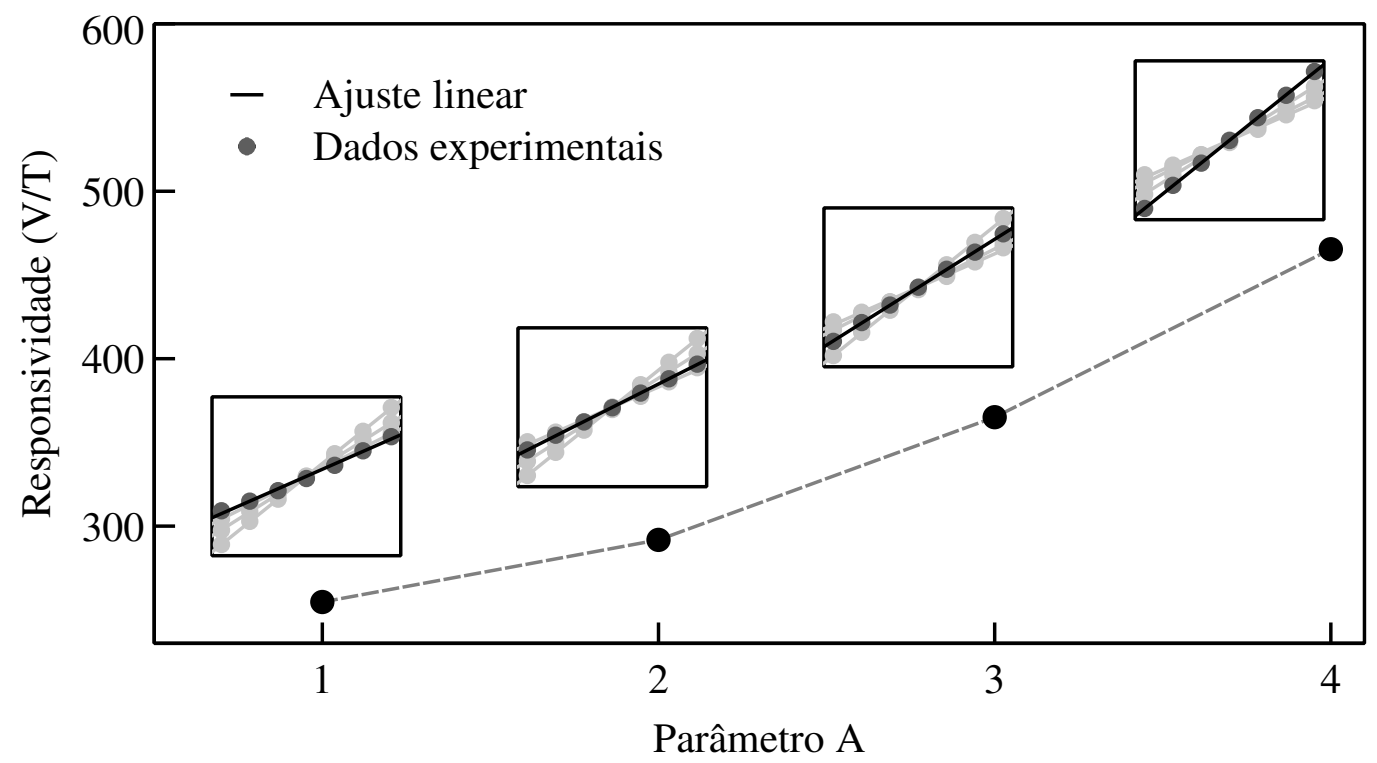

Figura 3.9.6 - Exemplo do comportamento da responsividade em função de um parâmetro A. 


\subsubsection{Efeito perming}

As medidas de perming foram feitas utilizando a mesma montagem experimental das curvas de resposta (figura 3.9.1). Aplicou-se um campo externo com amplitude $B_{0}=B_{p}$, onde $\left|B_{p}\right| \leq 4,8 \mathrm{mT}$, por $200 \mathrm{~ms}$, relaxou-se o sistema por $0,5 \mathrm{~s} \mathrm{em} B_{0}=0$ e a saída foi medida. Em seguida o mesmo procedimento foi aplicado para um campo externo no sentido oposto $B_{0}=-B_{p}$ (ver figura 3.9.7). Aumentando gradualmente a intensidade do choque foram construídos relações entre esta intensidade e o nível base do sensor (valor da saída quando o campo externo é nulo). Estas medidas não são univocas, no sentido que o valor depende da história magnética do núcleo. Há situações onde existe uma clara relação entre as duas quantidades enquanto em outras os resultados são menos diretos. A figura 3.9.8 mostra duas medidas exemplificando cada um dos casos (a e b, respectivamente). Estas foram feitas com o mesmo sensor variando-se apenas um parâmetro.

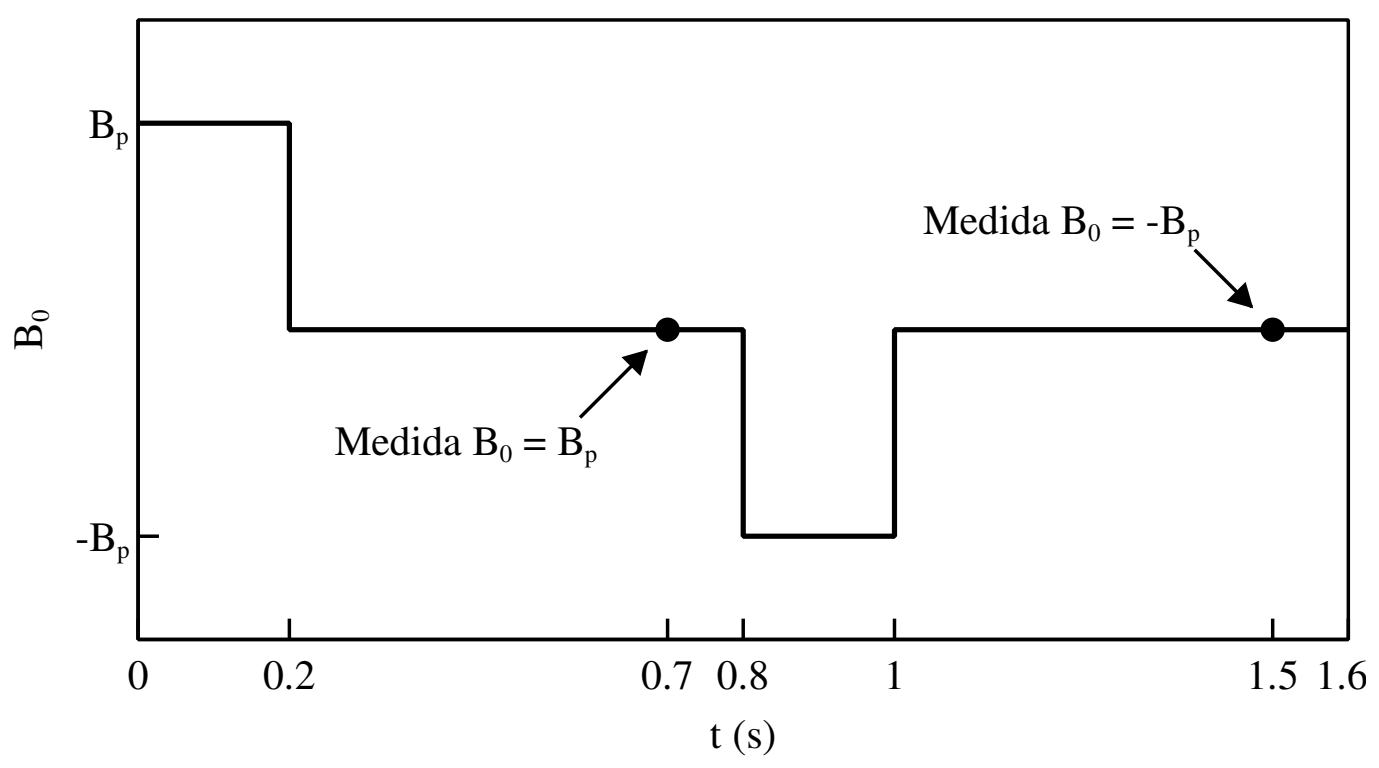

Figura 3.9.7 - Campo externo aplicado em uma medida do efeito perming.

Como referência será utilizada a diferença entre o maior e o menor valor medido, independente de $B_{p}$. Esta é uma estimativa da flutuação máxima da saída do sensor quando submetido a choques de campo externo de até $\pm 4.8 \mathrm{mT}$. A partir deste valor, pode-se comparar diferentes sensores e parâmetros quanto a sua susceptibilidade ao efeito de perming como exemplifica a figura 3.9.9. Note que os valores obtidos por este método são potencialmente maiores do que os contidos na literatura (por exemplo os da tabela 1.8.1) pois nem sempre o maior valor de perming está associado ao maior choque de campo. Também não é claro se foram aplicados choques nos dois sentidos. 

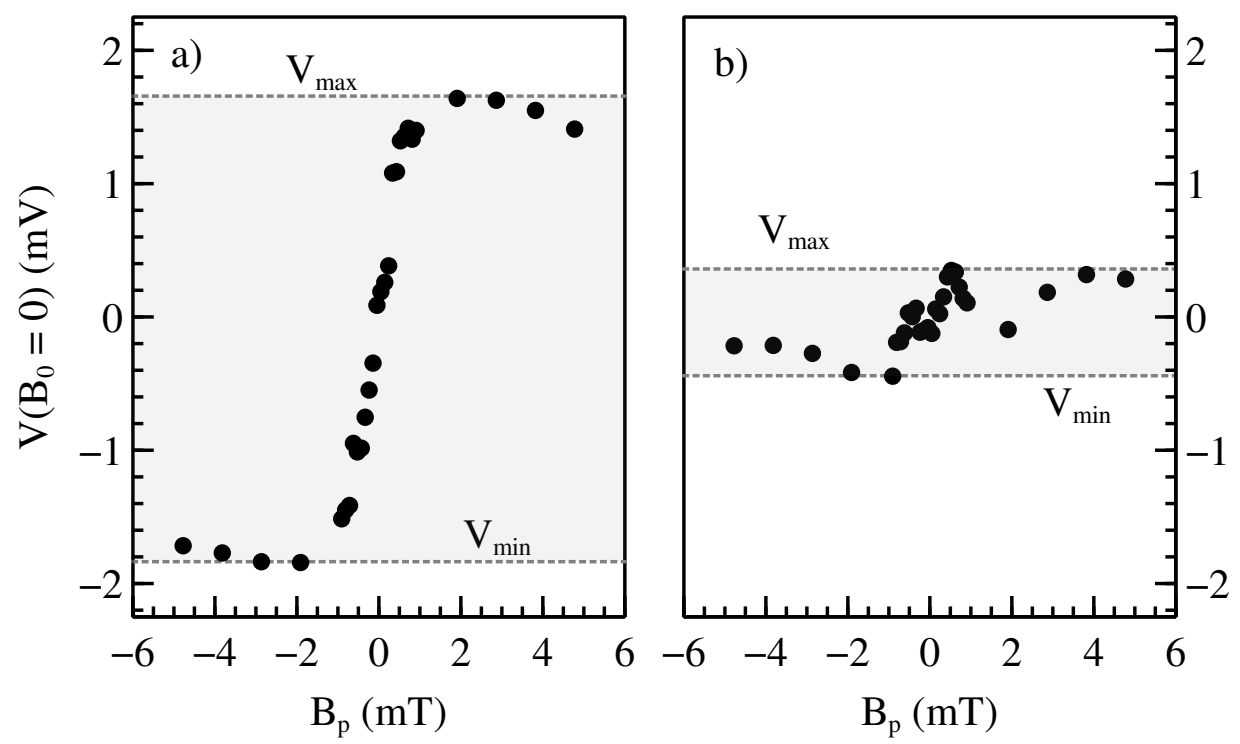

Figura 3.9.8 - Exemplo de medida do efeito perming em função da amplitude do choque de campo.

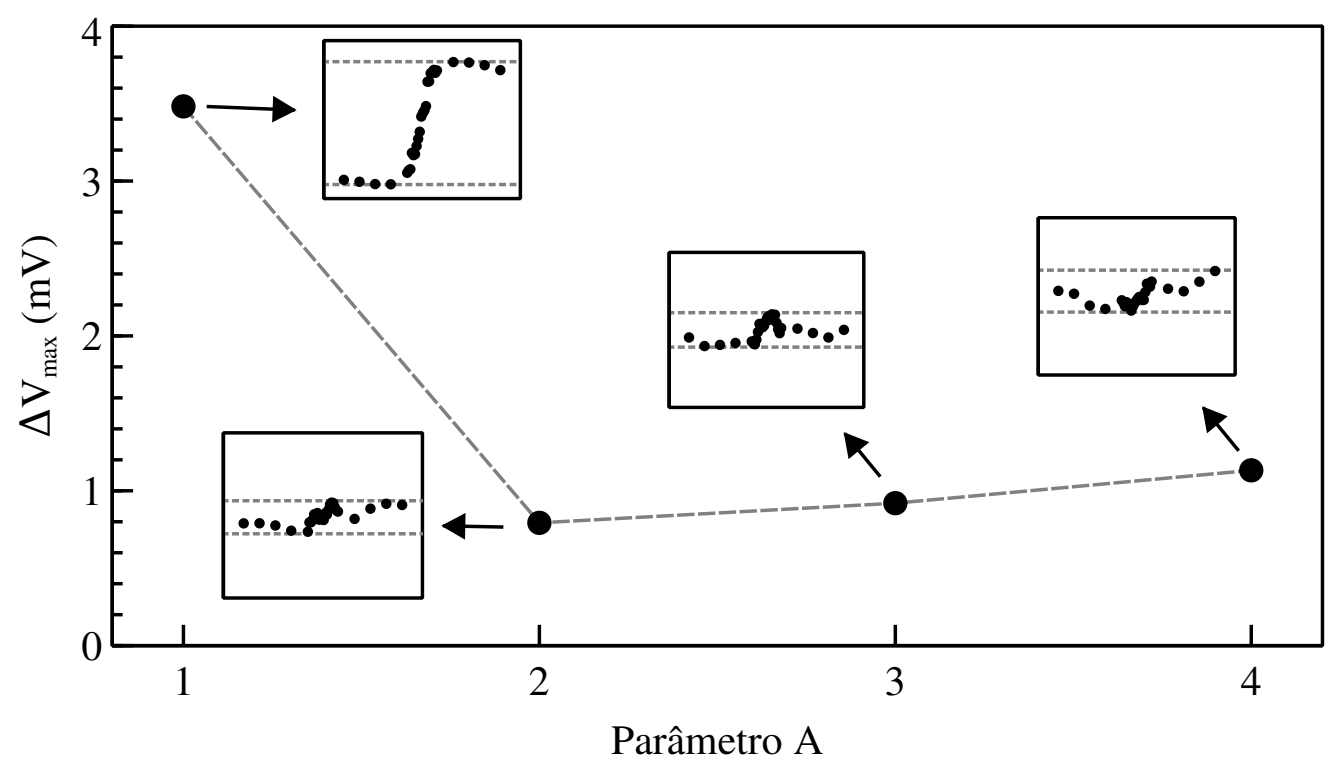

Figura 3.9.9 - Exemplo de comportamento do efeito perming em função de um parâmetro A.

\subsubsection{Ruído}

As medidas de ruído sem dúvidas são as mais difíceis de serem feitas. É grande a quantidade de detalhes importantes e um problema em qualquer das etapas pode mascarar os resultados. A primeira coisa importante a ser notada é que o ruído medido é a soma dos ruídos produzidos em todo o sistema: equipamentos, externo e do sensor. Em geral não é possível separar as componentes do sinal de saída. A estratégia então é minimizar as componentes não desejadas, isto é, outras que não o ruído intrínseco do dispositivo. É necessário que a soma de todas as outras componentes esteja abaixo da desejada para que tenha-se uma medida significativa. Por 
outro lado, uma vez garantida a blindagem de campos externos, pode-se encarar o valor medido como o ruído do sistema como um todo.

\subsubsection{Montagem experimental ruído.}

Foram testadas duas montagens experimentais nas medidas de ruído, onde a amplificação da excitação foi feita de forma distinta. Inicialmente somente a montagem da figura 3.9.10, que utiliza o gerador de funções em conjunto com um amplificador de potência, foi utilizada. Esta tem a limitação de amplitude de aproximadamente 1 A. Também há uma contaminação de sua saída pelos $60 \mathrm{~Hz}$ da rede, assim como seus harmônicos. Este problema é bastante agravado quando foi utilizada uma componente dc, e as medidas feitas com base no primeiro harmônico da excitação. Por este motivo foi construído um modulador de corrente (figura 3.9.11) que pode ser alimentado por uma bateria $12 \mathrm{~V}$ ou uma fonte de tensão. A montagem experimental utilizando este equipamento é mostrada na figura 3.9.12.

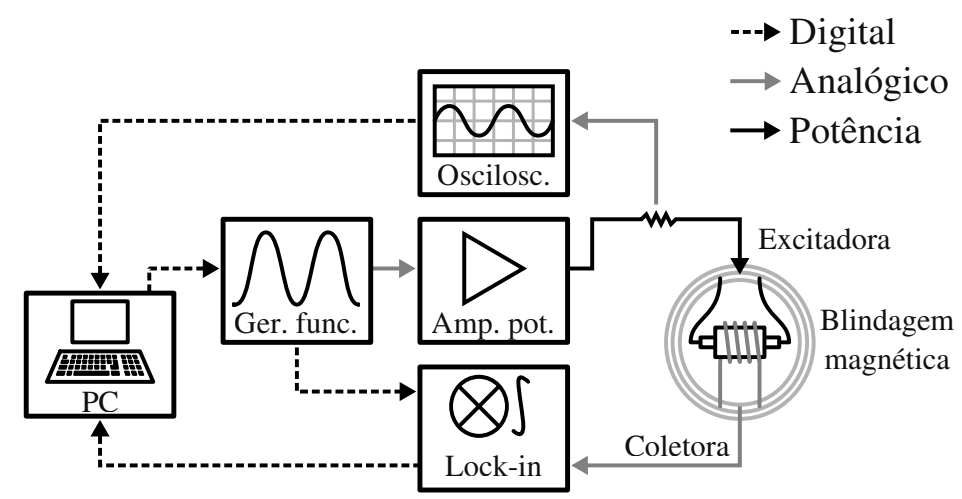

Figura 3.9.10 - Montagem experimental das medidas de ruído utilizando o gerador de funções. A parte lógica das medidas é feita utilizando-se scripts que rodam em um computador. Estes controlam os parâmetros de um gerador de função (Agilent 33220A) responsável pelo sinal de excitação. Um amplificador de potência (baseado em um OPA564) fornece o ganho de corrente, alimentando as bobinas excitadoras do sensor. Um osciloscópio (Tektronix TDS2024B) mede a queda de potencial em cima de um resistor em série com a excitação, fornecendo o valor atual da corrente de excitação. Já no ramo de saída do sensor, tem-se as bobinas coletoras ligadas a um amplificador lock-in (Signal Recovery DSP 7280). Este amplificador recebe o sinal de referência do gerador de função. O sensor é posicionado em uma blindagem magnética cilíndrica com três camadas de mu-metal. 


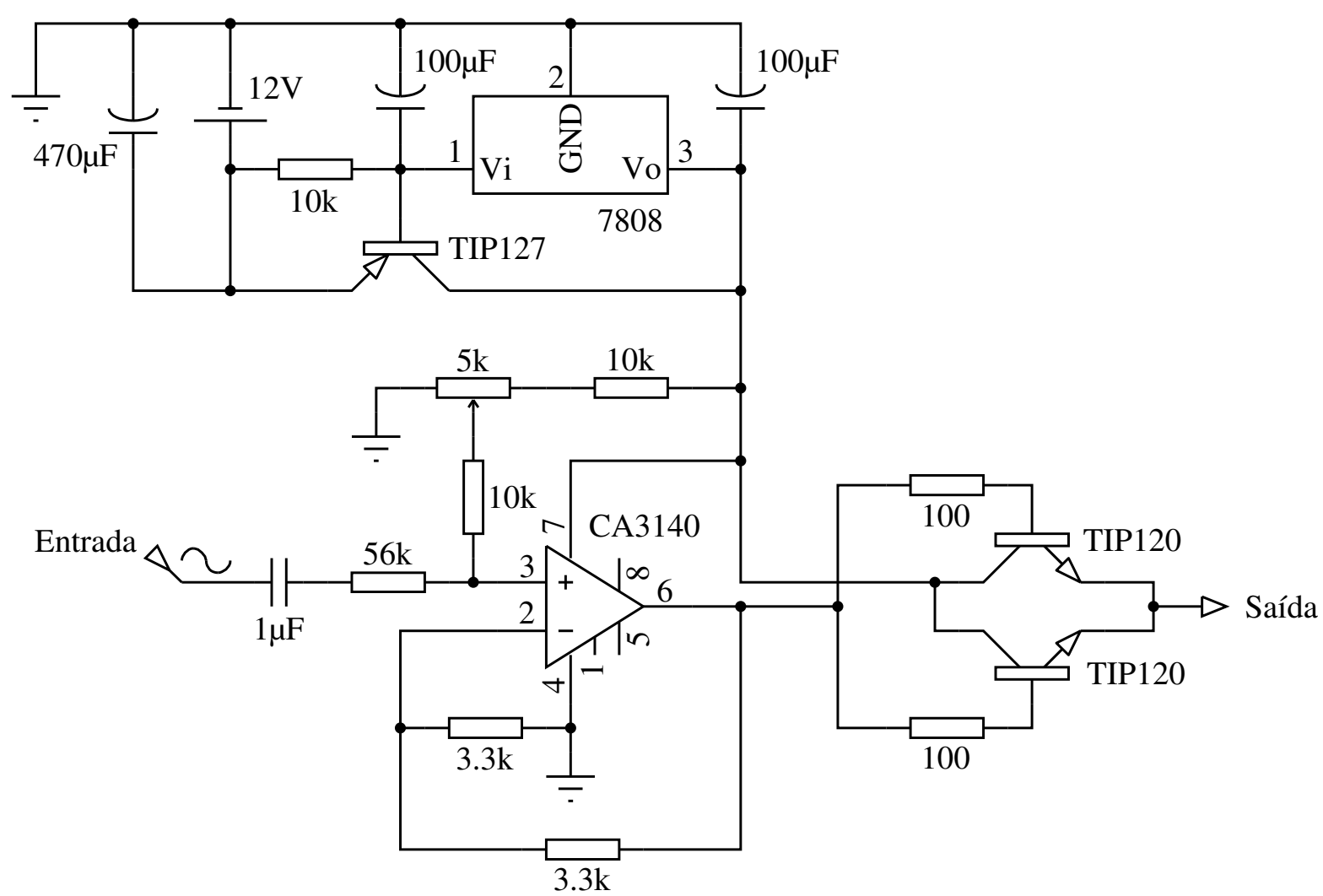

Figura 3.9.11 - Modulador de corrente. Utilizando como fonte uma bateria $12 \mathrm{~V}$ o circuito modula a corrente de saída de acordo com o sinal de entrada e uma componente DC ajustada manualmente (potenciômetro de $5 \mathrm{~K} \Omega$ ). Correntes superiores a $2 \mathrm{~A}$ são possíveis sem o ruído da rede elétrica.

Foram coletados séries temporais de $15 \mathrm{~s}$ contendo 15000 pontos cada (intervalo de $1 \mathrm{~ms}$ entre pontos). Um exemplo pode ser visto na figura 3.9.13. A partir desta série e utilizando o método descrito no apêndice B chega-se ao valor $r m s$ do ruído contido na faixa de 0,1 a $10 \mathrm{~Hz}$. Variando-se um parâmetro A pode-se construir a sua relação com o ruído, como mostra a figura 3.9 .14

\subsubsection{Normalização}

Os resultados das medidas de perming e de ruído descritas estão em função da tensão de saída dos sensores. Para que representem seu efeito na capacidade de medir o campo magnético é necessário normalizá-las pela responsividade. Por exemplo divide-se os valores contidos nas figuras 3.9.9 e 3.9.14 pelos da figura 3.9.6, resultando na figura 3.9.15 


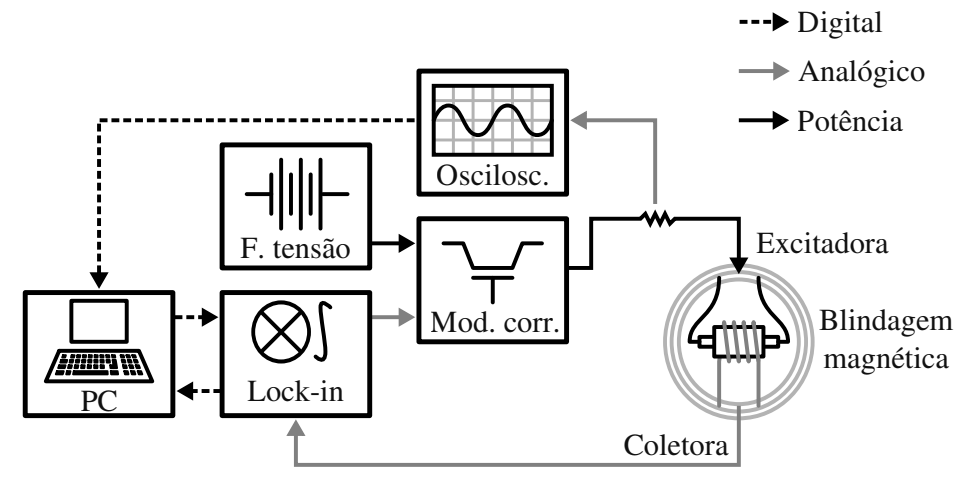

Figura 3.9.12 - Montagem experimental, medidas de ruído utilizando o modulador de corrente. A parte lógica das medidas é feita utilizando-se scripts que rodam em um computador. Estes controlam os parâmetros de um amplificador lock-in (Signal Recovery DSP 7280) que através de seu oscilador interno fornece o sinal de excitação. Um modulador de corrente (ver equema na figura3.9.11) alimentado por uma fonte de tensão (bateria $12 \mathrm{~V}$ ou HP 6653A) fornece o ganho de corrente necessário para as bobinas de excitação. Um osciloscópio (Tektronix TDS2024B) mede a queda de potencial em cima de um resistor em série com a excitação, fornecendo o valor atual da corrente de excitação. Já no ramo de saída do sensor, tem-se as bobinas coletoras ligadas ao amplificador lock-in (Signal Recovery DSP 7280) no modo diferencial. O sensor é posicionado em uma blindagem magnética cilíndrica com três camadas de mu-metal.

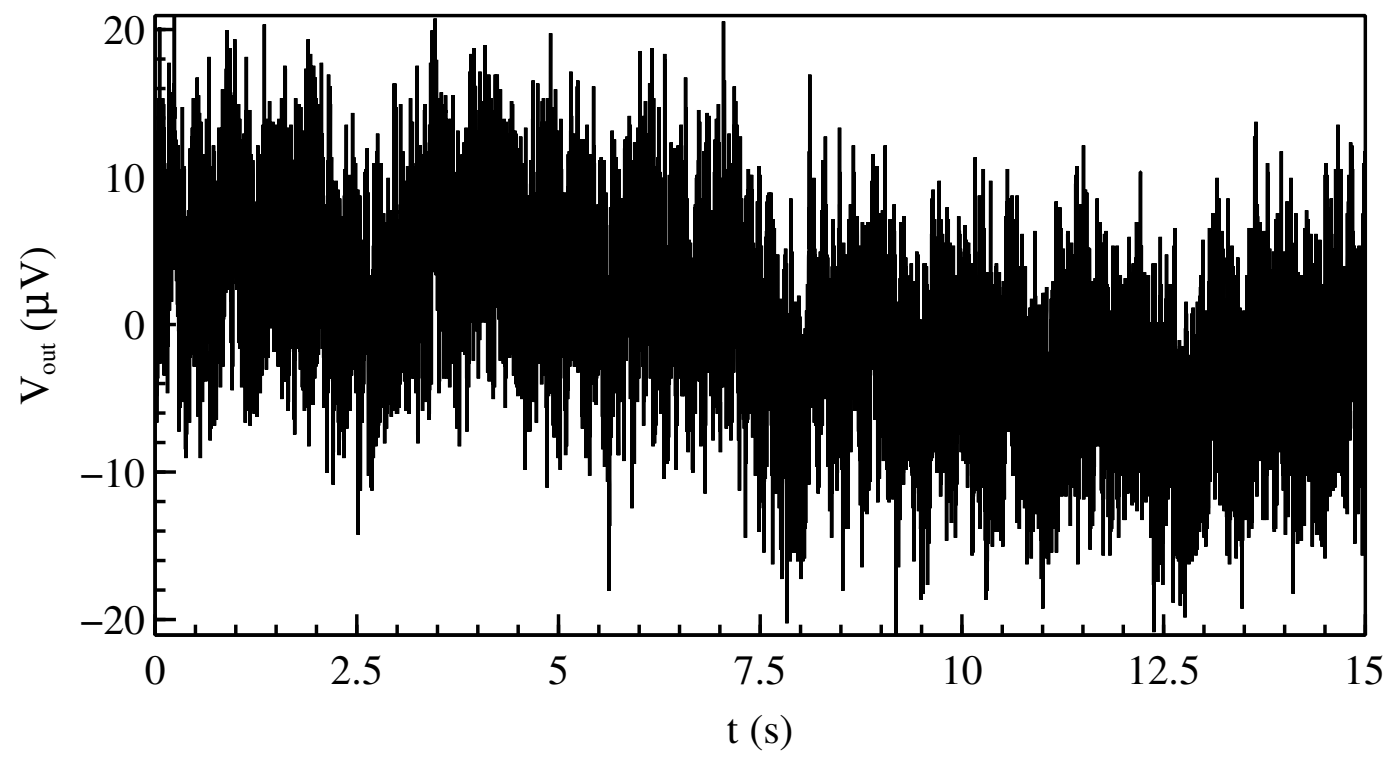

Figura 3.9.13 - Exemplo do sinal gerado pelos sensores dentro da blindagem $\left(B_{0}=0\right)$, isto é, o ruído. Os valores foram deslocados artificialmente para em torno de $V_{\text {out }}=0$. 


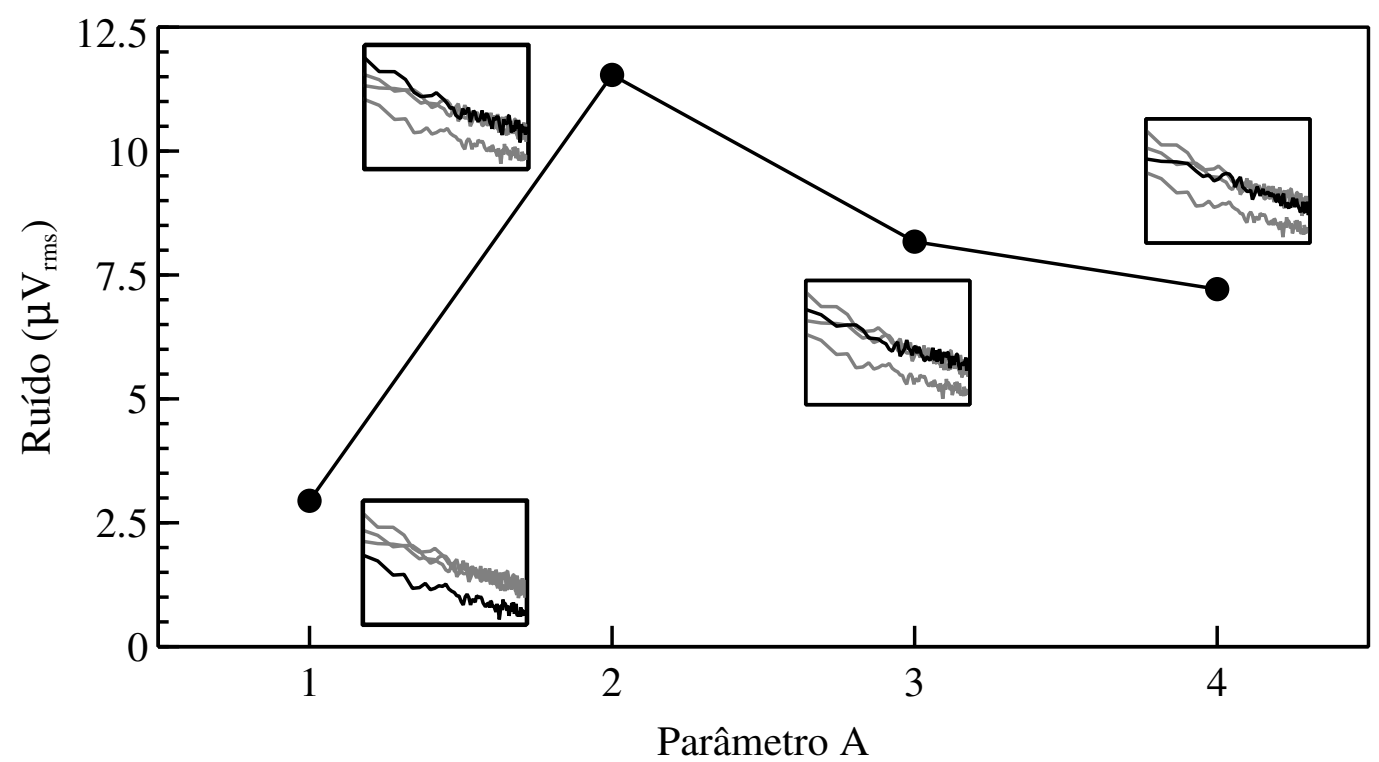

Figura 3.9.14 - Exemplo de dependência do ruído $r m s$ com um parâmetro A. As inserções mostram a média da PSD para cada valor de A, evidenciando a utilizada no cálculo do valor do ponto.
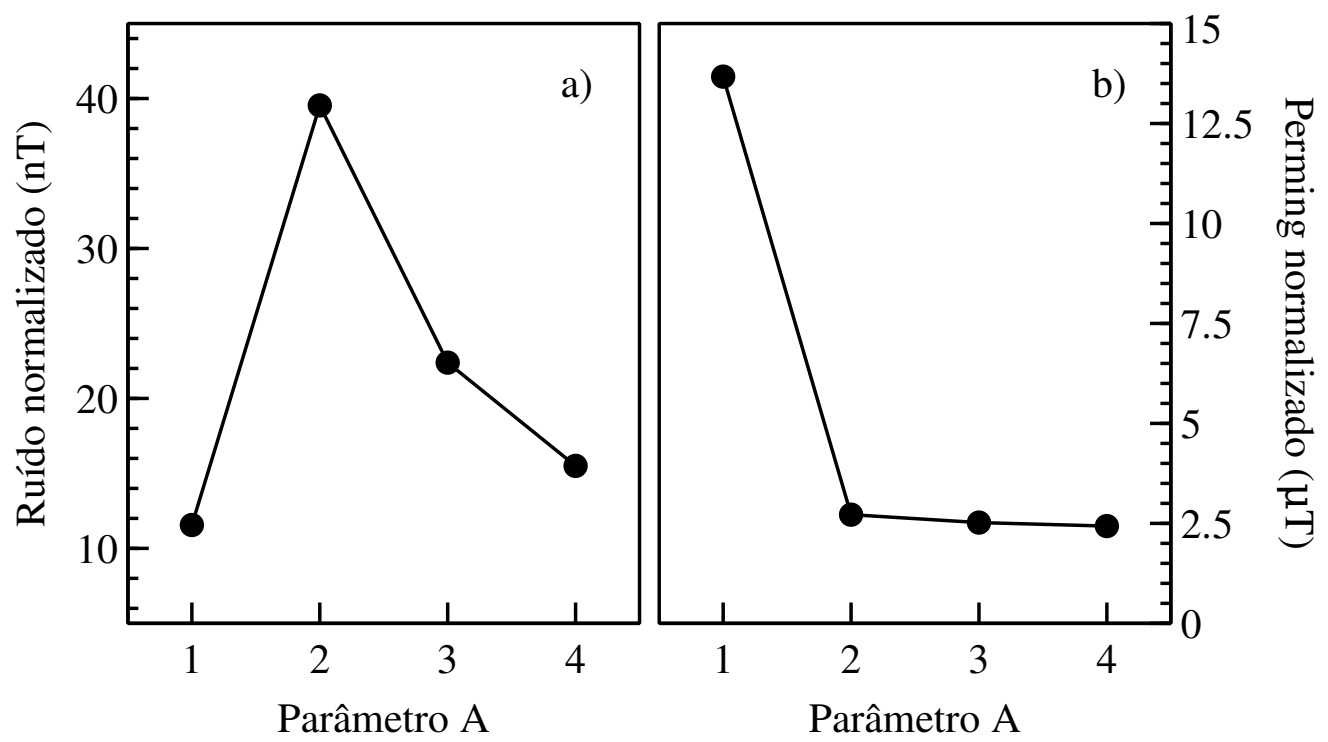

Figura 3.9.15 - Exemplo de ruído (a) e perming (b) normalizados. 


\subsection{Alguns resultados numéricos de responsividade}

Para melhor entender os resultados experimentais é importante ter-se uma referência. Para isto serão utilizados os comportamentos previstos pelas equações deduzidas para o fluxgate ortogonal operado no modo convencional (equação 1.6.10) e a equação para o modo saturado (equação 3.4.20). Enquanto que a primeira necessita da curva de chaveamento experimental, a segunda faz uso de somente a magnetização de saturação. Note, entretanto, que nada impede que a componente contínua no campo de excitação seja adicionada na equação convencional. Deste modo, aumentando-a gradualmente, obtém-se uma transição suave entre os modos de operação.

Como exemplo, considere o sensor N50. A curva de chaveamento do seu núcleo, calculada com a equação 1.6.11 a partir dos dado contidos na figura 3.8.5h, está mostrada na figura 3.10.1.

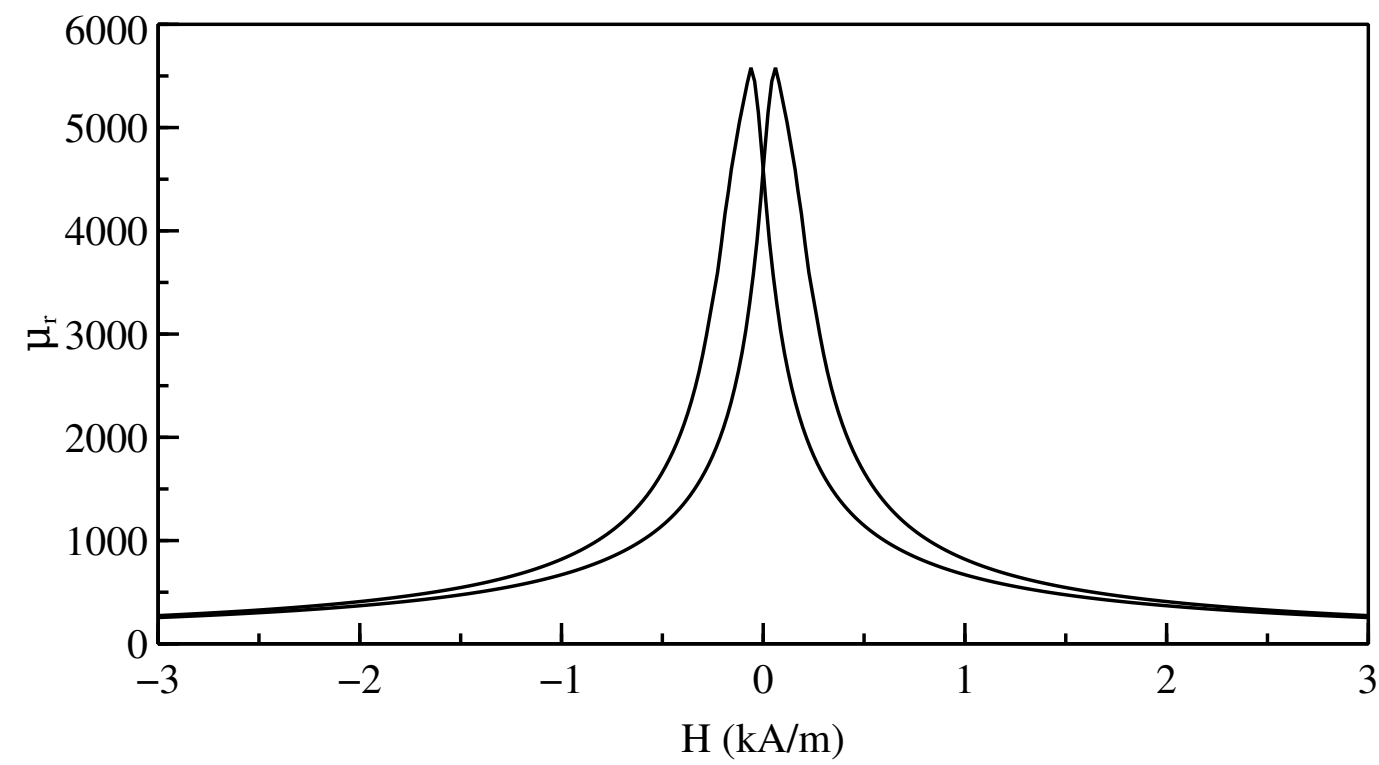

Figura 3.10.1 - Curva de chaveamento ortogonal do sensor N50.

O fator de desmagnetização para um cilindro longo pode ser obtido através da equação

$$
D \approx(d / \ell)^{2}[2,01 \log (\ell / d)-0,46]
$$

onde $\ell$ é o comprimento e $d$ o diâmetro [73]. Para um tubo pode-se aproximar $D$ pela diferença entres os fatores dos cilindros com o diâmetro externo e interno [74]. Utilizando as dimensões do $\mathrm{N} 50, \ell=15 \times 10^{-3} \mathrm{~m}, d_{C u}=90 \times 10^{-6} \mathrm{~m} \mathrm{e} d_{e}=45 \times 10^{-6} \mathrm{~m}$, chega-se a

$$
D \approx 1 \times 10^{-4} \text {. }
$$

$D_{2}$ foi considerado nulo.

O próximo passo é definir um $H_{e x c}$ único para inserir nas equações. Note que ao passar uma corrente pelo sensor produz-se um campo $H$ dependente do raio. Para não complicar demais 
o problema, serão feitas duas aproximações. A primeira é considerar este $H_{\text {exc }}$ uniforme, com valor calculado para o diâmetro médio do núcleo, $d_{n}=67,5 \mu \mathrm{m}$. A segunda é considerar a que corrente se distribui uniformemente por todo o fio, isto é, substrato de cobre mais núcleo. Desta forma tem-se

$$
H_{e x c}=I_{e x c} \frac{d_{n}}{\pi d_{e}^{2}},
$$

que leva a $H_{e x c} \approx 2,65 \times 10^{3} I_{e x c}$. Finalmente será considerada uma corrente de excitação do tipo

$$
I_{e x c}=I_{d c}+I_{a c} \operatorname{sen}(2 \pi f t)
$$

com a frequência $f=100 \mathrm{kHz}$. Já a magnetização de saturação do núcleo foi medida em $M_{\text {sat }}=800 \mathrm{kA} / \mathrm{m}$.

Tem-se agora todos os dados para gerar os sinais de saída do sensor pelas equações 1.6.10 e 3.4.20, e calcular as curvas de responsividade numericamente. Começando pelo caso em que $I_{a c}$ é mantida fixa e $I_{d c}$ é aumentada gradativamente, dando origem ao gráfico da figura 3.10.2.

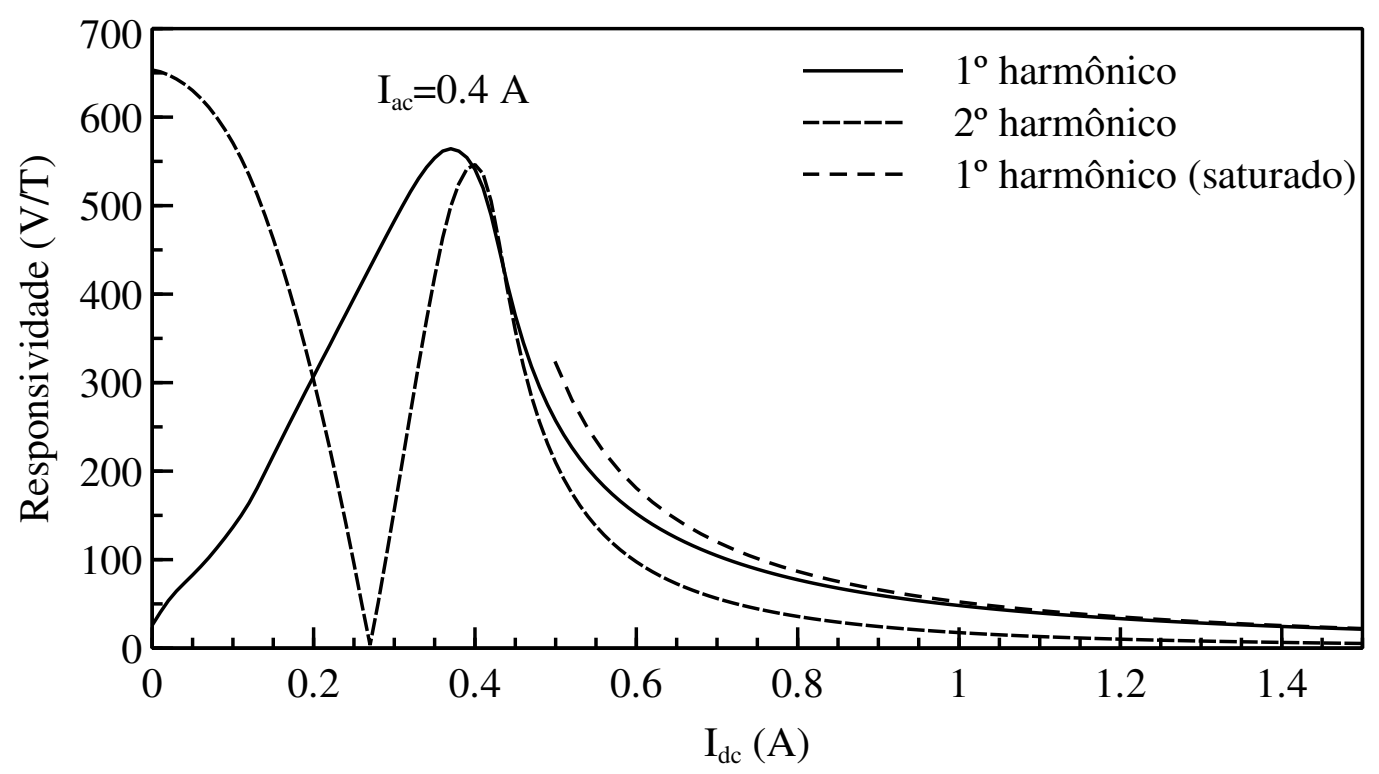

Figura 3.10.2 - Responsividade do sensor N50 calculada numericamente em função deslocamento da excitação para o primeiro e segundo harmônio. Foi utilizada a equação tradicional em conjunto com a permeabilidade relativa medida, e a permeabilidade saturada. É possível ver a transição entre os modos de operação, com a queda de responsividade do segundo harmônico e o ganho do primeiro.

Vê-se com o incremento da componente constante na excitação a queda da responsividade no segundo harmônico e o ganho no primeiro. O segundo harmônico muda de fase e volta a subir mas permanece abaixo do primeiro para $I_{d c}$ altos. Ainda com o aumento de $I_{d c}$, a responsividade na frequência fundamental se aproxima do comportamento previsto pelo modo saturado. 
Variando-se agora a componente alternada da corrente, pode-se construir as curvas de responsividade para o modo puramente convencional $\left(I_{d c}=0\right)$, similares ao resultados mostrados para os sensores paralelos da seção 2 (figuras 2.3.4 e 2.4.21), e ir aumentado-a até o sensor ser operado constantemente na saturação, como mostra a figura 3.10.3.

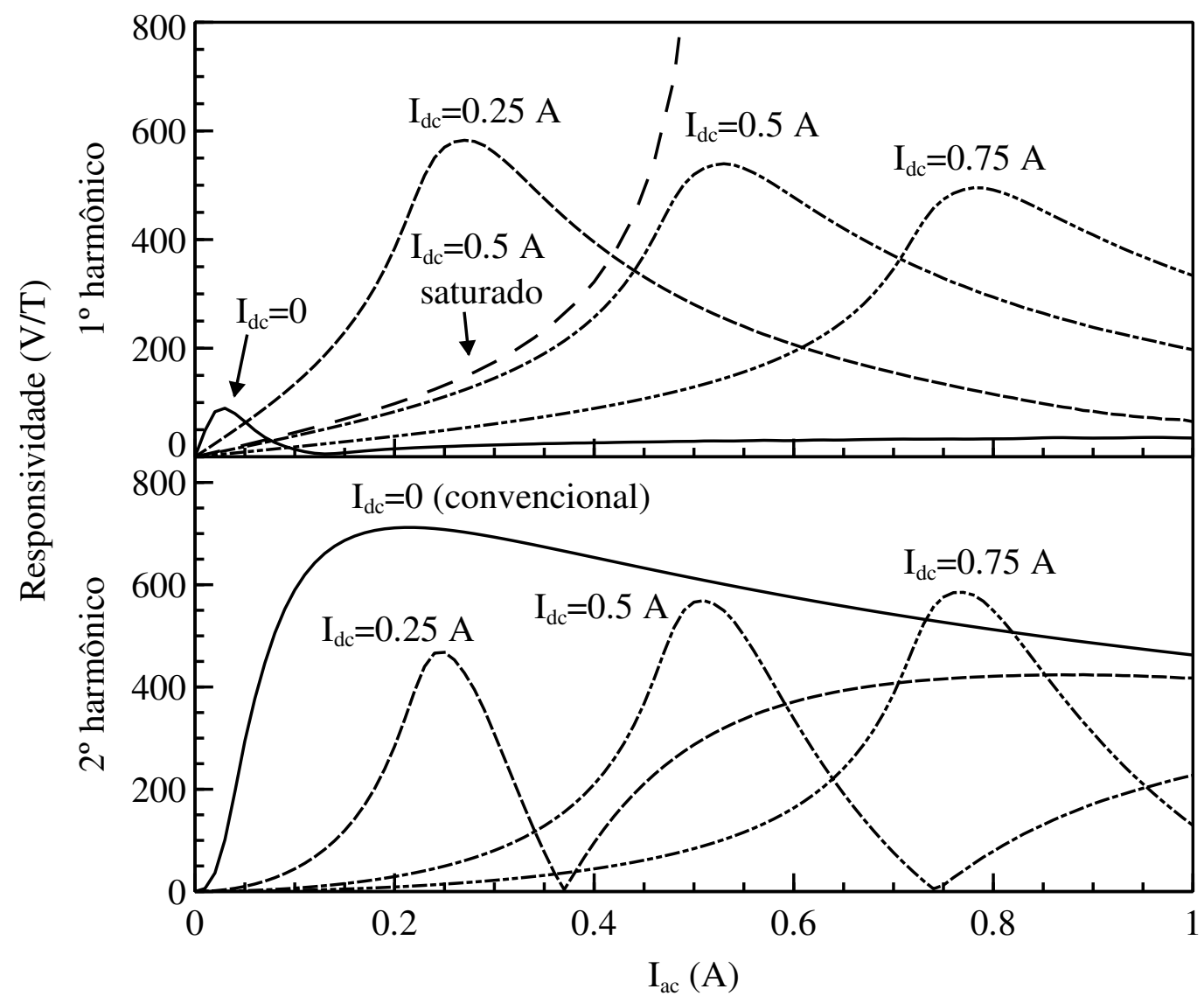

Figura 3.10.3 - Responsividade do sensor N50 calculada numericamente em função da corrente de excitação alternada para alguns valores de corrente contínua. (a) Harmônico fundamental e (b) segundo harmônico da excitação.

No modo de operação convencional quase não há componente fundamental no sinal. Tem-se um aumento acentuado do segundo harmônico, seguido de um lento declínio para correntes altas. Uma vez aplicada a corrente $I_{d c}$, o primeiro harmônico se torna dominante, especialmente para baixas correntes alternadas. A curva de responsividade do modo fundamental também possui um máximo, aproximadamente no ponto em que passa a haver a inversão de sentido na excitação $\left(I_{a c}=I_{d c}\right)$. Entretanto já não se está mais na região de interesse, pois agora a magnetização se dá predominantemente pelo movimento das paredes dos domínios, justamente o que se pretende evitar.

A responsividade prevista pela permeabilidade de saturação é um pouco superior a calculada pela curva de chaveamento, isto para valores baixos de $I_{a c}$, pois a responsividade 
saturada diverge para $I_{a c} \approx I_{d c}$. Uma das causas desta diferença é o acréscimo do campo coercivo no denominador da permeabilidade (equação 1.6.11).

\subsection{Resultados experimentais}

Para cada sensor construído (tabela 3.11.2) foram realizadas medidas para as combinações entre os parâmetros da tabela 3.11.1. Como o volume de dados resultante é grande, separou-se os sensores em três grupos por similaridades: os sensores com diâmetro do substrato de $120 \mu \mathrm{m}$ e núcleo de $\mathrm{NiFe}$ compõem o grupo A, os sensores com diâmetro do substrato de 45 $\mu \mathrm{m}$ e núcleo de NiFe compõem o grupo B e os sensores com diâmetro do substrato de $45 \mu \mathrm{m}$ e núcleo de NiFeP compõem o grupo C. Para cada grupo serão mostrados os dados dos parâmetro de saída em função dos parâmetros de entrada individualmente.

\begin{tabular}{llr}
\hline Saída & Excitação & Modo de operação \\
\hline $\begin{array}{l}\text { Responsividade } \\
\text { perming }\end{array}$ & $I_{a c}$ & Convencional $\left(2^{\circ}\right.$ harmônico, $\left.I_{d c}=0\right)$ \\
Ruído & $I_{d c}{ }^{*}$ & Excitação deslocada $\left(1^{\circ}\right.$ harmônico, $\left.I_{d c}-I_{a c}>0\right)$ \\
\hline
\end{tabular}

Tabela 3.11.1 - Conjunto de medidas realizadas para cada sensor. *Somente para o modo de operação com excitação deslocada.

\begin{tabular}{lllllllll}
\hline Grupo & Sensor & Núcleo & $\rho_{d}\left(\mathrm{~mA} / \mathrm{cm}^{2}\right)$ & $\mathrm{I}_{\phi}(\mathrm{A})$ & $\mathrm{d}_{C u}(\mu \mathrm{m})$ & $\mathrm{d}_{e}(\mu \mathrm{m})$ & $\ell(\mathrm{mm})$ & espiras \\
\hline \multirow{4}{*}{$\mathrm{A}$} & $\mathrm{N} 14 \mathrm{I} 00$ & $\mathrm{NiFe}$ & 14 & 0 & 120 & 144 & 15 & 150 \\
& $\mathrm{~N} 40 \mathrm{I} 00$ & $\mathrm{NiFe}$ & 40 & 0 & 120 & 144 & 15 & 150 \\
& $\mathrm{~N} 40 \mathrm{I} 05$ & $\mathrm{NiFe}$ & 40 & 0,5 & 120 & 144 & 15 & 150 \\
& $\mathrm{~N} 40110$ & $\mathrm{NiFe}$ & 40 & 1,0 & 120 & 144 & 15 & 150 \\
& $\mathrm{~N} 40115$ & $\mathrm{NiFe}$ & 40 & 1,5 & 120 & 144 & 15 & 150 \\
\hline \multirow{4}{*}{$\mathrm{B}$} & $\mathrm{N} 15$ & $\mathrm{NiFe}$ & 15 & 0 & 45 & 90 & 15 & 200 \\
& $\mathrm{~N} 25$ & $\mathrm{NiFe}$ & 25 & 0 & 45 & 90 & 15 & 200 \\
& $\mathrm{~N} 40$ & $\mathrm{NiFe}$ & 40 & 0 & 45 & 90 & 15 & 200 \\
& $\mathrm{~N} 50$ & $\mathrm{NiFe}$ & 50 & 0 & 45 & 90 & 15 & 200 \\
\hline \multirow{4}{*}{$\mathrm{C}$} & $\mathrm{P} 09$ & $\mathrm{NiFeP}$ & 900 & 0 & 45 & 95 & 15 & 200 \\
& $\mathrm{P} 13$ & $\mathrm{NiFeP}$ & 1300 & 0 & 45 & 95 & 15 & 200 \\
& $\mathrm{P} 16$ & $\mathrm{NiFeP}$ & 1600 & 0 & 45 & 95 & 15 & 200 \\
& $\mathrm{P} 28$ & $\mathrm{NiFeP}$ & 2800 & 0 & 45 & 95 & 15 & 200 \\
\hline
\end{tabular}

Tabela 3.11.2 - Reimpressão da tabela 3.6.2 com a separação dos sensores em grupos. $\rho_{d}$ é a densidade de corrente utilizada na eletrodeposição (a área de referência é a do fio de cobre), $\mathrm{I}_{\phi}$ a corrente passada pelo fio durante a eletrodeposição responsável pelo campo tangencial, $\mathrm{d}_{C u}$ o diâmetro do fio de cobre utilizado como substrato, $\mathrm{d}_{e}$ o diâmetro externo final, $\ell$ o comprimento do fio e na última coluna o número de espiras da bobina coletora. 
Como já foi dito, não é possível atribuir um valor de $H_{\text {exc }}$ para uma dada corrente $I_{\text {exc }}$ uma vez que o campo $H$ gerado pela corrente em um fio depende do raio. Poderia-se utilizar um valor médio como foi feito no caso do cálculo numérico da responsividade na seção anterior. Mas a simplificação da distribuição da corrente dentro do fio utilizada não é realista. Não foi considerada a diferença de resistividade elétrica dos diferentes materiais do núcleo, tampouco o efeito pelicular (correntes alternadas tendem a fluir próximas a superfície de um condutor devido ao campo magnético induzido). Optou-se então por apresentar os resultados diretamente em função da corrente de excitação $I_{e x c}=I_{d c}+I_{a c} \operatorname{sen}(\omega t)$. Todas as medidas fora feitas utilizando-se $I_{a c}$ senoidal com frequência de $100 \mathrm{kHz}$.

Para cada parâmetro de entrada, foi escolhido um valor de referência. Escolha baseada nos melhores resultados obtidos em testes preliminares, além de algumas considerações geométricas para manter os campos de excitação com intensidade similar entre todos os dispositivos (veja a tabela 3.11.3). Utilizando-os pode-se construir as curvas de cada parâmetro de saída em função da propriedade única do sensor dentro de seu grupo. Por exemplo o comportamento da responsividade com o aumento da densidade de corrente na eletrodeposição. Além disto, estes serão os valores utilizados na comparação entre todos os sensores independente do grupo. Por fim, são a média de 3 medidas independentes em contraste com os valores únicos dos outros pontos. Quando, na discussão dos resultados, for citado um valor de saída medido sem a especificação dos parâmetros de entrada associados, subentende-se os valores de referência.

\begin{tabular}{lrr}
\hline Grupo & $\mathrm{A}$ & $\mathrm{B}, \mathrm{C}$ \\
\hline$H_{\text {exc }} / I_{\text {exc }}(\mathrm{kA} / \mathrm{m}$ por A) & 2,03 & 2,65 \\
$I_{a c}(\mathrm{~A})$, convencional & 0,9 & 0,6 \\
$H_{a c}(\mathrm{kA} / \mathrm{m})$, convencional & 1,83 & 1,32 \\
$I_{d c}(\mathrm{~A})$, FORM & 0,65 & 0,5 \\
$H_{d c}(\mathrm{kA} / \mathrm{m})$, FORM & 1,32 & 1,32 \\
$I_{a c}(\mathrm{~A})$, FORM & 0,15 & 0,15 \\
$H_{a c}(\mathrm{kA} / \mathrm{m})$, FORM & 0,3 & 0,4 \\
\hline
\end{tabular}

Tabela 3.11.3 - Parâmetros de entrada de referência e o campo aproximado que geram (equação 3.10.3). Nem sempre foi possível manter o campo constante entre os grupos devido a limitações no equipamento e superaquecimento das amostras. 


\subsubsection{Grupo A}

\subsubsection{Responsividade}

A figura 3.11.1a mostra as medidas de responsividade para os sensores do grupo A operando no modo convencional. Os valores de centenas de V/T encontrados são relativamente altos para dispositivos com estas dimensões (veja a tabela 1.8.1), resultado do bom acoplamento entre a bobina e o núcleo. Exceto para o sensor N14I00, o aumento de $I_{\text {exc }}$ eleva a responsividade. Estes sensores ainda não atingiram o máximo da responsividade. O que difere o N14I00 dos demais é o formato de sua curva de magnetização (figura 3.8.3a), com maior permeabilidade máxima. Já a corrente passada pelo fio durante a eletrodeposição (figura 3.11.1b), gerando o campo magnético tangencial, teve efeito negativo na responsividade, reduzindo-a para $240 \mathrm{~V} / \mathrm{T}$ no caso de $I_{\phi}=1.5 \mathrm{~A}$.

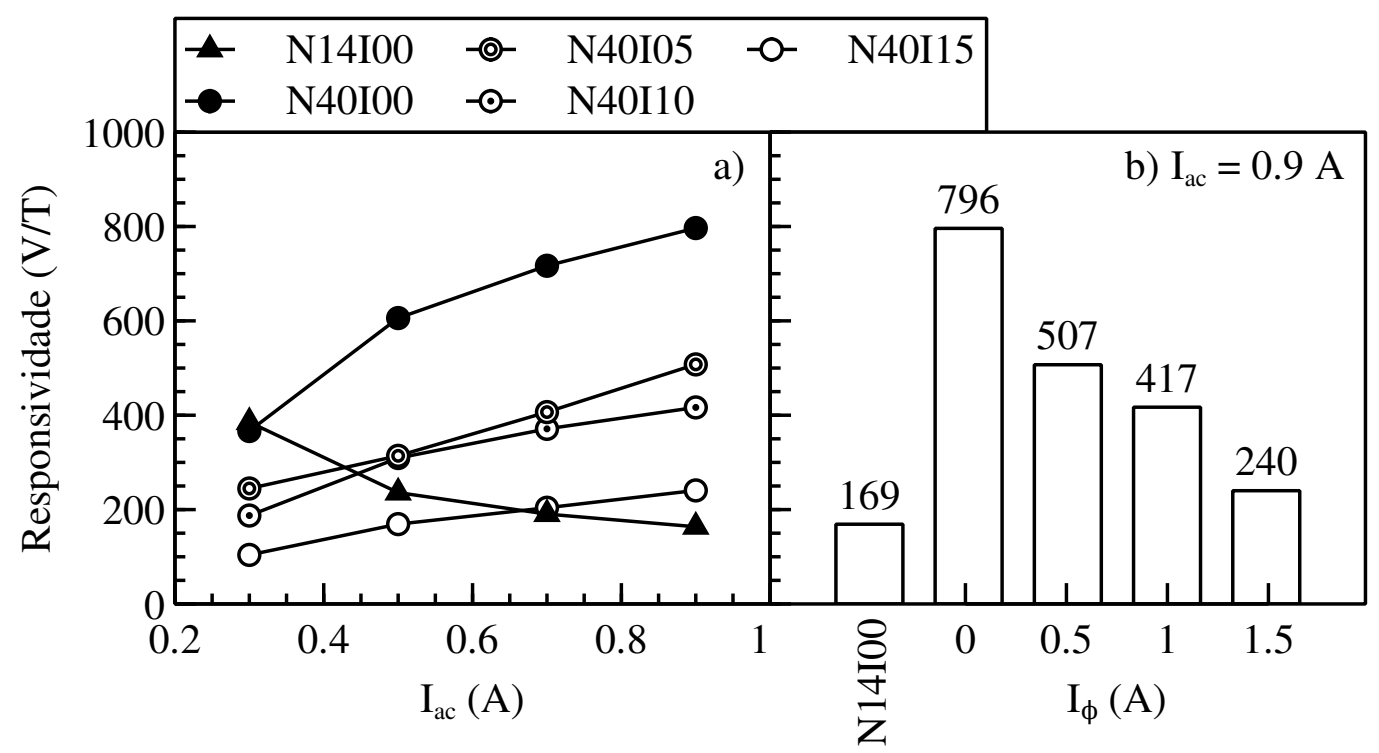

Figura 3.11.1 - Responsividade dos sensores do grupo A para o modo de operação convencional. (a) Valores da responsividade em função da amplitude da corrente de excitação variável. (b) Valores de referência em função da corrente passada pelo fio durante a eletrodeposição. 
Quando aplicada a corrente constante $I_{d c}$ a responsividade dos sensores foi reduzida (figura 3.11.2), como o previsto nas simulações numéricas. Mesmo assim os valores, especialmente para a amostra N40I00, são altos. Já o sensor N14I00 apresentou a menor responsividade. Desta vez o ganho proporcional foi de quase 20 vezes quando a densidade de corrente passou de 14 para $40 \mathrm{~mA} / \mathrm{cm}^{2}$. Novamente a corrente $I_{\phi}$ teve um efeito negativo na responsividade. $O$ formato da curva da figura 3.11.2b mostra que os sensores deste grupo estão operando perto do máximo na responsividade descrito na figura 3.10.2 e relativamente longe do modo permanentemente saturado.

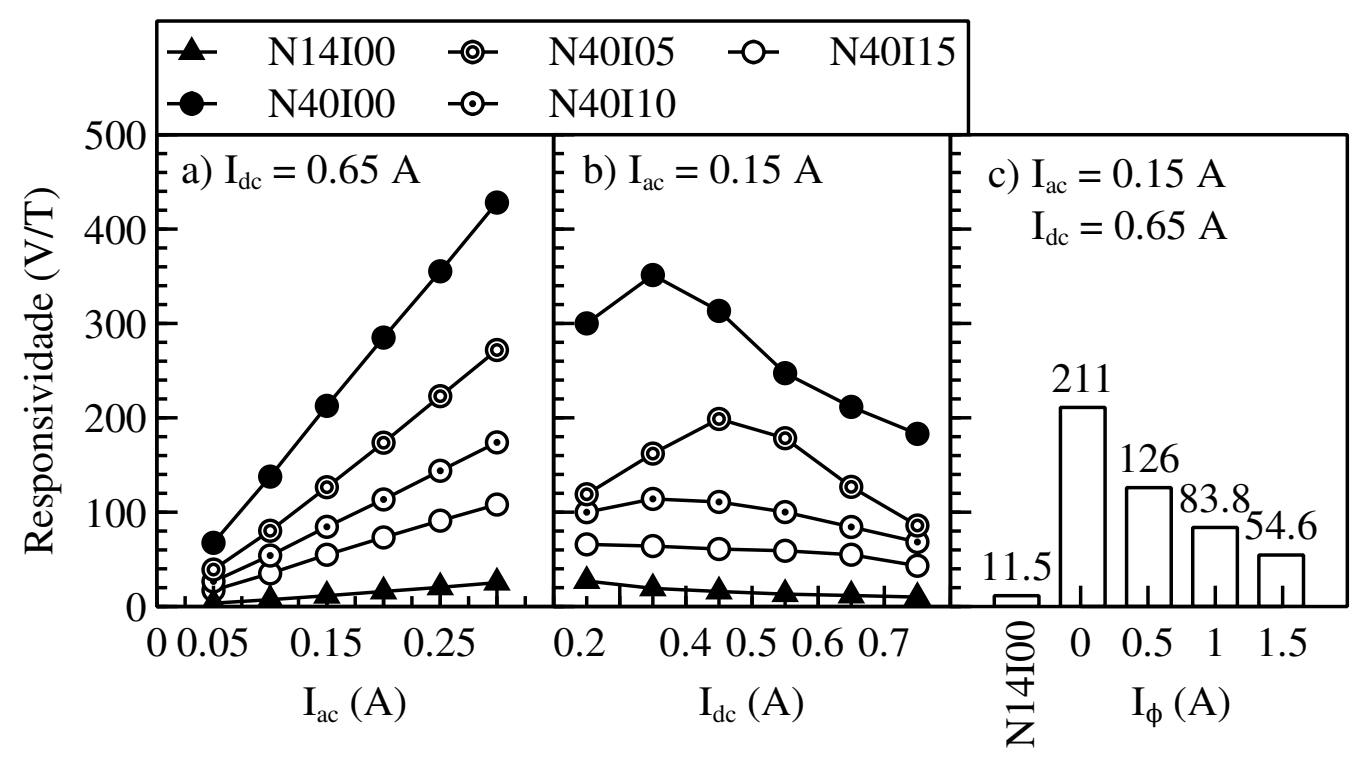

Figura 3.11.2 - Responsividade dos sensores do grupo A com a aplicação de $H_{d c}$. Valores de responsividade em função de (a) amplitude da corrente de excitação contínua e (b) amplitude da corrente de excitação variável. (c) Valores de referência em função da corrente passada pelo fio durante a eletrodeposição. 


\subsubsection{Efeito perming}

No modo convencional os sensores do grupo A apresentaram um deslocamento máximo no nível base de sua saída na faixa de $2 \mu \mathrm{T}$ para uma excitação de 0,9 A. De forma geral há pouca variação entre as amostras, como pode ser visto na figura 3.11.3. Como era esperado, a elevação da corrente de excitação reduziu o efeito perming, principalmente para valores baixos.

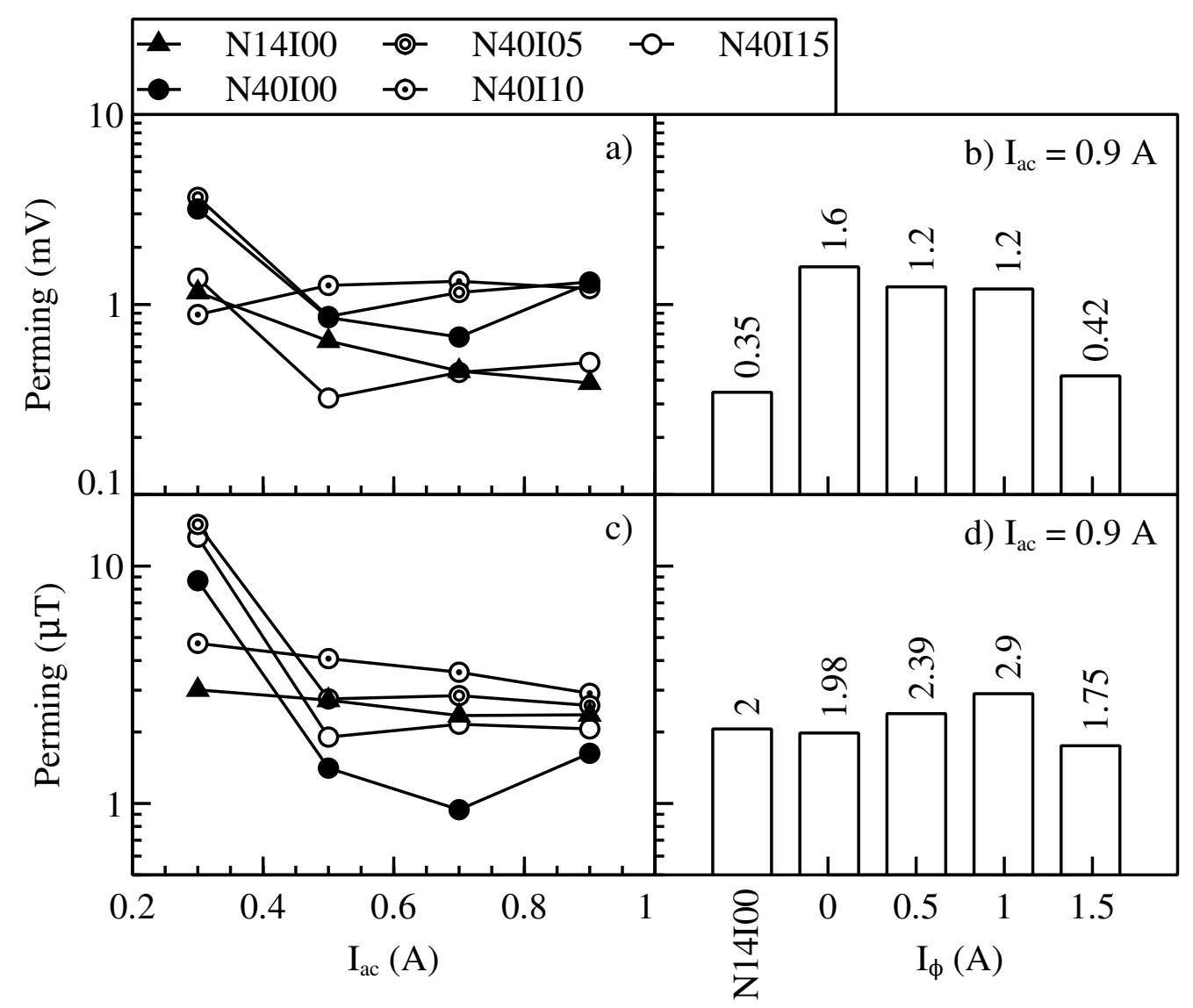

Figura 3.11.3 - Efeito perming para os sensores do grupo A operados no modo convencional. Valores de perming não normalizados (a) e normalizados (c) em função amplitude da corrente de excitação variável. Valores de referência não normalizado (b) e normalizado (d) em função da corrente passada pelo fio durante a eletrodeposição. 
A adição do campo de excitação constante aumentou significativamente o efeito, como mostra a figura 3.11.4. Agora têm-se valores de dezenas de $\mu \mathrm{T}$. Maiores correntes $I_{a c}$ reduzem o perming, muito em consequência do ganho de responsividade, já que para os valores não normalizados o comportamento é inverso. Também o aumento da corrente $I_{d c}$ reduz o efeito para a maioria dos sensores, mas a perda de responsividade associada atenua este ganho. Embora o sensor N14I00 tenha apresentado os menores valores absolutos (em V), quando normalizado passou a ser o dispositivo com piores resultados. A corrente $I_{\phi}$ foi responsável por um aumento considerável no perming, mas para $I_{\phi}=1,5 \mathrm{~A}$ o valor original foi restaurado.

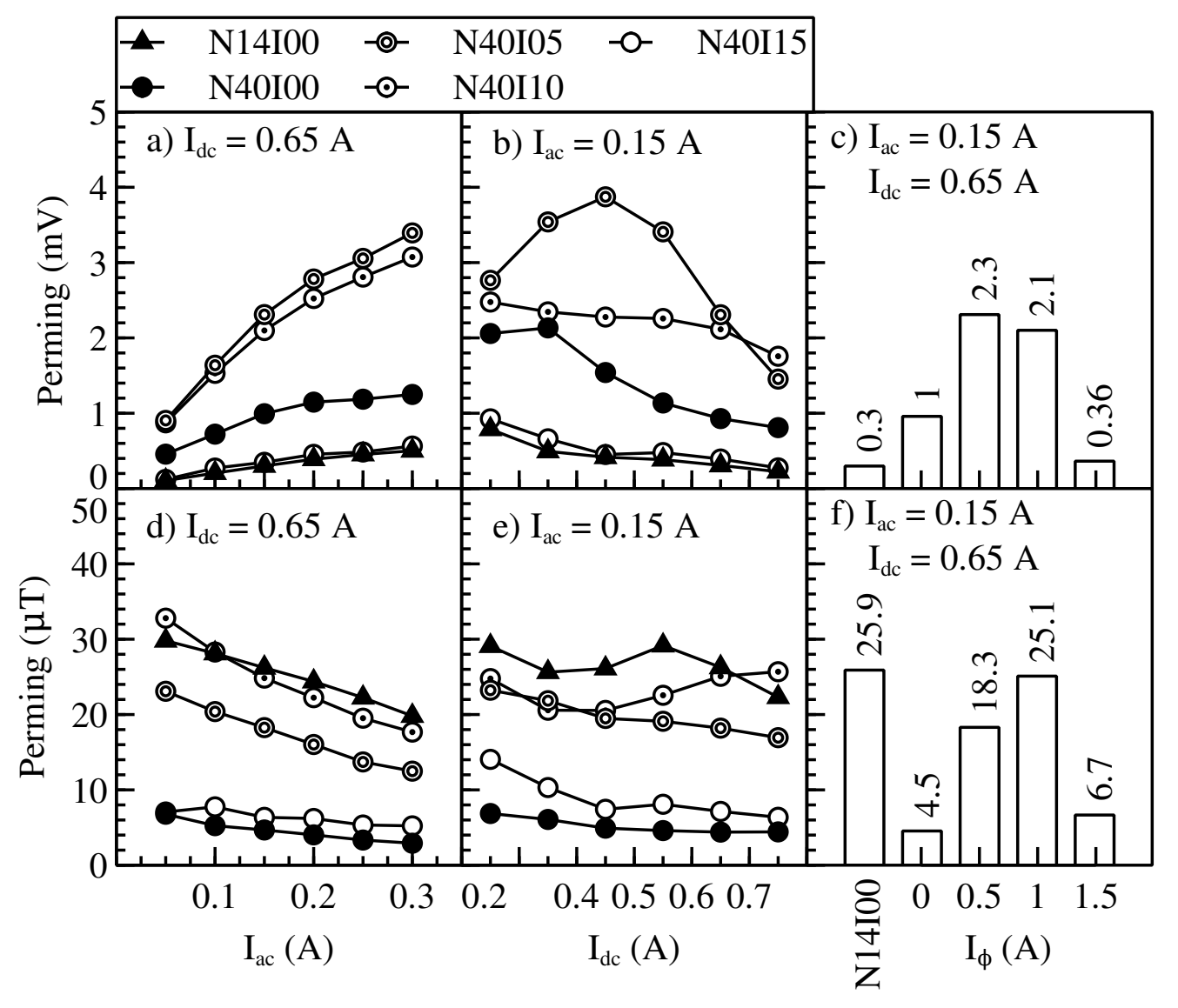

Figura 3.11.4 - Efeito perming para os sensores do grupo A com a aplicação de $H_{d c}$. Valores de perming não normalizados (a) e normalizados (d) em função amplitude da corrente de excitação variável. Valores de perming não normalizados (b) e normalizados (e) em função amplitude da corrente de excitação contínua. Valor de referência não normalizado (c) e normalizado (f) em função da corrente passada pelo fio durante a eletrodeposição. 


\subsubsection{Ruído}

No modo convencional o ruído dos sensores do grupo A atingiram valores mínimos na casa dos $10 \mu \mathrm{T}$ para as melhores amostras, N40I00 e N40I05. Por outro lado N14I00 e N40I15 apresentaram valores superiores a $50 \mu \mathrm{T}$. Não é possível, pelas medidas mostradas na figura 3.11.5, atribuir uma redução no ruído com o aumento de $I_{a c}$ como o esperado. Pode-se ver, entretanto, seu aumento quando foi aplicada a corrente $I_{\phi}=1$ e $1,5 \mathrm{~A}$.

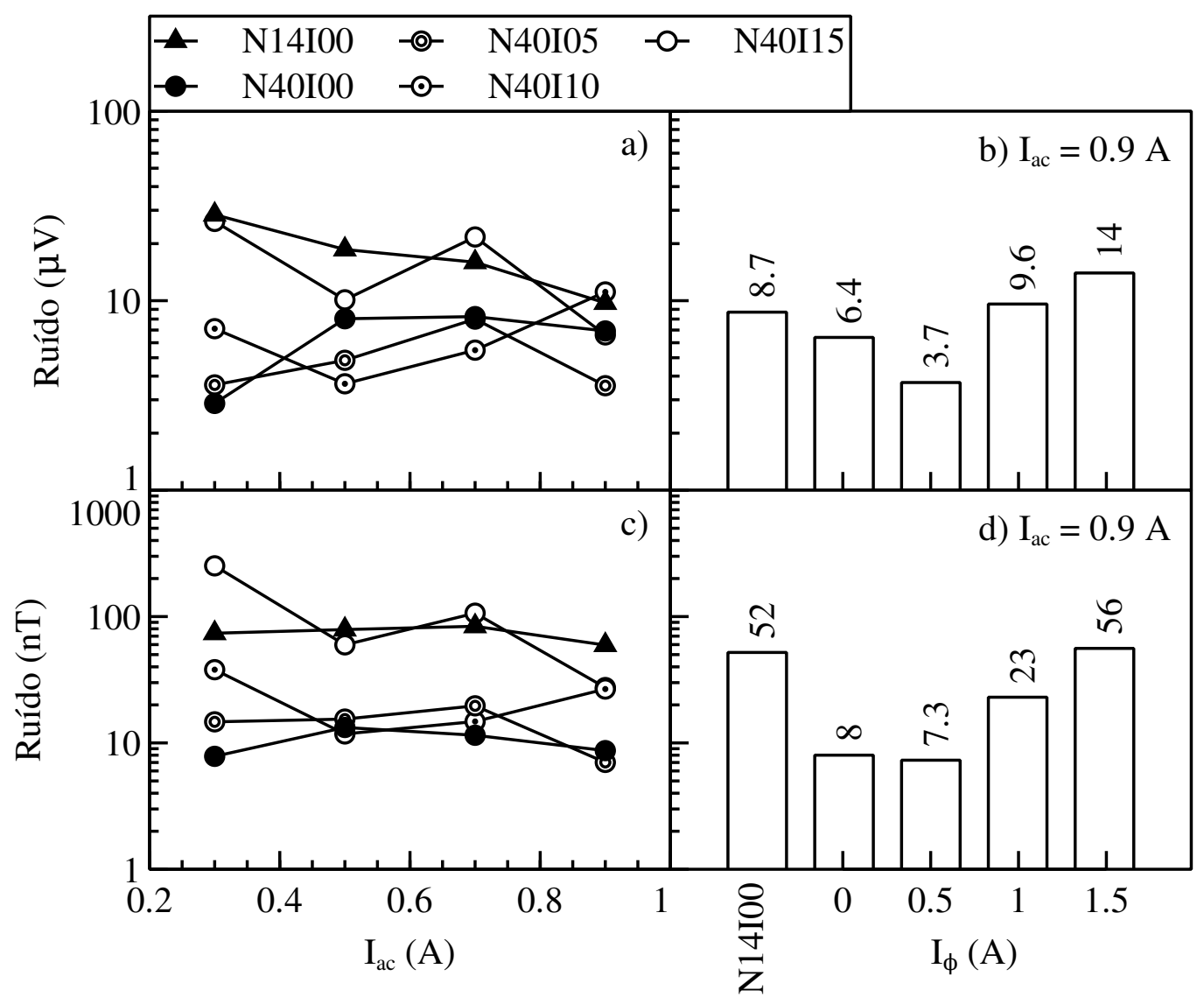

Figura 3.11.5 - Ruído rms presente na faixa de 0,1 a $10 \mathrm{~Hz}$ gerado pelos sensores do grupo A operados no modo convencional. Valores de ruído não normalizados (a) e normalizado (c) em função amplitude da corrente de excitação variável. Valor de referência não normalizado (b) e normalizado (d) em função da corrente passada pelo fio durante a eletrodeposição. 
Houve uma considerável redução dos níveis de ruído para todos os sensores do grupo A quando aplicado o campo $H_{d c}$, como mostra a figura 3.11.6. N40I00 obteve os melhores resultados com valores tão baixos quanto $0,3 \mathrm{nT} r m s$, e $0,55 \mathrm{nT} r m s$ para o valor de referência dos parâmetros. Por outro lado, a amostra N14I00 apresentou os maiores níveis, quase duas ordens de grandeza acima. $\mathrm{O}$ aumento da densidade de corrente na eletrodeposição de 14 para $40 \mathrm{~mA} / \mathrm{cm}^{2}$ melhora esta característica dos sensores, o oposto do que ocorre com a corrente $I_{\phi}$.

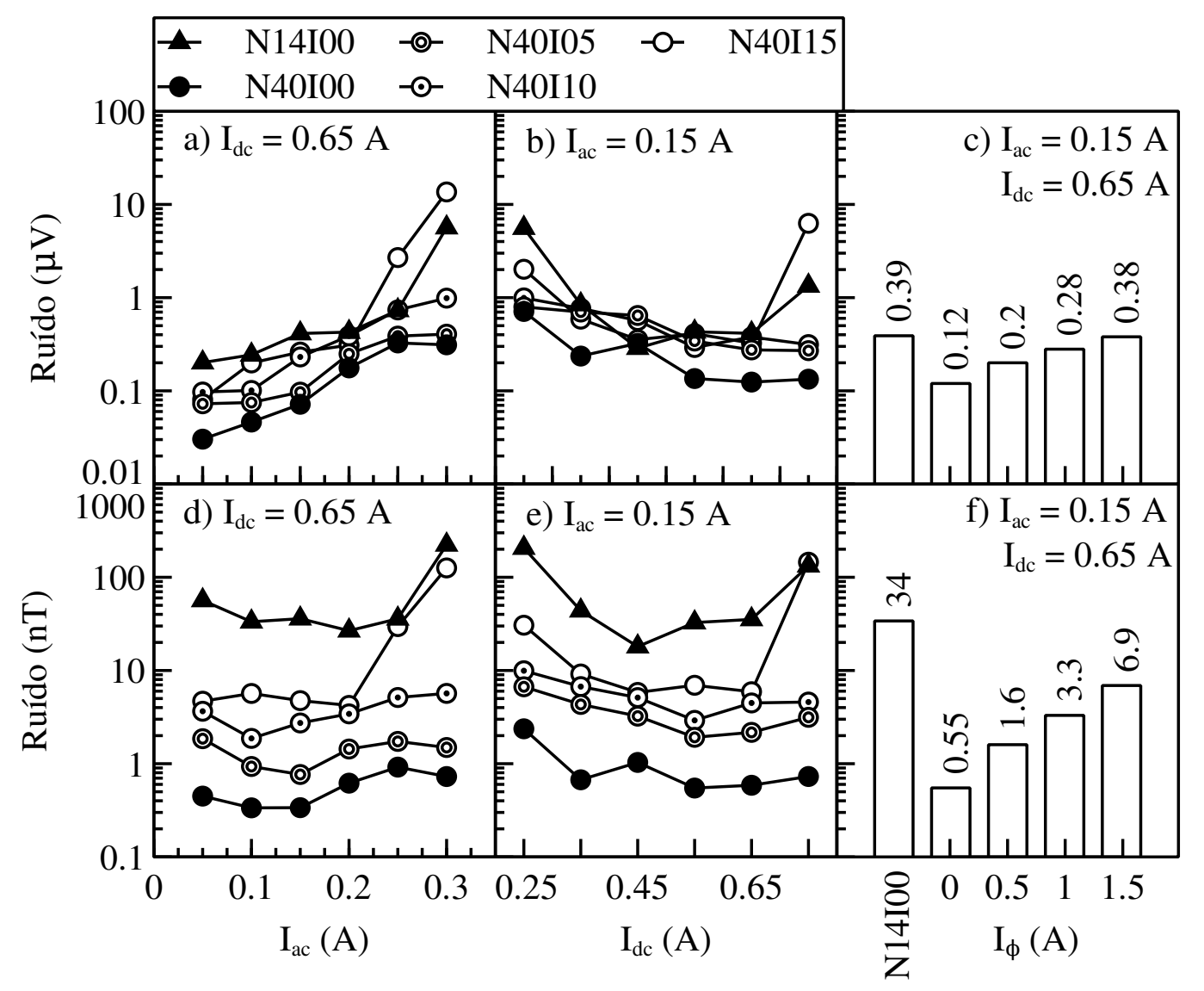

Figura 3.11.6 - Ruído rms presente na faixa de 0,1 a $10 \mathrm{~Hz}$ gerado pelos sensores do grupo A com a aplicação de $H_{d c}$. Valores de ruído não normalizados (a) e normalizadoa (d) em função amplitude da corrente de excitação variável. Valores de ruído não normalizados (b) e normalizado (e) em função amplitude da corrente de excitação contínua. Valor de referência não normalizado (c) e normalizado (f) em função da corrente passada pelo fio durante a eletrodeposição. 


\subsubsection{Grupo B}

\subsubsection{Responsividade}

O deslocamento do máximo da responsividade para maiores $I_{a c}$ com o aumento de $\rho_{d}$ também pode ser vista no caso dos sensores do grupo B (figura 3.11.7a).

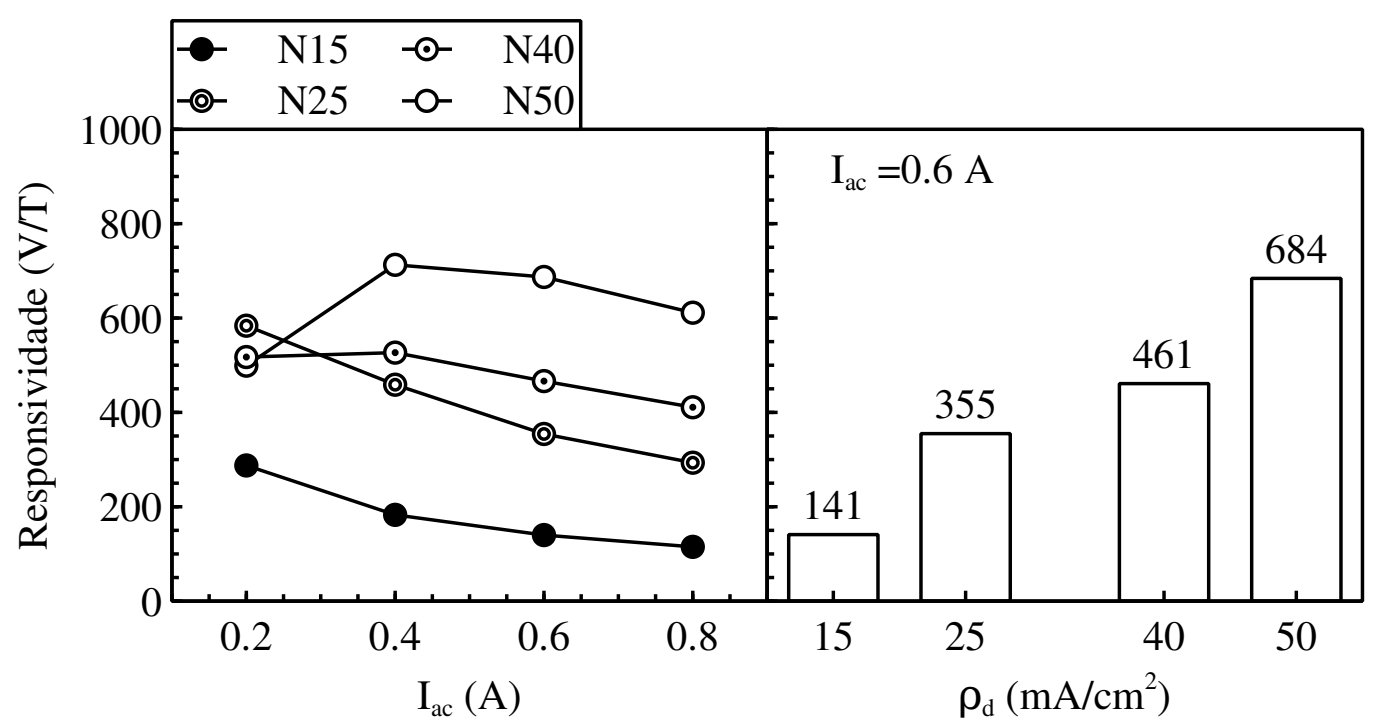

Figura 3.11.7 - Responsividade dos sensores do grupo B para o modo de operação convencional. (a) Valores da responsividade em função da amplitude da corrente de excitação variável. (b) Valores de referência em função da densidade de corrente utilizada na eletrodeposição.

Note que, devido a mudança do diâmetro do núcleo, a relação entre o campo e corrente de excitação aumentou. Mudou também a dinâmica da eletrodeposição, e um valor de $\rho_{d}$ para fios de cobre de $45 \mu \mathrm{m}$ corresponde a um valor menor para os de $120 \mu \mathrm{m}$. Desta forma mesmo o $\mathrm{N} 50$, com $\rho_{d}=50 \mathrm{~mA} / \mathrm{cm}^{2}$, já apresenta uma inclinação negativa para 0,8 A. A figura 3.11.8a mostra o comportamento calculado para os extremos de $\rho_{d}$, onde aparece o deslocamento do máximo e também a perda de responsividade. Quando fixado $I_{a c}$ em 0,6 A vê-se esta dependência positiva da responsividade com a densidade de corrente na eletrodeposição (figura 3.11.7b), correlacionada com o aumento da concentração de Ni no filme. 


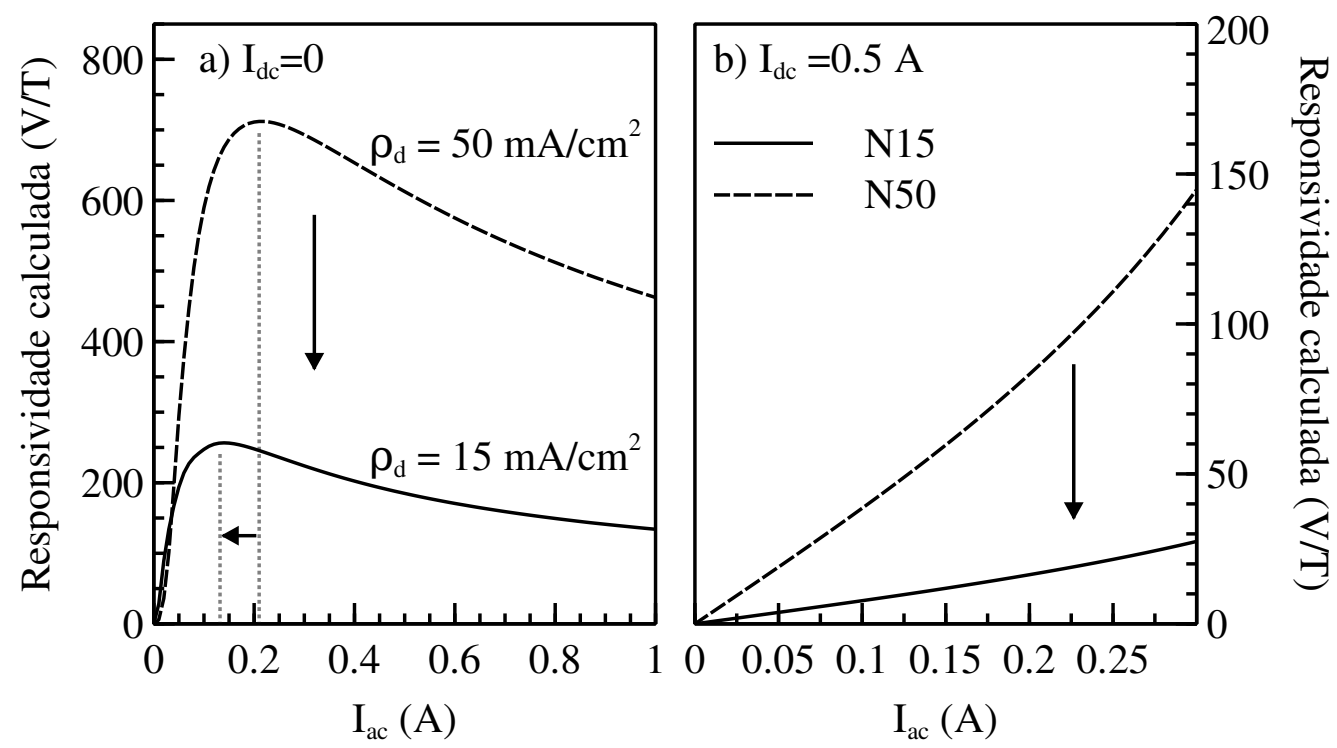

Figura 3.11.8 - Responsividade calculada para os sensores N50 e N15 pela equação 1.6.10.

Novamente os valores absolutos da responsividade são altos para as dimensões dos sensores. Note que embora as dimensões do núcleo tenham diminuído em relação aos sensores do grupo A, o volume foi mantido e o número de espiras passou de 150 para 200. 
As curvas de responsividade destes sensores operados com o deslocamento da excitação (3.11.9) reproduzem bem o comportamento previsto pelos modelos matemáticos mostrados na seção 3.10. Entretanto somente a amostra N50 é bem descrita pela permeabilidade de saturação, utilizando a equação 3.4.20. Quanto menor o valor de $\rho_{d}$ mais afastadas as medidas estão dos valores previstos por esta. Não pode-se explicar a queda de responsividade observada somente pela mudança da magnetização de saturação (listadas na figura 3.8.7). Considere que para a geometria dos sensores tem-se uma média de $H_{d c}=1,6 \mathrm{kA} / \mathrm{m}$ para $0,6 \mathrm{~A}$, que claramente não satura as amostras como mostra as curvas de magnetização da figura 3.8.5. Mais do que os valores de $M_{s a t}$ e $H_{s a t}$, a responsividade depende do grau de saturação do filme, que na região de operação, cresce com o aumento de $\rho_{d}$. Isto pode ser visto na figura 3.11.8b.

Na figura 3.11.9b é possível ver a aproximação entre os pontos experimentais e a curva prevista pelo modelo matemático a medida que $I_{d c}$ aumenta. Para valores altos tem-se uma virtual coincidência. Levando em conta as aproximações feitas no cálculo de $H_{\text {exc }}$ (seção 3.10) a concordância com a previsão teórica é, até certo ponto, surpreendente.

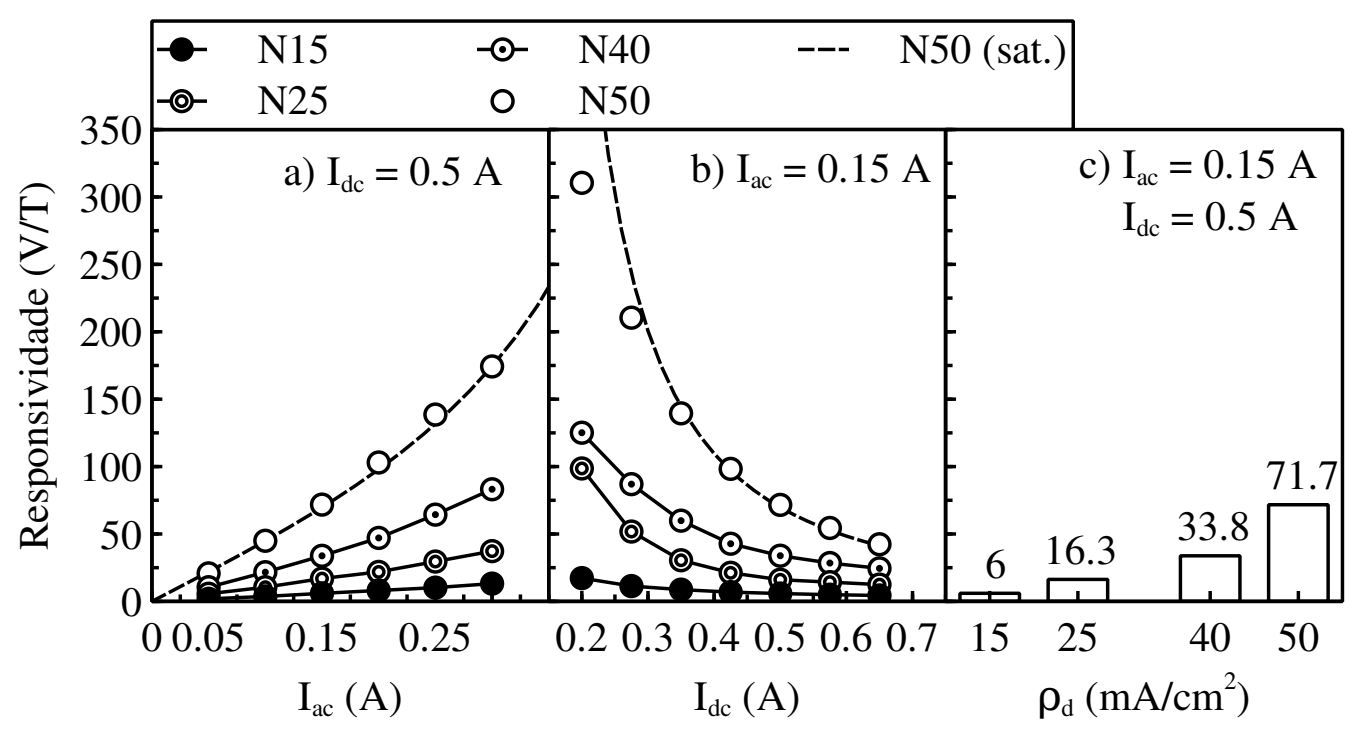

Figura 3.11.9 - Responsividade dos sensores do grupo B com a aplicação de $H_{d c}$. Adicionalmente tem-se as curva de responsividade calculada numericamente utilizando a equação $3.4 .20 \mathrm{com} M_{\text {sat }}=800 \mathrm{kA} / \mathrm{m}, D_{1}=0,0001, D_{2}=0$ e uma relação entre corrente de excitação e campo gerado de $2,65 \mathrm{kA} / \mathrm{m}$ por A. Valores de responsividade em função de (a) amplitude da corrente de excitação contínua e (b) amplitude da corrente de excitação variável. (c) Valores de referência em função da densidade de corrente utilizada na eletrodeposição. 


\subsubsection{Perming}

As medidas do efeito perming para os sensores do grupo B operados no modo convencional estão mostradas na figura 3.11.10. Pode-se ver a redução neste parâmetro com o aumento da amplitude de excitação, especialmente para N15. Para os valores normalizados, esta amostra apresentou o maior deslocamento da linha base da saída, com valor de referência de 12,4 $\mu \mathrm{m}$ enquanto que os outros obtiveram valores na casa dos $5 \mu \mathrm{m}$. Novamente a aproximação da liga para o ponto de maior permeabilidade magnética, $\mathrm{Ni}_{80} \mathrm{Fe}_{20}$, melhorou as características do sensor.

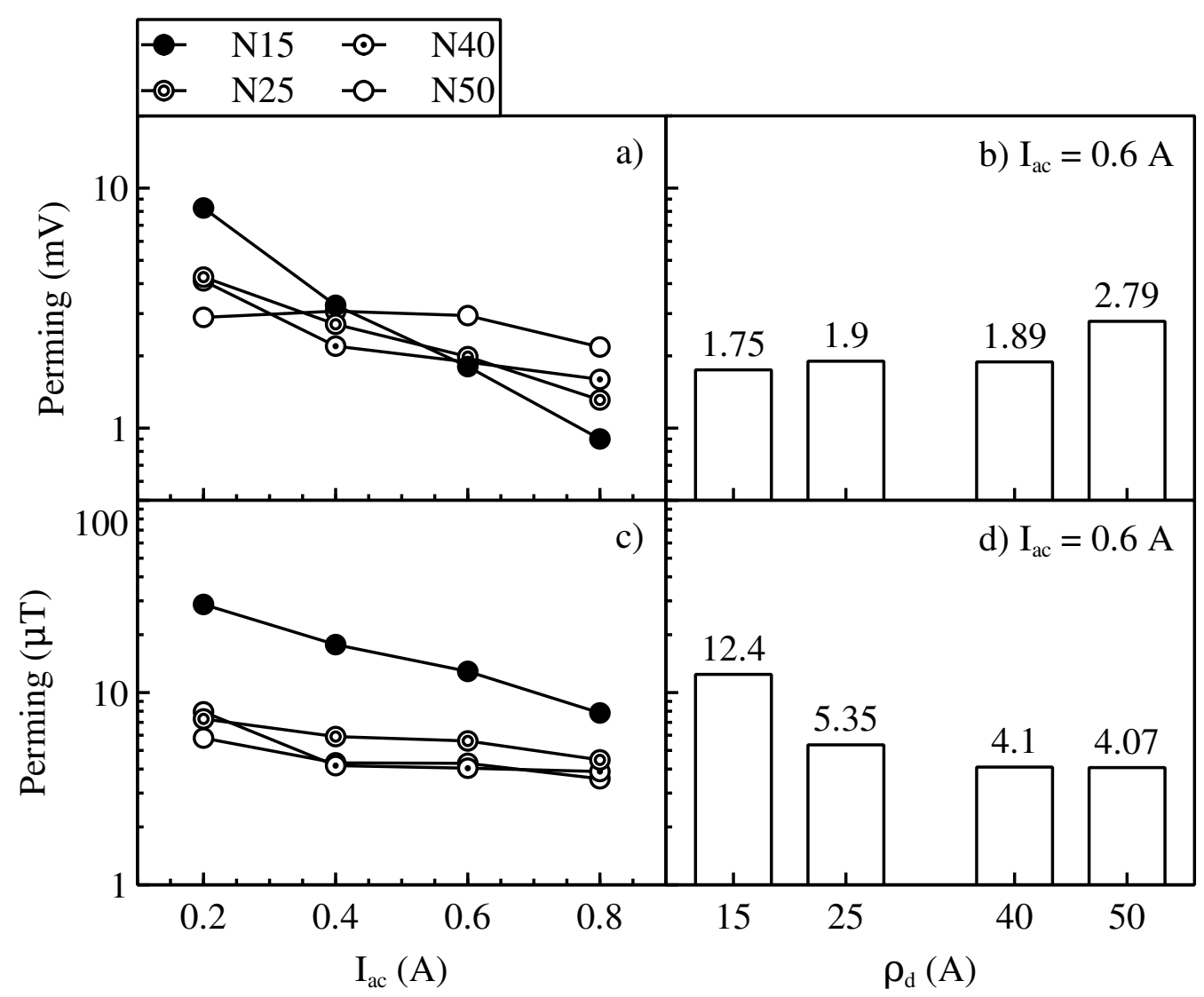

Figura 3.11.10 - Efeito perming para os sensores do grupo B operados no modo convencional. Valores de perming não normalizados (a) e normalizados (c) em função amplitude da corrente de excitação variável. Valores de referência não normalizado (b) e normalizado (d) em função da densidade de corrente utilizada na eletrodeposição. 
Assim como nos sensores do grupo A, a aplicação da componente constante nos sensores aumenta a amplitude do efeito perming. Além disto, manteve-se as tendências de redução dos valores normalizados com o aumento de $I_{a c}$ e $I_{d c}$, como pode ser visto na figura 3.11.11. A normalização reverteu o comportamento crescente do efeito perming em relação à $\rho_{d}$ para os valores de referência. Novamente a amostra N50 obteve os melhores valores do ponto de vista de um sensor magnético.

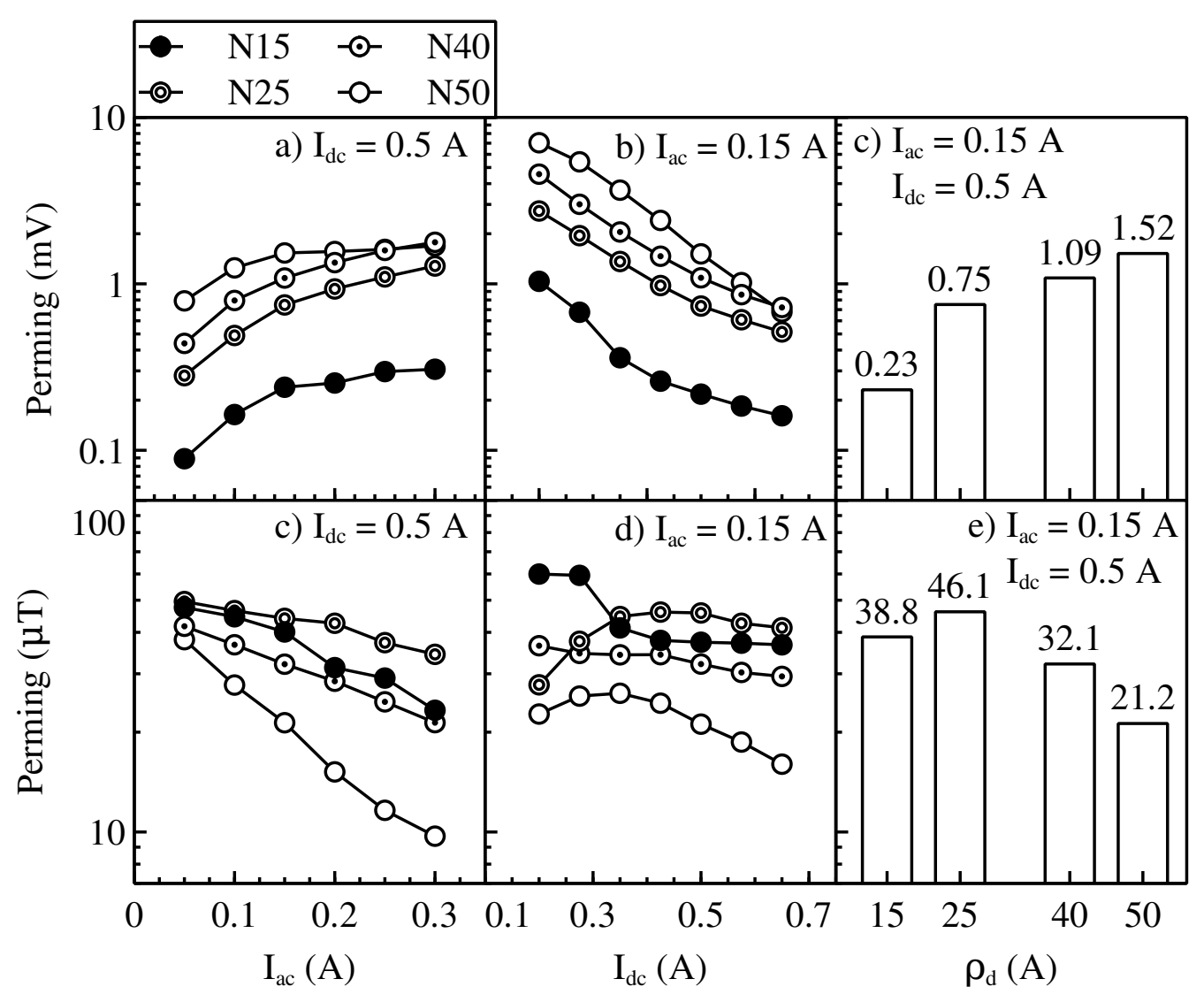

Figura 3.11.11 - Efeito perming para os sensores do grupo B com a aplicação de $H_{d c}$. Valores de perming não normalizados (a) e normalizados (d) em função amplitude da corrente de excitação variável. Valores de perming não normalizados (b) e normalizado (e) em função amplitude da corrente de excitação contínua. Valor de referência não normalizado (c) e normalizado (f) em função da densidade de corrente utilizada na eletrodeposição. 


\subsubsection{Ruído}

No modo de operação convencional os sensores do grupo B apresentaram ruído mínimo na casa de $10 \mathrm{nT} \mathrm{rms}$, atingido pelas amostras eletrodepositadas com maior densidade de corrente. De maneira geral o aumento da amplitude de excitação diminuiu as flutuações até 0,6 A voltando a subir para $0,8 \mathrm{~A}$.

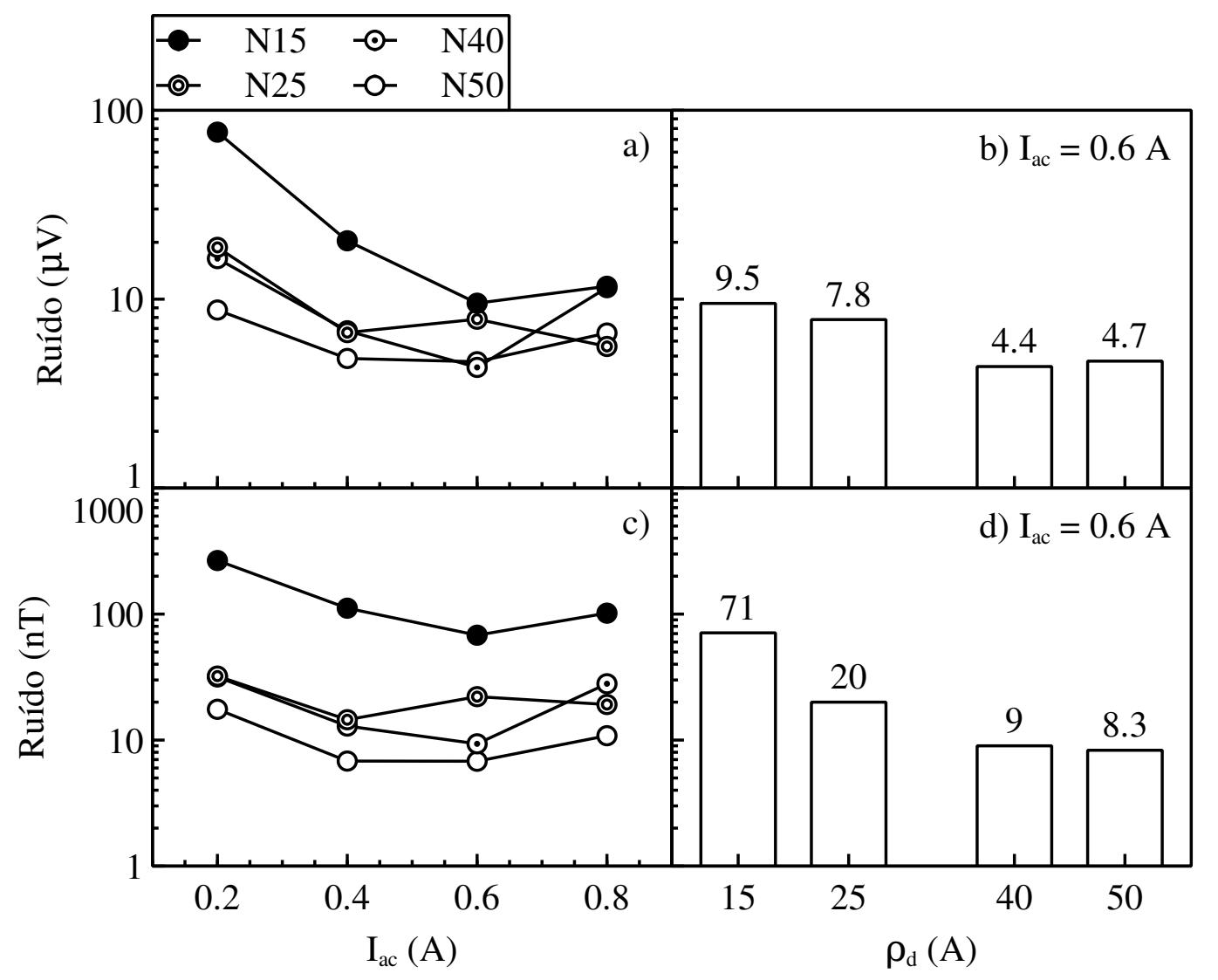

Figura 3.11.12 - Ruído rms presente na faixa de 0,1 a $10 \mathrm{~Hz}$ gerado pelos sensores do grupo B operados no modo convencional. Valores de ruído não normalizados (a) e normalizado (c) em função amplitude da corrente de excitação variável. Valor de referência não normalizado (b) e normalizado (d) em função da densidade de corrente utilizada na eletrodeposição. 
O ruído foi atenuado pela adição da componente constante na excitação, como mostra a figura 3.11.21. Valores tão baixo quanto $1 \mathrm{nT} r m s$ foram medidos para o sensor N50. Não normalizados, os níveis de ruído apresentaram uma tendência crescente em função de $I_{a c}$ mas a normalização suprimiu este efeito deixando-os aproximadamente constantes. Exceto pelos picos em $I_{a c}=0,425 \mathrm{~A}$, para as amostras N15 e N25, o ruído não normalizado apresentou uma queda acentuada com o aumento de $I_{d c}$. Já os valores normalizados têm uma tendência de queda consistente somente para N50, amostra com os melhores resultados do grupo.

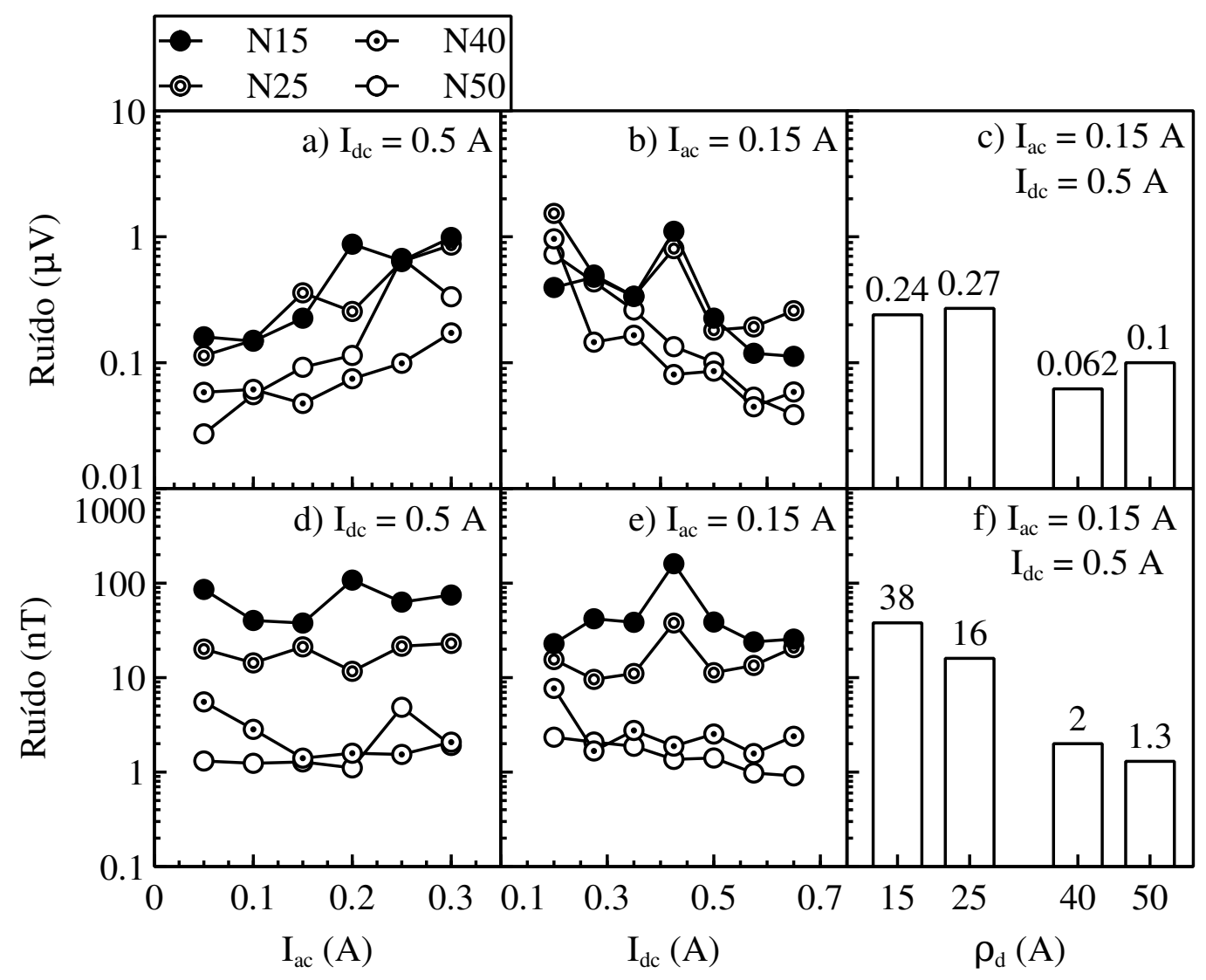

Figura 3.11.13 - Ruído rms presente na faixa de 0,1 a $10 \mathrm{~Hz}$ gerado pelos sensores do grupo B com a aplicação de $H_{d c}$. Valores de ruído não normalizados (a) e normalizados (d) em função amplitude da corrente de excitação variável. Valores de ruído não normalizados (b) e normalizado (e) em função amplitude da corrente de excitação contínua. Valor de referência não normalizado (c) e normalizado (f) em função da densidade de corrente utilizada na eletrodeposição.

Especialmente para o grupo B (exceto N15) foram realizadas as medidas de ruído utilizando o modulador de corrente na tentativa de reduzir o ruído eletrônico. Estas estão mostradas na figura 3.11.14. Embora tenha havido uma redução consistente nos valores obtidos a diferença foi pequena. As menores flutuações destas medidas entretanto, permitem observar melhor a fraca dependência do ruído com as amplitude de excitação. Basicamente o ruído é 
proporcional a responsividade nas faixas analisadas. Uma das fontes de ruído compatíveis com este comportamento são as extremidades do fio, onde foi feito o contato elétrico (veja as figuras 3.6.8 e 3.6.9). Nestes pontos o fio ainda tem a camada externa de NiFe mas a corrente já não flui na direção axial e sim na direção radial, deixando-os sem a excitação necessária para suprimir os saltos de Barkhausen. O ruído causado por estes saltos se propaga pelo comprimento do fio sendo capturado pela bobina coletora [75]. Seria necessário refinar o processo de fabricação de modo a eletrodepositar somente na faixa central do fio de cobre para suprimir este possível efeito.

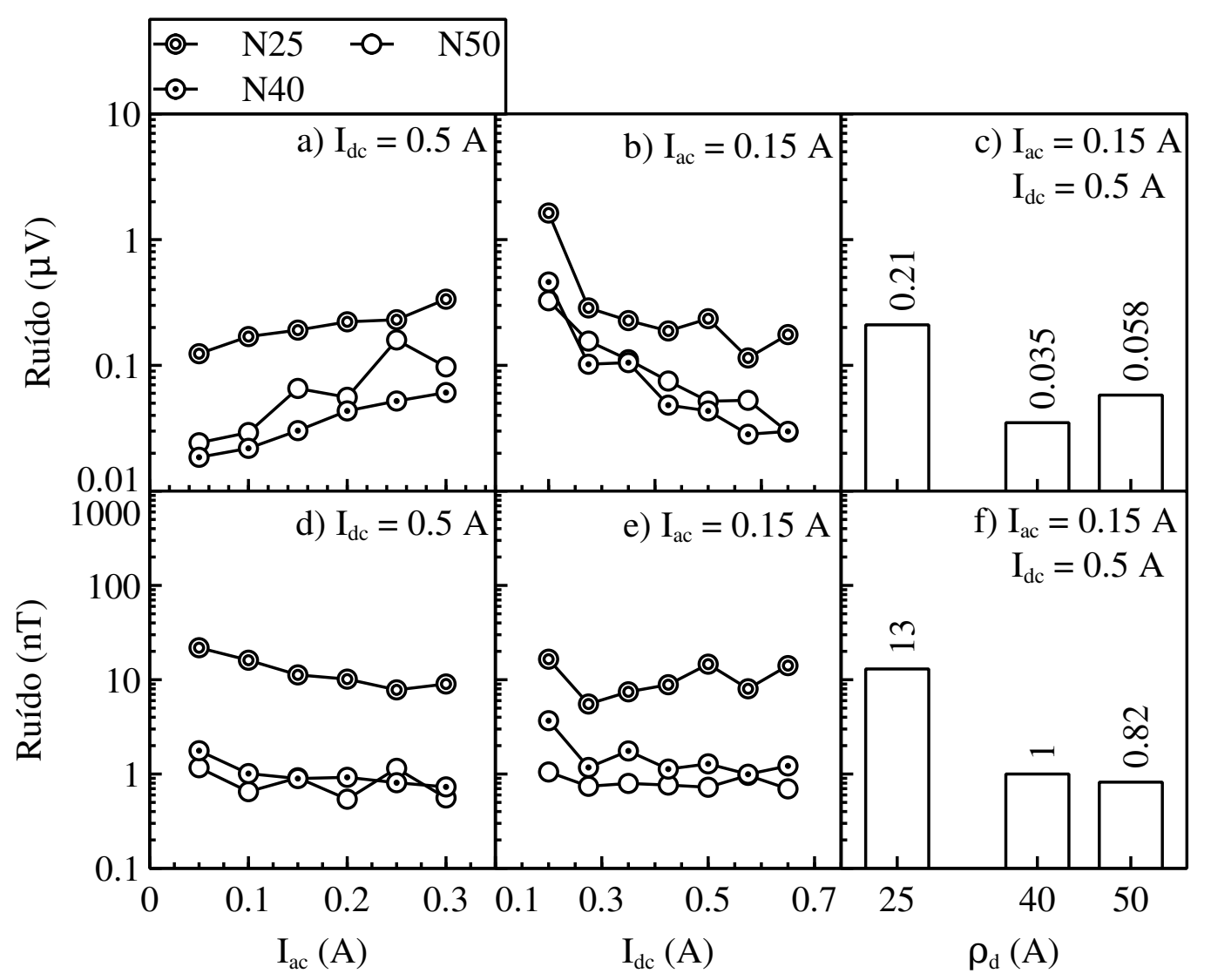

Figura 3.11.14 - Ruído rms presente na faixa de 0,1 a $10 \mathrm{~Hz}$ gerado pelos sensores do grupo B com a aplicação de $H_{d c}$, medido com o modulador de corrente (figura 3.9.11). Valores de ruído não normalizados (a) e normalizados (d) em função amplitude da corrente de excitação variável. Valores de ruído não normalizados (b) e normalizado (e) em função amplitude da corrente de excitação contínua. Valor de referência não normalizado (c) e normalizado (f) em função da densidade de corrente utilizada na eletrodeposição. 


\subsubsection{Grupo C}

\subsubsection{Responsividade}

As curvas de resposta dos sensores com NiFeP, principalmente operados com $H_{d c} \neq 0$, têm forma assimétrica e pouco linear na origem, de maneira que é difícil definir uma responsividade. Veja por exemplo as curvas de resposta do sensor P13 mostradas na figura 3.11.15. Operados no modo convencional o principal problema é a curta região linear, com poucos pontos para se extrair a responsividade. Por outro lado, com a componente contínua na excitação (figura 3.11.15b), a assimetria das medidas em relação a $B_{0}=0$ mostra que o núcleo possui uma forte anisotropia magnética. Utilizou-se apenas os pontos vizinhos a $B_{0}=0$ para o cálculo da responsividade nestes casos. Como será visto, os modelos matemáticos descritos não descrevem bem os resultados por conta da forte anisotropia.

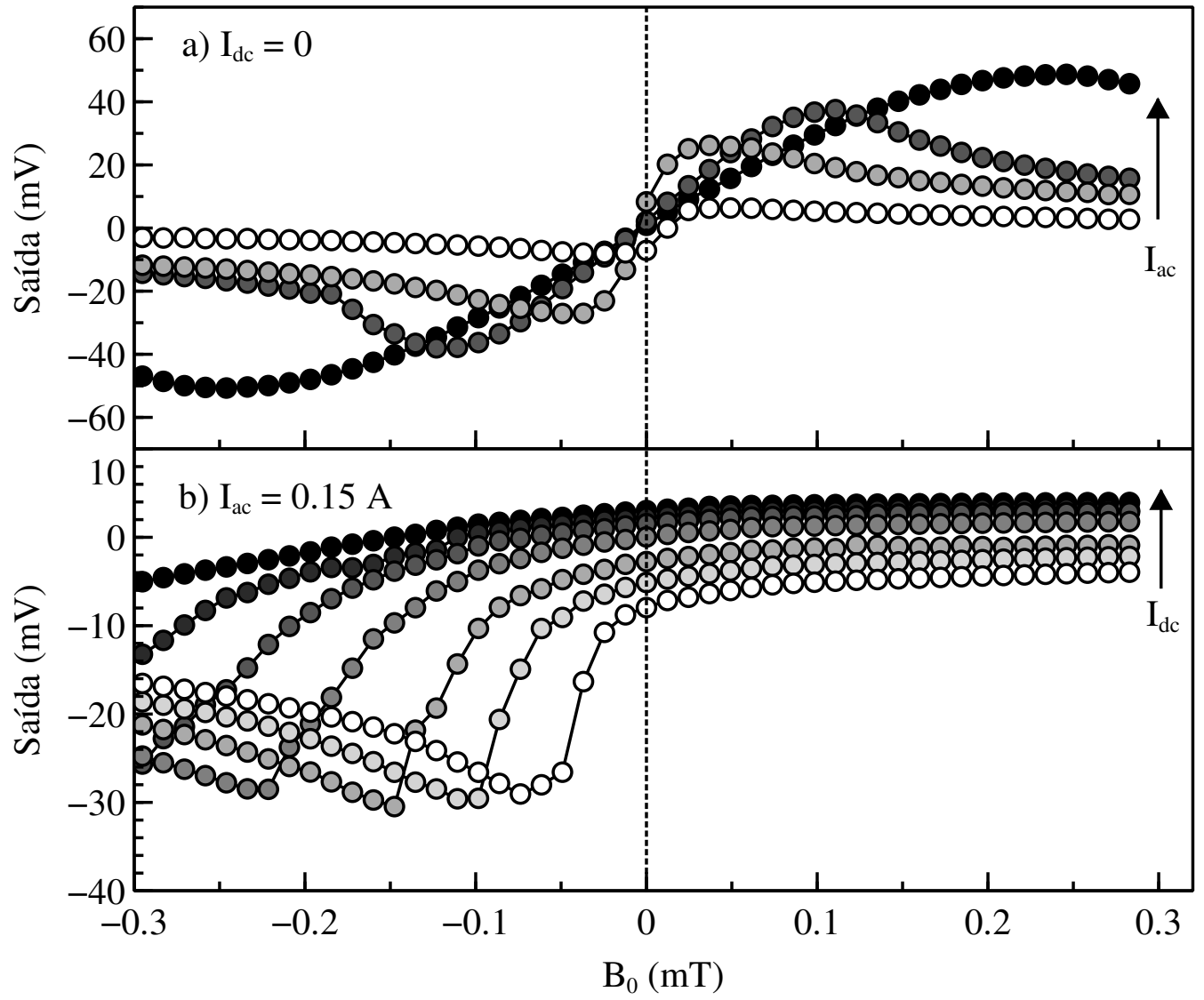

Figura 3.11.15 - Curvas de resposta do sensor P13 exemplificando a baixa quantidade de pontos para se obter a responsividade quando em modo convencional e a falta de simetria obtidas para as amostras do grupo C.

Feitas estas considerações, a responsividade dos sensores do grupo $\mathrm{C}$ apresentaram grande dispersão, variando de 20 a $800 \mathrm{~V} / \mathrm{T}$, como mostra a figura 3.11.16. Estes extremos são para os sensores depositados com densidade de corrente próxima, $\rho_{d}=0,9$ e 1,3 A/cm². Após 
este ganho abrupto inicial, a responsividade diminui de forma mais lenta para densidades maiores. Entretanto a amostra P16 ainda não atingiu o máximo da curva para o valor de referência $\left(I_{a c}=\right.$ $0,6 \mathrm{~A})$.

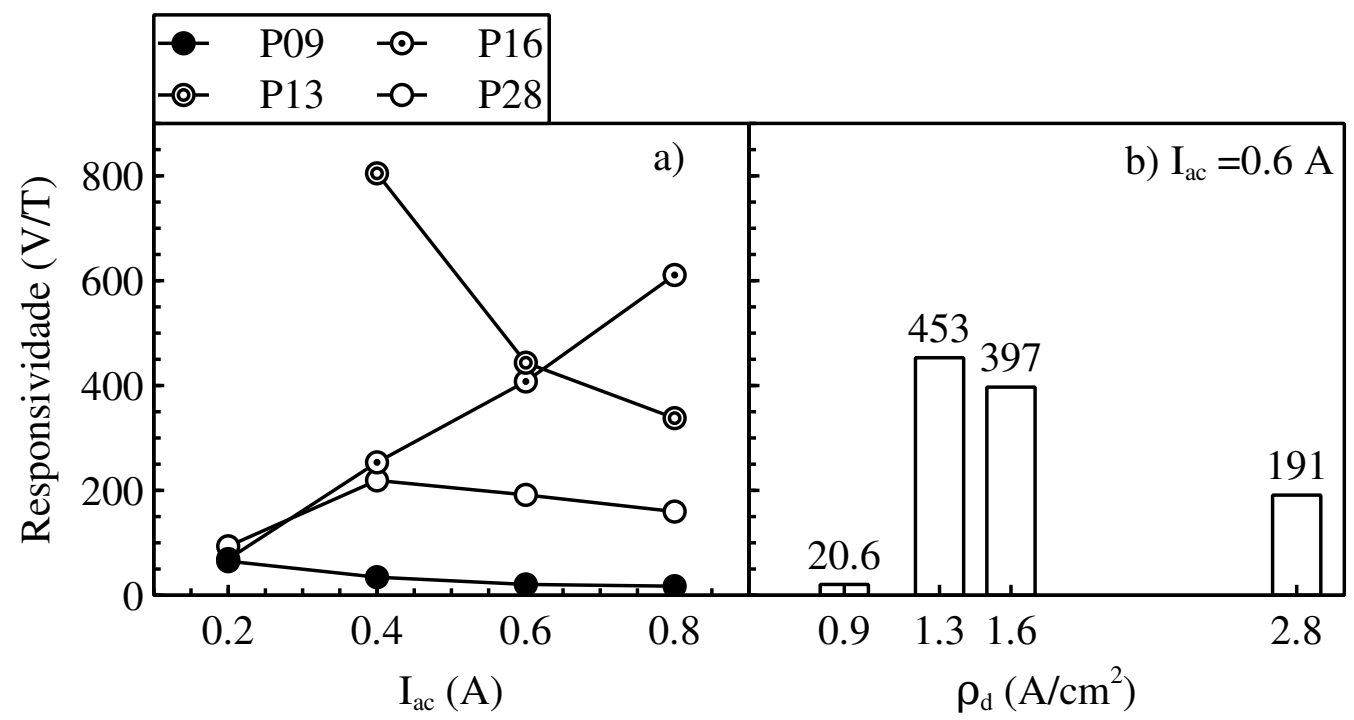

Figura 3.11.16 - Responsividade dos sensores do grupo C para o modo de operação convencional. (a) Valores da responsividade em função da amplitude da corrente de excitação variável. (b) Valores de referência em função da densidade de corrente utilizada na eletrodeposição. 
As posições do P13 e do P16 se invertem quando operados com o deslocamento na excitação (figura 3.11.17), com o segundo atingindo as maiores responsividades. Note entretanto o comportamento anômalo deste quando variado $I_{d c}$.

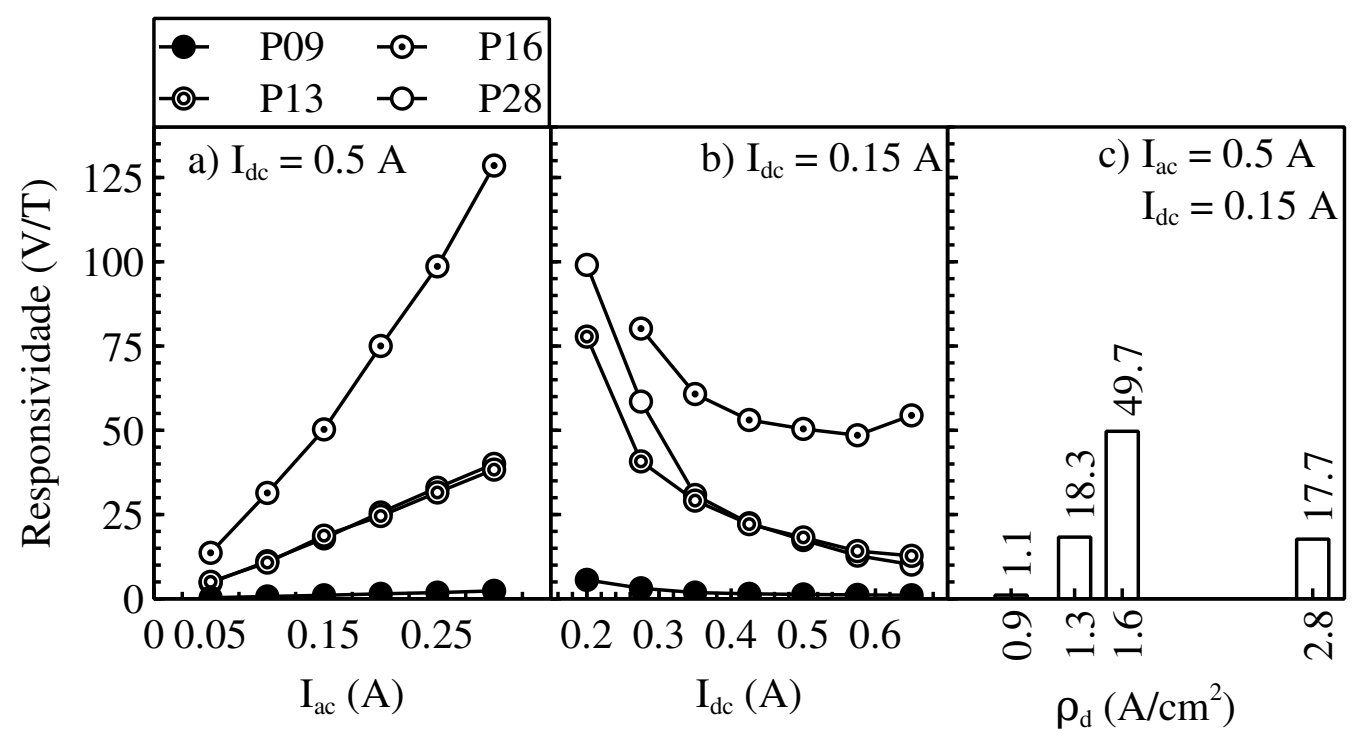

Figura 3.11.17 - Responsividade dos sensores do grupo C com a aplicação de $H_{d c}$. Valores de responsividade em função de (a) amplitude da corrente de excitação contínua e (b) amplitude da corrente de excitação variável. (c) Valores de referência em função da densidade de corrente utilizada na eletrodeposição. 


\subsubsection{Perming}

O efeito perming medido para amostras do grupo $\mathrm{C}$ seguiu, em linhas gerais, os resultados já encontrados para o grupo B. Para os valores de excitação de referência, quando operados no modo ortogonal convencional, obteve-se um deslocamento máximo no nível base dos sensores de alguns poucos $\mu \mathrm{T}$ (figura 3.11.18) que sobem para $\sim 30 \mu \mathrm{T}$ quando $I_{d c} \neq 0$ (figura 3.11.19). Além disto, o aumento de $I_{a c}$ diminui a amplitude normalizada do efeito pelo ganho de responsividade. Por outro lado as amostras mais responsivas, P13 e P16, não se saíram melhores que as outras, como era geralmente o caso para os sensores de NiFe. De fato, P16 obteve os maiores valores de perming para os dois modos de operação.

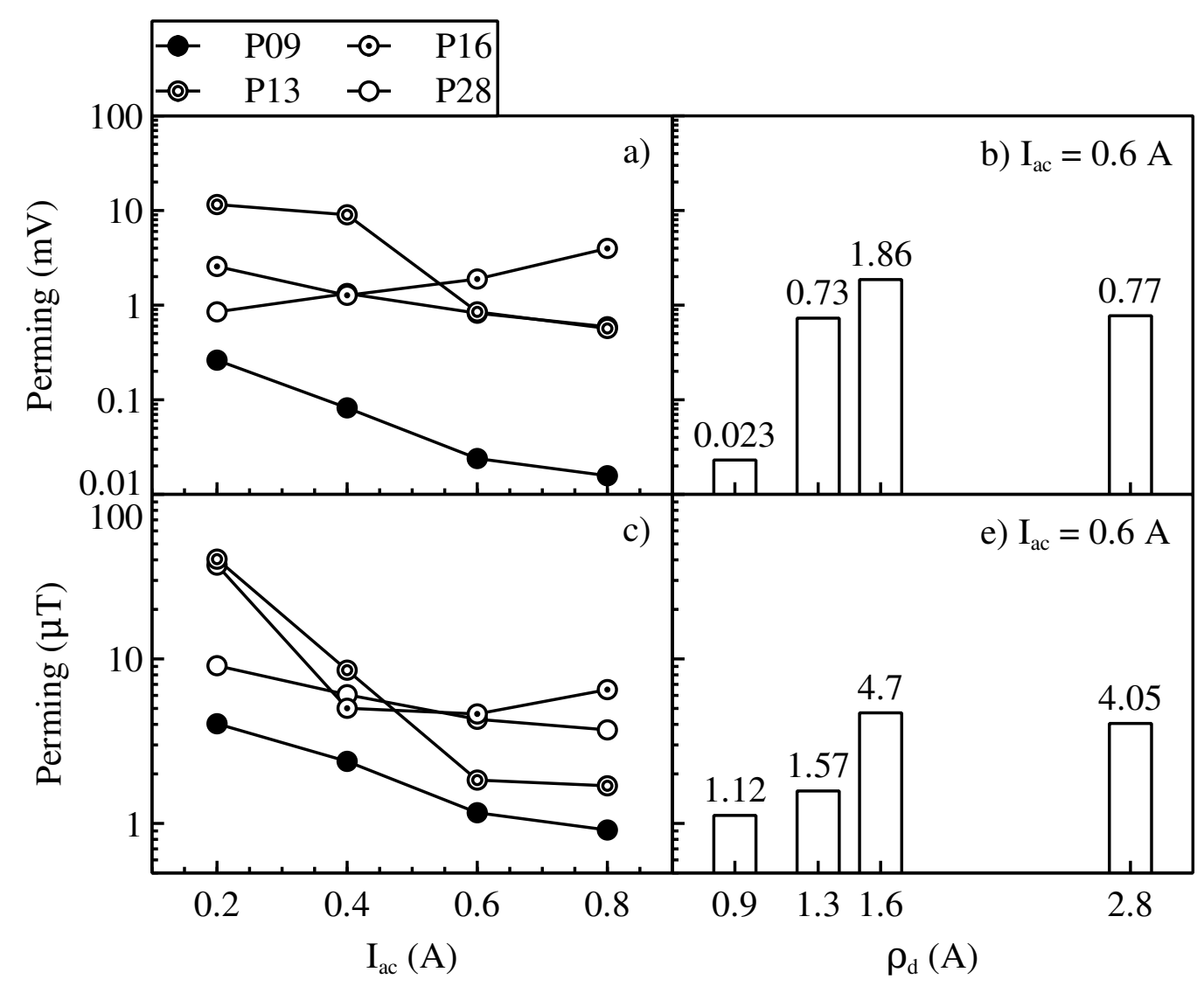

Figura 3.11.18 - Efeito perming para os sensores do grupo C operados no modo convencional. Valores de perming não normalizados (a) e normalizados (c) em função amplitude da corrente de excitação variável. Valores de referência não normalizado (b) e normalizado (d) em função da densidade de corrente utilizada na eletrodeposição. 


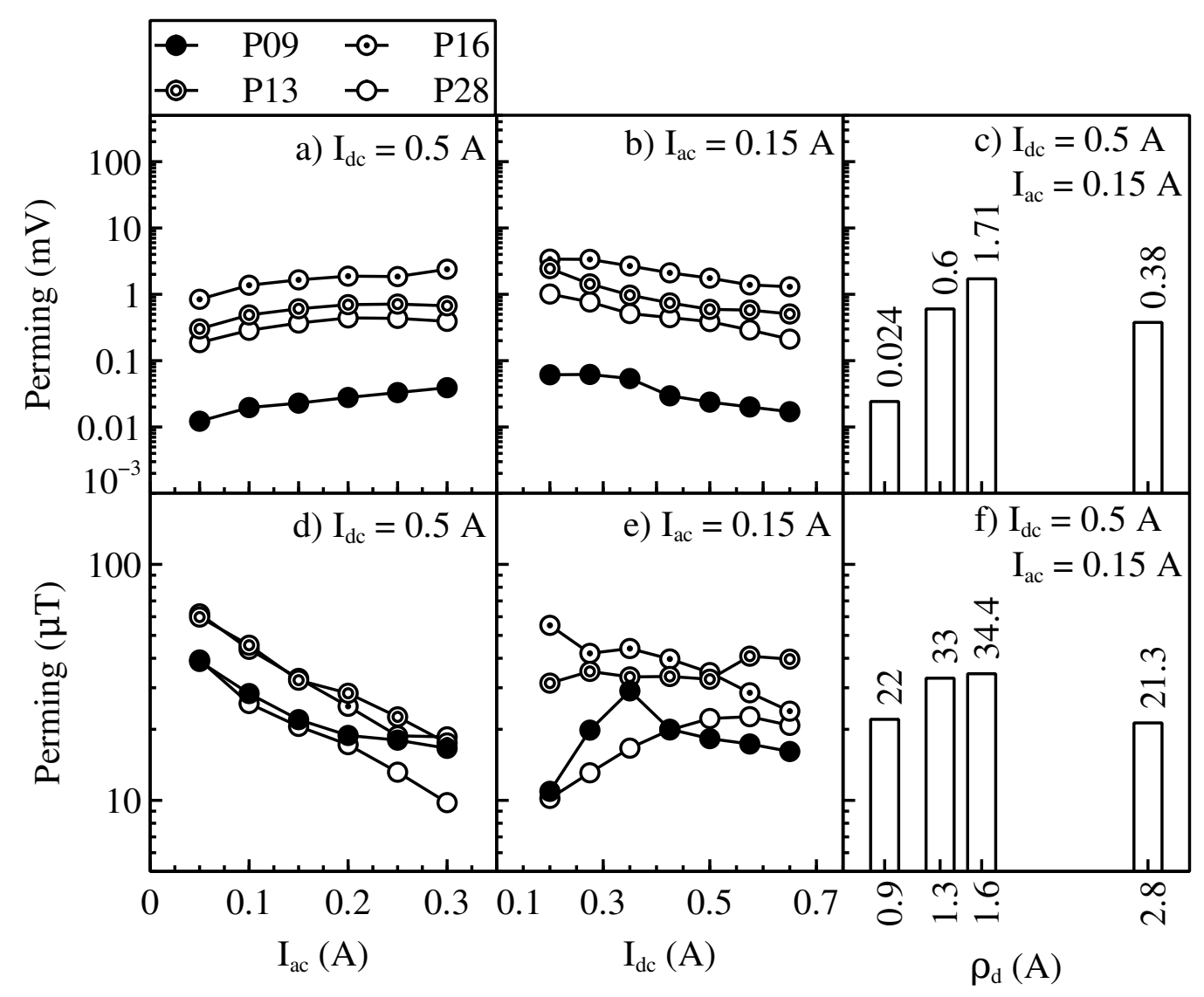

Figura 3.11.19 - Efeito perming para os sensores do grupo C com a aplicação de $H_{d c}$. Valores de perming não normalizados (a) e normalizados (d) em função amplitude da corrente de excitação variável. Valores de perming não normalizados (b) e normalizado (e) em função amplitude da corrente de excitação contínua. Valor de referência não normalizado (c) e normalizado (f) em função da densidade de corrente utilizada na eletrodeposição. 


\subsubsection{Ruído}

Os níveis de ruído dos sensores do grupo C medidos para o modo de operação convencional ficaram bem acima dos outros, como mostra a figura 3.11.20. Também não há uma tendência de redução com o aumento de $I_{a c}$.

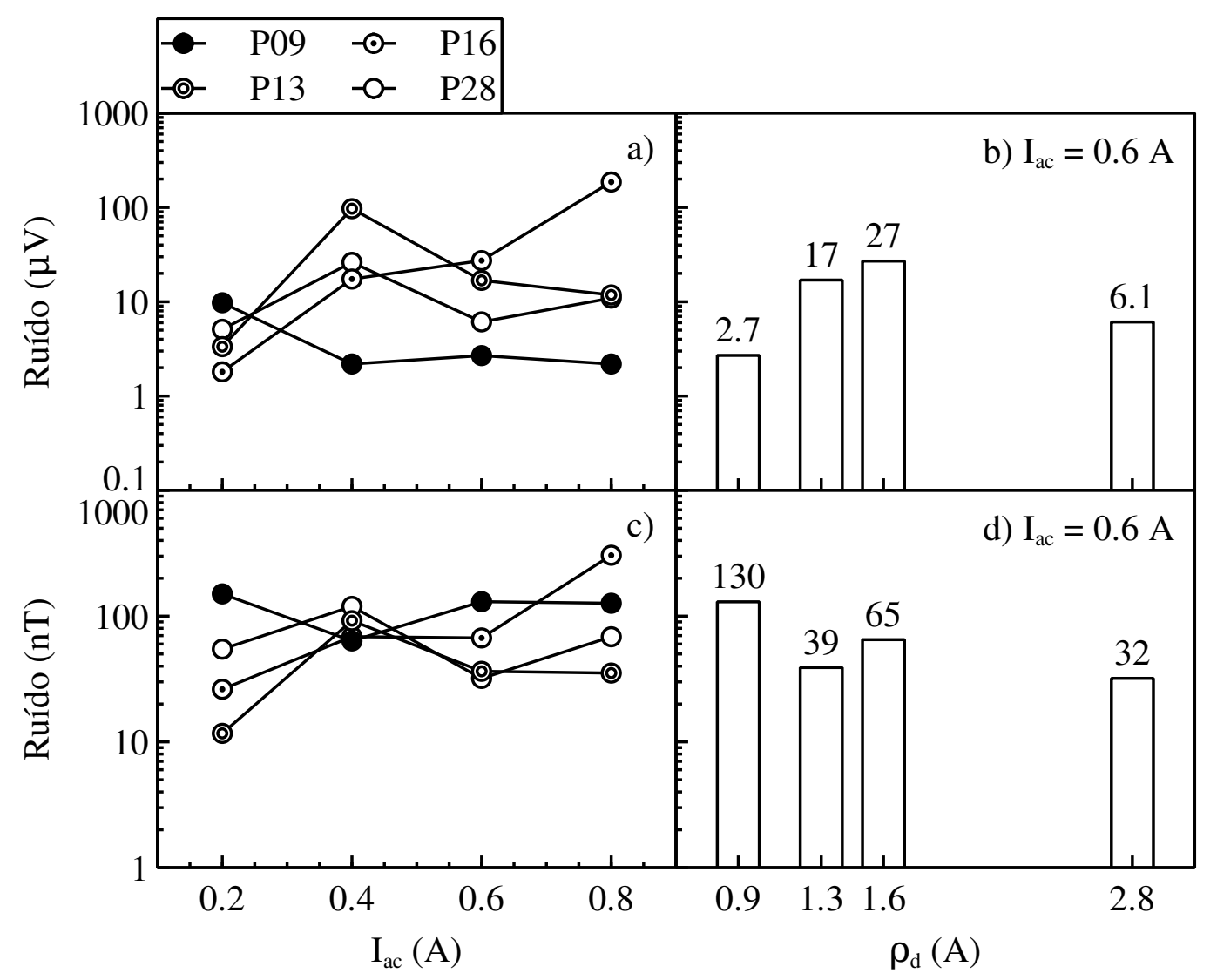

Figura 3.11.20 - Ruído rms presente na faixa de $0,1 \mathrm{a} 10 \mathrm{~Hz}$ gerado pelos sensores do grupo $\mathrm{C}$ operados no modo convencional. Valores de ruído não normalizados (a) e normalizado (c) em função amplitude da corrente de excitação variável. Valor de referência não normalizado (b) e normalizado (d) em função da densidade de corrente utilizada na eletrodeposição.

Novamente a aplicação do campo de excitação constante reduziu os níveis de ruído, como mostra a figura 3.11.21. Entretanto as medidas continuam com grandes flutuações, algumas causadas pelo mesmo tipo de fenômeno discutido na seção 2.3.4. Por exemplo, veja na figura 3.11.22 um trecho do sinal utilizado para estimar o valor do ruído do sensor P09 para $I_{d c}=0.35$ A, correspondente ao pico na figura 3.11.21e. O sinal oscila entre dois valores médios. 


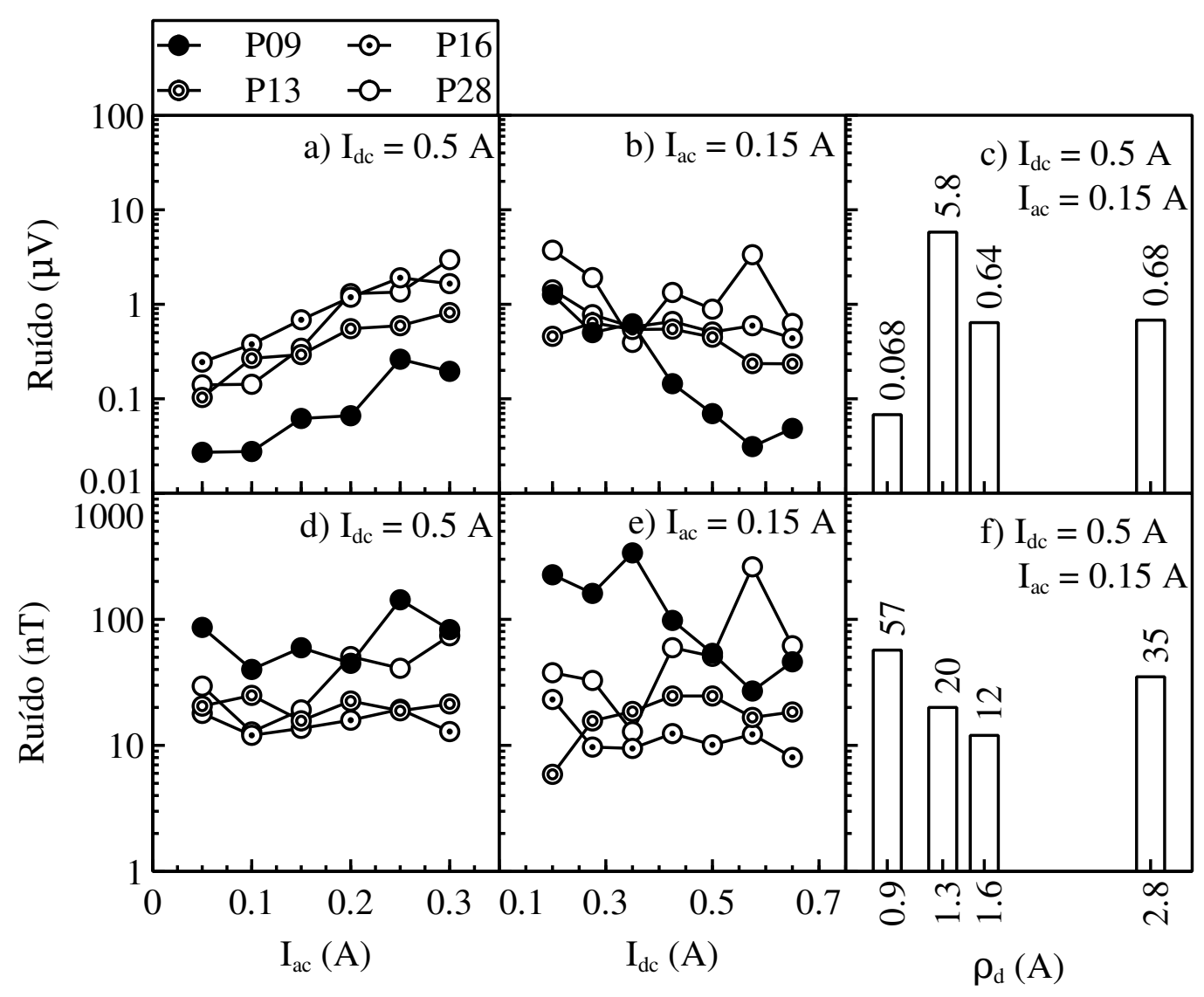

Figura 3.11.21 - Ruído rms presente na faixa de 0,1 a $10 \mathrm{~Hz}$ gerado pelos sensores do grupo B com a aplicação de $H_{d c}$. Valores de ruído não normalizados (a) e normalizadoa (d) em função amplitude da corrente de excitação variável. Valores de ruído não normalizados (b) e normalizado (e) em função amplitude da corrente de excitação contínua. Valor de referência não normalizado (c) e normalizado (f) em função da densidade de corrente utilizada na eletrodeposição. 


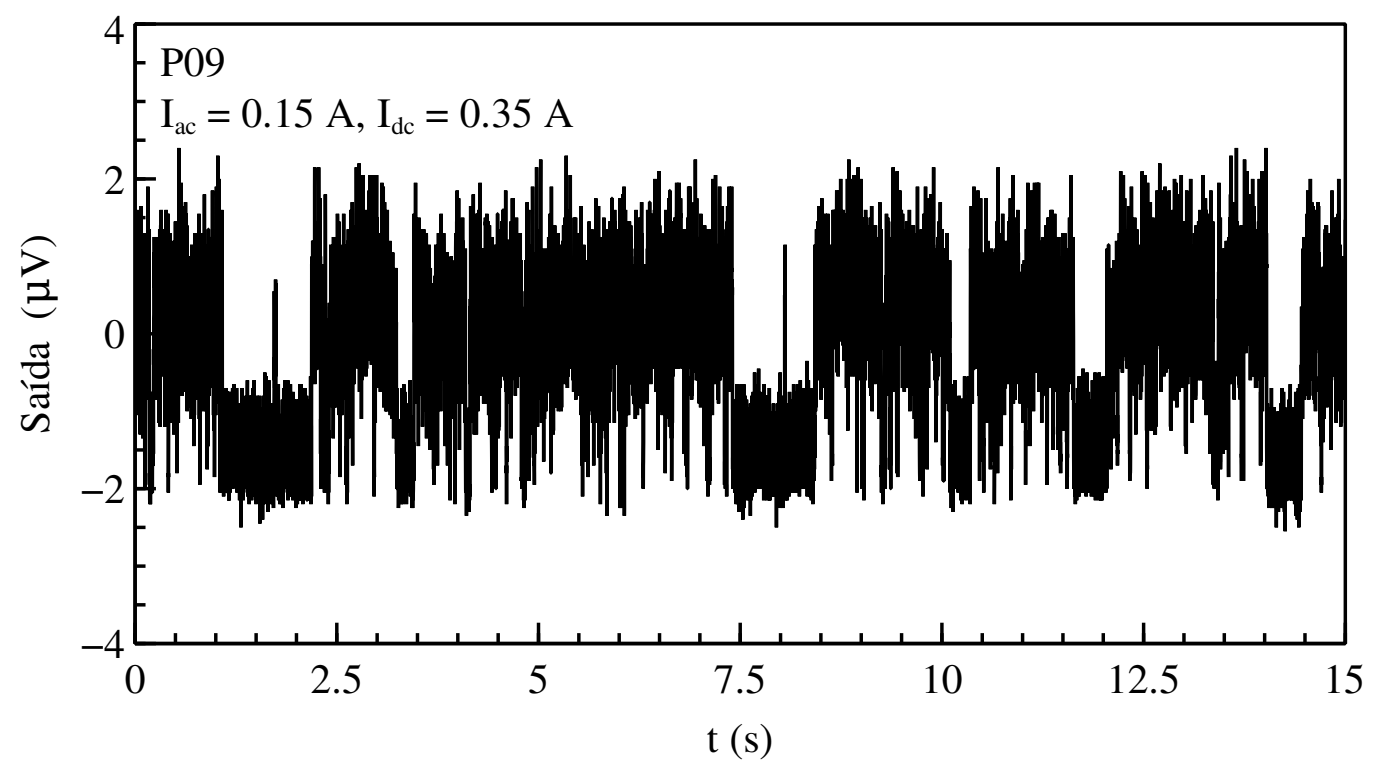

Figura 3.11.22 - Trecho da série temporal coletada para o sensor P09 utilizada estimar o valor do ruído para $I_{d c}=0,35 \mathrm{~A}$ e $I_{d c}=0,15 \mathrm{~A}$. As flutuações entre dois níveis elevam o valor do ruído. 


\subsubsection{Comparação entre os valores de referência e conclusões}

A figura 3.11.23 mostra a responsividade para todos os sensores medida com os parâmetros de entrada de referência. São os mesmos dados mostrados anteriormente, agora reunidos. Fica clara a grande diferença entre os dois métodos de operação no quesito responsividade. $\mathrm{O}$ modo convencional leva ampla vantagem. Os sensores do grupo A apresentaram os valores maiores mesmo utilizando menor número de espiras, principalmente quando deslocada a excitação. Possivelmente, com o diâmetro maior do substrato de cobre, a densidade de $40 \mathrm{~mA} / \mathrm{cm}^{2}$ produziu filmes com maior quantidade de níquel e menor grão cristalino, mesmo comparando com os 50 $\mathrm{mA} / \mathrm{cm}^{2}$ iniciais do N50. Note que a camada mais externa deste sensor foi eletrodepositada a $25 \mathrm{~mA} / \mathrm{cm}^{2}$ devido ao acréscimo de material durante o processo. Da mesma maneira a camada externa dos sensores do grupo A (exceto por N14I00) foram formadas a $33,3 \mathrm{~mA} / \mathrm{cm}^{2}$. Soma-se isto a mudança na dinâmica na eletrodeposição e fica evidente esta maior quantidade de níquel e o menor grão cristalino, associados a maiores densidades de corrente. Os melhores resultados ficaram por conta do N40I00, com aproximadamente $800 \mathrm{~V} / \mathrm{T}$ e do N50 com $684 \mathrm{~V} / \mathrm{T}$.

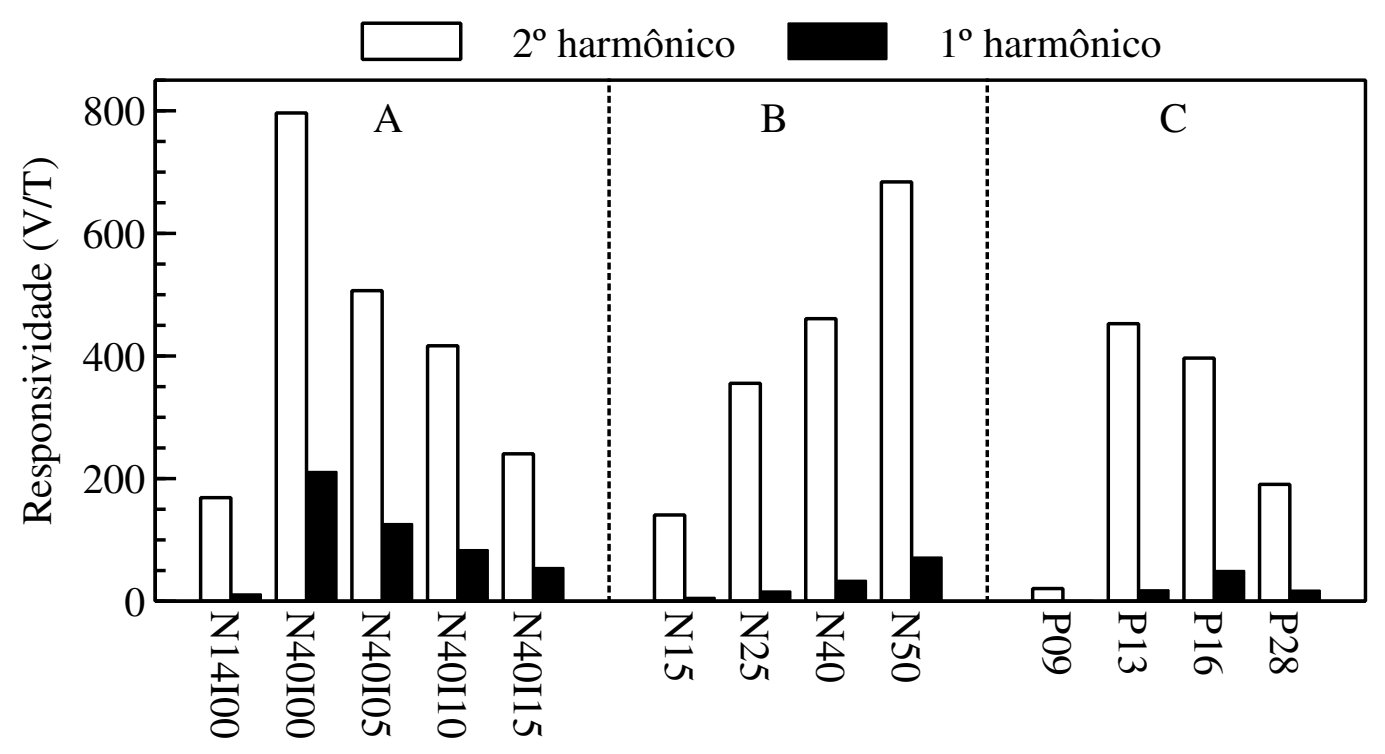

Figura 3.11.23 - Responsividades medidas para todos os sensores com a excitação de referência. 
Quanto ao efeito perming tem-se novamente uma grande diferença entre os modos de operação, como pode ser visto na figura 3.11.24 (perceba que a escala agora é logarítmica). O modo convencional, em que a magnetização do núcleo é revertida a cada ciclo da excitação, é mais eficiente em "limpar" a história da magnetização do núcleo [76]. Claramente esta reversão é um processo muito mais turbulento que somente variar a intensidade do campo $H_{\text {exc }}$ em uma direção fixa. O resultado de evitar esta turbulência, operando-se com uma corrente constante, é o aumento de aproximadamente uma ordem de grandeza no efeito perming. Uma possível solução seria inverter o sentido da excitação a cada $\mathrm{N}$ ciclos, mas não utilizar o sinal gerado durante a transição na medida do campo externo. Esta técnica foi já utilizada para anular o nível de base do sensor, isto é, a saída se anular quando não há campo externo [77].

O destaque para o modo convencional foram as amostras P09 e P13, e os sensores do grupo A. Já N40I00 foi o sensor menos afetado por choques de campo externos quando aplicado $I_{d c}$.

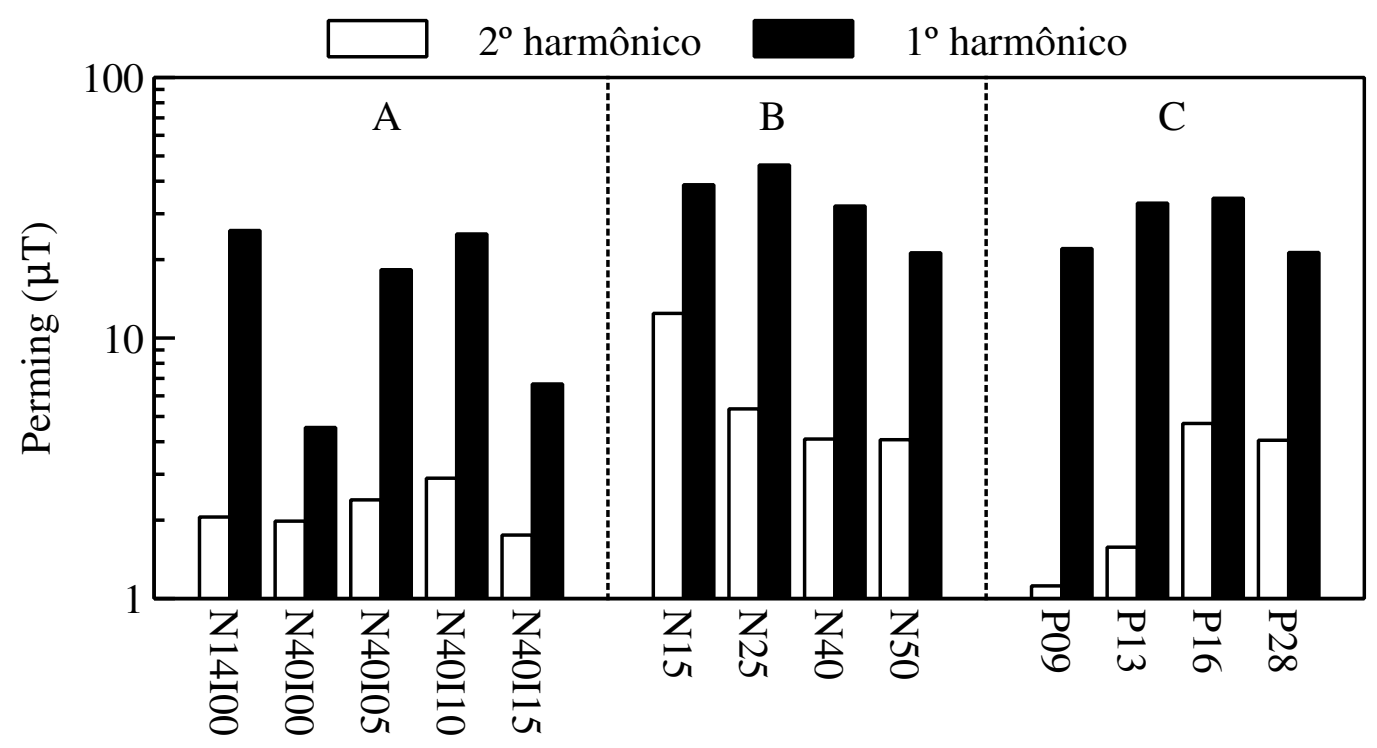

Figura 3.11.24 - Efeito perming medido para todos os sensores com a excitação de referência.

Por outro lado pode-se ver a redução do ruído causada por $I_{d c}$ na figura 3.11.25, com algumas exceções como o grupo C e N1400 e N15. As melhores amostras N40I00 e N50 atingiram valores abaixo de $1 \mathrm{nT}(550 \mathrm{pT}$ e $820 \mathrm{pT} r m s$ entre $0.1 \mathrm{e} 10 \mathrm{~Hz})$, cerca de uma ordem de grandeza menor que quando operados no modo convencional. Com $I_{d c}=0$ quatro sensores apresentaram basicamente os mesmos resultados, cerca de $8 \mathrm{nT} \mathrm{rms,} \mathrm{N40I00,} \mathrm{N40I05,} \mathrm{N40} \mathrm{e}$ N50. As amostras contendo fósforo obtiveram na média os níveis mais altos de ruído em ambos modos de operação. 


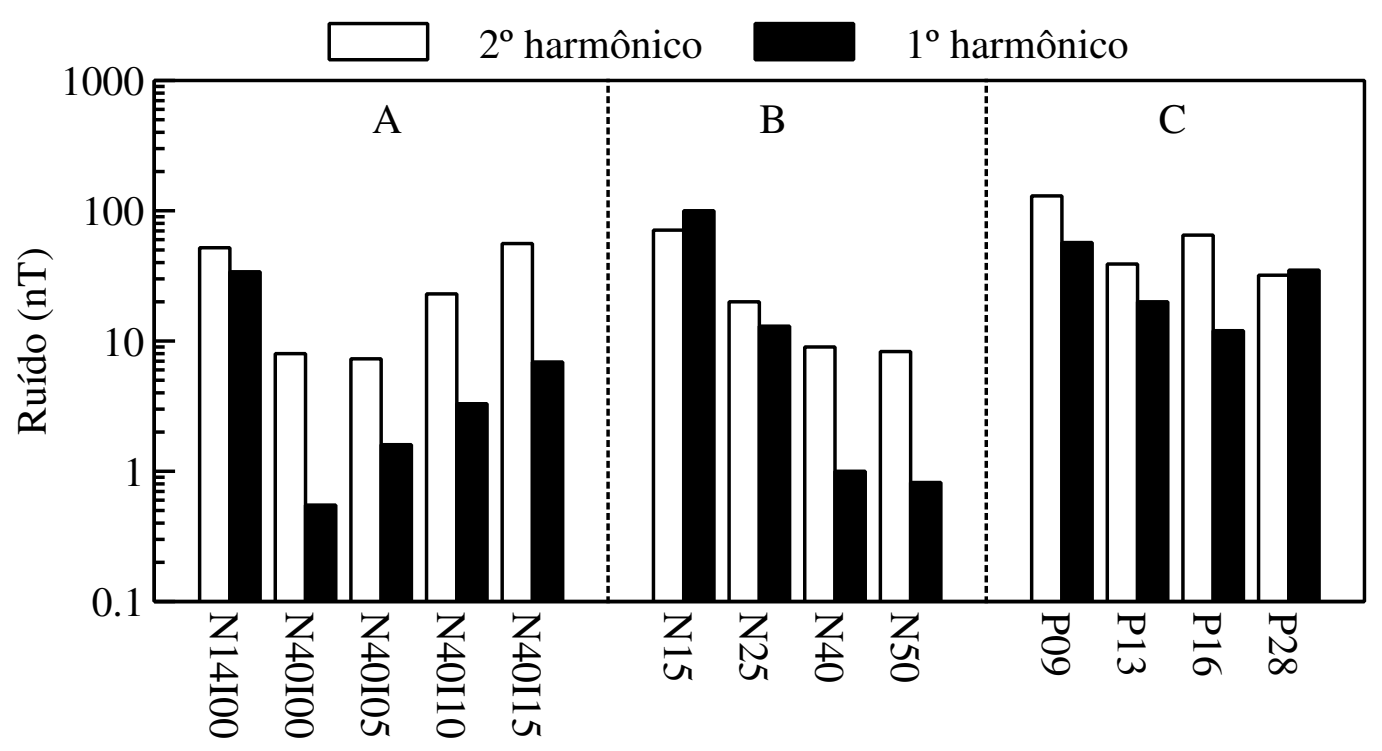

Figura 3.11.25 - Ruído medido para todos os sensores com a excitação de referência.

De maneira geral, com base nos resultados mostrados, o sensor que apresentou as melhores características foi o denominado N40I00, com substrato de $120 \mu \mathrm{m}$ de diâmetro e núcleo de $\mathrm{NiFe}$ eletrodepositado com densidade de corrente de $40 \mathrm{~mA} / \mathrm{cm}^{2}$ sem campo tangencial.

\subsubsection{Algumas melhorias possíveis}

Algumas melhorias possíveis já foram mencionadas, como a não deposição do núcleo nas extremidades do fio. Por outro lado, não foi feito nenhum tipo de tratamento térmico nas amostras. Como também já foi discutido, as propriedades magnéticas do NiFe melhoram se estas forem recozidas [55]. Isto pode ser obtido pelo efeito Joule de uma corrente passada pelo fio em atmosfera inerte [59, 57]. Exitem ainda outras técnicas de eletrodeposição, como pulsada, em que o tamanho do grão cristalino pode ser controlado [78] e deposição sob um campo longitudinal onde pode-se controlar o alinhamento dos grãos [79]. É possível também utilizar múltiplos fios a fim de melhorar a responsividade [76] e diminuir o ruído [80]. Outro fator que merece atenção é o estresse causado durante o enrolamento da bobina que pode ter mudado algumas propriedades do núcleo como anisotropia [81] e causado defeitos estruturais. Talvez uma saída seja construir os solenoides separadamente em algum molde e depois inserir o núcleo. 


\section{Conclusão}

Foram projetados, construídos e caracterizados sensores magnéticos tipo fluxgate com dimensões reduzidas.

Primeiramente foram feitos dispositivos planos microfabricados com o foco na redução da complexidade de construção. Mesmo assim a microfabricação envolveu inúmeras etapas e muitas delas pouco testadas no contexto utilizado. Por isto foi um processo iterativo com muitos ajustes e mudanças de projeto. Todavia o resultado final foi muito satisfatório, com sensores funcionais e com boa resposta. É fácil passar por um gráfico como o da figura 2.4.20 sem considerar a quantidade de planejamento envolvido e, principalmente, de detalhes na obtenção de um dispositivo funcional, capaz de transformar um campo magnético em um sinal elétrico.

Os dois leiautes construídos apresentaram baixa responsividade, $\sim 16 \mathrm{e} \sim 8 \mathrm{~V} / \mathrm{T}$, mas estes valores são facilmente melhorados com o aumento da resolução espacial utilizada na construção das bobinas. Para o leiaute com as bobinas extras de excitação, o aumento da resolução também traria um ganho na excitação, reduzindo o ruído. Ruído que ficou um pouco acima dos valores encontrados na literatura para sensores similares. Foram medidos 40 e $59 \mathrm{nT} r m s$ na faixa de 0,1 a $10 \mathrm{~Hz}$, com o menor valor respectivo ao leiaute mais simples, contra típicos $20 \mathrm{nT}$ da literatura. Este foi o preço pago pela simplificação do processo, tendo-se todas as bobinas no mesmo plano. Note entretanto que estes sensores de menor ruído mencionados utilizam bobinas com melhor resolução. Extrapolando os dados obtidos, se as bobinas tivessem sido construídas com espaçamento entre trilhas de $40 \mu \mathrm{m}$ contra os $60 \mu \mathrm{m}$ utilizados, chegaria-se à faixa de $10 \mathrm{nT}$. $40 \mu \mathrm{m}$ que ainda são o dobro do utilizado nos trabalhos com ruído na casa dos $20 \mathrm{nT}$. Baseado nisto pode-se dizer que é possível construir sensores como os descritos, com um processo de microfabricação simplificado e níveis de ruído similares aos dispositivos semelhantes contidos na literatura.

Também foram projetados e construídos sensores fluxgate de outro tipo que, depois de anos de esquecimento, têm recebido atenção: os ortogonais. Isto porque permitem geometrias mais simples, úteis na miniaturização. Permitem também a operação com uma componente constante na excitação que, na maioria dos casos, reduz o ruído. Seguindo esta linha, foi proposta uma equação para a permeabilidade aparente aplicável no caso em que esta componente constate é forte o suficiente para manter o núcleo em permanente saturação. Evita-se assim os saltos de Barkhausen associados a mudança de magnetização para campos baixos, grande fonte de ruído. Para validar o modelo matemático foi construído um sensor com o núcleo na forma de um filme retangular. Deste modo todos os parâmetros da equação puderam ser variados e os resultados teóricos e experimentais comparados. O que aparentemente seria um teste simples, se mostrou extremamente complicado. Efeitos secundários, como o fator de 
acoplamento e pequenas imprecisões no alinhamento do sistema, se mostraram por vezes ordens de grandeza maiores que o efeito das variáveis de interesse. Foi necessário um fino ajuste no sistema e nas dimensões do núcleo, assim como a utilização de fatores corretivos, para se chegar a resultados satisfatórios. Com a quantidade de valores experimentais envolvidos foi necessário um ajuste multiparamétrico, respeitando as incertezas experimentais. Por fim obteve-se uma boa concordância do modelo com os valores medidos. Partiu-se então para a construção dos sensores onde o núcleo é eletrodepositado sobre um fio de cobre e a excitação é feita passando-se uma corrente por este. A ideia foi operá-los em saturação, onde o mecanismo de modulação da permeabilidade magnética do núcleo se dá pela rotação da magnetização e não pelo movimento das paredes dos domínios magnéticos. Mas garantir a saturação das ligas eletrodepositadas necessita de uma corrente muito alta, isto para uma saturação virtual uma vez que não é possível saturar totalmente um material real. Entretanto o modelo matemático cumpriu um papel talvez mais importante que o inicial de apenas descrever o comportamento do sistema. Serviu de referência, onde os desvios de comportamento dos sensores reais indicavam problemas ou a presença de fenômenos não modelados. Por exemplo os sensores com núcleo de $\mathrm{NiFeP}$ apresentaram curvas de resposta completamente diferentes das previstas, e mesmo com o aumento da corrente de excitação não se tinha uma convergência. A provável causa é uma forte anisotropia divergindo da previsão teórica que usou a anisotropia como premissa. De forma mais sutil, algumas amostras apresentaram responsividade menor do que a prevista e pode-se verificar, utilizando a curva de magnetização medida experimentalmente, que este era o resultado da falta de saturação. Por outro lado o modelo previu com ótima precisão as curvas de responsividade da amostra com mais alta permeabilidade, fácil de saturar.

Com a mudança na forma de operar os sensores abriu-se novas possibilidades para o material do núcleo. Mas verificou-se que, para o limitado grupo de materiais testados, os melhores sensores foram os construídos com as ligas perto da composição $\mathrm{Ni}_{80} \mathrm{Fe}_{20}$, conhecida por sua boa aplicabilidade em sensores fluxgate. Entretanto este foi o máximo de níquel utilizado em amostras que tiveram a sua composição medida. Supôs-se conhecer bem as propriedades dos filmes eletrodepositados para uma gama de densidades de corrente. Este inclusive foi o tema de uma dissertação de mestrado de um ex-integrante do grupo de pesquisa. Os resultados já haviam sindo utilizados com sucesso na construção dos sensores planos. Desta maneira pensou-se não ser necessário repetir as medidas de composição. Entretanto não foi levado em conta o efeito da geometria do substrato. Descobriu-se que para os diâmetros dos fios utilizados, principalmente o de $45 \mu \mathrm{m}$, a densidade de corrente necessária para se obter $\mathrm{Ni}_{80} \mathrm{Fe}_{20}$ era consideravelmente maior. A suspeita surgiu durante a deposição de NiFeP em que a densidade necessária para se obter um filme ferromagnético era muito superior à reportada na literatura. Resolveu-se então acrescentar duas amostras de NiFe com substrato de $45 \mu \mathrm{m}$ ao lote de fios com NiFeP para a análise de composição. Os resultados mostraram este fenômeno. Claramente este é um ponto que necessita maior investigação. Por exemplo um dos melhores sensores obtidos não teve sua composição medida. Mas pelo diâmetro do substrato e a densidade de corrente utilizada na 
eletrodeposição pode-se dizer que esta tem concentração de níquel maior que 80 . Na verdade já havia esta suspeita, que densidades de corrente maiores que a associada ao $\mathrm{Ni}_{80} \mathrm{Fe}_{20}$ levariam a melhores sensores ortogonais. Os valores utilizados nos dispositivos com substrato de $45 \mu \mathrm{m}$ foram pensados para cobrir esta região. Entretanto, como se constatou depois, as mais altas densidades apenas chegaram na composição 80/20. Foram construídos três grupos de sensores ortogonais: substrato de $120 \mu \mathrm{m}$ com núcleo de NiFe eletrodepositado com a aplicação de um campo magnético circunferencial; substrato de $45 \mu \mathrm{m}$ com núcleo de NiFe e diversas densidades de corrente de eletrodeposição; substrato de $45 \mu \mathrm{m}$ com núcleo de NiFeP e diversas densidades de corrente de eletrodeposição.

Foi feito mapeamento de três parâmetros de saída dos sensores (responsividade, perming e ruído) em função dos parâmetros de excitação (amplitude de corrente alternada e contínua) para cada um dos 13 dispositivos. A frequência de excitação foi mantida constante em $100 \mathrm{kHz}$. Quando a corrente contínua da excitação é nula o sensor está operando em modo convencional, com resposta no segundo harmônico da excitação. Quando esta atinge valores maiores que a componente alternada, a resposta passa a ser majoritariamente no primeiro harmônico. Temse a transição no mecanismo de modulação da permeabilidade, passando para a rotação da magnetização a medida que esta corrente aumenta. Pode-se destacar dois dispositivos que obtiveram os melhores resultados em ambos os modos de operação. O primeiro utilizando substrato de $45 \mu \mathrm{m}$ e núcleo de NiFe eletrodepositado com densidade de corrente de $50 \mathrm{~mA} / \mathrm{cm}^{2}$. O menor ruído atingido foi de $820 \mathrm{pT} r m s$ na faixa de 0,1 a $10 \mathrm{~Hz}$, isto para uma corrente contínua de 0,5 A e alternada de 0,15 . Associado a este ponto, obteve-se uma responsividade $71,7 \mathrm{~V} / \mathrm{T}$ e um perming de 21,2 $\mu \mathrm{T}$. Já o segundo sensor utilizou substrato de $120 \mu \mathrm{m}$ e núcleo de $\mathrm{NiFe}$ eletrodepositado com densidade de corrente de $40 \mathrm{~mA} / \mathrm{cm}^{2}$, sem campo circunferencial. Neste caso o menor ruído atingido foi de 550 pT rms na faixa de $0,1 \mathrm{a} 10 \mathrm{~Hz}$, isto para uma corrente contínua de 0,65 A e alternada de 0,15 . Associado a este ponto, está uma responsividade de $211 \mathrm{~V} / \mathrm{T}$ e um perming de 4,5 $\mu \mathrm{T}$. Quando operados no modo convencional estes sensores apresentaram um aumento no ruído de aproximadamente 10 vezes, ambos $8 \mathrm{nT}$, para correntes alternadas de 0,6 A e 0,9 A respectivamente. Entretanto a responsividade de segundo harmônico associada a estes pontos foi muito superior, $684 \mathrm{~V} / \mathrm{T}$ e $796 \mathrm{~V} / \mathrm{T}$ respectivamente. No modo convencional quase todos os sensores foram menos afetados pelo perming. No caso do melhor exemplar com substrato de $45 \mu \mathrm{m}$, registrou-se apenas um quinto do deslocamento máximo do nível base da saída para choques magnéticos de até 4,8 mT. Os valores medidos passaram para 4 $\mu \mathrm{T}$. Já o sensor de $120 \mu \mathrm{m}$ teve uma redução no efeito de aproximadamente $50 \%$ com o valor de 1,98 $\mu \mathrm{T}$. Inverter o sentido de magnetização a cada ciclo da excitação é mais eficiente em "limpar" a memória magnética do núcleo. Mas isto também pode ser feito no modo de operação saturado, mudando o sentido da corrente contínua com uma frequência menor que a excitação ou simplesmente aplicando pulsos periódicos, sem utilizar o sinal gerado por estes no cálculo do campo. Neste caso teria-se sensores de baixo ruído e baixo efeito perming. Também são possíveis outras melhorias como o recozimento do núcleo em um forno ou por efeito joule. Por 
fim, uma mudança simples seria evitar a deposição de material ferromagnético nas extremidades do substrato, onde os contatos são feitos, para evitar que esta parte não excitada corretamente contamine o sinal com o ruído gerado pelos saltos de Barkhausen.

Finalmente, comparando os resultados com o objetivo inicial de tornar sensores magnéticos tipo fluxgate menores, mas simples e com melhor resolução, vê-se progresso, mas também muito trabalho a frente. 


\section{Referências}

[1] D. J. Griffiths, Introduction to Electrodynamics. Benjamin Cummings, 3 ed., Jan. 1999. 23, 27

[2] A. F. A A O Carneiro, "Biomagnetismo: Aspectos instrumentais e aplicações," pp. 324-338, 2000. 25

[3] S. Tumanski, Handbook of magnetic measurements. Boca Raton, FL: CRC Press, 2011. $25,26,108$

[4] K. Sternickel and A. I. Braginski, "Biomagnetism using SQUIDs: status and perspectives," Superconductor Science and Technology, vol. 19, p. S160, Mar. 2006. 26

[5] P. Ripka, Magnetic Sensors and Magnetometers. Artech House Publishers, Jan. 2001. 26, $33,42,43,57,95,97,175$

[6] S. A. Macintyre, Magnetic field measurement. CRC Press, 1999. 26

[7] P. Ripka, "Advances in fluxgate sensors," Sensors and Actuators A: Physical, vol. 106, pp. 8-14, Sept. 2003. 27, 31, 39, 97

[8] F. Primdahl, “The fluxgate magnetometer," Journal of Physics E: Scientific Instruments, vol. 12, pp. 241-253, Apr. 1979. 30, 35

[9] P. Ripka, S. O. Choi, A. Tipek, S. Kawahito, and M. Ishida, "Pulse excitation of microfluxgate sensors," IEEE Transactions on Magnetics, vol. 37, pp. 1998 -2000, July 2001. 30,47

[10] P. Ripka and W. G. Hurley, "Excitation efficiency of fluxgate sensors," Sensors and Actuators A: Physical, vol. 129, pp. 75-79, May 2006. 30

[11] F. Primdahl, "The fluxgate mechanism, part i: The gating curves of parallel and orthogonal fluxgates," IEEE Transactions on Magnetics, vol. 6, pp. 376- 383, June 1970. 35, 38

[12] P. Ripka, "Review of fluxgate sensors," Sensors and Actuators A: Physical, vol. 33, pp. 129_ 141, June 1992. 35

[13] T. M. Liakopoulos and C. H. Ahn, "A micro-fluxgate magnetic sensor using micromachined planar solenoid coils," Sensors and Actuators A: Physical, vol. 77, pp. 66-72, Sept. 1999. 39,41

[14] C. Lei, R. Wang, Y. Zhou, and Z. Zhou, "MEMS micro fluxgate sensors with mutual vertical excitation coils and detection coils," Microsystem Technologies, vol. 15, pp. 969-972, Apr. 2009. $39,45,47$ 
[15] S. Choi, S. Kawahito, Y. Matsumoto, M. Ishida, and Y. Tadokoro, "An integrated micro fluxgate magnetic sensor," Sensors and Actuators A: Physical, vol. 55, pp. 121-126, July 1996. 40,47

[16] S. B. Ubizskii and L. P. Pavlyk, "The pendulum-like fluxgate magnetic field sensor," Sensors and Actuators A: Physical, vol. 141, pp. 440-446, Feb. 2008. 44, 84

[17] G. P. Farrell and E. W. Hill, "The limit of fluxgate sensitivity due to barkhausen noise for single layer and bi-layer permalloy thin film cores," IEEE Transactions on Magnetics, vol. 31, pp. 4050-4052, Nov. 1995. 44

[18] R. H. Koch, J. G. Deak, and G. Grinstein, "Fundamental limits to magnetic-field sensitivity of flux-gate magnetic-field sensors," Applied Physics Letters, vol. 75, no. 24, p. 3862, 1999. 44

[19] N. A. Spaldin, Magnetic Materials: Fundamentals and Applications. Cambridge University Press, 2 ed., Sept. 2010. 44

[20] P. Ripka, S. Choi, A. Tipek, S. Kawahito, and M. Ishida, "Symmetrical core improves micro-fluxgate sensors," Sensors and Actuators A: Physical, vol. 92, pp. 30-36, Aug. 2001. 45

[21] P. Ripka, S. Kawahito, S. Choi, A. Tipek, and M. Ishida, "Micro-fluxgate sensor with closed core," Sensors and Actuators A: Physical, vol. 91, pp. 65-69, June 2001. 45, 47, 80

[22] H.-S. Park, J.-S. Hwang, W.-Y. Choi, D.-S. Shim, K.-W. Na, and S.-O. Choi, "Development of micro-fluxgate sensors with electroplated magnetic cores for electronic compass," Sensors and Actuators A: Physical, vol. 114, pp. 224-229, Sept. 2004. 45

[23] O. Zorlu, P. Kejik, F. Vincent, and R. S. Popovic, "A novel planar magnetic sensor based on orthogonal fluxgate principle," in Research in Microelectronics and Electronics, 2005 PhD, vol. 1, pp. 241- 244 vol.1, IEEE, July 2005. 45

[24] P.-M. Wu and C. Ahn, "Design of a low-power micromachined fluxgate sensor using localized core saturation method," IEEE Sensors Journal, vol. 8, pp. 308 -313, Mar. 2008. 45

[25] E. Delevoye, M. Audoin, M. Beranger, R. Cuchet, R. Hida, and T. Jager, "Microfluxgate sensors for high frequency and low power applications," Sensors and Actuators A: Physical, vol. 145-146, pp. 271-277, July 2008. 45, 47, 112

[26] C.-C. Lu, Y.-T. Liu, F.-Y. Jhao, and J.-T. Jeng, "Responsivity and noise of a wire-bonded CMOS micro-fluxgate sensor," Sensors and Actuators A: Physical, vol. 179, pp. 39-43, June 2012. 45, 47 
[27] W. Y. Choi, J. S. Hwang, and S. O. Choi, "A micro fluxgate magnetic sensor using new printed circuit board technology," Key Engineering Materials, vol. 326-328, pp. 1487-1490, 2006. 47

[28] I. Vincueria, M. Tudanca, C. Aroca, E. Lopez, M. Sanchez, and P. Sanchez, "Flux-gate sensor based on planar technology," IEEE Transactions on Magnetics, vol. 30, pp. 5042 -5045, Nov. 1994. 47

[29] A. Baschirotto, E. Dallago, P. Malcovati, M. Marchesi, and G. Venchi, "A fluxgate magnetic sensor: From PCB to micro-integrated technology," IEEE Transactions on Instrumentation and Measurement, vol. 56, pp. 25 -31, Feb. 2007. 47

[30] L. Rovati and S. Cattini, "Zero-field readout electronics for planar fluxgate sensors without compensation coil," IEEE Transactions on Industrial Electronics, vol. 59, pp. 571-578, Jan. 2012. 47

[31] S. Kawahito, H. Satoh, M. Sutoh, and Y. Todokoro, "High-resolution micro-fluxgate sensing elements using closely coupled coil structures," Sensors and Actuators A: Physical, vol. 54, pp. 612-617, June 1996. 47

[32] W.-Y. Choi, J.-S. Hwang, and S.-O. Choi, "The microfluxgate magnetic sensor having closed magnetic path,” IEEE Sensors Journal, vol. 4, pp. 768 - 771, Dec. 2004. 47

[33] A. Tipek, P. Ripka, T. O'Donnell, and J. Kubik, "PCB technology used in fluxgate sensor construction," Sensors and Actuators A: Physical, vol. 115, pp. 286-292, Sept. 2004. 47

[34] M. R. Kirchhoff, J. Güttler, A. Waldschik, M. Feldmann, and S. Büttgenbach, "Revised fabrication process for micro-fluxgate-magnetometers: Usage of electrodepositable photoresist," Microelectronic Engineering, vol. 85, pp. 1047-1049, May 2008. 47

[35] T. Heimfarth, Microssensores magnéticos tipo fluxgate planar utilizando ligas de NiFe eletrodepositadas. Master's dissertation, Feb. 2010. 50

[36] J.-M. Quemper, S. Nicolas, J. Gilles, J. Grandchamp, A. Bosseboeuf, T. Bourouina, and E. Dufour-Gergam, "Permalloy electroplating through photoresist molds," Sensors and Actuators A: Physical, vol. 74, pp. 1-4, Apr. 1999. 50, 71

[37] T. C. dos Santos and M. Mulato, "Analysis of electrodeposited NiFe thin films for the development of planar fluxgate magnetic sensors," MRS Online Proceedings Library, vol. 998, 2007. 50, 96, 106

[38] D. Scouten, "Sensor noise in low-level flux-gate magnetometers," IEEE Transactions on Magnetics, vol. 8, pp. 223 - 231, June 1972. 56 
[39] T. C. d. Santos, Ligas magnéticas NiFe e NiFeCo eletrodepositadas, voltadas para aplicações em micro-sensores magnéticos tipo fluxgate planar. Master's dissertation, Aug. 2007. 71,96

[40] D. J. Craik, Ferromagnetism and ferromagnetic domains,. Wiley, 1965. 82

[41] D. Scouten, "Barkhausen discontinuities in the saturation region," IEEE Transactions on Magnetics, vol. 6, no. 2, pp. 383-385, 1970. 82

[42] J.-y. Valet, “Anisotropic thin ferromagnetic film magnetometer,” Nov. 1971. 83

[43] J. Deak, A. H. Miklich, J. Slonczewski, and R. H. Koch, "A low-noise single-domain fluxgate sensor," Applied Physics Letters, vol. 69, no. 8, p. 1157, 1996. 83

[44] H. J. Williams and M. Goertz, "Domain structure of perminvar having a rectangular hysteresis loop," Journal of Applied Physics, vol. 23, pp. 316-323, Mar. 1952. 83

[45] R. H. Koch and J. R. Rozen, "Low-noise flux-gate magnetic-field sensors using ring- and rod-core geometries," Applied Physics Letters, vol. 78, no. 13, p. 1897, 2001. 83

[46] I. Sasada, "Orthogonal fluxgate mechanism operated with dc biased excitation," Journal of Applied Physics, vol. 91, no. 10, p. 7789, 2002. 82, 83, 84

[47] A. Garcia and C. Moron, "Biaxial magnetometer sensor," IEEE Transactions on Magnetics, vol. 38, pp. 3312-3314, Sept. 2002. 83

[48] A. Garcia, C. Moron, and M. Mora, "Theoretical calculation for a two-axis magnetometer based on magnetization rotation," Sensors and Actuators A: Physical, vol. 81, pp. 204-207, Apr. 2000. 83

[49] P. M. Vetoshko, M. V. Valeiko, and P. I. Nikitin, "Epitaxial yttrium iron garnet film as an active medium of an even-harmonic magnetic field transducer," Sensors and Actuators A: Physical, vol. 106, pp. 270-273, Sept. 2003. 84

[50] E. Paperno, "Suppression of magnetic noise in the fundamental-mode orthogonal fluxgate," Sensors and Actuators A: Physical, vol. 116, pp. 405-409, Oct. 2004. 82, 84

[51] E. Paperno, E. Weiss, and A. Plotkin, "A tube-core orthogonal fluxgate operated in fundamental mode," IEEE Transactions on Magnetics, vol. 44, pp. 4018-4021, Nov. 2008. 84

[52] M. Butta, S. Yamashita, and I. Sasada, "Reduction of noise in fundamental mode orthogonal fluxgates by optimization of excitation current," IEEE Transactions on Magnetics, vol. 47, pp. 3748-3751, Oct. 2011. 82, 84 
[53] R. Moskowitz and E. Della Torre, "Theoretical aspects of demagnetization tensors," IEEE Transactions on Magnetics, vol. 2, pp. 739-744, Dec. 1966. 86

[54] D.-X. Chen, J. Brug, and R. B. Goldfarb, "Demagnetizing factors for cylinders," IEEE Transactions on Magnetics, vol. 27, no. 4, pp. 3601-3619, 1991. 86

[55] B. Lewis, "The permalloy problem and magnetic annealing in bulk nickel-iron alloys," British Journal of Applied Physics, vol. 15, p. 407, Apr. 1964. 96, 110, 154

[56] X. P. Li, Z. J. Zhao, H. L. Seet, W. M. Heng, T. B. Oh, and J. Y. Lee, "Effect of magnetic field on the magnetic properties of electroplated NiFe/Cu composite wires," Journal of Applied Physics, vol. 94, pp. 6655-6658, Nov. 2003. 97

[57] X. Li, H. Seet, J. Fan, and J. Yi, "Electrodeposition and characteristics of Ni80Fe20/Cu composite wires," Journal of Magnetism and Magnetic Materials, vol. 304, pp. 111-116, Sept. 2006. 97, 154

[58] E. Kubo, N. Ooi, H. Aoki, D. Watanabe, J.-H. Jeong, C. Kimura, and T. Sugino, "Effect of magnetic field on permeability of electroplated permalloy for microdevices," Japanese Journal of Applied Physics, vol. 49, p. 04DB17, Apr. 2010. 97

[59] M. Ghanaatshoar, N. Azad, M. H. Banitaba, and B. Shokri, "Giant magnetoimpedance effect of ac-dc joule annealed electroplated $\mathrm{NiFe} / \mathrm{Cu}$ composite wires," physica status solidi (c), vol. 8, no. 11-12, p. 3055-3058, 2011. 97, 154

[60] T. Egami, "Magnetic amorphous alloys: physics and technological applications," Reports on Progress in Physics, vol. 47, p. 1601, Dec. 1984. 97

[61] K. Sridharan and K. Sheppard, "Crystallization of amorphous iron-nickel-phosphorus alloys prepared by electrodeposition," Journal of Materials Processing Technology, vol. 68, pp. 109-116, June 1997. 97, 99

[62] I. R. Walker, "Removal of enamel from ultrafine monofilamentary wires," Review of Scientific Instruments, vol. 75, pp. 1169-1174, Mar. 2004. 98

[63] C. Gao and F. U. Baiyang ZHOU (Institute for Materials Research, "Effects of the composition of electrodeposited fe-ni-p alloy on the thermostability and magnetic properties," vol. 13, pp. 137-140, Oct. 2009. 99

[64] K. Sridharan and K. Sheppard, "Electrochemical characterization of fe-ni-p alloy electrodeposition," Journal of Applied Electrochemistry, vol. 27, pp. 1198-1206, Oct. 1997. 99, 106

[65] C.-h. GAO, "Stability of electrodeposited amorphous ni-fe-p alloys," Transactions of Nonferrous Metals Society of China, vol. 16, pp. 1325-1330, Dec. 2006. 99 
[66] C.-h. GAO and Y. Zhao, "Wear mechanism of electrodeposited amorphous ni-fe-p alloys," Transactions of Nonferrous Metals Society of China, vol. 14, pp. 255-259, 2004. 99

[67] Y. D. Yu, G. Y. Wei, H. F. Guo, J. W. Lou, and H. L. Ge, "Study on preparation of NiFeP films by pulse electrodeposition," Surface Engineering, vol. 28, pp. 30-36, Feb. 2012. 99

[68] P. Malathy and Vijayanthy, "Electrodeposition of ni-fe-p alloy," Bulletin of Electrochemistry, vol. 15 , no. 5-6, pp. 211-214, 1999. 100, 106

[69] H. Seet, X. Li, Z. Zhao, L. Wong, H. Zheng, and K. Lee, "Current density effect on magnetic properties of nanocrystalline electroplated Ni80Fe20/Cu composite wires," Journal of Magnetism and Magnetic Materials, vol. 302, pp. 113-117, July 2006. 106

[70] A. C. Mishra, "Microstructure, magnetic and magnetoimpedance properties in electrodeposited $\mathrm{NiFe} / \mathrm{Cu}$ and $\mathrm{CoNiFe} / \mathrm{Cu}$ wire with thiourea additive in plating bath," Physica B: Condensed Matter, vol. 407, pp. 923-934, Mar. 2012. 107

[71] J. Y. Park and M. G. Allen, "Electroplated and screen-printed magnetic materials applicable to micromachined magnetic devices," pp. 154-167, Sept. 1998. 112

[72] J. Groenland, C. Eijkel, J. Fluitman, and R. de Ridder, "Permalloy thin-film magnetic sensors," Sensors and Actuators A: Physical, vol. 30, pp. 89-100, Jan. 1992.112

[73] R. Bozorth and D. Chapin, "Demagnetizing factors of rods," Journal of Applied Physics, vol. 13, pp. 320-326, May 1942. 125

[74] J. Burger, "The theoretical output of a ring core fluxgate sensor," IEEE Transactions on Magnetics, vol. 8, pp. 791-796, Dec. 1972. 125

[75] M. Butta and I. Sasada, "Noise correlation in fundamental mode orthogonal fluxgate," Journal of Applied Physics, vol. 111, pp. 07E517-07E517-3, Mar. 2012. 143

[76] P. Ripka, X. Li, and J. Fan, "Multiwire core fluxgate," Sensors and Actuators A: Physical, vol. 156, pp. 265-268, Nov. 2009. 153, 154

[77] E. Weiss and E. Paperno, "Noise investigation of the orthogonal fluxgate employing alternating direct current bias," Journal of Applied Physics, vol. 109, no. 7, p. 07E529, 2011. 153

[78] H. L. Seet, X. P. Li, Z. J. Zhao, Y. K. Kong, H. M. Zheng, and W. C. Ng, "Development of high permeability nanocrystalline permalloy by electrodeposition," Journal of Applied Physics, vol. 97, p. 10N304, May 2005. 154

[79] X. P. Li, Z. J. Zhao, H. L. Seet, W. M. Heng, T. B. Oh, and J. Y. Lee, "Magnetically controlled electroplating of $\mathrm{NiFe} / \mathrm{Cu}$ composite wires," Electrochemical and Solid-State Letters, vol. 7, pp. C1-C3, Jan. 2004. 154 
[80] F. Jie, N. Ning, W. Ji, H. Chiriac, and L. Xiaoping, "Study of the noise in multicore orthogonal fluxgate sensors based on ni-Fe/Cu composite microwire arrays," IEEE Transactions on Magnetics, vol. 45, pp. 4451-4454, Oct. 2009. 154

[81] M. Butta, P. Ripka, S. Atalay, F. E. Atalay, and X. P. Li, "Fluxgate effect in twisted magnetic wire," Journal of Magnetism and Magnetic Materials, vol. 320, pp. e974-e978, Oct. 2008. 154

[82] P. Stoica and R. L. Moses, Spectral analysis of signals. Upper Saddle River, N.J.: Pearson/Prentice Hall, 2005. 173

[83] A. Aharoni, "Demagnetizing factors for rectangular ferromagnetic prisms," Journal of Applied Physics, vol. 83, pp. 3432-3434, Mar. 1998. 178

[84] R. I. Joseph, "Ballistic demagnetizing factor in uniformly magnetized rectangular prisms," Journal of Applied Physics, vol. 38, pp. 2405-2406, Apr. 1967. 178

[85] D.-X. Chen, E. Pardo, and A. Sanchez, "Demagnetizing factors of rectangular prisms and ellipsoids," IEEE Transactions on Magnetics, vol. 38, pp. 1742 -1752, July 2002. 178, 180 

Anexos 



\section{ANEXO A - Método de obtenção de curvas de magnetização}

\section{A.1 Equação da magnetização}

A amostra depositada sobre um substrato de cobre é colocada no centro de uma bobina e imersa em um campo magnético externo $H_{0}$ paralelo à normal da bobina como mostra a figura A.1.1.

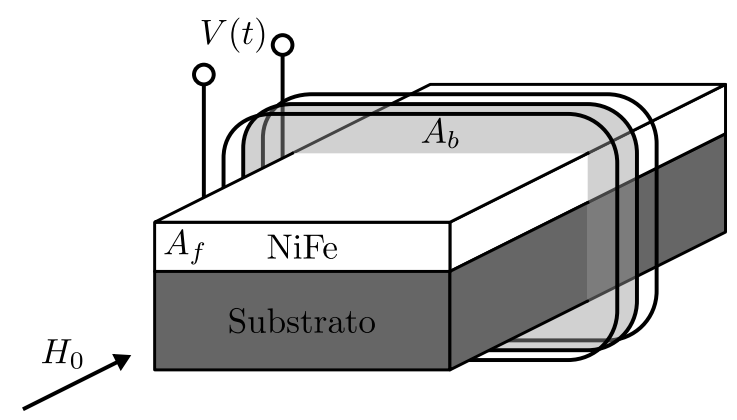

Figura A.1.1 - Montagem para a medida da curva de magnetização.

Considerando-se a permeabilidade do substrato aproximadamente igual a do vácuo ( $\mu_{C u} \approx \mu_{0}$ ) e a bobina composta por $n$ espiras perfeitamente condutoras, pode-se escrever o potencial induzido nas suas extremidades como:

$$
\begin{aligned}
V(t) & =-n \frac{\mathrm{d} \Phi}{\mathrm{d} t} \\
& =-n \frac{\mathrm{d}}{\mathrm{d} t} \int_{A_{b}} B(t, \mathbf{r}) \cdot \mathrm{d} \mathbf{A}_{b} \\
& =-n \mu_{0} \frac{\mathrm{d}}{\mathrm{d} t} \int_{A_{b}}[\mathbf{H}(t, \mathbf{r})+\mathbf{M}(t, \mathbf{r})] \cdot \hat{\mathbf{A}}_{b} \mathrm{~d} A_{b} \\
& =-n \mu_{0} \frac{\mathrm{d}}{\mathrm{d} t} \int_{A_{b}}[H(t, \mathbf{r})+M(t, \mathbf{r})] \mathrm{d} A_{b},
\end{aligned}
$$

onde $\hat{\mathbf{A}}_{b}$ é o versor paralelo ao eixo da bobina. $H$ e $M$ são as componentes associadas a esta direção dos campos $\mathbf{H}$ e $\mathbf{M}$ respectivamente. $H$ pode ser decomposto como $H=H_{0}+H_{d}$, onde a primeira componente é o campo externo aplicado e a segunda o campo de demagnetização. Este pode ser aproximado por $H_{d} \approx-D M$, onde $D$ é o fator de desmagnetização. Desta maneira 
tem-se que

$$
\begin{aligned}
V(t) & =-n \mu_{0} \frac{\mathrm{d}}{\mathrm{d} t} \int_{A_{b}}\left[H_{0}(t, \mathbf{r})+H_{d}(t, \mathbf{r})+M(t, \mathbf{r})\right] \mathrm{d} A_{b} \\
& =-n \mu_{0} \frac{\mathrm{d}}{\mathrm{d} t} \int_{A_{b}}\left[H_{0}(t, \mathbf{r})+(1-D) M(t, \mathbf{r})\right] \mathrm{d} A_{b} .
\end{aligned}
$$

Para resolver esta integral é necessário fazer-se algumas aproximações: o campo $H_{0}$, gerado externamente, é considerado espacialmente homogêneo; o campo de desmagnetização (representado pelo termo $-D M$ ) assim como $M$ são espacialmente homogêneos dentro de $A_{f}$ e nulos fora. Desta forma pode-se separar a integral em dois termos,

$$
\begin{aligned}
V(t) & =-n \mu_{0} \frac{\mathrm{d}}{\mathrm{d} t}\left[\int_{A_{b}} H_{0}(t) \mathrm{d} A_{b}+\int_{A_{f}}(1-D) M(t) \mathrm{d} A_{f}\right] \\
& =-n \mu_{0}\left[A_{b} \frac{\mathrm{d} H_{0}(t)}{\mathrm{d} t}+(1-D) A_{f} \frac{\mathrm{d} M(t)}{\mathrm{d} t}\right] .
\end{aligned}
$$

Integrando esta última equação entre 0 e $t^{\prime}$, tem-se

$$
\begin{aligned}
\int_{0}^{t^{\prime}} V(t) \mathrm{d} t & =-n \mu_{0}\left[A_{b} \int_{0}^{t^{\prime}} \frac{\mathrm{d} H_{0}(t)}{\mathrm{d} t} \mathrm{~d} t+(1-D) A_{f} \int_{0}^{t^{\prime}} \frac{\mathrm{d} M(t)}{\mathrm{d} t} \mathrm{~d} t\right] \\
V^{\prime}\left(t^{\prime}\right) & =-n \mu_{0} A_{b}\left[H_{0}\left(t^{\prime}\right)-H_{0}(0)\right]+(1-D) A_{f}\left[M\left(t^{\prime}\right)-M(0)\right] \\
V^{\prime}\left(t^{\prime}\right) & =-n \mu_{0} A_{b} H_{0}\left(t^{\prime}\right)+(1-D) A_{f} M\left(t^{\prime}\right)+C
\end{aligned}
$$

onde $V^{\prime}\left(t^{\prime}\right)=\int_{0}^{t^{\prime}} V \mathrm{~d} t$ e a constante $C=-n \mu_{0}\left[A_{b} H_{0}(0)+(1-D) A_{f} M(0)\right]$. Esta constante depende do estado inicial da amostra $\left(M\left(t^{\prime}=0\right)\right)$ que em geral não é facilmente acessível. Utilizando-se uma excitação periódica com período $T$ com média nula (uma função senoidal por exemplo) e com amplitude suficiente para saturar a amostra, tem-se que a média da magnetização também é nula. Desta forma

$$
\begin{aligned}
& \int_{0}^{T} V^{\prime}\left(t^{\prime}\right) \mathrm{d} t^{\prime}=-n \mu_{0} \int_{0}^{T}\left[A_{b} H_{0}\left(t^{\prime}\right)+(1-D) A_{f} M\left(t^{\prime}\right)\right] \mathrm{d} t^{\prime}+\int_{0}^{T} C \mathrm{~d} t^{\prime} \\
& \int_{0}^{T} V^{\prime}\left(t^{\prime}\right) \mathrm{d} t^{\prime}=T C
\end{aligned}
$$

de modo que

$$
C=\frac{1}{T} \int_{0}^{T} V^{\prime}\left(t^{\prime}\right) \mathrm{d} t^{\prime}=\overline{V^{\prime}}
$$

Pode-se agora escrever a dependência temporal da magnetização a partir da equação A.1.4, isto é

$$
M\left(t^{\prime}\right)=-\frac{1}{(1-D) A_{f}}\left[\frac{V^{\prime}\left(t^{\prime}\right)-\overline{V^{\prime}}}{n \mu_{0}}+A_{b} H_{0}\left(t^{\prime}\right)\right]
$$

Uma vez que $H_{0}\left(t^{\prime}\right)$ é conhecido pode-se construir a curva $M\left(H_{0}\right)$ a partir do parâmetro $t^{\prime}$. 


\section{A.2 Sistema experimental}

O sistema experimental utilizado para medir as curvas $M\left(H_{0}\right)$ dos núcleos ferromagnéticos está representado na figura A.2.1

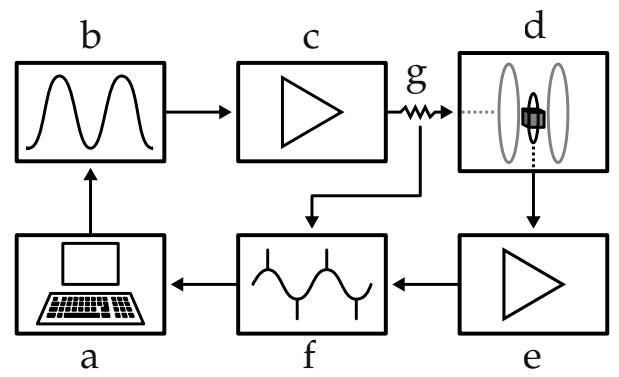

Figura A.2.1 - Sistema experimental utilizado nas medidas das curvas $M\left(H_{0}\right)$. Um computador (a) controla os parâmetros de um gerador de funções (b) que determina a forma de onda de $H_{0}$. O sinal passa por um amplificador de potência (c) responsável pelo ganho de corrente para a alimentação de uma bobina de Helmholtz (d) geradora de $H_{0}$. Ainda em (d) está a amostra com a bobina coletora (figura A.1.1) em cujos terminais desta estão ligados a um pré-amplificador (e). Finalmente o sinal coletado é digitalizado por um osciloscópio (f) e transmitido ao computador para análise. $\mathrm{O}$ campo $H_{0}$ também é medido pelo osciloscópio através da queda de potencial em um resistor ( $\mathrm{g}$ ) colocado em série com a bobina de Helmholtz.

\section{A.3 Exemplo}

A figuras A.3.1 e A.3.2 mostram um exemplo dos sinais envolvidos na medida, e a própria curva $M\left(H_{0}\right)$, respectivamente. 


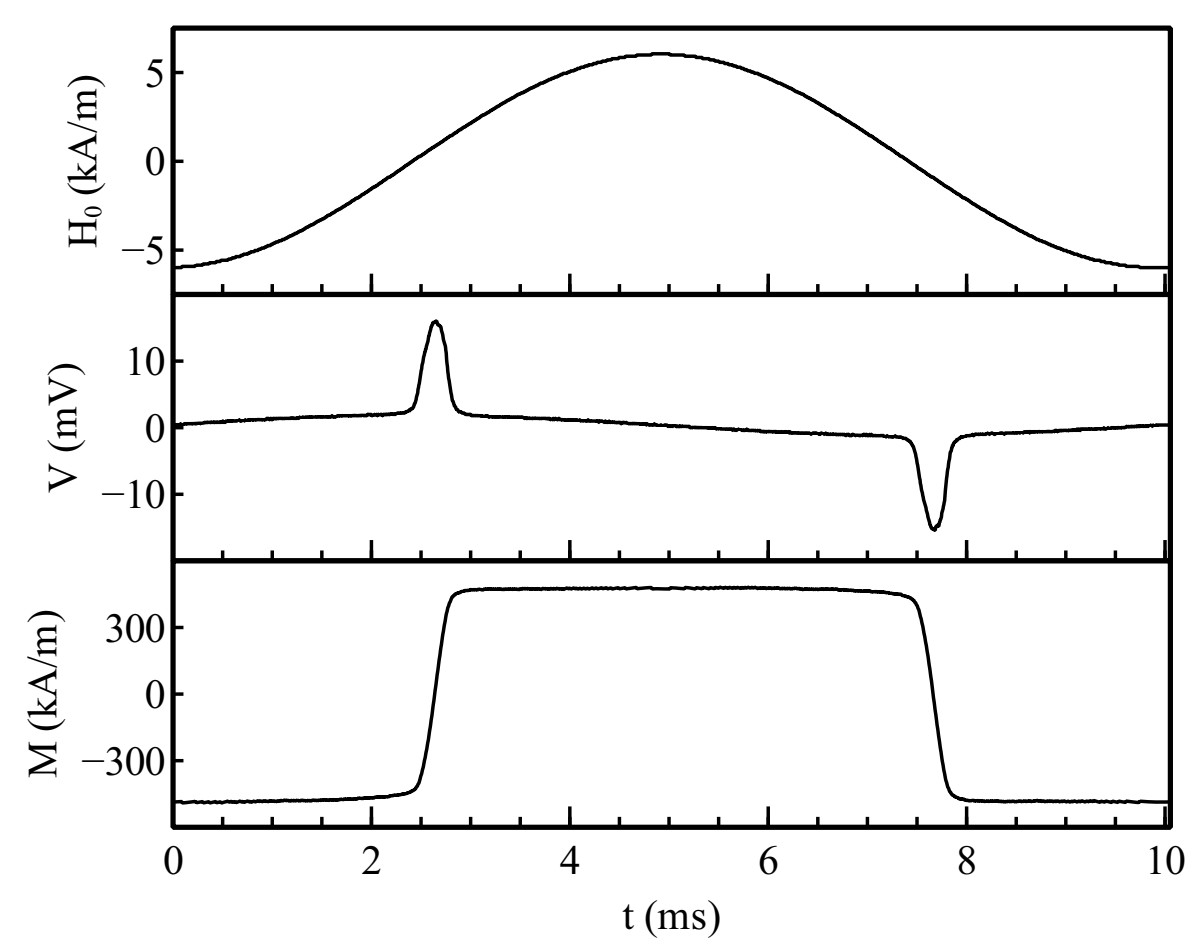

Figura A.3.1 - Exemplo dos sinais envolvidos na medida da magnetização de uma amostra de NiFe. O campo externo $H_{0}$ senoidal está mostrado no topo. O sinal capturado pela bobina coletora $(V(t))$ é mostrado no meio. Por último tem-se a magnetização calculada a partir da equação A.1.7.

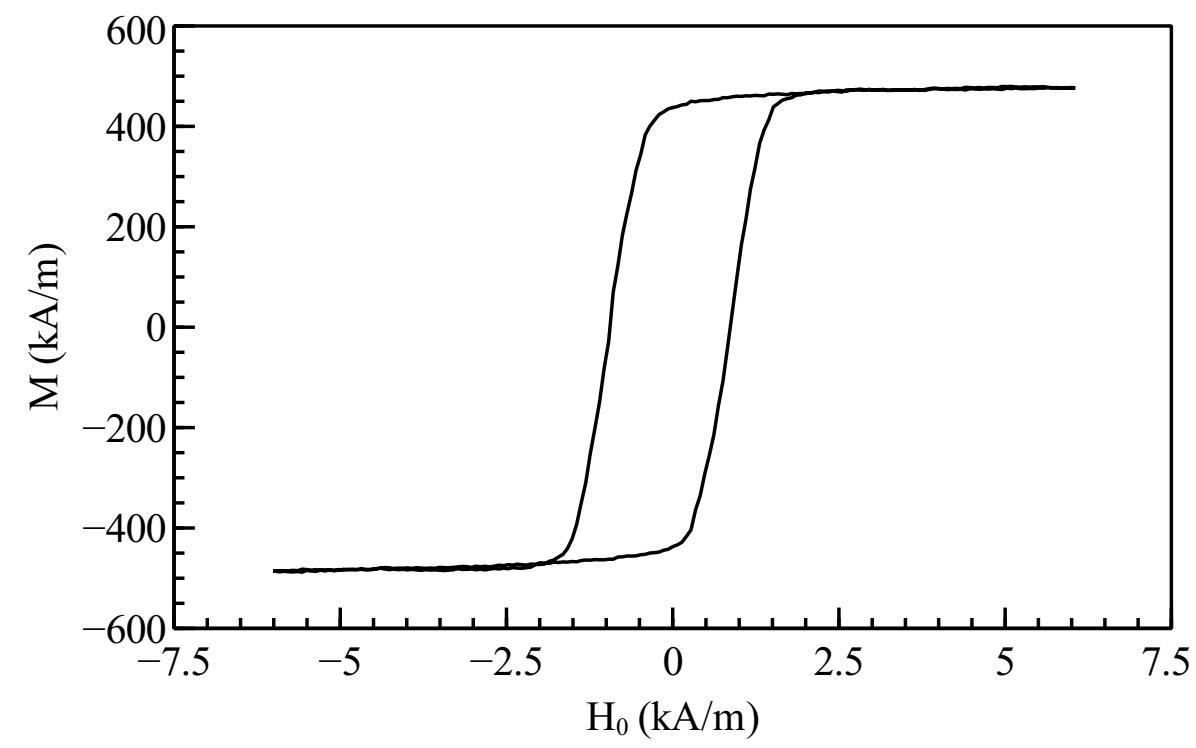

Figura A.3.2 - Curva de magnetização em função do campo externo aplicado $\left(M\left(H_{0}\right)\right)$ de uma amostra de NiFe utilizando o método descrito nesta secção. 


\section{ANEXO B - Análise do ruído}

O ruído é tratado como uma variável aleatória, e assim, somente é possível fazer afirmações probabilísticas sobre seu comportamento. Normalmente a análise do ruído contido em um sinal é feita através de sua densidade espectral de potência (PSD, do inglês Power Spectral Density). Esta mostra a distribuição da potência do sinal pela frequência. No caso de sinais aleatórios com duração finita e com amostragem discreta $V\left(t_{n}\right)$ para $n=0,1,2,3, .$. somente é possível estimar a PSD em uma faixa de frequências. Existem muitos métodos para se fazer esta estimativa, divididos em dois grupos, os paramétricos e os não paramétricos. No primeiro grupo é necessário postular um modelo para os dados de maneira a ser possível parametrizar o espectro. Já os métodos não paramétricos se baseiam na aplicação direta da definição da PSD: o sinal analisado é varrido por um filtro passa-banda fino onde as componentes da potência em cada frequência são separadas [82]. Embora métodos paramétricos sejam mais precisos, são mais complicados. Este ganho em precisão pode ser compensado aumentando-se a quantidade de dados. Por simplicidade, foi escolhido um método não paramétrico, mais especificamente o método de Welch. Baseia-se em fazer a média de vários periodogramas de segmentos do sinal original. A vantagem de se utilizar este método em relação ao periodograma simples, é a redução da variância na estimativa da PSD. Em contrapartida perde-se resolução na frequência. Esta é uma boa troca para os fins deste trabalho.

\section{B.1 Periodograma}

O periodograma é definido como

$$
P_{k}=\frac{1}{N}\left|\sum_{n=0}^{N-1} V_{n} e^{-\frac{i 2 \pi n k}{N}}\right|^{2},
$$

onde $P_{k}$ é a k-ésima componente do periodograma $(k=0,1,2, \ldots N)$, e $V_{n}$ a n-ésima componente do sinal $(n=0,1,2, \ldots N)$. Para valores de $k>N / 2$ a equação descreve frequências negativas. Se $V$ é um sinal real tem-se que $P(f)=P(-f)\left(P_{k}=P_{N-k+1}\right.$ para $\left.k=1,2,3, \ldots, N\right)$. Desta forma, para obter-se a potência total contida em uma frequência deve-se somar as partes positivas e negativas, ou multiplicar por 2 as positivas. Note que para $k=0$, que representa a componente dc do sinal, toda a potência está contida em um só termo e este não deve ser multiplicado por 2. Caso $\mathrm{N}$ seja par o mesmo pode acontecer para a frequência de Nyquist $(k=N / 2)$, que será o caso dos sinal analisados. Desta forma pode reescrever a estimativa de potência do sinal contida 
em faixa de frequência $f_{k}-\Delta f / 2 \leq f_{k}>f_{k}+\Delta f / 2$ como

$$
P\left(f_{k}\right)=\left\{\begin{array}{ll}
2 P_{k} & \text { para } k=1,2,3, \ldots, N / 2-1 \\
P_{k} & \text { para } k=0, N / 2
\end{array} .\right.
$$

Estritamente falando, o método de Welch divide o sinal de comprimento $\mathrm{N}$ em $\mathrm{m}$ segmentos, usualmente com superposição de $50 \%$, e calcula o periodograma médio. O que foi feito é ligeiramente diferente. Coletou-se $M$ séries distintas de comprimento $N$. Cada série foi dividida em $S$ segmentos com superposição de $50 \%$ com o antecessor. Calculou-se os periodogramas utilizando a equação B.1.2 e fez-se a média entre todos os $M \cdot S$ segmentos. Desta maneira evitou-se que houvessem segmentos contendo pontos de duas séries distintas. Esta diferença no procedimento tem dois motivos. Primeiramente, o estado do núcleo dos sensores depende de sua história magnética e consequentemente o ruído também. Logo este não depende somente dos parâmetros de excitação. "Reiniciando"o sistema entre medidas e fazendo-se a média entre elas resulta em uma menor dependência na história magnética. Note que esta técnica é somente para mitigar o problema, e outra bem mais elaborada seria necessário para estudar este efeito em detalhes. O segundo motivo é mais simples: o equipamento utilizado nas medidas tem uma memória que limita o número de pontos coletados. O periodograma médio utilizado pode ser escrito como

$$
\bar{P}\left(f_{k}\right)=\frac{1}{M S} \sum_{m=1}^{M} \sum_{s=1}^{S} P_{m, s}\left(f_{k}\right),
$$

onde $P_{m, s}\left(f_{k}\right)$ é o periodograma da medida $m$ segmento $s$.

\section{B.2 Ruído rms}

O valor representativo do ruído é média quadrática ( $r m s$, do ingles root mean square) da amplitude contida em um intervalo de frequência definido pelo limite superior $f_{H}$ e inferior $f_{D}$ do periodograma. Ou seja

$$
N_{r m s}=\sqrt{\int_{f_{L}}^{f_{H}} P(f) d f}
$$

ou no caso do sinal discreto em questão,

$$
N_{r m s}=\sqrt{\frac{f_{k_{H}}-f_{k_{L}}}{k_{H}-k_{L}} \sum_{k=k_{L}}^{k_{H}} \bar{P}\left(f_{k}\right)},
$$

onde $k_{H}$ e $k_{L}$ são os índices associados as frequências limites.

Outra forma de se obter uma valor representativo do ruído levando em conta o fato de sensores fluxgate apresentarem ruído com comportamento $1 / f$ na faixa de milihertz até kilohertz, 
ou seja $P(f)=P(1) / f$ [5]. Como esta consideração a equação B.2.1 toma a forma

$$
N_{r m s}=\sqrt{P(1) \ln \left(f_{H} / f_{L}\right)}
$$

Esta é uma alternativa interessante em alguns casos, como quando o ruídos extrínsecos ao sensor impossibilitam a medida em frequências altas mas não em $1 \mathrm{~Hz}$. Note entretanto que a escolha dos limites de frequência simplesmente servem para poder-se comparar com outras medidas integradas na mesma faixa. Caso não for este o interesse, pode apresentar diretamente o valor da densidade espectral do ruído na frequência de $1 \mathrm{~Hz}$, ou seja $\sqrt{P(1)}$. De fato, isto é o que muitos autores fazem.

A figura B.2.1 mostra um exemplo com cinco periodogramas obtidos utilizando a equação B.1.2 e a média destes, descrita na equação B.1.3 na faixa de frequência de $0,1 \mathrm{~Hz}$ a $10 \mathrm{~Hz}$.

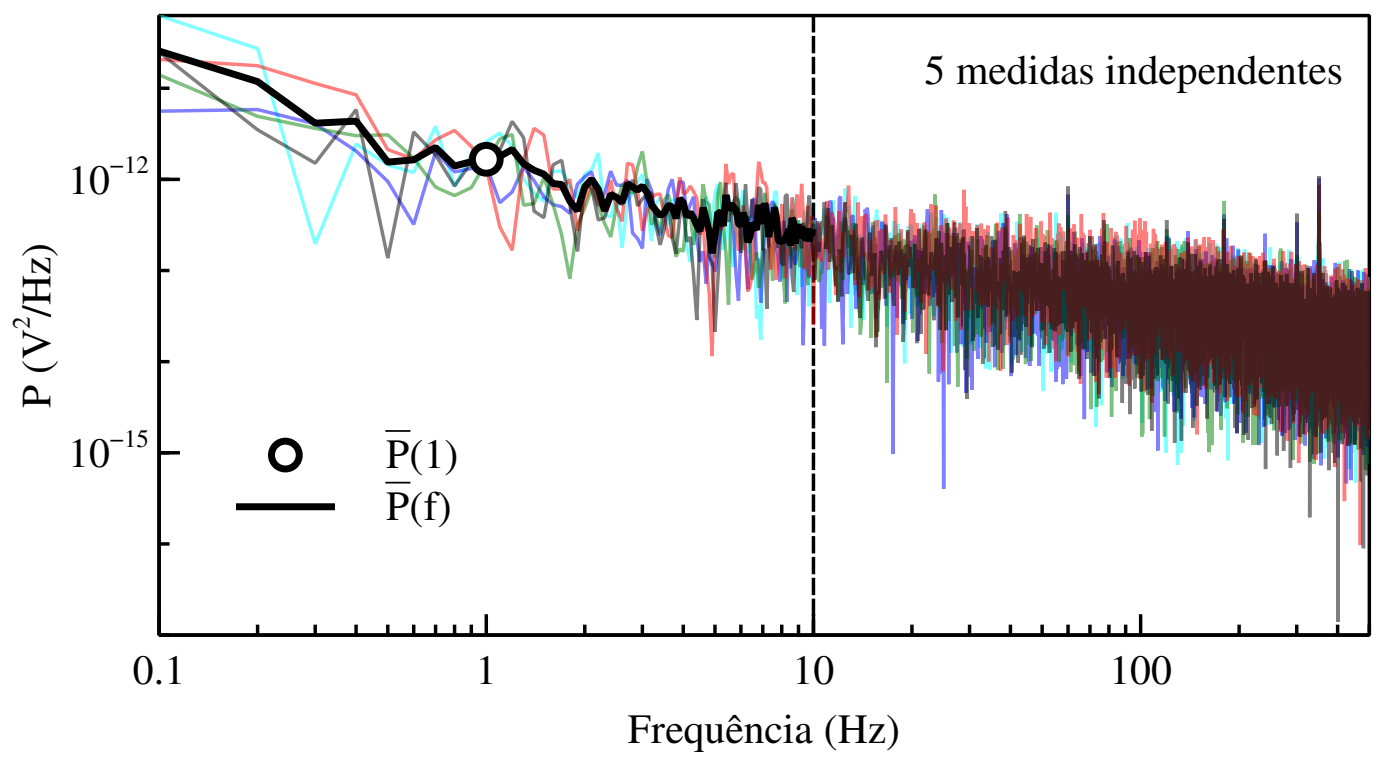

Figura B.2.1 - Exemplo de estimativa da densidade espectral de potência. Cinco periodogramas são obtidos a partir de cinco séries temporais coletadas. O periodograma médio entre $0.1 \mathrm{~Hz}$ e $10 \mathrm{~Hz}$ é utilizado para obter-se um valore representativo do ruído contido nos sinais. Há também a possibilidade de utilizar-se somente o valor de $\bar{P}(1)$. 



\section{ANEXO C - Cálculo dos fatores de desmag- netização por carga magnética induzida}

\section{C.1 Campo de desmagnetização}

Em problemas de magnetostática, quando não há correntes livres ou na região de interesse o campo gerado por estas é considerado uniforme, tem-se que

$$
\nabla \times \mathbf{H}=0
$$

pode-se então escrever este campo como o divergente de um escalar, ou seja

$$
\mathbf{H}=\nabla U(\mathbf{r})
$$

Por outro lado, quando este mesmo problema envolve materias magnéticos, o campo $\mathbf{H}$ pode ser geralmente separado em duas partes, o campo externo $\left(\mathbf{H}_{0}\right)$ e o campo de desmagnetização $\left(\mathbf{H}_{\mathrm{d}}\right)$ que tem origem no material, de forma que

$$
\mathbf{H}(\mathbf{r})=\mathbf{H}_{0}(\mathbf{r})+\mathbf{H}_{\mathrm{d}}(\mathbf{r}),
$$

onde $\mathbf{r}$ é a posição. $\mathbf{H}_{\mathrm{d}}$ tem sua origem nos dipolos magéticos não compensados nas extremidades do material que podem ser tratados matematicamente como cargas magéticas induzidas. Também pode-se escrever

$$
\mathbf{H}_{\mathrm{d}}(\mathbf{r})=-\nabla U_{\mathrm{d}}(\mathbf{r})
$$

onde

$$
U_{\mathrm{d}}(\mathbf{r})=-\frac{1}{4 \pi} \int_{V} \frac{\rho\left(\mathbf{r}^{\prime}\right)}{\left|\mathbf{r}-\mathbf{r}^{\prime}\right|} \mathrm{d} V^{\prime}+\frac{1}{4 \pi} \int_{S} \frac{\sigma\left(\mathbf{r}^{\prime}\right)}{\left|\mathbf{r}-\mathbf{r}^{\prime}\right|} \mathrm{d} a^{\prime}
$$

com as definições:

$$
\rho \equiv-\nabla \cdot \mathbf{M}
$$

densidade volumétrica de cargas induzidas, e

$$
\sigma \equiv \mathbf{M} \cdot \hat{\mathbf{n}}
$$

densidade superficial de cargas magnéticas induzidas.

Substituindo-se a equação C.1.5 na equação C.1.4, chega-se a

$$
\mathbf{H}_{\mathrm{d}}(\mathbf{r})=-\frac{1}{4 \pi} \int_{V} \frac{\rho\left(\mathbf{r}^{\prime}\right)\left(\mathbf{r}-\mathbf{r}^{\prime}\right)}{\left|\mathbf{r}-\mathbf{r}^{\prime}\right|^{3}} \mathrm{~d} V^{\prime}+\frac{1}{4 \pi} \int_{S} \frac{\sigma\left(\mathbf{r}^{\prime}\right)\left(\mathbf{r}-\mathbf{r}^{\prime}\right)}{\left|\mathbf{r}-\mathbf{r}^{\prime}\right|^{3}} \mathrm{~d} a^{\prime}
$$




\section{C.2 Prisma retangular}

O problema do cálculo do fator de desmagnetização de um prisma retangular é abordado em vários trabalhos, como for exemplo [83, 84, 85].

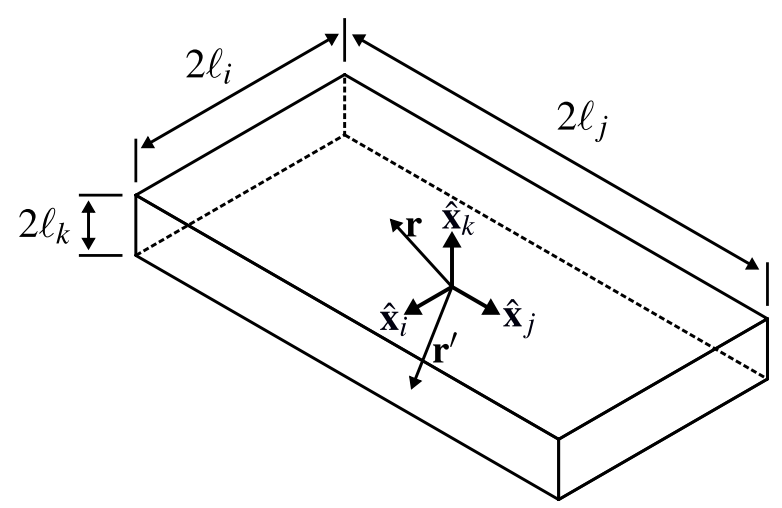

Figura C.2.1 - Prisma retangular com o sistema de coordenadas.

Considere um prisma retangular como o da figura C.2.1 com magnetização uniforme. Neste caso tem-se que $\rho=0$, e o campo de desmagnetização pode ser escrito como

$$
\mathbf{H}_{\mathrm{d}}(\mathbf{r})=\frac{1}{4 \pi} \int_{S} \frac{\sigma\left(\mathbf{r}^{\prime}\right)\left(\mathbf{r}-\mathbf{r}^{\prime}\right)}{\left|\mathbf{r}-\mathbf{r}^{\prime}\right|^{3}} \mathrm{~d} a^{\prime}
$$

Para cada componente $i$ do campo $\mathbf{H}$ pode-se escrever uma equação

$$
\begin{aligned}
H_{\mathrm{d}, i}(\mathbf{r}) & =\frac{1}{4 \pi} \int_{S} \frac{\sigma\left(\mathbf{r}^{\prime}\right)\left(x_{i}-x_{i}^{\prime}\right)}{\left|\mathbf{r}-\mathbf{r}^{\prime}\right|^{3}} \mathrm{~d} a^{\prime} \\
& =\frac{1}{4 \pi}\left[M_{i} f_{i, i}(\mathbf{r})+M_{j} f_{i, j}(\mathbf{r})+M_{k} f_{i, k}(\mathbf{r})\right],
\end{aligned}
$$

onde $M_{i}$ é a componente $i$ da magnetização e as funções $f_{i, \alpha}$ são as integrais da componente $i$ nas superfícies do prisma ortogonais a componente $\alpha$. Note que $i, j, k=1,2,3$ mas $i \neq j \neq k$, ou seja, cada um dos índices representa uma componente distinta.

$$
f_{i, \alpha}(\mathbf{r})=\left.\left.\left.\left(\iint \frac{x_{i}-x_{i}^{\prime}}{R^{3}} \mathrm{~d} a_{\alpha}^{\prime}\right)\right|_{x_{i}^{\prime}=-\ell_{i}} ^{x_{i}^{\prime}=\ell_{i}}\right|_{x_{j}^{\prime}=-\ell_{j}} ^{x_{j}^{\prime}=\ell_{j}}\right|_{x_{k}^{\prime}=-\ell_{k}} ^{x_{k}^{\prime}=\ell_{k}},
$$

onde $R=\sqrt{\left(x_{i}-x_{i}^{\prime}\right)^{2}+\left(x_{j}-x_{j}^{\prime}\right)^{2}+\left(x_{k}-x_{k}^{\prime}\right)^{2}}$ e $\mathrm{d} a_{\alpha}^{\prime}$ é o diferencial da superfície ortogonal a $\alpha$, por exemplo $\mathrm{d} a_{j}^{\prime}=\mathrm{d} x_{i}^{\prime} \mathrm{d} x_{k}^{\prime}$. Os limites são aplicados depois de todas as integrações. Resolvendo as integrais implícitas tem-se dois casos, quando $\alpha=i$

$$
\begin{aligned}
\iint \frac{x_{i}-x_{i}^{\prime}}{R^{3}} \mathrm{~d} x_{j}^{\prime} \mathrm{d} x_{k}^{\prime} & =\int \frac{\left(x_{i}-x_{i}^{\prime}\right)\left(x_{j}-x_{j}^{\prime}\right)}{\left[\left(x_{i}-x_{i}^{\prime}\right)^{2}+\left(x_{k}-x_{k}^{\prime}\right)^{2}\right] R} \mathrm{~d} x_{k}^{\prime} \\
& =\arctan \left(\frac{\left(x_{j}-x_{j}^{\prime}\right)\left(x_{k}-x_{k}^{\prime}\right)}{\left(x_{i}-x_{i}^{\prime}\right) R}\right),
\end{aligned}
$$


e quando $\alpha \neq i$

$$
\iint \frac{x_{i}-x_{i}^{\prime}}{R^{3}} \mathrm{~d} x_{i}^{\prime} \mathrm{d} x_{\alpha}^{\prime}=\int \frac{1}{R} \mathrm{~d} x_{\alpha}^{\prime}=\ln \left[2 R+2\left(x_{\alpha}-x_{\alpha}^{\prime}\right)\right]
$$

Deste modo pode-se escrever $f_{i, \alpha}$ como

$$
f_{i, \alpha}=\left\{\begin{array}{l}
\left.\left.\left.\arctan \left(\frac{\left(x_{j}-x_{j}^{\prime}\right)\left(x_{k}-x_{k}^{\prime}\right)}{\left(x_{i}-x_{i}^{\prime}\right) R}\right)\right|_{x_{i}^{\prime}=-\ell_{i}} ^{x_{i}^{\prime}=\ell_{i}}\right|_{x_{j}^{\prime}=-\ell_{j}} ^{x_{j}^{\prime}=\ell_{j}}\right|_{x_{k}^{\prime}=-\ell_{k}} ^{x_{k}^{\prime}=\ell_{k}} \\
\left.\left.\left.\ln \left[2 R+2\left(x_{\alpha}-x_{\alpha}^{\prime}\right)\right]\right|_{x_{i}^{\prime}=-\ell_{i}} ^{x_{i}^{\prime}=\ell_{i}}\right|_{x_{j}^{\prime}=-\ell_{j}} ^{x_{j}^{\prime}=\ell_{j}}\right|_{x_{k}^{\prime}=-\ell_{k}} ^{x_{k}^{\prime}=\ell_{k}}
\end{array}\right.
$$

Com o conjunto de equações C.2.6 e C.2.2 pode-se chegar ao a todas as componentes do campo de desmagnetização. Entretanto o número de termos é grande (24 por componente).

\section{C.3 Fator de desmagnetização fluxométrico.}

O fator de desmagnetização fluxométrico associado a uma componente $i$ é calculado com a média do campo de desmagnetização no plano central do prisma ortogonal a esta componente como mostra a figura C.3.1, ou seja:

$$
D_{i}=-\frac{1}{A M_{i}} \iint H_{\mathrm{d}, i}(\mathbf{r}) \mathrm{d} a .
$$

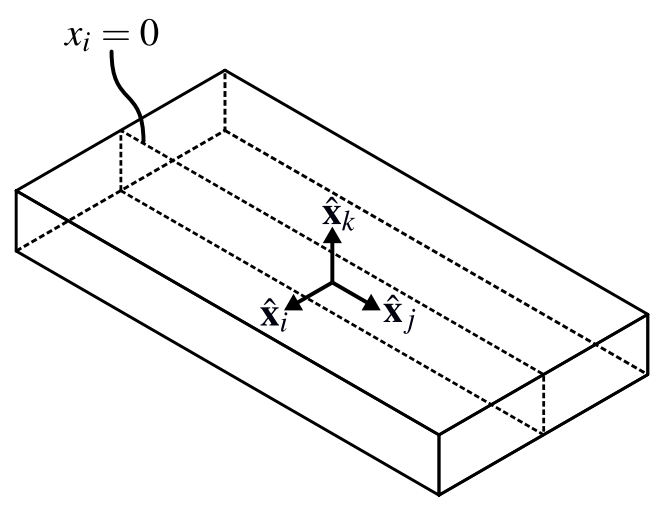

Figura C.3.1 - Plano central sobre o qual é calculada a média de $H_{d, i}$, dado origem ao fator de desmagnetização associado a coordenada $i, D_{i}$.

Fazendo-se $x_{i}=0$ tem-se que $f_{i, \alpha}=0$ para $\alpha \neq i$. Isto pode ser verificado levando-se em conta a simetria do problema, ou seja $R\left(x_{i}=0, x_{i}^{\prime}=\ell_{i}\right)=R\left(x_{i}=0, x_{i}^{\prime}=-\ell_{i}\right)$, assim para cada termo haverá um par igual mas com sinail oposto. Este resultado mostra que é possivel escrever, mesmo para o fator de desmagnetização fluxométrico, um tensor de magnetização diagonal utilizando o sistema de coordenadas descrito. Isto porque cada componente do campo $H_{\mathrm{d}, i}$ depende somente da componente $i$ da magnetização $\left(M_{i}\right)$ ou seja

$$
\mathbf{H}_{\mathrm{d}}=-\bar{D} \mathbf{M}
$$


onde

$$
\bar{D}=\left(\begin{array}{ccc}
D_{1} & 0 & 0 \\
0 & D_{2} & 0 \\
0 & 0 & D_{3}
\end{array}\right)
$$

$\mathrm{e}$

$$
D_{i}=-\frac{1}{16 \pi \ell_{j} \ell_{k}} \int_{-\ell_{k}}^{\ell_{k}} \int_{-\ell_{j}}^{\ell_{j}} f_{i, i}\left(x_{i}=0\right) \mathrm{d} x_{j} \mathrm{~d} x_{k}
$$

Para calcular estas integrais é conveniente fazer uma mudança de variável redefinindo a origem do sistema de coordenadas, $x_{j}^{\prime \prime}=x_{j}-x_{j}^{\prime}$ e $x_{k}^{\prime \prime}=x_{k}-x_{k}^{\prime}$. Assim tem-se

$$
\begin{gathered}
D_{i}=\left.\left.\left.\frac{1}{16 \pi \ell_{j} \ell_{k}} \int_{-x_{k}^{\prime}-\ell_{k}}^{-x_{k}^{\prime}+\ell_{k}} \int_{-x_{j}^{\prime}-\ell_{j}}^{-x_{j}^{\prime}+\ell_{j}} \tan ^{-1}\left(\frac{x_{j}^{\prime \prime} x_{k}^{\prime \prime}}{x_{i}^{\prime} R^{\prime \prime}}\right) \mathrm{d} x_{j}^{\prime \prime} \mathrm{d} x_{k}^{\prime \prime}\right|_{x_{i}^{\prime}=-\ell_{i}} ^{x_{i}^{\prime}=\ell_{i}}\right|_{x_{j}^{\prime}=-\ell_{j}} ^{x_{j}^{\prime}=\ell_{j}}\right|_{x_{k}^{\prime}=-\ell_{k}} ^{x_{k}^{\prime}=\ell_{k}} \\
=\frac{1}{32 \pi \ell_{j} \ell_{k}} \int_{-x_{k}^{\prime}-\ell_{k}}^{-x_{k}^{\prime}+\ell_{k}}\left[2 x_{j}^{\prime \prime} \tan ^{-1}\left(\frac{x_{j}^{\prime \prime} x_{k}^{\prime \prime}}{x_{i}^{\prime} R^{\prime \prime}}\right)+x_{i}^{\prime} \ln \left(R^{\prime \prime}+x_{k}^{\prime \prime}\right)\right. \\
\left.-x_{i}^{\prime} \ln \left(R^{\prime \prime}-x_{k}^{\prime \prime}\right)\right]\left.\left.\mathrm{d} x_{k}^{\prime \prime}\right|_{x_{j}^{\prime \prime}=-x_{j}^{\prime}-\ell_{j}} ^{x_{j}^{\prime \prime}=-x_{j}^{\prime}+\ell_{j}}\right|_{x_{i, j, k}^{\prime}=-\ell_{i, j, k}^{\prime}} ^{x_{i, j}^{\prime}=\ell_{i, k}}
\end{gathered}
$$

e finalmente,

$$
\begin{aligned}
D_{i} & =\frac{1}{32 \pi \ell_{j} \ell_{k}}\left[2 x_{j}^{\prime \prime} x_{k}^{\prime \prime} \tan ^{-1}\left(\frac{x_{j}^{\prime \prime} x_{k}^{\prime \prime}}{x_{i}^{\prime} R^{\prime \prime}}\right)+x_{i}^{\prime} x_{j}^{\prime \prime} \ln \left(\frac{R^{\prime \prime}+x_{j}^{\prime \prime}}{R^{\prime \prime}-x_{j}^{\prime \prime}}\right)\right. \\
& \left.+x_{i}^{\prime} x_{k}^{\prime \prime} \ln \left(\frac{R^{\prime \prime}+x_{k}^{\prime \prime}}{R^{\prime \prime}-x_{k}^{\prime \prime}}\right)-2 x_{i}^{\prime} R^{\prime \prime}\right]\left.\left.\right|_{x_{j, k}^{\prime \prime}=-x_{j, k}^{\prime}-\ell_{j, k}} ^{x_{j, k}^{\prime \prime}=-x_{j, k}^{\prime}+\ell_{j, k}}\right|_{x_{i, j, k}^{\prime}=-\ell_{i, j, k}^{\prime}} ^{x_{i, j}^{\prime}=\ell_{i, j, k}}
\end{aligned}
$$

onde $R^{\prime \prime}=\sqrt{x_{i}^{\prime 2}+x^{\prime \prime}{ }_{j}^{2}+x^{\prime \prime 2}}{ }_{k}$. Claro que é possível simplificar esta expressão reduzindo o número de termos, mas na maneira que está escrita facilita o cálculo do fator computacionalmente utilizando-se 5 laços (for). Isto não é tão direto, por exemplo, na forma final apresentado em [85].

\section{C.4 Fator de acoplamento}

Quando uma bobina tem dimensões maiores que o material ferromagnético uma fração deste "volta" por dentro da bobina reduzindo o fluxo líquido (veja a figura C.4.1). 


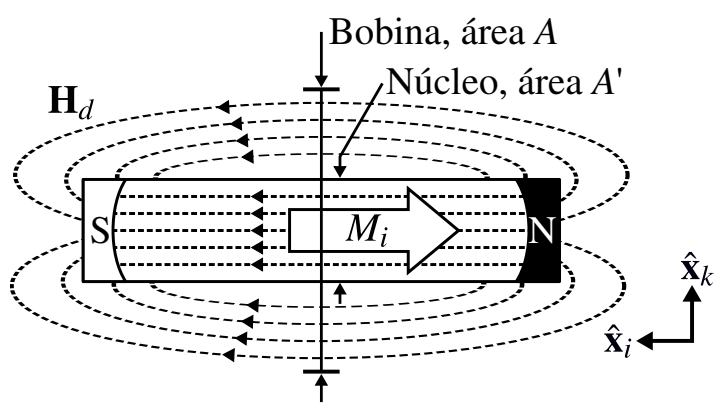

Figura C.4.1 - Uma bobina maior que o núcleo tem menor fluxo devido a magnetização.

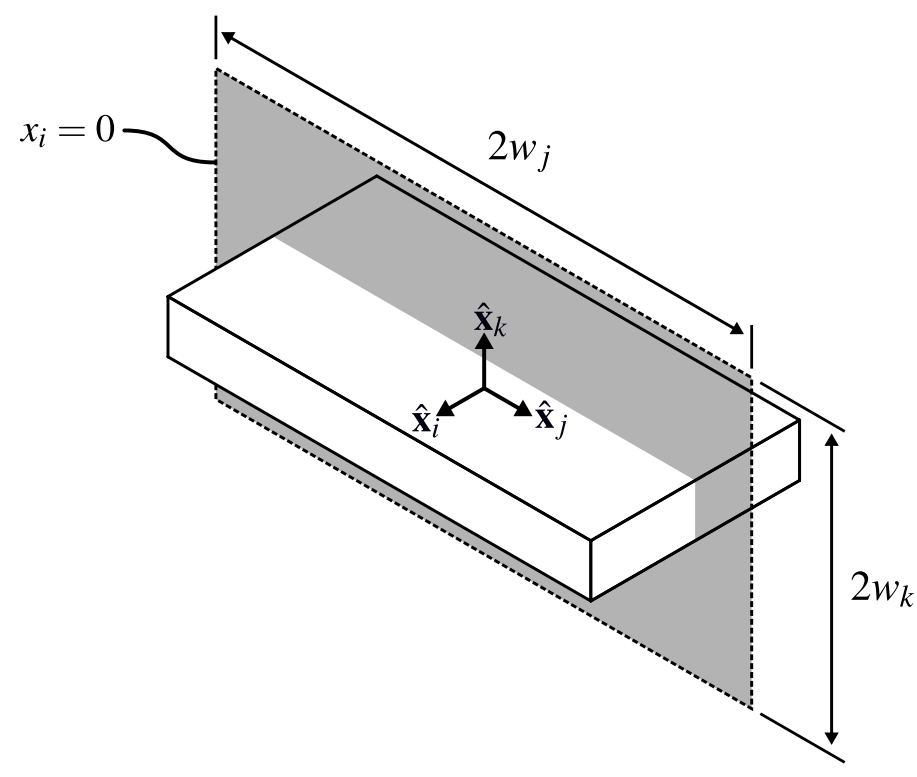

Figura C.4.2 - O fator de acoplamento compensa a redução no fluxo que passa pela bobina causado pelas cargas magnéticas induzidas.

$\mathrm{Na}$ verdade o fator de desmagnetização mede precisamente esta redução no fluxo para seção transveral do núcleo. Para o caso de uma bobina maior, como mostra a figura C.4.2, pode-se definir um fator de acoplamento $D_{a}$ de modo que

$$
D_{a, i} \int_{A} M_{i} \mathrm{~d} a=\int_{A} M_{i}-H_{d, i} \mathrm{~d} a
$$

mas $M_{i}$ é nulo fora do material e constante dentro, logo,

$$
\begin{aligned}
D_{a, i} & =\frac{\int_{A} M_{i}-H_{d, i} \mathrm{~d} a}{\int_{A} M_{i} \mathrm{~d} a} \\
& =\frac{A^{\prime} M_{i}-\int_{A} H_{d, i} \mathrm{~d} a}{A^{\prime} M_{i}} \\
& =1-\frac{1}{A^{\prime} M_{i}} \int_{A} f_{i, i}\left(x_{i}=0\right) \mathrm{d} a,
\end{aligned}
$$


onde $A^{\prime}$ é a seção transversal do material (núcleo). Adaptando o resultado da equação C.3.6, tem-se

$$
\begin{aligned}
D_{a, i}=1 & -\frac{1}{32 \pi \ell_{j} \ell_{k}}\left[2 x_{j}^{\prime \prime} x_{k}^{\prime \prime} \tan ^{-1}\left(\frac{x_{j}^{\prime \prime} x_{k}^{\prime \prime}}{x_{i}^{\prime} R^{\prime \prime}}\right)+x_{i}^{\prime} x_{j}^{\prime \prime} \ln \left(\frac{R^{\prime \prime}+x_{j}^{\prime \prime}}{R^{\prime \prime}-x_{j}^{\prime \prime}}\right)\right. \\
& \left.+x_{i}^{\prime} x_{k}^{\prime \prime} \ln \left(\frac{R^{\prime \prime}+x_{k}^{\prime \prime}}{R^{\prime \prime}-x_{k}^{\prime \prime}}\right)-2 x_{i}^{\prime} R^{\prime \prime}\right]\left.\left.\right|_{x_{j, k}^{\prime \prime}=-x_{j, k}^{\prime}-w_{j, k}} ^{x_{j, k}^{\prime}+w_{j, k}}\right|_{x_{i, j, k}^{\prime}=-\ell_{i, j, k}^{\prime}} ^{x_{i, j}^{\prime}=\ell_{i, j, k}}
\end{aligned}
$$

onde $R^{\prime \prime}=\sqrt{x_{i}^{\prime 2}+x_{j}^{\prime \prime 2}+x_{k}^{\prime \prime 2}}, x_{j}^{\prime \prime}=x_{j}-x_{j}^{\prime}$ e $x_{k}^{\prime \prime}=x_{k}-x_{k}^{\prime}$.

\section{C.5 Fator de desmagnetização paralelo}

De maneria análoga pode-se calcular também a média do campo $H_{d, i}$ no plano $x_{j}=0$ (veja a figura C.5.1). Esta média não tem um nome especial como o fator de desmagnetização fluxométrico. As considerações sobre a simetria que levam à $f_{i, \alpha}=0$ para $\alpha \neq i$ continuam válidas. Denominando o fator de $D_{i}^{\prime}$, pode-se escreve-lo como

$$
D_{i}^{\prime}=-\frac{1}{16 \pi \ell_{i} \ell_{k}} \int_{-\ell_{i}}^{\ell_{i}} \int_{-\ell_{k}}^{\ell_{k}} f_{i, i}\left(x_{j}=0\right) \mathrm{d} x_{k} \mathrm{~d} x_{i}
$$

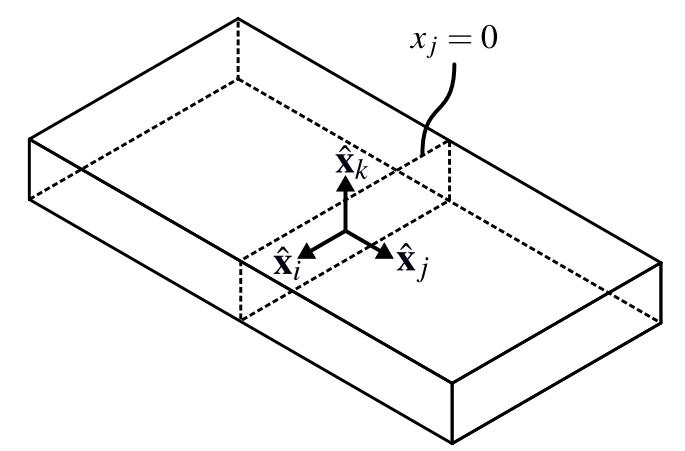

Figura C.5.1 - Plano central sobre o qual é calculada a média de $H_{d, i}$, dado origem ao fator de desmagnetização ortogonal associado a coordenada i, $D_{i}^{\prime}$.

Novamenteo é conveniente fazer uma mudança de variável redefinindo a origem do 
sistema de coordenadas, $x_{i}^{\prime \prime}=x_{i}-x_{i}^{\prime}$ e $x_{k}^{\prime \prime}=x_{k}-x_{k}^{\prime}$. Assim tem-se

$$
\begin{aligned}
& D_{i}^{\prime}=\left.\left.\left.\frac{1}{16 \pi \ell_{i} \ell_{k}} \int_{-x_{i}^{\prime}-\ell_{i}}^{-x_{i}^{\prime}+\ell_{i}} \int_{-x_{k}^{\prime}-\ell_{k}}^{-x_{k}^{\prime}+\ell_{k}} \tan ^{-1}\left(\frac{x_{j}^{\prime} x_{k}^{\prime \prime}}{x_{i}^{\prime \prime} R^{\prime \prime}}\right) \mathrm{d} x_{k}^{\prime \prime} \mathrm{d} x_{i}^{\prime \prime}\right|_{x_{i}^{\prime}=-\ell_{i}} ^{x_{i}^{\prime}=\ell_{i}}\right|_{x_{j}^{\prime}=-\ell_{j}} ^{x_{j}^{\prime}=\ell_{j}}\right|_{x_{k}^{\prime}=-\ell_{k}} ^{x_{k}^{\prime}=\ell_{k}} \\
&=\left.\left.\frac{1}{32 \pi \ell_{i} \ell_{k}} \int_{-x_{i}^{\prime}-\ell_{i}}^{-x_{i}^{\prime}+\ell_{i}}\left[2 x_{k}^{\prime} \tan ^{-1}\left(\frac{x_{j}^{\prime} x_{k}^{\prime \prime}}{x_{i}^{\prime \prime} R^{\prime \prime}}\right)+x_{i}^{\prime \prime} \ln \left(\frac{R^{\prime \prime}+x_{j}^{\prime}}{R^{\prime \prime}-x_{j}^{\prime}}\right)\right] \mathrm{d} x_{i}^{\prime \prime}\right|_{x_{k}^{\prime \prime}=-x_{k}^{\prime}-\ell_{k}} ^{x_{k}^{\prime \prime}=-x_{k}^{\prime}+\ell_{k}}\right|_{x_{i, j, k}^{\prime}=-\ell_{i, j, k}} ^{x_{i, j}=\ell_{i, j, k}} \\
&= \frac{1}{32 \pi \ell_{i} \ell_{k}}\left[2 x_{i}^{\prime \prime} x_{k}^{\prime \prime} \tan ^{-1}\left(\frac{x_{j}^{\prime} x_{k}^{\prime \prime}}{x_{i}^{\prime \prime} R^{\prime \prime}}\right)+\frac{1}{2}\left(x_{i}^{\prime \prime 2}-x_{k}^{\prime \prime 2}\right) \ln \left(\frac{R^{\prime \prime}+x_{j}^{\prime}}{R^{\prime \prime}-x_{j}^{\prime}}\right)\right. \\
&\left.-x_{j}^{\prime \prime} x_{k}^{\prime \prime} \ln \left(\frac{R^{\prime \prime}+x_{k}^{\prime \prime}}{R^{\prime \prime}-x_{k}^{\prime \prime}}\right)+2 x_{j}^{\prime} R^{\prime \prime}\right]\left.\right|_{x_{i, k}^{\prime \prime}=-x_{i, k}^{\prime}-\ell_{i, k}} ^{x_{i, k}^{\prime \prime}=-x_{i, k}^{\prime}+\left.\ell_{i, k}\right|_{x_{i, j, k}^{\prime}} ^{x_{i, j}^{\prime}=\ell_{i, j, k}}}
\end{aligned}
$$

onde $R^{\prime \prime}=\sqrt{x^{\prime \prime 2}{ }_{i}+x_{j}^{\prime 2}+x^{\prime \prime 2}}$. 